\title{
The physiological role of leptin in man
}

Citation for published version (APA):

Hukshorn, C. J. (2005). The physiological role of leptin in man. [Doctoral Thesis, Maastricht University]. Universitaire Pers Maastricht. https://doi.org/10.26481/dis.20050204ch

Document status and date:

Published: 01/01/2005

DOI:

10.26481/dis.20050204ch

Document Version:

Publisher's PDF, also known as Version of record

\section{Please check the document version of this publication:}

- A submitted manuscript is the version of the article upon submission and before peer-review. There can be important differences between the submitted version and the official published version of record.

People interested in the research are advised to contact the author for the final version of the publication, or visit the DOI to the publisher's website.

- The final author version and the galley proof are versions of the publication after peer review.

- The final published version features the final layout of the paper including the volume, issue and page numbers.

Link to publication

\footnotetext{
General rights rights.

- You may freely distribute the URL identifying the publication in the public portal. please follow below link for the End User Agreement:

www.umlib.nl/taverne-license

Take down policy

If you believe that this document breaches copyright please contact us at:

repository@maastrichtuniversity.nl

providing details and we will investigate your claim.
}

Copyright and moral rights for the publications made accessible in the public portal are retained by the authors and/or other copyright owners and it is a condition of accessing publications that users recognise and abide by the legal requirements associated with these

- Users may download and print one copy of any publication from the public portal for the purpose of private study or research.

- You may not further distribute the material or use it for any profit-making activity or commercial gain

If the publication is distributed under the terms of Article $25 \mathrm{fa}$ of the Dutch Copyright Act, indicated by the "Taverne" license above, 


\title{
The physiological role of leptin in man
}

\author{
Chris Hukshorn
}




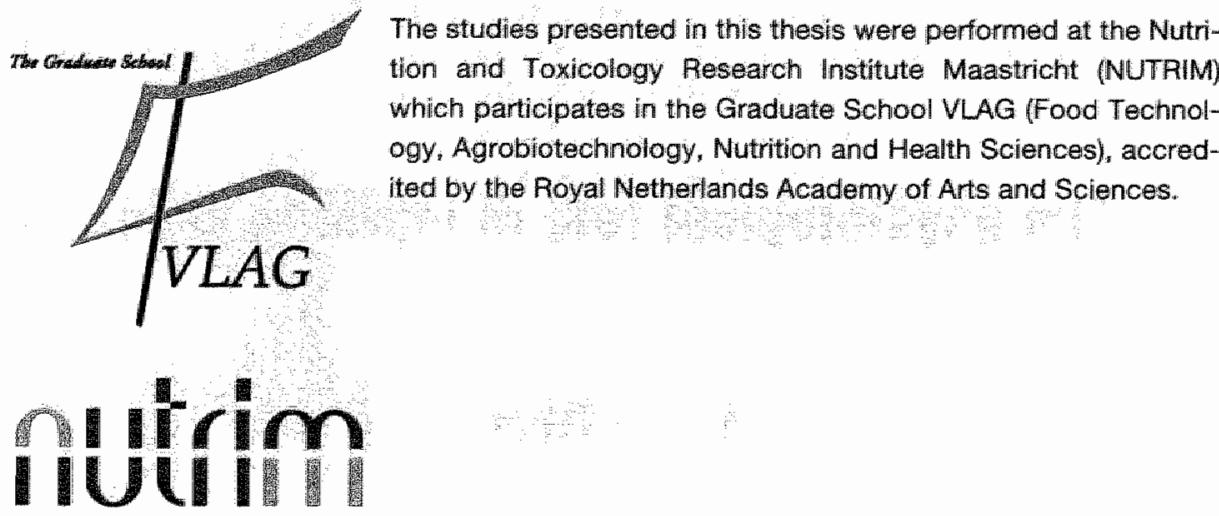

Vormgeving en druk: Datawyse / Universitaire Pers Maastricht

ISBN $90 \quad 52784515$

(․) copyright 2005 Hukshiom, Maastricht 


\title{
The physiological role of leptin in man
}

\author{
PROEFSCHRIFT
}

ter verkrijging van de graad van doctor

aan de Universiteit Maastricht, op gezag van de Rector Magnificus,

Prof. mr. G.P.M.F. Mols

volgens het besluit van het College van Decanen,

in het openbaar te verdedigen

op vrijdag 4 februari 2005 om 14:00 uur

door

Christian John Hukshorn

Geboren te Epping (Engeland) op 11 juni 1971

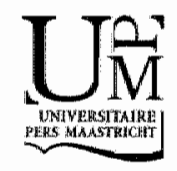




\section{Promotor}

Prof dr. ir. W.HM. Saris

\section{Co-promator}

Dr. MS Westerterp-Plantenga

\section{Beoordelingscommissie}

Prof dr. Ir. R.P. Mensink (voorzitter)

Dr S. Faroogi (University of Cambridge, United Kingdom)

Prof dr, JF,C, Glatz

Prof. dr. A.C. Nieuwenhuijzen Kruseman

Dr. H. Pijl (LUMC) 
Nicht die Wahrheit, in deren Besitz irgendein Mensch ist oder zu sein vermeint, macht den Wert des Menschen aus, sondern die aufrichtige Mühe, die er angewandt hat. hinter die Wahrheit zu kommen.

Gotthold Ephraim Lessing (1729 - 1781) 


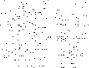

a

as

$\mathrm{ses}$

$\mathrm{s}$ 


\section{CONTENTS}

$\begin{array}{ll}\text { Abbreviations } & 8\end{array}$

Chapter 1 General introduction 11

Chapter 2 CSF total leptin levels after administration of pegylated human $\begin{array}{ll}\text { recombinant leptin (PEG-OB) } & 37\end{array}$

Chapter 3 Weekly subcutaneous pegylated recombinant native human leptin (PEG-OB) administration in obese men

Chapter 4 The effect of pegylated recombinant human leptin (PEG-OB) on weight loss and inflammatory status in obese subjects

Chapter 5 Pegylated human recombinant leptin (PEG-OB) causes additional weight loss in severe energy-restricted overweight men

Chapter 6 The effect of pegylated human recombinant leptin (PEG-OB) on neuroendocrine adaptations to semi-starvation in overweight men

Chapter 7 Leptin and the proinflammatory state associated with human obesity 89

Chapter 8 Experimentally induced hyperleptinemia supresses luteinizinghormone pulsatility in underweight women

Chapter 9 General discussion

Summary

Samenvalting

Dankwoord

Curriculum vitae

Publications 


\section{Abbreviations}

\begin{tabular}{|c|c|}
\hline ACTH & adrenocorticotrophic hormone \\
\hline AgRP & agouth-related paptide \\
\hline AMP & adenosine monophosphate \\
\hline ANOWA & analysils of variance \\
\hline $\mathrm{BBB}$ & blood-brain barrier \\
\hline BMI & body mass index \\
\hline${ }^{\circ} \mathrm{C}$ & degrees Celsius \\
\hline OAMP & cyclic AMP \\
\hline CART & cocaine- and amphetamine-regulated transcript \\
\hline CNS & central nervous system \\
\hline $\mathrm{CO}_{2}$ & carbon diloxide : \\
\hline $\mathrm{OAH}$ & corticotropin-releasing hormone \\
\hline CAP & C-reactive protein \\
\hline CSF & cerebrospinal fluid \\
\hline$d$ & $\operatorname{day}(\mathrm{s})$ \\
\hline$d b / d b$ mouse & diabetes mouse \\
\hline DHEA-S & dehydroepiandrosterone sulfate \\
\hline ECG & electrocardiogram \\
\hline EDTA & ethylenediamin tetraacetic acid \\
\hline ELISA & enzyme-linked immunosorbent assay \\
\hline falfa rat & Zucker rat \\
\hline FFA & free fatty acid \\
\hline $\mathrm{FFM}$ & fat-free mass \\
\hline FSH & follicle stimulating hormone \\
\hline $\mathrm{FT}_{3}$ & free $T_{3}$ \\
\hline $\mathbb{F T}_{4}$ & free $T_{4}$ \\
\hline$g$ & $\operatorname{gram}(s)$ \\
\hline 9 & unit of gravity \\
\hline $\mathrm{GH}$ & growth hormone \\
\hline GHAH & growth hormone releasing harmone \\
\hline GnPHM & gomadotropin releasing hormone \\
\hline h & hour(s) \\
\hline HDL & high-density lipoprotein \\
\hline HPA. & hypothalamic-pituitary-adrenal \\
\hline ICAM & Intercellular adhesion molecule \\
\hline HOV & intracerebroventricular \\
\hline IGF & insulin-like growth factor \\
\hline IGFBP & IGF -binding protein \\
\hline liL & interleukin \\
\hline IFS & insulin receptor substrate \\
\hline l.v. & intravenous(y) \\
\hline JAK & Janus-family tyrosine kinase \\
\hline koal & kilocalorie(s) \\
\hline $\mathrm{KDa}$ & kilodalton(s) \\
\hline $\mathrm{kg}$ & kïlogram(s) \\
\hline Kat: & rate constant for plasma glucose disappearance \\
\hline L. & liter(s) \\
\hline LDL & low-density lipoprotein \\
\hline $\mathrm{LH}$ & luteinizing hormone \\
\hline LPS & lipopolysaccharide \\
\hline
\end{tabular}


in

min

$\mathrm{MC}$

$\mathrm{MCH}$

N:S

mo

ImPNA

MSH

$n$

$N \mathbb{E}$

no.

NIO

NPY

NIS

$\mathrm{O}_{2}$

ob/ob mouse

$\mathrm{Ob}-\mathrm{R}$

$P$

PAI

PEG

PEG-OB

PIBK

POMC

PRL

PTP

RNA

$\mathrm{RQ}$

$\mathrm{rt}_{3}$

S.c.

SD

SEM

$S H B G$

SHP2

SMR

SNS

SOCS

STAT

STNF-A

$T_{1 / 2}$

$T_{3}$

$T_{4 i}$

TBG

TGF

TNF

tPA

TRH

TSH

U

VLCD

VLED

WWF

W

wk

$y(r s)$ meter(s)

minute(s)

melanocortin

melanin-concentrating homone

megajoule(s)

month(s)

messenger RNA

melanocyte stimulating hormone

number in study, group

norepinephrine

nuimber

nitric oxide

meuropeptide $Y$

not significant

oxygen

abese mouse

leptin receptor

probability

plasminogen activator inhibitor

polyethylene glycols

pegylated recombinant human leptin

phosphatid ylinositol-3'-kinase

proopiomelanocortín

prolactin

phosphotyrosine phosphatase

ribonucleic acid

respiratory quotient

reverse $T_{3}$

subcutaneous(ly)

standard deviation

standard error of the mean

sex hormone binding prottein

SH2-containing phosphatase

slleeping metabolic rate

sympathetic nervous system

siuppressor of cytokine sigrialing

signal transducer and activator of transcription

soluble TNF $\alpha$-receptors

halfilife

3,5,3'-tritodothyronine

thyroxime

thyroxine-binding globulin

transforming growth factor

tumor necrosis factor

tissue plasminogen activator

thyrotropin-releasing hormone

thyroid stimulating hormone

unit(s)

very-low-calorie diet

very-low-energy diet

von Willebrand factor

vatt(s)

week $(s)$

yoar(s) 
CHAPTER 1

\section{General Introduction}




\section{The discovery of the leptin pathway}

The discovery of the hormone leptin (also known as $\mathrm{OB}$ protein) by Friedman and colleagues in December 1994 had an enormous impact both on understanding the molecular control of energy balance and on attitudes to the scientific study of obesity (1). Over the last 10 years more than 5000 papers have been published on leptin (from the Greek leptos, meaning thin), leading to an ever-advancing body of knowledge. The leptin pathway appeared to be the long-sought peripheral signal pathway from the adipose tissue to the brain involved in the regulation of feeding and energy balance.

In 1950 , a spontaneous recessive genetic mutation resulting in profound obesity and diabetes was identified in an inbred mice collony (2). Shortly after the discovery of the obese (ob/ab) mouse, additional recessively inherited forms of obesity, called the diabetes $(d b / d b)$ mouse and the Zucker (fa/fa) rat were described $(3,4)$. Despite being genetically different, these animals expressed identical phenotypical characteristics, such as massive obesity of early onset, hyperphagia, hypothermia, type 2 diabetes, dyslipidemia, hypercortisolemia, decreased immune function, and infertility due to hypogonadotropic hypogonadism.

In the 1970's, classic parablosis experiments in which the circulations of ob/ob and $d b / d b$ mice were connected "resulted in dramatic weight loss due to hypophagia in $o b / o b$ mice, while retention of increased food intake and weight in their $d b / d b$ pair-mates was observed $(5,6)$. These results led to the hypothesis that the ob gene encoded a circulating substance that affected the energy balance and consequently body weight control. In addition, it was suggested that the receptor of this unknown substance was encoded by, or under control of, the db gene. It was not until 1994 that this hypothesis could be verified and a new endocrine system was revealled.

\section{The ob gene}

The mouse ob gene is positioned on chromosome 6 and encodes a 4.5 kilobase messenger ribonuleleic acid (mRNA) transciript $(1,7)$. In humans, the ob gene is positioned on chromosome $7 q 31.3(8)$. The ob gene encompasses 650 kilobase and consists of 3 exons separated by 2 introns. The coding region is located in exons 2 and 3 . In addition, it possesses a highly conserved open reading frame with a 21-amino acid secretory signal sequence, a 5 "weader sequence of 97 basepairs and a long $3^{\prime}$-untranslated region of approximately 3700 basepairs downstream. Several regulatory elements have been identified within the promotor, including cyclic adenosine monophosphate (CAMP) and glucocorticoid response elements, CCATT/enhancer, and SP1 binding sites (9-11). Further analysis revealed a high degree of homology among various species. For example, human leptin is $84 \%$ identical to mouse leptin and $83 \%$ identical to rat leptin. The transcript encodes an 18 kilodalton (kDa) protein containing a signal sequence, which is cleaved to a $16 \mathrm{kDa}$ product (167 amino acids) and is not modified post-translationally (12). Structural analysis indicates that leptin has similarities to members of the long-chain helical cytokine family $(13,14)$. The protein is an elongated molecule $(2.0 \times 2.5 \times 4.5 \mathrm{~nm})$ and consists of four anti-parallel $\alpha$-helices connected by two long crossover links and one short loop arranged in a left-handed helical bundle, which forms a two-layer packing. The skew angle between the two layers is about $20^{\circ}$. Cysteine residue 96 and 146 form a disulfide bond (necessary for its biological activity) between the C-terminus of the protein and the beginning of one of the loops (15). 
Other conserved regions observed between leptin of different species are located within the four $\alpha$-helices. Leptin activity appears to be localized (al least partially) in the carboxy terminal region of the protein, in domains between residues 106 and 167 $(15,16)$. Leptin does not appear to be stored in substantial amounts suggesting that it is secreted by a constitutive mechanism (17).

The ob transcript is mutant in both of the available strains of $o b / o b$ mice. In the $o b^{2 J}$ mice, a $\sim 5$-kilobase ETn transposon is inserted into the first intron of the ob gene (18). This mutation results in the synthesis of hybrid RNAs in which the splice donor of the non-coding ob first exon is joined to splice acceptors in the transposon leading to the failure of mature ob RNA synthesils. The genetically obese C57BL/6J $a b / O b^{1 \mathrm{~J}}$ mice have a single base mutation $(\mathrm{C} \rightarrow T$ transition) at codon 105 of the leptin gene resulting in the replacement of arginine by a premature stopcodon and the subsequent production of a truncated inactive form of leptin that cannot be secreted and is apparently degraded in the adipocyte $(1,19)$.

\section{The db gene}

The leptin receptor (Ob-R) was cloned in December 1995 from the mouse choroid plexus and was genetically mapped to the same interval of mouse chromosome 4 that contains the $d b$ locus (20). The human leptin receptor gene is lociated on chromosome 1p32. The leptin receptor is a single membrane spanning protein, structurally related to the class I cytokine receptor family, which include receptors for interleukin-6 (IL-6), interleukin-12 (IL-12), prolactin and oncostatin. In addition, signaling capabilities of interleukin 6-type cytokine receptors thave been described (21). The extracellular domain contains two cytokine-like binding motifs (WSXWS), two conserved dllsulfide links in the $\mathrm{N}$-terminus, and a fibronectin type III domain. The leptin receptor has also been highly conserved between mice and humans (20). At least six splice variants of the single gene exist due to alternative splicing: Ob-Ra, Ob-Rb, Ob-Rc, Ob-Rd, $\mathrm{Ob}-\mathrm{Re}$, and $\mathrm{Ob}-\mathrm{Rf}(22,23)$. All isoforms have an identical extracellular ligand-binding domain (840 amino acids) and transmembrane domain ( 34 amino acids; with the exception of $\mathrm{Ob}-\mathrm{Re}$ ) but have a variable intracellular domain "characteristic for each of the receptor isoforms. The physiologically most important isoform is the long form (Ob-Rb also known as $\left.O b-R_{U}\right)$, which is the only isoform that contains an intact long intracellular signaling domain ( 302 amino acids) and is expressed particularly in areas of the hypothalamus, such as the arcuate nucleus, the ventromedial nucleus, and the paraventricular nucleus $(24,25)$. However, the Ob-Rb variant is also present in several peripheral tissues such as kidneys, adrenal medulla, $\beta$-cells of the pancreas, the placenta, T-lymphocytes, endothelial cells, muscle, ovaries and adipose tissue (26-31). In most peripheral tissues, the majority of the detected transcripts encode isoforms bearing a short intracellular domain. $\mathrm{Ob}-\mathrm{Ra}$ is highly expressed in the choroid plexus and the microvessels of the blood-brain barrier suggesting it might be involved in the transport of leptin over the blood-brain barrier $(32,33)$. The shortest form of the receptor (Ob-Re) does not have a transmembrane domain and might represent a soluble form of the receptor (22). Furthermore, soluble leptin receptor is generated by the ectodomain shedding of the membrane-anchored receptor by proteolytic cleavage (34).

After ligand binding (affinity in nanomolar range), the leptin receptor is activated by formation of homodimers resulting in auto- or cross-phosphorylation and subsequent 
activation of the Janus-family tyrosine kinases 2 (JAK2). Activated JAK2 subsequently phosphorylates four specific tyrosine residues of the cytoplasmic domain of the receptor $(974,985,1077$ and 1138$)$ that immediately bind signal transducers and activators of transcription (particularly STAT3, in some cases also STAT1 and STAT5) and SH2-containing phosphatase (SHP2), which are then phosphorylated by JAK2. This results in the activation of both the JAK-STAT3 and SHP2-GRB2-RAS/RAF-MAPKERK1/2 pathways which induce the transcription of specific genes (suppressor of cytokine signaling-3 (SOCS3), FOS, JUN, and others) (35-38). Recent studies suggest that SOCS3 and phosphotyrosine phosphatase 1B (PTP1B) might serve to limit/restrain leptin action (39-41). Furthermore, leptin-activated $O B-R b$ regulates well-known insulin targets; such as insulin receptor substrate 1/2 (IRS1/2) and phosphatidylinositol 3-kinase $(\mathrm{P} \mid 3 \mathrm{~K})$, suggesting interaction in different ways between the leptin and the Insulin signaling pathways depending on tissue type and cell line $(42)$.

In contrast, the short intracellular domain (34 amino acids) of the Ob-Ra does not contain any intracellular tyrosine residues. However, both forms of the receptor can mediate leptin internalization via coated pits, degradation in lysosomes, and receptor downregulation (43).

Several mutations in the leptin receptor gene of mice $\left(d b, d b^{P a s}, d b^{3 y}\right)$ and rats $\left(f a, f a^{k}\right.$, $\mathrm{NIH} \mathrm{fa}$ ) have been described. In the C57Bl/Ks db/db mouse, a $\mathrm{G}$ to T mutation leads to a transcript containing an insert with a premature stop codon " as a result of abnormal RNA splicing of the long form resulting in the replacement of the $\mathrm{Ob}-\mathrm{Rb}$ isoform by the Ob-Ra isoform $(22,44)$. This specific mutation establishes the Ob-Rb isoform as

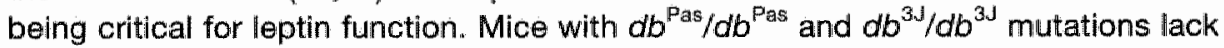
transmembrane and intracytoplasmic domains resulting in the absence of all receptor species $(45,46)$. A missense mutation (A to $G$, responsible for the replacement of glutamine by proline in position 269) has been identified in the extracellular domain of the leptin receptor in the Zucker fa/fa rat and thus reduces the leptin-binding affinity and signal transduction of the receptor $(47,48)$. However, fa/fa rats are capable of responding to high doses of leptin administrated by intracerebroventricular (ICV) injection, consistent with a partial function of the receptor (49). The Koletsky $\mathrm{fa}^{k} / \mathrm{fa}^{k}$ rat mutation is a nonsense mutation at base $+2289\left(\mathrm{Tyr}^{763}\right)$ in the gene just before the transmembrane domain resulting in fallure to express all isoforms of the leptin receptor (50).

\section{Leptin production, metabolism and circulation}

Leptin is primarily synthesized in and secreted into the bloodstream by white adipose tissue but production at a lower level has also been reported in extra-adipose tissue including gastric epithelium (51), placenta trophoblast (52), ovary (53), skeletal muscle (54), liver (55), mammary epithelium (56), and the brain (57). Adipocyte size is an important determinant of leptin synthesis, as larger adipocytes contain more leptin than smaller ones in the same individual (58). Consequently, most obese humans have markedly elevated leptin concentrations compared with lean humans. An even stronger correlation exists between leptin levels and percentage of body fat (59).

Since adipose tissue is a highly heterogeneous organ, considerable differences between sites in the relative level of ob RNA exist $(60,61)$. Furthermore, substantial de- 
velopmental shifts in the importance of different adipose tissue sites to leptin production and even species variations have been demonstrated (60,62). In contrast to rodents, subcutaneous adipose tissue in adult humans appears to be more impottant in leptin production than the omental tissue $(63,64)$.

As for many other physiological processes, leptim production in adipose tissue is under nutritional, hormonal, and neural control. In addition, acute regulation of leptin synthesis is superimposed on the intrinsic production. During energy balance conditions, the level of leptin is a representation of the size of the total adipose tissue mass. Short-term fasting induces a sharp fall in the level of ob RNA and circulating leptin concentrations without significant changes in body fat (65) while the opposite occurs with overfeeding (66). These results suggest that leptin can function as both an indicator of energy stores and energy balance. However, leptin does not appear to function as a satiety signal because leptin levels do not rise in response to individual meals (65).

Nutritional regulation of leptin is partially mediated by insulin which stimulates leptin both in vivo and in vitro $(67-69)$. The rate of insulin-stimulated glucose utilization in adipocytes appears to be an important factorlinking leptin secretion to body fat mass (70). The suggested mechanism involves glucose flux through the hexosamine pathway (54). In both humans and rodents, the postprandial rise in leptin follows the peak insulin secretion $(71,72)$. The fall in insulin levels during fasting might mediate the transient dissociation of leptin levels from body fat changes and the subsequent decline in leptin levels associated with this condition by affecting the adipocyte glucose metabolism (65). Several other hormonal factors regulate leptin levels. Glucocorticoids directly stimulate leptin synthesis in wivo and chronic elevated cortisol levels increase leptin expression $(73,74)$. A number of studies have shown that there is a sexual dimorphism in leptin levels: females have higher levels than men regardless of fat imass. This might be attributable to sex differences in body fat distribution and also testosterone levels which is known to inhibit leptin synthesis (ovarian sex steroids have no effect) (75). Recently, it was observed that prolactin induced leptin synthesis and secretion in white adipose tissue while melatonin decreased leptin levels $(76,77)$. Conflicting reports exist on the effects of hypo- and hyperthyroidism and growth hormone on ob gene expression (78). In addition, leptin synthesis is stimulated by cytokines (and thus by acute infection), e.g. tumor necrosis factor (TNF), leukemia inhibitory factor, and interleukin-1 (IL-1) (79-81). Colld exposure and catecholamines lead to a direct suppression of the $a b$ gene through activation of the $\beta$-adrenergic system $(82-84)$. This has led to the view that the sympathetic nervous system (SNS) provides a negative feedback loop to leptin production in white adipose tissue.

Circulating leptin has a half-life of approximately 25 minutes in humans, which is not altered by the presence of obesity (85). The majority of leptin is removed from the circulation by the kidney where it is degraded and excreted in the urine (86).

Leptin exhibits a circadian rhythm with a nocturnal rise reaching its peak between 01:00 $\mathrm{h}$ and $04: 00 \mathrm{~h}(72,87-90)$. This circadian variation occurs in both man and woman and is not dependent on age but appears to be blunted in obesity (90-92). This rhythm is not entirely endogenously generated: the circadian variation is partially modulated by the day's eating pattern and activity $(93,94)$. In conditions associated with very low levels of circulating leptin, like anorexia nervosa and in very lean female athletes, the circadian variation disappears (95-97). Also in one patient with pheochromocytoma the circadian variation disappeared (98). The cause of the circa- 
dian rhythm of leptin is uncertain. However, the activity of the SNS has been implicated (99). Leptin is also secreted in a pulsatile fashion. The pulse amplitude is related to the concentration of leptin and is therefore greater in obese subjects and women $(87-89,100)$. Obesity is associated with a dampened pulsatility (92). The factor(s) that induce this pulsatile secretion of leptin are unknown although also a role of the SNS has been suggested.

In blood, leptin appears to circulate both in the free form as well as bound to the soluble leptin receptor (Ob-Re) and other yet unidentified binding proteins (101). An additional pool of leptin might exist in various tissues, and contribute to the maintenance of plasma leptin (102). Obesity appears to be associated with decreasing levels of circullating soluble receptor in humans, while weight loss increases it $(103,104)$. In addition, most soluble leptin receptor is bound to leptin in obese individuals contrary to lean individuals (75\% in the obese vs. $33 \%$ in the lean) $(104,105)$. In contrast, the free fraction of leptin in the circulation is reported to be higher in obese individuals and during pregnancy (101). The soluble receptor levels appears to be regulated by gendier, sex steroids, and leptin itself and have a circadlan rhythm inverse to that of leptin (106). Binding of leptin with the soluble receptor has been suggested to increase the bioavailability of leptin in plasma $(101,107)$ as well as to decrease binding of leptin to membrane bound leptin receptors (108). However, the role of the soluble receptor in the regulation of the physiological function of leptin remains unclear.

\section{Leptin transport and action in the brain}

ICV administration of leptin results in a more potent anorectic effect compared to systemic administration suggesting that the hypothalamus is the major site of action of leptin (109). To exert its functions, leptin must gain access to specific regions in the hypothalamus and most likely needs to cross the blood-brain barrler (BBB).

The concentration of leptin in the cerebrospinal fluid (CSF) in humans is related to that of leptin in serum and varies from 1 to $20 \%$ of the latter. However, the ratio of leptin in CSF to serum differs at different concentration of leptin being the highest when leptin levels in serum are low, as in anorexia nervosa and lowest when leptin levels are high, as in obesity $(110,111)$. This curvilinear relationship has been attributed to the presence of a saturable system that transports leptin across the BBB (112). A recent report has suggested that the leptin transport system is saturated and operating at maximum rate at near physiological concentrations in lean individuals, which implies that the elevated leptin levels observed in obesity cannot produce biological effects (113). In addition, this view suggests that administration of exogenous leptin would not produce biological effects due to this characteristic of the pathway. However, results of a double-blind clinical trial demonstrated that exogenous leptin has biological effect (114). Data of a separate cohort of this trial indicated that exogenously administrated leptin crossed the BBB, despite the very high serum leptin concentrations present that would be expected to saturate the transport system completely (115). The investigators of this study explain these results by implying that they are consistent with the proposed existence of a non-saturable pathway and the hypothesis that more than one pathway may be involved in the transpart of leptin to the brain. CSF leptin is present but markedly reduced in obese Koletsky rats which totally lack membrane leptin receptors "indicating that other transport mechanisms exist (50). 
Three potential mechanisms have been proposed for leptin to enter into the central nervous system (CNS) (78). The OB-Ra is the most abundant $\mathrm{OB}-\mathrm{R}$ isoform at the BBB and its presence was demonstrated in the choroid plexus and in the vascular endothelium of the human brain (116-118). Also the binding and internalizing of leptin by this receptor isoform was demonstrated (119). The expression of high levels of the $\mathrm{Ob}-\mathrm{Ra}$ in the endothelial cells of the BBB would permit access through the capillary wall to the specific hypothalamic nuclei and other locations, to exert its actions. A second route could be the transportation of leptin (receptor-mediated and by diffusion) through the choroid plexus and ventricular system into the CSF and subsequently into the brain. Finally, leptin might enter the brain by diffusion through the circumventricular organs, which lack tight junctions.

The OB-Rb is enriched in the base of the hypothalamus, the site of leptin"s action on food intake and bodyweight. The orexigenic (appetite-stimulating) neuropeptide $Y$ (NPY) and agouti-related peptide (AgRP) are expressed in the same neurons in the medial arcuate nucleus, whereas the anorexigenic (appetite-suppressing) proopiomelanocortin (POMC) and cocaine- and amphetamine-regulated transcript (CART) are co-expressed in the lateral arcuate nucleus. The majority of both the NPY/AgRP and POMC/CART neurons co-localized in the arcuate nucleus (adjacent to the third ventricle) co-express leptin receptors and are regulated by leptin in an opposing manner $(120,121)$. Activation of the leptin receptor results in the intibition of NPY/AgRP neurons and activation of POMC/CART neurons (122). Leptin-activated POMC/CART neurons become depolarized (directly and indirectly through $\gamma$-aminobutyric acid) and release the anorexigenic neuropeptides CART and $\alpha-m e l a n o c y t e$ stimulating hormone ( $\alpha-M S H$, a product of POMC). $\alpha-M S H$ is thought to regulate feeding through melanocortin 4 (MC4) receptors in the hypothalamus (123). In addition, NPY/AgRP neurons send collateral inputs to the POMC/CART neurons that may chronically inhibit these neurons (124). Leptin-activated NPY/AgRP neurons become hyperpolarized and reduce the release of the orexigenic neuropeptides NPY and AgRP (124). AgRP antagonizes the actions of $\alpha-M S H$ at the MC4 receptors (125). Populations of the first-order neurons that produce NPY/AgRP and POMC/CART project intra-hypothalamically to second-order neurons in the paraventricular nucleus, lateral hypothalamic area, perifornical area, and zona incerta as well as extra-hypothalamically $(126,127)$. Candidate second-order neurons include those that express thyrotropin-releasing hormone (TRH), conticotropin-releasing hormone (CRH), and oxytocin in the paraventricular nucleus which cause anorexia, and neurons that express orexins (also known as hypocretins) and melanin-concentrating hormone $(\mathrm{MCH})$ in the lateral hypothalamic area and perifornical area which increase feeding (122). These neural circuits represent the main known downstream mediators of leptin's biological effects on food intake. Recently, two reports suggested that leptin is a regulator of both synaptic plasticity and axon guidance within the hypothalamus (128-130). Furthermore, inhibition of hypothalamic AMP-activated protein kinase appears to be necessary for leptin's effects on food intake (131).

\section{Leptin and the neuroendocrine axes}

Soon after its identification, it became apparent that leptin was also involved in the control of different neuroendacrine systems. The first clue suggesting that leptin 
might be involved in the regulation of the neuroendocrine system during starvation emerged with the observation that leptin deficient ob/ob mice have neuroendocine abnomalities similar to those during starvation $(132,133)$. A classic replacement study preventing the characteristic fall in leptin during fasting blunted the activation of the hypothalamic-pituitary-adrenal (HPA) axis, and the suppression of the thyroid and reproductive axes (132).

\section{Leptin and the corticotropic axis}

Genetically obese mice exhibit an overactive HPA axis resulting in hypercortisolemia throughout life and an exaggerated cortisol response to stress $(134,135)$. Corticosterone, the most critical hormone of the HPA axis, is elevated in rodents during fasting (132). As starvation is a type of stress, the actions of cortisol that relate to the stress response would be advantageous. Furthermore, cortisol promotes the shift to hepatic glucose production that is needed by the CNS when exogenous sources of nutrition are limited.

Leptin administration reversed the hypercortisolemia in $o b / a b$ mice and was able to block corticosterone and adrenocorticotrophic hormone (ACTH) secretion in response to Immobilization stress $(135,136)$. In addition, leptin blunted the stimulation of the HPA axis induced by an acute fast (132). Rodent data suggests that leptin may inhibit the HPA axis both centrally and peripherally. In vitro, leptin directly inhibited the release of $\mathrm{CRH}$ by hypothalamic neurons (135). Indirectly, leptin might suppress the HPA axis by inhibition of NPY, which normally activates the HPA axis. Despite the expression of leptin and the leptin receptor in corticotrope cells of the anterior pituitary, no effect of leptin upon ACTH secretion was detected $(135,137)$. One in vivo study, showing that rising leptin levels may have an independent effect on preventing insulim-induced stimulation of corticosterone secretion, supports a central mechanism (138). Leptin receptors are present in adrenal tissue, cortex as well as medulla $(139,140)$. Several studies found an direct inhibitory effect of leptin on ACTH-induced glucocorticoid biosynthesis and secretion in adrenalcortical cells in vitro $(139,141-143)$.

\section{Leptin and the thyroid axis}

Marked hypothalamic hypothyroidism and hypothermia is present in genetically obese mice (144). Similarly, the thyroid hormone economy in rodents accompanying starvation are characterized by low plasma $3,5,3^{\prime}$-triiodothyronine $\left(\mathrm{T}_{3}\right)$, and thyroxine $\left(T_{4}\right)$ and paradoxically low or normal thyroid stimulating hormone (TSH) levels (145). In addition, the glycosylation pattern of TSH during starvation is changed resulting in reduced bioactivity (146). Despite low thyroid hormone levels, starvation results in low pituitary TSH content, reduced expression of TRH in the paraventricular nucleus and a decrease in the concentration of TRH in the hypophysial portal blood suggesting a reset of the set point in the thyroid hormone feedback system. Since thyroid hormones are important regulators of basal energy expenditure (in addition to other mechanisms), it is theorized that the decreased levels during starvation is an adaptation to conserve the available energy stores as much as possible $(133,147)$. In rodents, systemic leptin administration blunted the fall of total and free $T_{4}$ and $T_{3}$ levels and prevented suppression of pro-TRH mRNA levels during fasting $(132,145)$. Several studies 
suggest that leptin regulates the TRH neurons through both direct and indirect pathways. TRH neurons in the paraventricular nucleus co-express the leptin receptor and secrete TRH protein in response to leptin $(148,149)$. In addition, recent evidence suggests that the TRH promotor is targeted by leptin in wivo (150). The a-MSH, NPY, and AgRP pathways, which all originate from the arcuate nucleus and subsequently project on TRH neurons in the paraventricular nucleus, have been proposed to mediate the indirect effect of leptin on TRH expression. Central administration of a-MSH pre. vents the fasting-induced suppression of TRH consistent with the known expression of its target, the MC4 receptor, on most TRH neurons. The neuropeptides NPY and $\mathrm{AgRP}$, which are induced during fasting, are potent negative regulators of TRH gene expression in the paraventricular nucleus $(149,151-157)$.

\section{Leptin and the somatotropic axis}

Mice who lack leptin have stunted linear growth. In addition, fasting in rodents is associated with a marked depression on spontaneaus pulsatile growth hormone (GH) secretion and reduced insulin-like growth factor 1 (IGF-1) levels. Chronic undernutrition has long been known to lead to stunted linear growth. This phenomenon may be a protective mechanism (mediated by low levels of IGF-1) in a period when calories are scarce, because when size increases also the metabolic needs of an individual rise. ICV administration of leptin stimulated both the spontaneous and growth hormone releasing hormone (GHRH) stimulated $\mathrm{GH}$ secretion in normal free-moving rats (158-160). Administration of leptin anti-serum to normal fed rats led to a decrease in GH secretion (158). Following leptin infusion, a reversal of the inhibitory effect exerted by fasting on pulsatile GH secretion was noted (160-162). Immunohistochemical studies demonstrated that a part of both the GHRH and the somatostatin hypothalamic neurons express leptin receptors and leptin subsequently was able to increase GHRH expression and suppress somatostatin expression (163-168). These results imply that leptin may act directly on both these neurons to modulate the release of these neurohormones and so stimulate GH secretion. The NPY pathway which originates from the arcuate nucleus has been proposed to mediate these indirect effects of leptin on $\mathrm{GH}$ release $(160,165,166)$.

\section{Leptin and the reproductive axis}

The first indication that leptin might influence reproduction came from the observation that both the $a b / a b$ as the $a b / d b$ mice are infertille and fail to undergo normal sexual maturation. Also undernutrition delays the onset of sexual maturation and in sexually mature animals disrupts normal reproductive function. The most likely teleological explanation for this specific neuroendocrine response is that the development of live and healthy progeny requires a large allotment of calories, and it would compromise both mother and fetus if the process began with insufficient calories stored as fat. It is less clear what benefit derives from the reproductive axis being diminished in starved males. Leptin administration was able to fully restore fertility to both female and male $a b / o b$ mice (but not to $d b / d b$ mice) and counteract the inhibitory effects of fasting on gonadotropin secretion in rodents $(132,169-172)$. In addition, ICV immunoneutralization of endogenous leptin disrupts cyclicity in female rats $(173,174)$. Furthermore, ab/ob mice with a transgene that expressed very low leptin levels corrected 
their sterlity without an effect on bodyweight suggesting that the reproductive system is very sensitive to leptin (175). The infertility of ob/ob mice could be corrected without leptin treatment but wa the inheritance of modifier genes (176). In contrast, it has been reported that male $a b / o b$ mice occasionally become fertille after body weight reduction, whereas: this never happened in female ob/ob mice which suggest a gender difference in the effect of leptin on reproduction $(176,177)$. Also the stage of sexual development appears to influence the net effect of leptin on gonadotropin secretion (178). ICV administration of leptin at doses that did not influence peripheral leptin levels restored luteinizing hormone (LH) secretion during fasting in rats, which suggests that leptin acts centrally to influence reproduction (179).

Using median eminence arcuate explants from adult rat it was demonstrated that leptin in subnanomolar concentrations significantly stimulated gonadotropin releasing hormone $(\mathrm{GnRH})$ release. In contrast, micromolar concentrations decreased $\mathrm{GnRH}$ production compared to controls (173). These results were confirmed by experiments performed in an immortalized GnRH-secreting neuronal cell line expressing the leptin receptor (180). Although previous studies suggest a direct effect of leptin on GnRH secretion, double-labeling studies thus far fail to demonstrate the expression of the leptin receptor in GnRH neurons with the only exception of immortalized cells $(163,180,181)$. While this cannot exclude a direct effect of leptin on GnRH neurons, an indirect effect through an intraneural circuit seems more likely (182). Several hypothalamic neural pathways have been examined as possible downstream effectors of leptin. Conflicting reports exist concerning the importance of the $\alpha-\mathrm{MSH}$ and AgRP pathways in mediating leptin action (183-188). Similarly, NPY demonstrated both stimulatory and inhibitory effects on $\mathrm{GnRH}$ secretion $(189,190)$. Recent studies in knockout mice lacking the POMC gene, $M_{3}$ receptor, $M C_{4}$ receptor, or NPY receptor and transgenic mice that overexpress AgRP did not show major malfunctions in reproduction (191-195). This suggests that these systems either are not critical in the reproductive effects of leptin or that reproduction has redundancy and possible pleiotrophy in its neuroendocrine system. Additional hypothalamic neural pathways have been proposed to mediate the indirect reproductive effects of leptin such as the CART peptide, orexin, galanin, prostaglandins, serotonin, and $\gamma$-aminobutyric acid neurons in the brainstem $(189,196-204)$. In addition, nitric oxide (NO) related mechanisms have been implicated in mediating leptin action on the GnRH-gonadotropin system $(199,205-207)$.

The leptin receptor has been identified in mouse and rat pituitary, ovine anterior pituitary, and human anterior pituitary indicating leptin may regulate pituitary function $(164,208,209)$. One study demonstrated a dose-related increase in follicle stimulating hormone (FSH) and $\mathrm{LH}$ release in male adult rats by leptin in vitro but only stimulatory effect on LH was shown in vivo (173). However, other experiments with fasted male rats demonstrated inhibitory effects of leptin on LH and FSH secretion suggesting that the actions of leptin on the pituitary are complex and might depend on the prevailing metabolic status (210). Co-localization of leptin with $\mathrm{LH}$ and FSH was observed together with expression of the leptin receptor in anterior pituitary cells implicating complex autocrine/paracrine regulatory interactions (137).

High levels of leptin receptor expression is present in the rat and human ovary $(28,211)$. Leptin directly inhibits insulin-induced steroidogenesis by isolated bovine granulosa cells though this effect was more potent in undifferentiated granulosa cells (211-213). In addition, leptin also impaired IGF-1, glucocorticoid, and gonadotro- 
pin-stimulated granulosa cell steroidgenesis in most studies $(28,212,214-218)$. Leptin directly antagonizes insulin's stimulatory effect on bovine thecal cell steroidgenesis (214). In human thecal cells, an inhibition of IGF-1 plus LH-induced andrastenedione secretion was observed (215). There is also evidence that leptin can prevent granulosa cell apoptosis in rat ovaries and serum-borne leptin accumulation in the ovary (219). Leptin treatment of perfused FSH-primed whole rat ovaries concomitantly with LH significantly decreased ovulation rate (218). In wivo, leptin administration in immature gonadotropin-primed rats led to a marked decline in ovulation rate (218).

The leptin receptor or its expression exist in murine spermatic cells, murine Leydig cells, murine testes, rat Leydig cells, and rat testis $(27,220-223)$. Expression of the leptin receptor was shown to be developmentally regulated and sensitive to regulation by gonadotropins (221). Furthermore, the passage of leptin across the blood-testes barrier appears to be mediated by a passive, non-saturable process (224). Experiments in Leydig cells and adult rat testicular slices showed an inhibitory effect of leptin on basal and human chorionic gonadotropin-induced testosterone secretion, but was ineffective at the pubertal age $(210,220,225)$. Immunohistochemical studies of mouse testis demonstrated the expressilon of leptin receptor on germ cells distributed in a age- and stage-dependent manner which may partially explain the infertility observed in leptin-deficient male mice (222).

In contrast to acute leptin treatment, constant infusion of leptin in fasted rats prevented the fall in prolactin (PRL) (226). The administration of a higher dose of leptin to these rats even led to further increases in PRL levels. Due to the fact that the Ob- $R$ is very scant in lactotropes, it is suggested that leptin controls prolactin release via a hypothalamic target (227).

\section{Leptin and the immune system}

Several in witro and in vivo studies have suggested a potential role for leptin in modulating the immune response (228). The discovery that the leptin receptor is widely expressed in various non-neuronal tissues including lymph nodes, monocytes, T-lymphocytes, and hemopoletic cells suggests that leptin also possesses immunoregulatory actions (229-234). Furthermore, the leptin receptor is structurally related to the class $\|$ cytokine receptor family and has been shown to have signaling capabilities of interleukin 6-type cytokine receptors (21).

Leptin deficient $o b / a b$ mice have several defects in their immune system similar to the immunological changes during starvation. Atrophy of the spleen, thymus, and lymph nodes is found in starved and $a b / o b$ mice predominantly due to decreased lymphocytes (especially T-lymphocytes) and increased rate of apoptosis which could be reversed by exogenous leptin (235). In addition, ob/ob mice cannot clear and eliminate circulating Escherichia coli as efficiently as normal mice and are more susceptible to bacterial pneumonia $(236,237)$. In vivo, the phagocytic function of macrophages is impaired in ob/ob mice. Leptin restored normal phagocytosis from macrophages derived from ab/ob mice but not $d b / d b$ mice (236). Moreover, the increase of TNF- $\alpha$ and IL-6 after lipopolysaccharide (LPS) administration is attenuated in $o b / a b$ mice and falfa rats compared to lean controls (236). Also leptin increased the LPS-induced secretion of TNF- $\alpha, \mid \mathrm{L}-6$, and IL- 12 by cultured peritoneal maciophages from normal lean mice (236). Lymphocytes from ob/ab mice show a defective mixed lymphocyte 
reaction with decreased production of the proinflammatory cytokines interleukin 2 $(\mathrm{IL}-2)$ and interferon-y and increased production of the anti-inflammatory cytokine interleukin 4 (1L-4). Leptin modulated T-lymphocyte activation toward T-helper 1 proinflammatory phenotype by stimulating the secretion of IL-2 and interferon-y but not IL-4 (29). In keeping with the previous observations, starved and leptin-deficient ob/ob mice appear to be less susceptible to the (lethal) effects of LPS and TNF- $\alpha$ which could be reversed by leptin treatment $(238,239)$. Also ob/ob mice are protected from T-cell mediated hepatotoxicity, experimental autoimmune encephalomyelitis, experimentally induced colitis and glomerulonephritis, and the course of albumin-induced arthritis is miller with reduced levels of antibodies (240-245). Interestingly, only hyperleptinaemic female mice develop autoimmunity, whereas hypoleptinaemic mice are protected, and treatment of experimental autoimmune encephalomyelitis-resistant $S \mathrm{JL} / \mathrm{J}$ male mice with recombinant leptin renders them susceptible (246). This result suggests that the elevated levels of leptin present in females might have a role in favoring the predisposition of females to the development of autoimmunity. The reduction in the mean delayed-type hypersensitivity response in mice during starvation was completely reversed by the injection of leptin (29). Recent experiments demonstrated that direct injection of leptin into the CNS cannot compensate for the immunosuppression that is associated with starvation-induced hypoleptinaemia which suggests that peripheral leptin has a dominant role in maintaining T-cell-mediated immune responses in radents (247).

The effects of leptin administration on preserving immunity during starvation in mice seem to be both direct through leptin receptors found on cells of the immune system as indirect through the prevention of the neuroendocrine adaptations during starvation. These observations suggest that one of the physiological functions of leptin is to inform the immiune system of the status of the energy balance/stores.

\section{Other actions of leptin}

Leptin appears to be a pleiotrophic hormone affecting many different tissues in the body. Stimulation of both angiogenesis and wound re-epithelialization have been reported $(30,248)$. Leptin increases sympathetic nerve activity to kidneys, adrenals, hindlimb skeletal muscle, and brown adipose tissue (249). In addition, blood pressure elevation in hyperleptinemic transgenic skinny mice was observed (250). However, the leptin receptor was demonstrated in endothelial cells and leptin administration resulted in a stimulation of NO release $(30,251)$. Together it was hypothesized that leptin is involved in the control of blood pressure by producing a central neurogenic pressor effect and inducing an opposing peripheral depressor effect through NO-dependent as well as NO-independent mechanisms (251-253). Thus, leptin has been implicated in the development of cardiovascular complications in obesity. Also several lines of evidence support leptin as a key factor linking energy intake to bone metabolism vila both central and peripheral mechanisms (25.4). The widespread expression of leptin and the leptin receptor in the placenta as well as in fetal tissue suggests that leptin may play a role in fetal development (255-257). Leptin is also possibly involved in brain development evidenced by the multiple defects present in $o b / a b$ and $a b / d b$ mice which were reversed by chronic leptin administration $(258,259)$. Gastric mucosa secretes leptin both into the blood and the gastric lumen and this secretion was in- 
creased by vagal stimulation $(51,260-262)$. Furthemore, the leptin receptor is also present on gastric epithelial cells and jejunal epithellum $(261,263)$. Interestingly, leptin increases in wivo the activity of vagal afferents from the gut which are known to relay digestive information to the brain (264-266). A behavioral study showed a synergistic effect between leptin and cholecystokinin to suppress food intake in lean mice (267-269). Leptin may play a complex role in the gut as a peripheral signal involved in the modulation of gastric acid secretion, intestinal motility, nutrient intake, and absorption $(263,270-273)$.

Leptin might exert effects on metabolism independent of its role in body weight regulation. A role of leptin as a regulator of glucose homeostasis was first established when the diabetic phenotype of ob/ob mice was reversed by a low-dose leptin treatment which failed to induce weight loss (274-276). However, a substantial amount of paradoxical observations followed on the effects of leptin on insulin secretion and insulin resistance. Leptin appears to act in a complex way on both peripheral tissues such as sikeletal muscle, liver, adipose tissue, and pancreas and vila the CNS to control basal and insulin-mediated glucose homeostasis. In contrast to the in vitro results which suggest an inhibitory role on glucose homeostasis, whole body studies implicate an insulin-sensitizing effect of leptin which may depend on central mechanisms $(277-279)$

The identification of functional leptin receptors in white adipose tissue suggests an autocrine-paracrine effect of leptin (280). Adenoviral transfer of leptin resulting in hyperleptinemic rats completed ablated fat tissue in contrast with their pair-fed controls suggesting a specific activity for leptin on lipid metabolism beyond its appetite reducing effects (281). Leptin induced an extraneural direct lipolytic action on adipocytes and nonadipocytes (282-286). Also leptin lowered the expression of lipogenic transcription factors and lipogenic enzymes and at the same time upregulated oxidative factors and enzymes in nonadipose target tissues resulting in an antilipogenic, pro-oxidative action on peripheral nonadipose target tissues $(31,287-289)$. It is proposed that an important function of leptin is to protect nonadipose tissue from lipotoxicity during high caloric intake by confining the storage of triglycerides to the adipocytes, while limiting triglycerides storage in nonadipocytes $(290-293)$

\section{The physiological role of leptin}

After the discovery of leptin most initial research was focused on its role in body weight regulation and pathophysiology of obesity $(45,294,295)$. Deficiency of leptin appeared to be the cause of severe obesity in the ob/ob mice (1). This was confirmed by several stuidies which showed that replacement with exogenous leptin was able to decrease body weight and body fat content in both leptin-deficient ob/ob mice and in a lesser extent in wild-type mice $(109,274-276,296)$. In addition, plasma levels concentrations correlated strongly with body mass index, percentage body fat, and fat mass $(59,297,298)$. Thus, the adipocyte-derived hormone leptin was considered to be well positioned to convey information about the amount of adipose tissue to the CNS allowing a negative feedback system. Leptin appeared to be the long-sought 'lipostat' molecule of the adipostatic model, which was postulated to explain the relative stability of weight over time in many animals and their capacity to resist overfeeding (299). 
The rising levels of lepth with increasing adiposity would generate a signall to inform the brain that excess energy is stored as fat which would allow the CNS to implement appropriate adaptations such as a reduction in appetite and an increase in energy expenditure in order to limit further weight gain. Conversely, reduced fat stores lead to a decrease in leptin levels, which the brain would perceive as a signal to push the organism to a positive energy balance. However, resistance to the proposed anti-obesity action of leptin is observed in both animals and humans. The high endogenous leptin levels present in obesity fail to prevent this condition. Similarly to insulin resistance in type 2 diabetes, hyperleptinemie was hypothesized to be the result of leptin insensitivity or resistance $(58,300)$. Several mechanisms proposed to explain this phenomenon include (post)receptor defects, dysiregulation of leptin symthesis/secretion, and impaired brain leptin transport. However, the widespread accurrence of leptin resistance might reflect the fact that the inability to store energy efficiently at times of abundance is evolutionarily disadvantageous. According to this alternative view, leptin has a broader physiological role and evolved as a signal whose reduction indicates starvation $(132,133)$.

\section{Outline of the thesis}

The increasing rates of obesity and consequent morbidity represent a major health problem world wide. The discovery of the leptin pathway and its central role in the regulation of food intake and energy expenditure promised new treatment options in human obesity.

Leptin must gain access to specific regions of the brain to exert its effects and therefore needs to cross the blood-brain barrier. The pilot study described in chapter 2 investigated the crucial question if the long-acting pegylated recombinant leptin (PEG-OB) used in all our trials could enter into the human CNS. In this study, leptin measurements were performed in CSF obtained from two volunteers four days after a single subcutaneous dose of PEG-OB was administrated.

The early view that leptiln functioned as a simple anti-obesity hormone was inconsistent with the widespread occurrence of leptin resistance. However, it was believed that leptin resistance might be overcome by therapeutic augmentation of circulating leptin levels. To test this hypothesis, two clinical trials were executed, which are described in chapter 3 and 4 . Both studies investigated the effect of weekly subcutaneous administration of respectively 20 and $60 \mathrm{mg}$ of $\mathrm{PEG}-\mathrm{OB}$ on energy homeostasis and metabolic changes in obese subjects on a mild hypocaloric diet.

According to an alternative view, leptin has a broader physiological role and evolved as a signal whose reduction indicates starvation and subsequently initiates the complex neural, metabollic, neuroendocrine, and behavioral responses thought to have survival value in periods of inadequate energy intake. A consequence of this hypothesis is that exogenous leptin should be able to blunt these fasting-induced adaptations when administrated during severe energy restriction. The answer to the question whether elevated leptin levels using PEG-OB changed the effects of semistarvation on weight loss or body-composition, energy expenditure, appetite, metabolic profile, and neuroendocrine measures in healthy overweight male subjects, is addressed in chapter 5 and 6. 
A growing body of evidence suggested that leptin is a modulator of the immune and proinflammatory responses. Chapters 4 and 7 describe two studies, which explored the suggested relationship between the elevated leptin levels and the low-grade systemic inflammation both present in human obesity.

The neuroendocrine data derived from our previous study (chapter 6) prompted us to investigate the physiological role of leptin in regulating reproductive function in another low-leptin state. To that end, a detailed study of the pulsatile characteristics of healthy young women with a low body fat mass and thus low circulating leptin levels was performed before and after the administration of $\mathrm{PEG}-\mathrm{OB}$, which is described in chapter 8.

Finally in chapter 9 , the results and interpretations of the above-described studies are discussed and put into a broader perspective.

\section{References}

1. Zhang, Y., Proenca, R., Maffei, M., Barone, M., Leopold, L. and Friedman "J.M. 1994. Positional claning of' the mouse obese gene and its human homologue. Nature. 372:425-432.

2. Ingalls, A.M., Dickie, M.M., and Snell, G.D. 1950. Obese, new mutation in house mouse. I Hared. $41: 317-318$.

3. Hummel, K.P., Dickie, M.M., and Coleman, D.L. 1966 . Diabetes, new mutation in the mouse. Science. 153:1127-1128.

4. Zucker, L.M., and Zucker, T.F. 1961. Fatty, a new mutation in the rat. 4 Hered. 52:275-278.

5. Coleman, D.L. 1973. Effects of parabiosis of obese with diabetes and normal mice. Diabetologia. 9:294-298.

6. Coleman, D.L. 1978. Obese and diabetes: two mutant genes causing diabetes-obesity syndromes ir mice. Diabetologia 14:141-148.

7. He, $Y .$, Chen, $H_{n,}$ Quon, M.J., and Reitman, M. 1995. The mouse obese gene. Genomic organization, promoter activity, and activation by CCAAT/enhancer-binding proteln alpha. J Biol Chem, 270:281887-28891.

8. Isse ${ }_{n}$ N., Ogawa, $Y .$, Tamura ${ }_{*} N_{*}$ et al, 1995. Structural organization and chromosomal assignment of the human obese gene. J Biol Chem. 270:27728-27733.

9. Gong, D.W., Bi, S., Pratley, R.E., and Weintraub, B.D. 1996. Genomic structure and promoter analysis of the human obese gene. J Biol Chem. 271:3971-3974.

10. Hwang, C.S., Mandrup, S., MacDougald, O.A., Geiman, D.E., and Lane, M.D. 1996. Transicriptional activation of the mouse obese (ob) gene by CCAAT/enhancer binding protein alpha. Proc Natl Acad' SCI USA. 93:873-877.

11. Miller, S.G., De Vos, P., Guerre-Millo, M. et af, 1996. The adipacyte specific transeription tactor C/EBPalpha modulates human ob gene expression. Proc Nat Acad Sci USA. 93:5507-5511.

12. Cahen, S.L., Hallaas, J.L., Friedman, J.M., et al. 1996. Human leptin characterization. Nature, 382:589.

13. Madej, T., Boguski, M.S., and Bryant, S.H. 1995. Threading analiysis suggests that the obasie gene product may be a helicall cytokine. FEBS Lett. 373:13-18.

14. Zhang ,F., Basinski, M.B., Beals, J.M. ot al. 1997. Crystal structure of the obese protein leptin-E100. Nature. 387:206-209.

15. Grasso, P., Leinung, M.C., Ingher, S.P., and Lee, D.W. 1997. In viwo effects of leptin-related synthetic peptides on body weight and food intake ln female ob/ob mice: localization of leptin activity to domalns between amino acid residues $106-140$. Endocrinology. 138:1413-1418.

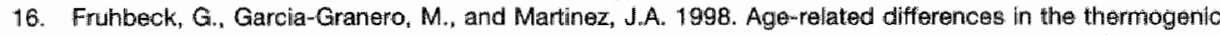
and ponderal effects following the administration of fragment peptides from the rat ob protein. Regw Pept. $73: 83-87$

17. Biarr, V.A., Malide, D. Zarnowslki, M.d., Tayior, S.I., and Cushman, S.W. 1997, lnsulin stimulates both leptin secretion and production by rat white adipose tissue. Endocrinology, 138:4463-4472.

18. Moon, B.C., and Friedman, J.M. 1997. The molecular basis of the obese mutation in ob2J micie. Qenomics. 42:152-156.

19. Rau, $H_{\text {. }}$ Reaves, B.J., O'Rahilly, $S_{n}$, and Whitehead, J.P. 1999. Truncated human leptin (delta 133) associated with extreme obesity undergoes proleasomal degradation after defective intracellular transport. Endocrinology. 140:1718-1723.

20. Tartaglia, $L$ A, Dembski, $M$, Weng, $X_{1,}$ et al. 1995. Identification and expression cloning of a leptin receptor" OB-A. Cell. $83: 1263 \times 1271$. 


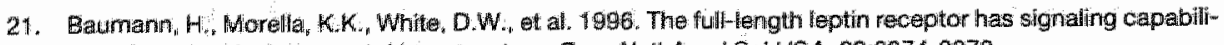
the of interleukin b-type cytokine receptors. Proc Nath Acad Sci USA 93:8374-8378.

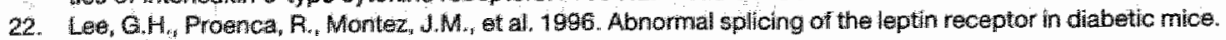
Naturs 379:632-635.

23. Tartaglia, L.A. 1997. The leptin receptor. J Biol Chem. 272:6093-6096.

24. Mercer, JG, Hoggard, N. Willarns, L.M. Lawrence, G.B., Hannah, L.T., and Traytum, P. 1996. Localizaw ton of lepth receptor thRNA and the long form splice variant (Ob-Rb) in mouse hypothalamus and adjacent brain regions by in stu hybrelization. FEBS Lett $367: 113-116$.

25. Guan, X.M., Hess, J.F, YU, H, Hey, P.,., and van der Ploeg, LH. 1997 . Differential expression of mRNA for leptin recaptor isoforms in the rat brain. Mol Cell Endocrinol. 133:1 .7.

26. Emilsson, V. Lu, Y.L, Cawthome, M.A., Morton, N.M., and Davenport, M. 1997. Expression of the functonall leptit receptor mRNA in pancreatic is sefs and direct inhibitony action of leptin on insulin secretion. Diabetes. $46,313-3-16$.

27. Hoggard, N, Mercer, J.G. Rayner, D.V., Moar, K, Trayhum, $P_{*}$ and Williams, L.M. 1997. Localization of leptin receptor mPNA splice variants in murine peripheral tissues by RT-PCR and in situ hybridization. Bocitem Brophys Res Commun. 232,383-387.

28. Kartsson, $C$, Lindell, $K$, Swensson, $E$. et al. 1997. Expression of functional leptin neceptors in the human ovary. J Chin Endocrinol Metab. B2:4144-4148.

29. Lord, G.M. Matarese, G., Howard, L.K., Baker, R.J., Bloom, S.R. and Lecinler, R.I. 1998. Leptin modulates the T-cell inmune response and reverses starvation-induced immunosuppression. Nature. 394:897 901.

30. Sierra-Honigmann, M.R., Nath, A.K., Murakami, $C_{\text {, }}$ et al. 1998. Biological action of leptîn as an angiogenic factor, Science. 281:1683-1686.

31. Minokosht, Y., Kim, Y.B., Peroni, O.D.; et al. 2002. Leptin stimulates fatty-acid oxidation by activating AMP-activated protelin kinase. Nature. 415:339-343.

32. Divos, $R_{\text {. }}$ Richards, J.G., Campfield, L.A., et al. 1996. OB protein binds specifically to the choroid plexus of mice and rats Proc Natl Acad Sci USA, 93:5668-5673.

33. Lynn, A.B., Gao, G.Y., Considine, R.W., Hyde, T.M., and Caro, J.F. 1996. Autoradiographic localization of leptin binding in the choroid plexus of ob/ob and $\mathrm{db} / \mathrm{db}$ mice. Biochem Biophys Res Commun. $219: 884-889$.

34. Maamra, M., Bidlingmaier, M. Postel-Winay, M.C., Wu, Z, Strasburger, C.J., and Ross, R.J. 2001. Generation of human soluble leptin receptor by proteolytic cleavage of membrane-anchored receptors. Endocrinology. 142:4389-4393.

35. Bjorbaek, C., Uotani, $S_{.}$, da Silva, $B_{*}$ and Flier, J.S. 1997. Diwergent signaling capacities of the long and shoit isoforms of the leptin receptor. J Biol Chem. 272:32686-32695.

36. Banks, A.S., Davis, S.M., Bates, S.H., and Myers, M.G. 2000. Activation of downstrearn signals by the long form of the leptin receptor. $J$ Biol Chem. 275:14563-14572.

37. Yamashita, T., Murakami, T. Olani, S. Kuwajima, M., and Shima, K. 1998. Leptin receptor signal transouction: OBRa and OBRb of fa type. Biochem Biophys Res Commun. 246:752-759.

33. Ghilardi, N., Zlegler, S., Whestner, A., Stoffel, R., Heim, M.H., and Skoda, R. C. 1996. Defective STAT signaling by the leptir receptor in diabetic mice. Proc NaU Acad Sci USA. 93:6231-6235.

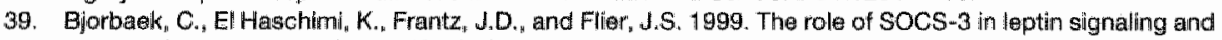
leptin redistance. I Biol Chem. 274:30059-30065.

40. Elchebly, M., Payette. P. Mchaliszyn, E., et al. 1999 . Increased insulin sensitivity and obesity resistance in mice llack king the protein tyrosine phosphatase $1 \mathrm{~B}$ gene. Science. $283: 15.44 \times 1548$.

41. Kaszubska, W. Falls, H.D., Schater, V.G., at al, 2002. Protein tyrosine phosphatase hB negatively regulates leptin siginaling in a hypothalamic cell lithe. Mol Cell Endocrinol, 195:109-118.

42. Niswender, K.D., and Schwertz, M.W. 2003. Insulin and leptiry revisited: adposity signals with overlapping physiologlcal and intracellular signaling capabilitles. Front Neuroendocrinol, 24:1-10.

43. Uotani, S., Bjorbeek, C., Tomoe, in, and Flier, J.S. 1999 . Functional properties of leptin receptor isoforms: intemalization and degradation of leptin and ligand-induced receptor downregulation. Diabetes. $48.279 \cdot 286$.

44. Chen, H. Charlat, O., Tartaglia, L.A., et al. 1996. Evidence that the diabetes gene encodes the leptin receptor: identification of a mutation in the leptin receptor gene in db/db mice. Cell. 84:49y-495.

45. Friadman. J.M. and Halaas, J.L. 1998, Leptin and the regulation of body weight un mammals. Nature. 395:763-770.

46. Li, C. ilotfi, E., Fidahusein, N. Connolly, E., and Friedman, J.M. 1998, Absence of soluble leptin receptor in plasma from $\mathrm{dbPas} / \mathrm{dbPas}$ and other $\mathrm{db} / \mathrm{db}$ mice. I Biol Chem. 273:10078-10082.

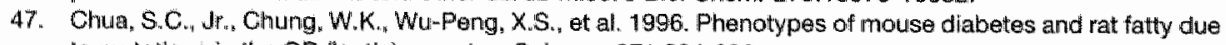
to mutations in the OB (leptir) receptor. Science. 271:994-996.

48. Whate, D.W., Wang , D.W., Chua, S.C., Jr, et all. 1997. Constitutive and impaired signaling of leptin receptors containing the Gin $\rightarrow$ Pro extracellular domain fatty mutation. Proc Natt Acad Sci USA. 94:10657-10662. 


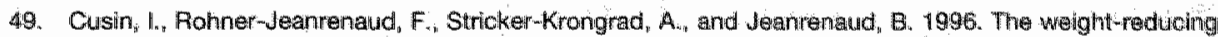
effect of an intracerebrowentric liar bolus injection of leptin in genetie ally obses fafa rats Reduced sensitivity compared with lean animals. Diabetes. $451446-1450$.

50. Takaya, K., Ogawa, Y., Hiraoka, J." et al. 1996. Nonsense mutation of lept in receptor in the obese spontameously hypertensive Koletsky rat. Nal Genet 14:130-131.

51. Bado, A. Levasseur, S., Attoub, S, et all. 1998. The stomach is source of leptin. Nature. $394: 790-793$

52. Masuzaki, H., Ogawa, $Y_{,}$Sagawa, N., el al. 1997. Nonadipose tissue production of leptin. leptin as a novel placenta derived hormone in humans. Nat Med, 3:1029-1033.

53. Cioffi, J.A., Van Blerkom, J., Antczak, M., Shafer, A., Wittmer, S., and Snodgrass, H.R. 1997. The expression of leptin and its receptors in pre-ovulatory human follicles. Mol Hum Rioprod. 3:467-472.

54. Wang, $\Downarrow_{.,}$Lu, R., Hawkins, M., Barzilai, N., and Rossetti, L. 1998. A nutrient-sensing pathway regulates leptin gene expression in muscle and fat. Nature. 393:684-688.

55. Potter, J.J., Womacik, L., Mezey, E, and Anania, F.A. 1998. Transififferentiation of rat hepatio stelliate cells results in leptin expression. Brochem Biophys Res Commun. 244:178-182.

56. Casabiell, X., Pineiro, V., Tome, M.A., Peino, R., Dleguez, C., and Casanueve, F.F. 1997. Presence of leptin in colostrum and/or breast milk from lactating mothers: a potential role in the regulation of nonatal food intake. J C/in Endacrinol Metab. 82:4270-4273.

57. Wiesner, G., Vaz, M., Collier, G., et al. 1999. Leptin is released from the human brain: Influence of adiposity and gender. J Clin Endocrinol Metab. 84:2270-2274.

58. Hamilton, B.S., Paglia, D. Kwar, A.Y., and Deitel, M. 1995. Increased obese mRNA expression in on ental fat cells from massively obese humans. Nat Med. 1:953-956.

59. Considine, R.V., Sinha, M.K., Heiman, M.L., et al. 1996. Serum immunoreactivemeptin conoentrations in normal-weight and obese humans. N Engl J Med. 334:292-295.

60. Trayhum, P., Thomas, M.E., Duncan, J.S., and Rayner, D.V. 1995. Effects of fasting and refeeding on ob gene expression in white adipose tissue of lean and obese (oblob) mice. FEBS Lett. 368:488 490.

61. Maffei, M. Fei, H, Lee, G.H., et al. 1995. Increased expression in adipocytes of ob RNA in mice with levsions of the hypothalamus and with mutations at the db locus. Proc Natl Acad Sci USA. 92:6957-6960.

62. Rayner, D.V., Dalgliesh, G.D., Duncan, J.S., Hardie, L.J., Hoggard, N.y and Trayhum, P. 1997. Postnatal development of the ob gene system: elevated leptin levels in suckling fa/fa rats. Am $J$ Physiol. 273:R446-R450.

63. Hube, $F$., Lietz, $U_{\text {, }}$ gel, M. ot al. 1996. Difference in leptin mRN.A lewels between omental and subcutaneous abdominal adipose tilssue from obese humans. Horm Metab Res. 28:690-693.

64. Montague, C.T., Prins, J.B., Sanders, L., Digby, J.E., and O'Rahilly, S. 1997. Depot- and sex-specific differences in human leptin mFNA expression: implications for the control of regional fat distribution. Diabetes. $46: 342-347$.

65. Boden, G., Chen, $X_{1}$, Mozzoli, M., and Fyan ${ }_{y}$ I. 1996. Effect of fasting on serum leptin in normal human subjects. J Clin Endacrinol Metab. 81:3419-3423.

66. Kolaczynstki, J.W., Ohannesian, J.P., Considine, R.V., Marco, C.C., and Caro, J.F. 1996. Response of leptin to short-term and prolonged overteeding in humans. J Clin Endocrinol Metab. 81:4162-4165.

67. Rentsch., J., and Chiesi, M. 1996. Regulation of ob gene MRNA levels in cultured adipocytes. FEBS Lett. 379:55-59.

68. Saladin, R., De Vos, P., Guerre Millo, M. at al. 1995. Transient increase in obese gene expressilon atter food intake or insullin administration. Nature. 377:527-529.

69. Boden, $G_{\text {." Chen }}, X_{*}$, Kolaczynski, J.W., and Polansky, M. 1997 . Effects of prolonged hyperinsulinemis on serum leptin in normal human subjects. J Cin Invest. 100:1107-1113.

70. Mueller, W.M., Gregoire, F.M., Stanhope, K.L., et all 1998. Evidence that glucose matabolism regullates leptin secretion from cultured rat adipocytes. Endocrinology. 139:551-55.

71. Sintha $\mathrm{r}_{\mathrm{r}}$ M.K., Sturis, J., Ohannesian, J., et al. 1996. Ultradian oscillations of leptin secretion if humbern. Biochem Eiophys Res Commum. 228:733-738.

72. Schoeller, D.A., Cella, L.K., Sinha, M.K., and Caro, J.F. 1997 . Entrainment of the diurnal rhythm of plazma leptin to meal timing. J Clin Invest. 100:11882-1887.

73. Slieker, L.J., Sloop, K.W., Surface, P.L., et al. 1996. Regulation of expression of ob mifNA and protein by glucocorticoids and CAMP. S Biol Chem. 271:530 -5304

74. Cizza, G., Lotsikas, A.J. Licinio J., Gold, P.W., and Chrousos, G.P. 1997. Plasma leptin levels do not change in patients with Cushing's disease shortly after correction of hypercortisolism. U' Chin Endocrinol Metab. 82:2747-2750.

75. Blum, W.F., Englaro, P., Hanitsch, S., et al. 1997. Plasma leptin levels in thealthy children and adolescents: dependence on body mass index, body fat mass, gender, pubertal stage, and testosterone. I chin Endocrinol Metab. 82 2904-2910.

76. Guallilo, O., Lago, F., Garcia, M., et al. 1999. Prolactin stimulates leptin secretion by rat white adipose tissue. Endocrinology. 140:5149-5153. 
77. Pasmusen, D.D, Boldt, B.M. Whinson, C.W., Yellon, S.M, and Matsumoto, A.M. 1999. Daily melatonin administration at middie age suppresses male rat visceral fat, plasma leptin, arid plasma instim to youthul lewets. Endocrindogy. 140:1009-1012.

78. Ahrma, R.S, arid Find, J.S. 2000. Leptin. Annu Rev Physiol. 62:413-437.

79. Grunteld, $\mathrm{C}$, , Zhao, $\mathrm{C}$. Fuller, d., all, 1996. Endotoxin and cytokines induce expression of leptin, the ob gene product, in hemsters. J Clin hwast. $97,2152-2157$.

80. Janik, JE, Curt, B.O., Considine, R., et alt. 1997. Interleukin 1 alpha increases serum leptin concentraWons in humansi, Chin Endocrinol Metab. 82:3084-3086.

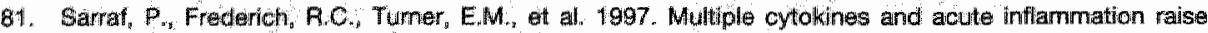
mouse leptin levels potential role inf infammatory anorexia. J Exp Med. 185:171-175.

82. L, H. Matheny, M, and Scarpace, P.J. 1997, beta 3-Adrenergic-mediated suppression of leptin gene expression in rats. Am J Physiol 272.E1031-E1036.

83. Trayhum, P., Durnean, JS, and Fayner, D.V. 1995. Acute cold-induced suppression of ob (abrese) gene expression in white adipose tissue of mice: medlation by the sympathetic system. Biochem $\mathrm{J} .311 \mathrm{Pt}$ $3): 720-733$.

84. Donahoo, W.T, Jensen, D.F,, Yost, T.J., and Eckel, R.H. 1997. lsoproterenol and somatostatin decrease plasma leptin in thumans: a novel mechamism regulating leptin secretion. I Clin Endocrinol Metab. B2:4139-4143.

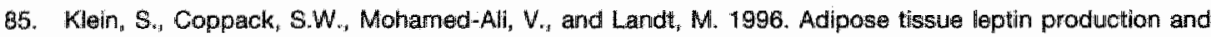
plasma leptin kinetics in humans. Diabutes. 45:984-987.

86. Meyer, C, Robson, D, Rackowsky, N., Nadkarni, $V_{\text {., }}$ and Gerich, 4.1997 . Rote of the kidney in himan leptin metabollsm. Am at Physiol. 273:E903-E907.

87. Licinio, J., Mantzoros, C., Negrao, $A_{1} B_{i}$ et all. 1997. Human leptin levels are pulsatile and inversely related to pituitary-adrenal function. Nat Med. 3:575-579.

88. Licinio, J., Negrao, A.B., Mantzoros, $C_{3}$, et al. 1998. Synchronicity of frequently sampled; 24-h concentra* thons of circulating leptin. luteinizing hormone, and estradiol in healthy women. Proc Nat/ Acad Sci USA. $95,2541-2546$.

89. Licinio, J., Negrao, A.B. Mantzoros, $C_{*}$, et al. 1898 . Sex differences in circulating human leptin pulse amplitude: clinical implications. J Clin Endocrinol Metab. 83:4140-4147.

90. Sintra, M.K. Ohanitesian, J.P., Heiman, M.L., et al. 1996. Noctumal rise of leptin in lean, obese, and non-insulin-dependent diabetes mellitus subjects. J' Clin lovest. 97:1344-1347.

91. Pombo, M. Herrera-Justiniano, E., Considine, $R_{1 .} V_{.,}$et al. 1997. Nocturnal rise of leptin in normal prepubertal and pubertal children and in patients with perinatal stalk-transection syndrome. I Clin Endocrinol Metab, 82:2751-2754.

92. Saad, M.F., Rilad-Gabriel, M.G., Khan, A. et al. 1998. Diurnal and ultradian thythmicity of plasma leptin: effects of gender and adiposity. J Clin Endocrinol Metab. 83:453-459.

93. Taylor, A.E., Hubbard, J., and Anderson, E.J. 1999. Impact of binge eating on metabolic and leptin dynamics in normal young women. $J$ CHin Endocrinol Metab. 84:428-434.

94. van Aggel Leijssen, D.P.C., van Baak, M.A. Tenenbaum, R., Camptield, L.A, and Saris, W.H.M. 1999. Regulation of average $24 \mathrm{~h} \mathrm{human}$ plasma leptin lewel; the influence of exercise and physiological changes in energy balance. Int J Obes Relat Motab Disord. 23:151-158.

95. Balligand, J.L Bricherd, S.M., Brichard, V., Dessageir, J.P., and Lambert, M. 1998. Hypoleptinemia in patients with anorexia nervosa: loss of circadian rthythm and unresponsiveness to short-term refeeding. Eur $d$ Endoctinal. 138:415*420.

96. Laughtin, G.A, and Yen, S.S. 1997. Hypoleptinemia in women athlletes: absence of a diurnal rhythm with amenorthea. $J$ Clin Endocrinol Metad. B2:318*321.

97. Laughlin, G.A., Dominguez, C.E., and Yen, S.S. 1998. Nutritional and endocrinemetabolic abernations in women with fumot tonal hypothalamic amenorriea. I Clin Endocrino/ Metab. 83:25i-32.

98. Sakane, N. Yoshida, T., Mizutani, T., and Nakagawa, $Y$. 1998, Serum leptin levels in a patient with pheochromocytoma.. J Clin Endocrinai Metab. 83:1400.

99. Himms Hagen, J.1998. Physiological roles of the leptin endocrine system: differences between mice and humans. Crit Rev Ctin Lab Sci. 36:575-655.

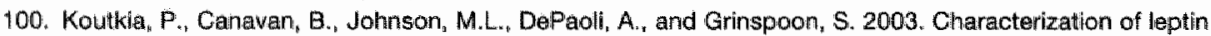
pulse dynamics and relationshlp to fat mass, growth homone, cortisol, and Insulin. Am I Physiol. 285:E372-E379.

101. Sinha, M.K., Opentanova, 1., Ohannesian, J.F., ot al. 1996. Evidence of free and boumd leptin in humar, circullation. Studies in lean and obese subjects and during short-term fasting. 1 Clin inwest. 98:1,277-1282.

102. Hill, R.A., Margetic "S., Pegg, G.G. and Gazzola, C. 1998 . Leptin: its pharmacokinetics and tissue distributhon. Int J Obes Relat Metab Disord. 22:765-770.

103. Lahlou, N., Issad, T., Lebouc, $Y_{\text {. }}$ et al. 2002. Mutations in the human leptin and leptin receptor genes as mode: $\$$ of serum leptin receptor regulation. Diabetes. 51:1980-1985.

104. van Dielen, F.M., van 't Veer, C., Butman, W.A., and Greve, J.W. 2002. Leptin and soluble leptin receptor lew is in obese and weight-losing Indiwiduals. J Clin Endocrinol Metab. 87:1708-1716. 
105. Wu, Z, Bidlingmaier, M. Lit, $C_{\text {. }}$, et al. 2002. Quantification of the soluble leptin receptor in human blood by ligand-mediated immunohunctional assay. 1 Chn Endocrinol Metab. $972931-2939$.

106. Chan, J.L., Bluher, S, Yiannakouris, N, Suchare, M.A., Kratzsch, d, and Mantzolos, O.S. 2002; Regulation of circulating soluble leptin receptor levels by gender, adiposity, sex steroids; and leptin: observational and interventional studies in humans. Diabetes. 51:2105-2112.

107. Houseknecht, K.L., Mantzoros, C.S., Kullawat, $R_{*}$, Hadro, E. Flier, J.S. and Kahn, B. B. 1996. Evidence for leptin binding to proteins in serum of rodents and humans: modulation with obesity. Diabotes: 45:1638-1643.

108. Liu, $C_{-i}$ Liu, X.J., Barry, G., Ling, N. Maki, R.A., and De Souza, E.B. 1997. Expression and characterization of a putative high affinity human soluble leptin receptor. Endocrinology. 138:3548-3554.

109. Schwartz M.W., Seeley, R.J., Campfield, L.A., Bum, P., and Beskin, D.G. 1996. Identification of targets of leptin action in rat typothalamus. J Clin Invest. $98: 1101-1106$.

110. Caro, J.F., Kalaczynski, J.W., Kyce, M.R., et al. 1996. Decreased cerebrospinal-fluid/serum leptin ratio in obesity: a possible mechanism for leptin resistance. Lancet. 348:159-161.

111. Mantzoros, C., Flier, J.S. Lesem, M.D. Brewertom, T.D., and Jimerson, D.C. 1997. Corabrospinall thid leptin in anorexia newosa: correlation with nutritional status and potential role in resistance to weight gain. $J$ Clin Endocrinol Metab. 82:1845-1851.

112. Schwartz, M.W., Peskind, E., Raskind, M., Boyko, E.J., and Porte, D., Jr. 1996. Carebrospinal thuid leptin levels: relationship to plasma levels and to adiposity in humans. Nat Med. $2: 589-593$.

113. Burguera, B., Couce, M.E., Cuman, G.L., et al. 2000 , Obesity is associated with a decreased leptin transport across the blood-brain barner' in rats. Diabetes. $49: 1219-1223$.

14. Heymsfield, S.B., Greenberg, A.S., Fujioka, K., et ali, 1999. Recombinant leptin for wieight loss in obese and lean adults - A randomized, controlled, dose-escatation trial J Am Med Assoc. 282:1568-1575.

115. Fujioka, K., Patane, J., Lubina, J., and Lau, D. 1999. CSF leptin levels after exogenous administretion of recombinant methionyl human leptim. I Am Med Assoc. 282:1517-1518.

116. Boado, R.J., Golden, P.L., Levin, N., and Pardridge, W.M. 1998. Up-regulation of blood-brain berrier short-form leptin receptor gene products in rats fed a high fat diet. INeurachem. $71: 1761-1764$.

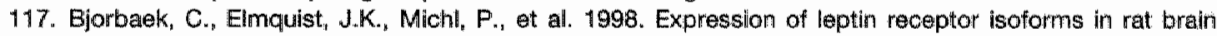
microvessels. Endocrinalogy, 139:3,485-3491.

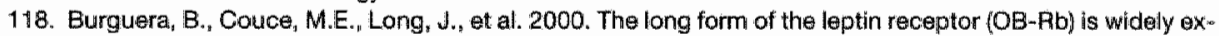
pressed in the human brain. Neuroendocrinology. 71:187-195.

119. Goiden, P.L., Maccagnam, T.4., and Pardridge, W.M. 1997. Human blood-brain barrier leptin receptor. Binding and endocytos is in isolated human brain microvessels. $J$ Clin invest. 99:14-18.

120. Baskin, D.G. Breininger, J.F ${ }_{* n}$ and Schwartz, M.W. 1999. Leptin receptor mAINA identifies a subpopulation of neuropeptide $Y$ neurons activated by fasting in rat hypothalamus. Diabetes. 48:828-833.

121. Cheung, C.C., Clifton, D.K. and Steiner, R.A. 1997. Proopiomelanocortin neurons are direct targets for leptin in the hypothalamus. Endocrinology. $138: 4489-4492$.

122. Schwartz, M.W., Woods, S.C., Porte, D., Seeley, Ri..., and Baskin, D.G. 2000. Central nervous system control of food intake. Nature. 404:661-671.

123. Seeley, R.J., Yagaloff, K.A., Fisher, S.L., et al. 1997. Melanocortin receptors in leptin effects. Nature. 390:349.

124. Cowley, M.A., Smart, J.L., Rubiristein, M., al. 2001. Leptin actiwates anorexigenic POMC nourongs through a reural network in the arcuate nucleus. Nature. $411: 480-484$.

125. Fan, W., Boston, B.A., Kestersom, R.A., Hruby, W.d., and Cone, R.D. 1997. Hole of melanocortineingle neum rons in feeding and the agouti obesity syndrome. Nature. 385:165-168.

126. Elmquist, J.K, Maratos Flier, E. Saper, C. B., and Fller, J.S. 1998. Uniraveling the central mervous system pathways underlying responses to leptin. Nat Neurasci. 1:445-450.

127. Elmquist, J.K., Elias, C.F., and Saper, C. B. 1999. From lesions to leptin hypothalamic control of food intake and body weight. Neuron. $22 \% 221-232$.

428. Bouret, S.G., Draper, S.J., and Simerly, R.B. 2004. Trophic action of lleptin on hypothalamic neurons that regullate feeding. Science. 304:108-110.

129. Pinto, S., Roseberry, A.G. LiL, H., et al. 2004 . Fiapid rewiring of arcuate nucleus feeding circuits by leptin. Science. 304:110-115.

130. Elmquist, J K., and Flier, J.S. 2004. Neuroscience. The fat-brain axis enters a new dimension. Science. 304:63-64.

131. Minokoshi, $Y_{\text {. }}$ Alquier, T., Furukawa, $N_{\text {, }}$ et al. 2004. AMP-kinase regulates food intake by responding to hormonal and nutrient signals in the hypothalamus. Nature. 428:569m574.

132. Ahima, R.S., Prabakaran, D., Mantzoros, $C_{\text {, }}$ et al. 1996. Role of leptin in the neuraendocrine response to fasting. Nature. $382: 250-252$.

133. Flier, U.S. 1998. Clinical review 94: What's in a name? In search of leptin's physiologic role. $J$ Chin Endocrinol Metab. 83:1407-1413. 
134. Ahina, R.S., Prabakaran, D, and Flier, J.S. 1998. Postnatul leptin surge and regulation of circadian mythm of leptin by fievding. Implications for eriergy homeostasts and neuroendocrine function. of chn hrest. $101: 1020-1027$

135. Heiman, M.L., Ahima, R.S., Craft, LS, Schoner, B., Stephens, T.W. and Flier, J.S. 1997. Leptin inhibition of the hypothalamic pitultary adrenal axis in response to stress. Endocrinology. 138:3859-3863.

136. Stephens; T.W., Basinsikl, M. Bristow, P.K, et al. 1995. The role of netropeptide $Y$ in the antiobesity action of the obese gene product Nature. 377:530-532.

137. Jin, H., Burguera, B, G, Cowce, M.E, et al. 1999. Leptin and leptin receptor expression in momal and neoplastic human pituitiary: ewdence of a regulatory role for leptin on pitutary ceill prolfferation. $J \mathrm{Cl} n$ Endocrinol Mettab, $84,2903-2911$.

138. Glovambattista, A, Chisari, A.N., Gaillard, R.C., and Spinedi, E. 2000. Food intakeinduced leptin secretion modulates hypothalamo-pituitary-adrenal axis response and hypothalamic ob-Rb expression to insilin administration, Nouroendownology, $72,341-349$.

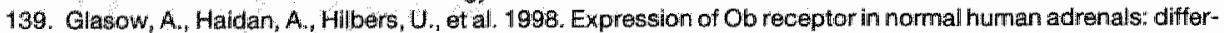
ential regulatlon of adrenocortical and adrenomedullany function by leptin. I Clin Endiocrinol Metab. 83:4459-4466.

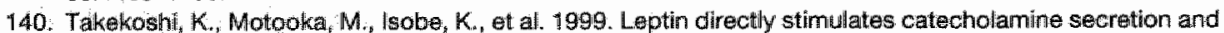
symthesis in cultured porcine adrenal medullary chromaffin cells. Blochem Biophys Res Commun. $261: 426-431$.

141. Pralong, F.P., Roduit, 17 , Waeber, $G_{i,}$ et al. 1998. Leptin inhibits directly glucocorticoid secretion by normal human and rat adrenal gland. Endocrinology. 139:4264-4268.

142. Bornstein, S.F. Uhimann, K., Haidan, A: Ehrhart Bornstein, M., and Scherbaum, W.A. 1997. Evidence for a novel perfpheral action of leptin as a metabolic signal to the adrenal gland: leptim inhibits cortisol release directly. Diabetes. $46: 1235 \cdots 1238$.

143. Salzmann, $C_{\text {, }}$ Otis, M., Long, H., Roberge, C., Gallo-Payet, N., and Walker, C.D. 2004. Inhibition of steroidogenic response to adrenocortic olropin by leptin: implications for the adrenal response to matemal sieparation in meonatal rats. Endocrinology; $145 * 1810-1822$

144. Oh, S.S., and Kaplan, M.L. 1994. Early trealment" of obese (ob/ob) mice with triiodothyronine increases oxygen consumption and temperature and decreases body fat content. Proc Soc Exp Biol Med. $207: 260-267$.

145. Legradi, G., Emerson, C.H. Ahirna, R.S., Flier, J.S., and Lechan, R.M. 1997. Leptin prevents fasting-induced suppression of prothyrottropin-releasing hormone messenger ribonucleic acid in netirons af the hypothalamic paraveritricular nucleusi. Endocrinology. 138:2569-2576.

146. Weintraub, B.D. Gesundheit, N., Taylor, T., and Gyves, P.W. 1989. Effect of TRH on TSH glycosylation and biological action. Ann N Y Acad Sol. 553:205-213.

147. Flier " ل.S., Harris, M., and Hollenberg, A.N. 2000. Leptin , nutrition, and the thyrolid: the why, the wherefore, and the wiring of Clim invest. 105:859-861.

148. Nillni, E.A., Vaslet, C., Harris, M, Hollenberg, A., Bjorbak, C., and Flier, J.S. 2000. Leptin regulates prothyrotropin-releasing hormone biosynthesis. Evidence fior direct and indirect pathways. $J$ Biol Chem. 275:36124-36133.

149. Harris, M., Aschkenasi, $C$., Elias, $C_{\text {. }} F_{\text {, }}$, et פl. 2001. Transcriptional regulation of the thyrotropin-releasing hormone gene by leptin and melanocortin signelling. J Clin knest, to7:111-120.

150. Gur, F "Bakal, K., Minokoshi, $Y .$, and Hollenberg. A.N. 2004. Leptin signaling targets the thyrotropin-releasing hormone gene promoter in wivo. Endocrinology. 145:2221-2227.

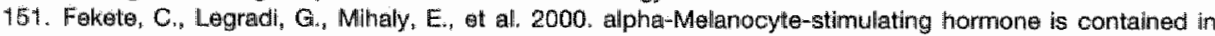
nerve torminals innervating thyrotroph-releasing hormone-synthesizing meurons th the hypothalamic paraventricular nucleus and prevents fasting-induced suppression of prothypotropin-releasing hormone gene xpression. J Naurosci. 20:1550-1558.

152. Kim, M.S. Small, G.d., Stanley, S.A., al al. 2000. The central melanocortin system affects the hypothalamo-pituitany thyroti axis and may mediate the affect of leptin. $/$ Clin Inves: 105:1005-1011.

153. Legrad, G., and Lechan. R.M. 1998. The arcuate nucleus is the major source for neuropeptide Yirnervation of thyrotropin-releasing hormone neurons in the hypothalamic paraventricular nucleus. Endochinology. $139: 3262-3270$.

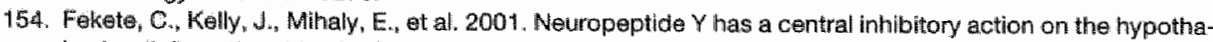
lamic-pituitary-thyroid axis. Endocrinology. 142:2606-2613.

155. Fekete; $\mathrm{C}$., Sarkar, $\mathrm{S}$. Rand, W.M., al. 2002. Agouti-related protein (AGRP) has a central inhibitory action on the hypothatamic-pituitary-thyroid (HPT) axis; comparisons between the effect of AGPP and neuropeptide $Y$ on energy homeostasis and the HPT axis. Endocrinology. 143:3846-3853.

156. Legradl, $G_{1}$, and Lechan, R.M. 1999. Agouti-related protein containing nerve terminals innervate thyratropin-releasing hormone neurons in the hypothatamic paraventricular mucleus. Endocrinology. $140: 3643-3652$ 
157. Whaty, E., Fekete, C., Tatro, J.B., Liposits; Z. Stopa, E.G., and Leonan, R.M. 20oo. Hypophysiotropic thyrotropin-releasing homone-sylnthesizing neurons in the human bypothalamus are intrenvated by neuropeptide Y, agouti-related protein, and alpha-melanocyte-stimulating homone. I Clin Endoennol Metab. 85:2596-2603.

158. Camo, E., Senaris, $R$, Considine, R.V., C. sanueva, F.F, and Dieguez: $G_{*} 1997$. Regulation of in vivo growth homone secretion by leptun. Endocrinology. 138:2203-2206.

159. Tannenbaum, G.S., Gurd, W., and Lapointe, M. 1998. Leptim is a potent stimulator of sportaneous pulsatile growth homone (GH) secretion and the GH response to GH-releasing homone. Endocrnology. $139: 3871-3875$.

160. Vuagnat; B.A., Pierroz, D.D., Lalaoui, M., et al. 1998. Exidence for a leptin-neuropeptide Y axis for the regulation of growth hormone secretion in the rat Neuroendocrinology. 67:291-300.

161. LaPaglia, $N_{.}$, Steiner, u., Kirsteins, L., Emanuele, M., and Emanuele, $N_{\text {. }}$ 1998. Leptin alters the response of the growth hormone releasing factor-growth hormone-insulin-like growth factor-l axis to fasting. J Endocrinol. 159:79-83.

162. Carro, E., Seoane, L.M., Senaris, R., Casanteva, F.F." and Dleguez, C. 2000. Leptin increases in vivo GH responses to GHRH and GH-releasing peptide-6 in food-deprived rats. Eur $J$ Endocrinol. 142:66-70.

163. Hakansson, M.L., Brown, H., Ghilardi, N., Skoda, R.C., and Moister, B. 1998, Leptin receptor immunoreactivity in chemically defined target neurons of the hypothalamus. J Neurosci. 18.559-572.

164. Iqbal, J., Pompolo, S., Murakami, T., and Clarke, I.J. 2000. Localization of long-form leptin receptor in the somatostatin-containing neurons in the sheep hypothalamus. Brain Res. 887:1 6 .

165. Quintela, M., Senarís, F., Heiman, M.L., Casanueva, F.F. and Dieguez, C. 1997, Leptin inhibitts in witro hy. pothalamic somatostatin secretion and somatostatin mRNA levels. Endocrinology. 138i5641-5644.

166. Carro, E., Seoane, L.M., Senaris, F. Considine, R.V., Casanueva, F. Fu, and Dieguez, C. 1998. Interaction between leptin and neuropeptide $Y$ on in viwo growth hormone secretion. Neuroendocrinology. $68: 187-191$.

167. Cocchi, D., Colonna, W.D., Bagnasco, M., Bonacci, D., and Muller, E.E. 1999. Leptin regulates GH secretion in the rat by acting on GHRH and somatostatinergic functions. If Endocrinol. $162: 95-99$.

168. Garro "E., Senaris "R.M., Seoane, L.M., et. al. 1999. Role of growth hormone (GH)-releasing hormone and somatostatin on leptin-induced GH secretion. Neuroendocrinology. $69: 3-10$.

169. Chehab, F.F., Lim, M.E., and Lu, R. 1996. Correction of the sterility defect in homozygous obese female mice by treatment with the human recombinant leptin. Nat Genat. 12:318-320.

170. Nagatani, S., Guthikonda, P., Thompson, R.C., Tsukanura, H. Maeda, K.I., and Foster, D.L. 1998. Evidence for GnRH regulation by leptin: leptîn administration prevents reduced pulsatile $\mathrm{LH}$ secretion during fasting. Neuroendocrinology. 67:370-376.

171. Konsaka, $A_{x,}$ Watanobe, $H_{4,}$ Kakizaki, $Y_{. b}$ Habu, $S$. , and Suda, $T$. 1999. A significant role of leptin in the generation of steroid-induced luteinizing hormone and prolactin surges in female rats. Blochem Biophys Res Commun. 254:578-581.

172. Gonzalez, L.C., Pinilla, L., Tena-Sempere, M., alnd Aguilar, E. 1999. Leptin(116-130) stimulates prolactin and luteinizing homons secretion in fasted adult male rats. Neuroendocrinology: 70:213-220.

173. Yu, W.H., Kimura, M., Walczewska, A., Karanth, S., and McCann, S.M. 1997 "Role of leptin in hypothalamic-pitutitary function. Proc Natl Acad Sci USA. 94:1023-1028.

174. Carro, E, Pinilla, L., Seoune, L.M., et al. 1997. Influence of endogenous leptin tone on the estrous cycle and luteinizing hormone pulsatility in female rats. Neuroendocrinology. 66:375 377 .

175. Ioffe, E "Moon, B., Connolly, E., and Friedman, J.M. 1998. Abnomal regulation of the leptin gene in the pathogenesis of obesity. Proc Natl Acad Sci USA, 95:11852-11857.

176. Ewart-Toland, $A_{w,}$ Nounzih $K_{n,}$, Quu, J., and Chehab, F.F. 1999. Effect of the genetic background on the reproduction of leptim-deficient abese mice. Endocrinology. 140:732-738.

177. Mounzih, $K_{\tau} L_{v}$ R. $_{\text {. }}$ and Chehab, F.F. 1997. Leptin treatment rescues the sterility of genetically obese ob/ob males. Endocrinology. 138:1190-1193,

178. Dearth, R.K., Hiney, J.K., and Dees. W.L. 2000. Leptin acts centrally to induce the prepubertal secretion of luteinizing hormone in the female rat. Peptides. 21:387-392.

179. Gruaz, N.M., Lalaoui, M., Plerroz, D.D., at al. 1998. Chronic administration of leptin into the lateral ventricle induces sexual maturation in severely food-restricted female rats. J Nauroendocrinol. 10:627-633.

180. Magni., P., Vettor, R.. Pagano, $C$, ot al. 1999. Expression of a leptin receptor in immortalized gonadotro. pin-releasing hormone-secreting neurons. Endocrinology. 140:1581-1585.

181. Finn "P.D. Cunningham, M.J., Pau, K.Y., Spies, H.G., Clifton, D.K., and Steiner, R.A. 1998. The stimulatory effect of leptin on the neuroendocrine reproductive axis of the monkey. Endocrinology, $139: 4652-4662$.

182. Cunningham, M.J., Clifton, D.K., and Steiner, R.A. 1999. Leptin"s actions on the reproductive axis: perspectives and mechanisms. Biol Reprod. 60:216-222.

183. Watanobe, H., Schioth, H.B., Wikberg; J.E., and Suda, T. 1999. The melenocortin 4 receptor mediates leptin stimulation of luteinizing homone and prolactin surges in steroid-primed ovarhectomized rats. Biochem Biophys fies Commun. 257:860 -864. 


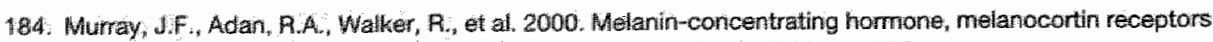
and regulation of luterizing hormone release. W Newroendocfinol. 12:217-223.

185. Sohioth, H.B., Kakizak, Y, Kohsaka, A., Suda, T., and Watanobs, H. 2001. Agouti-related peptice preverits steroid induced futeinting homone and prolactin surges in female rats. Neuroreport, 12:687-690.

186. Suliniley, S.A., Small, C.J., Km, M.S. , et al. 1999. Agouti related peptide (Agrp) stimulates the hypothalamo pitutary gonadal axis in wivo \& in vitro in male rats. Enclochnology. $140-5459-5462$.

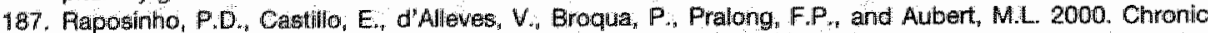
blockade of the melanocortin 4 receptor subtype leads to abesity independertly of neuropeptide $Y$ action, with no adverse effects on the gonadotropic and somatotropic axes. Endocnnology. 141:44:9-4427.

188. Hohmann, J.G. Teal, T.H. cilton, D.K. et al. 2000. Differential role of melanocortins in mediating leptin's central ffects on leeding and reproduction. Am J Physiol. 278:R50-P59.

189. Lebrethicin, M.C., Vandersmissen, E., Gerard, A., Parent, A.S., Junlen, J.L., and Bourguignon, a.P. 2000. In witro stimulation of the prepubertal rat gonadotropin-releasing hormone pulse generator by leptin and metropeptide $Y$ through disthot mechanisms. Endocrinology. 141:1464-1469.

190. Plerroz D. D., Catzeffis, C.., Aebi, A.C., Fivier, J.E, and Aubert, M.L. 1996. Chronic administration of neuropeptide $Y$ into the lateral veintricle inhibits both the pituitary-testicular axis and growth homone and insulin-Hke growth factor 1 secretion in intact adult male rats. Endocrinology. 137:3-12.

191. Yaswen, Ln, Diehi, N. Breminam. M.B., and Hochgeschwender, U. 1990. Obesity in the mause model of pro-opiomelanocortin deficiency responds to peripheral melanocortin. Nat Med. 5:1066-1070.

192. Chen, A.S., Marsh, D.J., Trumbauser, M.E, et all, 2000. Inactivation of the mouse melanocortin-3 receptor results in increased fat mass and reduced lean body mass. Nat Genet. 26:97-102.

193. Huszar, $D_{* i}$ Lynch, C.A. Fairchill-Huntress, $V_{\text {., et al. }} 1997$. Targeted disruption of the melanocortin-4 receptor results in obestity in mice. Cell. 88:131-141.

194. Erickson, J.C. Ahima, R.S., Hollopeter, G. Flier, J.S., and Palmiter, R.D. 1997. Endocrine function of neuropeptide Y knockout mice. Regur Pept. 70:199-202.

195. Oilmann, M.M. Wison, B.D., Yang. Y.K., et al, 1997. Antagonism of central melanocortin receptors in vitro and in vivo by agouti-relatted protein, Science. 27B:135-138.

196. Lebrethon, M.C., Vandersmissen, E., Gerard, A., Parent, A.S., and Bourguignon, J.P. 2000. Cocaine and amphetamine-regulated-transcript peptide mediation of leptin stimulatory effect on the rat gonadotrom pin-releasing hormone pullse generator in vitro. J Neuraendocrinol. 12:383-385.

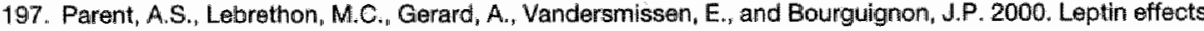
on pulsatile gonadotropin releasing hormone secretion from the adult rat hypothalamus and interaction with cocaine and amphetamine regulated transcript peptide and neuropeptide Y. Regul Pept, 92:17-24.

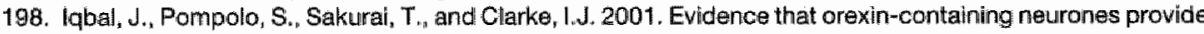
direct imput to gonadotropin-releasing homone neurones in the ovine hypothalamus. J Neuroendocninol. 13:1033-1041.

199. Gundlach, A.L. 2002. Galianin/GALP and galanin receptors: role in central control of feeding, bady weight/obesity and reproduction? Eur J Pharmacol. 440:255-268.

200. Brunatti, L., Orlaindo, G., Michelotto, B., Ragazzoni, E., and Vacca, M. 1999. Leptin stimulates prostaglandirn E2 and F2alpha, but not nitric oxide production in neonatal rat hypothalamusi. Eur $J$ Phamacol, $369.299-304$.

201. Finn, $P_{\text {.D. }}$, Cunningham, M.J., Alckard, D.G., Clifton, D.K., and Steiner, P.A. 2001. Serotonergic neurons are targets for leptiri in the monkey. II Cin Endocrinol Metab. 86:422-426.

202. Leslie, A. A, Sanders, S.J., Anderson, S.I, Schuhler, S., Horan, T.L, and Ebling, F.J. 2001. Appositions bewoen cociane and amphetaminerelated transcript- and gonadotropin releasing hormone-immunoreactive neurons in the hypothalamus of the Siberian hamster. Neurosci Lett. 314:119-114.

203. Rondini, T.A., Baddini, S.P., Sousa, L.F, Bittencourt, J.C., and Elias, C.F. 2004. Hypothalamic cocaineand amphetamimeregulated transcript newrons project to areas expressing gonadotropin releasing hormone immunoreactivity and to the anteroventral periventricular nucleus in male and female rats. Neurosciance. $125: 735-748$.

204. Sullivan, S.D., and Moenter, S.M. 2004. Gamma-aminobutyric acid neurons integrate and rapidly transmit permissive and inhibitory metabolic cues to gonadotropin releasing hormone neurons. Endocrinology. 145:1194-1:202

205. $Y u_{n}$ W.H. Walczewska, A. Karanth, S., and McCann, S.M. 1997. Nitric oxide mediates Heptin-induced luteinizing hormonereleesing hormone (LHRH) and LHRH and leptim-induced LH release from the pituitary gland. Endocrinology. 138.5055-50.58.

206. De Biasl, S.N., Apfelbaum, L.I, and Aptelbaum, M.E. 2001. In vitro effect of leptin on LiH release by anterior pltuitary glands from femalle rats at the time of spontaneous and steroid-inducied LH surge. Eur $J$ Endocrinol. 145:659-665.

207. Watanobe, H., and Schioth, H.B. 2001. Nitric oxide mediates leptin-induced preovulatory luteinizing hormone and prolactim surges in rats. Brain Res. 923:193-197.

208. Jin, L., Zhang. S., Burguera, B.G., et al. 2000. Leptin and leptin receptor expression in rat and mouse pituitary cells. Endocrinology, 141:333-339. 


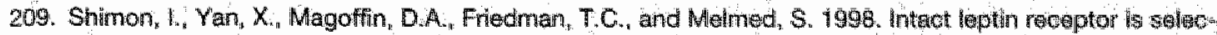
wely expressed in human fetal pitutary and pituitany adenomas and signals human fatal pitultary rowth homone secretion. J Cin Endocrinol Matab. 83:4059-4064.

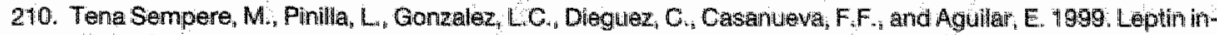
thibits testosterone secretion from acult rat testis in vitro. II Endochnol. 161:211-218.

211. Spicer, L.4, and Franciseo, C.C. 1997. The adipose obese gene product, teptin; evidence of a direct inhibitory role in ovarian function. Endocrinology. $138: 3374,3379$.

212. Spicer, L.J., Chamberiain, C.S., and Francisco, C.C. 2000. Ovarian action of leptin affects on instlin wike growth factor-1-stimulated function of granulosia and thecal cells. Encocrine 12:53-59.

213. Brannian, J.D., Zhao, Y, and McElroy, M. 1999. Leptin inhibits gonadotrophin-stimulated granulos cell progesterone production by antagonizing insulin action. Hum Reprod. 14:1445-1442.

214. Zachow, R.,., and Magoffin, D.A. 1997. Direct intraovarian effects of teptin: impaiment of the synergistio action of insulin-like growth factor-l on follicle-stimulating homone-dependent estradiol- 7 beta production by rat ovarian granulosa cells. Endocrinology. $138: 847-850$.

215. Agarwal, S.K., Wogel, K. Weitsman, S.A., and Magoffin, D.A. 1999. Leptin antagonizes the insulin-like growth factor-l augmentation of steroldogemesis in giranulosa and theca cells of the human avary. I Clin Endocrinol Metab. 84:1072-1076.

216. Barkan, D., dia, H., Dantes, A., Vardimon, L., Arnsterdam, A., and Aubinstein, M. 1999. Leptin modulates the glucacorticoid-induced ovarian steroidogenesis. Endocrinology. 140:1731-1738.

217. Kitawaki, J., Kusuki. $\mathrm{h}_{n}$, Koshiba, $H_{\text {, }}$ Tsukamoto, $K_{*}$ and Honjo, $H$. 1999. Leptin directly stimulates aromatase activity in human luteinized granulosa cells. Mol Hum Reprod. 5:708-713.

218. Duggal, P.S., Van-Der-Hoek, K.H. Milmer, C.R., at al. 2000. The in vivo and in vitro effects of exogenous leptin on owulation in the rat. Endocrinology. 141:1971-1976.

219. Almog, B., Gold, R., Tajima, K., et al. 2001. Leptin attenuates follicular apoptosis and accelerates the onset of puberty in immature rats. Mol Cell Endocrinol. $1831179-191$.

220. Caprio, M., Isidori, A.M., Carta, A.R., Moretti, C., Dufau, M.L., and frabbri, A. 1999. Expression of fiunctional leptin receptors in rodent Leydig cells. Endocrinalogy. 140:4939-4947.

221. Tena-Sempere, M., Pinilla, L., Zhang, F.P., et al. 2001. Dewelopmental and hormonal regulation of leptin receptor (Ob-R) messenger ribonucleic acid expression in rat testis. Biol Reprod. 64:634-643.

222. El-Hefnawy, T., lloffe, S., and Dym, M. 2000. Expression of the leptin receptor during germ cell development in the mouse testis. Endocrinology. 1414:2624-2630.

223. Caprio, M., Fabbrinî, E., Ricci, G., et al. 2003. Ontogenesis of leptin receptor in rat Leydig cells. Biol Reprod. 68:1199-1207.

224. Banks, W.A. McLay, F.N., Kastin , A.J., Sarmiento, U, and Scully, S. 1999. Passage of leptin across the blood-testis barrier. Am I Physiol. 276:E1099-E1104.

225. Tena-Sempere, M., Pinilla, L., Gonzalez, L.C., et al. 2000. In vitro pituitary and testicular effects of the leptin-related synthetic peptide leptin(116-130) amide inwolve actions both similar to and distinct from those of the native leptin molecule in the adult rat. Eur J Endocrinol. 1:42:406-410.

226. Watanobe, H., Schioth, H.B., and Suda, T. 2000. Stimulation of prolactin secretion by chronic, but not acute, administration of leptin in the rat. Brain Res. $887: 426-431$.

227. Watanobe, $H_{. "}$ and Habu, S. 2002. Leptin regulates growth hormone-releasing factor, somatostatin and alpha-melanocyte-stimulating hormone but not neuropeptide Y release in rat hypothalamus in vivo: rale: tion with growth hormone secretion. J Neurosch, 22:6265-6271.

228. La Cava, A., and Matarese, G. 2004. The weight of leptin in immunity. Nat Rev /mmunol. 4:371-379.

229. Loflmann, B., Gruminger, S., Stricker Krongrad, A, and Chiesi, M. 1997. Detection and quantification of the leptin receptor splice variants Ob- $\mathrm{Ra}_{\mathrm{a}} \mathrm{b}$, and, e in different mouse tissues. Blochem Blophys Res Commun. 238:648-652.

230. Gainsford, T., Willson, T.A., Metcalf, D. et al. 1996. Leptin can induce proliferation, differentiation, and functional activation of hemopoietic cells. Proc Nati Acad Scil USA. 93:14564-14568.

231. Cioffi, J.A., Shafer, A.W., Zupancic, T.J., all. 1996. Novel B219/OB receptor isoforms: possible role of Heptin in hematopoiesis and reproduction. Nat Med. 2:585-589.

232. Gabay, C., Dreyer, M., Pellegrinelli, N., Chicheportiche, $\mathrm{A}$, and Meier, C.A. 2001, Leptin directly induces the secretion of interleukin 1 receptoi antagonist in humain monocytes. $J \mathrm{CHin}$ Endocrinol Moteb. $86 \div 783 \times 791$.

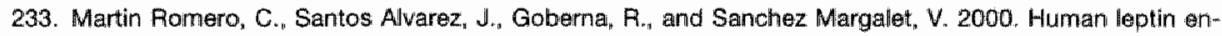
hances activation and proliferation of human circulating T lymphocytes. Cell /mmunol. 199:15-24.

234. Zarkesh-Esfahani, H., Pockley, G. Metcalfe, P.A.y, et al .2001. High-dose leptutin activates human leukow cytes via receptor expression on monocytes. I Immunol. 167:4593-4599.

235. Howard, J.K., Lord, G.M., Matarese, G., et al. 1999. Leptin protects mice from starvation-inducod lymphoid atrophy and increases thymic cellularity in ob/ob mice. J Clim Irvest. 104:1051-1059.

236. Loffreda, S, Yang, S.Q., Lin, H.Z, at al. 1998. Leptin regulates proinflammatory immune responses. FASEB J. 12:57-65. 
237. Mancuso, P. Gotthchak, A, Phare, S.M., Peters-Golden, M.. Lukacs, N.W., and Hufnagle, G.B. 2002. Leptin-defleient mice shibit impaired host defense in Grami-negative prieumonia. I Immunol $168 \div 40184024$

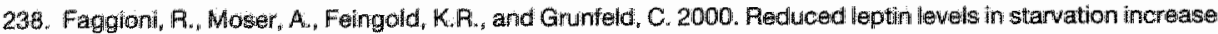
susceptibillty to endotoxic shock. Am I Pathol. 156:1781 -1787.

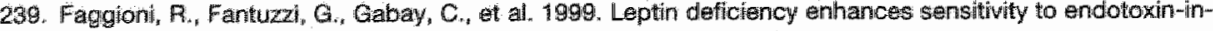
duced lethality. Am I Physiol, 276:R136-R142.

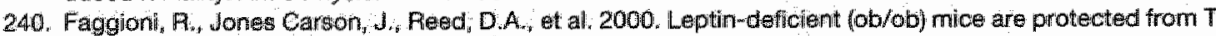
cell-mediated hepatotoxicity: Fole of tumor necrosis factor alpha and IL-18. Proc Mat Acad SCI USA. $97.2367-2372$.

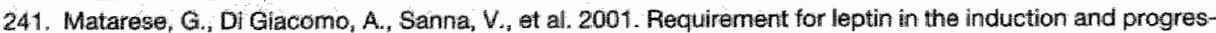
son of autoimmun encephalomyelitis. $J$ immunol. 166:5909-5916.

242. Sanna, V., Di Giacomo, A., La Cava, A, et al 2003. Laptin surge precedes onset of autoimmune encephalomivilis and comelates with development of pathogenic $T$ cell responses. J Cin trvest. $111241-250$.

243. Siegmund, B, Lohr, H.A, and Fantuzz, G. 2002. Leptin: a piwotal mediatior of intestinal inflemmation in mice. Gastroenterology. 122:2011-2025.

244. Tarzi, P.M., Cook, H.T., Jackson, I, Pusey, C.D., and Lord, G.M. 2004. Leptin deficient mice are protected from accelerated nephrotoxic nephritis. Am J Pathol. 164:385-390.

245: Busso, N., So, A. Chobaz-Poclat, $V$., al 2002. Leptin signaling deficiency impairs humoral and cellular immune responses and attenuates experimental arthritis. $J$ Immunol. 168:875-882.

246. Matarese, G., Samna, V., Di Giacomo, A. $_{\text {. }}$ et al. 2001. Leptin potentiates experimental autoimmune oncephalomy elitis in SJL female mice and confers susceptibility to males. Eur J Immunol. 31:13:24-1332.

247. Zhang, $Y_{,}$Wilsey, J.T, Frase, C.D., al. 2002. Peripheral but not central leptin prevents the immuriosuppression assoclated with hypoleptinemia in rats. J Endocrinol. 174:455-461.

248. Frank, S., Stalmeyer, B., Kampfer, H., Kolb, N., and Pfeilschilter, J. 2000. Leptin enhances wound re-epithelizalization and constitutes a direct function of leptin in skin repair. J'Clin lnwest. 106:501-509.

249. Haynes, W.G., Sivitz, W.I., Morgan, D.A., Walsh, S.,A and Mark, A.L. 1997. Sympathetic and cardlorenal actions of lleptin. Hypertension: 30:619-623.

250. Alzawa Abe, M. Ogawa, $Y_{\text {, }}$ Masuzaki $\mathrm{H}_{\text {, , et al }}$ 2000. Pathophysiological role of leptin in obesity-related thypertension. J Clin Invest, 105:1243-1252.

251. Frithbeck, Gi, 1999. Pivotal role of nitric oxide in the controll of blood pressure after leptin adiministration. Diabetes, 48:903-908.

252. Fruhbeck, G. 2001. A heliocentric view of leptin. Proc Mutr Sac. 60:301-318.

253. Ren, J.2004. Leptin and hyperleptinemia - from friend to foe for cardiovascular function, $J$ Endocrinol. $18 \#: 1-10$.

254. Cock, T.A., and Auwerx, J, 2003. Leptin: cutting the fat off the bone. Lancet-362;1572-1574.

255. Matsuda, $J_{.}$, Yokota, $\mathrm{l}$, lida, $\mathrm{M}_{\text {. }}$ et al. 1997. Serum leptin concentration in cord blood: relations hip to birth weight and gender. J Clin Endocrinol Metab. 82:1642-1644.

256. Schubring, $\mathrm{C}$. Kiess, W., Englaro, P., et al. 1997. Levels of leptin in maternal serum, ammiotic filuid, and arterial and venous cord blood: relation to neonatal and placental weight. $J$ Chrs Endocrinol Metab. Q2:4 480 - 1483

257. Hoggard, N. Hunter, L., Dumcan, „J.S. Willams, L.M., Trayhurit, P., and Mercer, J.G. 1997. Leptin and leptin receptor mANA and protein expression in the murine fetus and placenta. Proc Natl Acad Soi USA. $94: 11073-11078$

258. Steppan, O.M., and Swick. A.G. 1999. A role for leptim in brair development. Biochem Blophys Res Commum. 256:600 60 2.

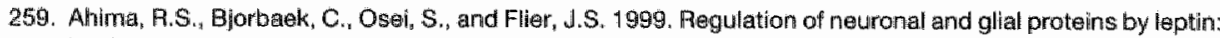
implications for brain development. Endocrinology. 140:2755-2762.

260. Cintii, S. Matteis, F.D., Pico, $\mathrm{C}_{n}$, et al. 2000 . Secretory granules of endocrine and chief cells of humaln stomach mucosa contain leptin. Int $J$ Obes Rielat Metab Disord. 24:789-793.

261. Sobhani, 1., Bado, A., Vissuzaine, $C_{.}$et al, 2000. Leptin secretion and leptin receptor in the human stomach. Gut. $47: 178-183$.

262. Sobhani, H., Buyse, M., Golat, H., et al. 2002. Vagal st imulation rapidly increases leptin secretion in human stomach. Gastroentiorology. 122:259-263.

263. Morton. N.M. Emilsson, V., Liu, Y.L." and Cawthome, M.A. 1998. Leptin action in intestinal cells. W Biol Chem. 273:26194-26201.

264. Yuan, C.S. Attele, A.S., Wu, J.A., Zhang, L., and Shi, Z.Q. 1999. Peripheral gastric leptin modulates brain stem neuronal activity in neonates. Am J Physiol 277:G626-G630.

265. Wang, Y.H., Tache, Y., Sheibel, A.B., Go V.L., and Wel, J.Y. 1997. Two types af leptin-responsive gastric vagal afferent terminals" an in vitro single-unit study in rats. Am J Physiol. 273:R833-R837.

266. Yuan, C.S. Attele. A.S., Dey, L., and Xie, J.T. 2000. Gastric effects of cholecystokinin and its interaction with leptin an brainstem neuronal activity in neonatal rats. J Phamacol Exp Ther. 295:177-182'. 
267. Barrachina, M.D., Martinez, V., Wang, L., Woi, J.Y, and Tache, Y'. 1997. Synergistic ntieraction between leptin and cholecystokinim to reduce short-term food intake in lean mice. Proc Nat Aced SCI USA. 94:10455-10460.

268. Matson, C.A. Wiater, M.F, Kujper, J.Ln and Weigle, D.S. 1997 , Symergy betwean leptin and cholecystokinin (CCK) to control daily caloric intake. Peptides. 19:1275-1278.

269. Matson, C.A. Reid, D.F, Camnon, T.A., and Fitter, R.C. 2000. Cholecystoklinin and laptin act synergistically to reduce body weight. Am I Physiol. 278:R892-R890.

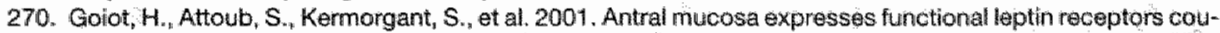
pled to STAT-3 signaling, which is invalved in the control of gastric secrations in the rat. Gastroenterology. $121: 1417-1427$.

271.. Inui, A. 2001. Ghrelin: an orexigenic and somatotrophic signal from the stomach. Nat Rov Neumosci. 2:551-560.

272. Attele, A.S. Shi, Z.Q., and Yuan, C.S. 2002. Leptin, gut, and food intake. Biochom Phamacol. 63:1579-1583.

273. Buyse, M., Berhoz, F. Guilmeau, S. et al. 2004. Pept1 mediated epithelial transport of dipeptides and cephalexin is enhanced by luminal leptin in the small intestine. J Clin thwest. 108:1483-1494.

274. Pelleymounter, M.A. Cullen, M.J., Baker, M.B., et al. 1995. Effects of the obese gene product on body weight regulation in ob/ob mice. Science. 269:540-543.

275. Halaas, J.L., Gajiwala, K.S., Maffei, M. ef al. 1995. Weightheducing effects of the plasma protein encoded by the abese gene. Science. 269:543-546.

276. Campfield, LA., Smith, F.J., Guiser, Y., Devos, R., and Bum, P. 1995. Recombinant mouse OB protein: ev* idence for a peripheral signal linking adipasity and central neural networks. Science. 269:546 549.

277. Ceddia, R.B., Koistinen, H.A. Zierath, J.R. and Sweeney, G. 2002. Analysis of paradoxickal obsentations: on the association between leptin and insulin resistance. FASEB J. 16:1163-1176.

278. Seutert, ل. 2004. Leptin effects on pancreatic betta-cell gene expression and function. Diabetes. 53 Suppl 1:S152-S158.

279. Havel, P.J. 2004. Update on adipocyte homones: regulation of energy balance and carbohydrate/lipid metabolism. Diabetes. 53 Suppl 1:S143-S151.

280. Bornsteim, S.R., Abu Asab, M. Glasow, A., et al. 2000, immnohistochemical and ultrastructural localization of leptin and leptin receptor in human white adipose tissue and differentiating human adipose cells in prim mary culture. Diabetes. 49:532-538.

281. Chen, $G_{1}$, Koyama, $K$, Yuan, $X_{* .1}$ et all 1996. Disappearance of body fat in nomal rats induced by adenovirus-mediated leptin gene therapy. Proc Natl Acad Sci USA. 93:14795-14799.

282. Bair, Y., Zhang, S., Kirm, K.S., Lee, J.K., and Kirr, K.H. 1996. Obese gene expression alters the ability of 30A5 preadipocytes to respond to lipogenic hormanes. J Biol Chem. 271:13939-13942.

283. Fruhbeck, G. Aguadio, M., and Martinez, J.A. 1997, In vitro lipolytic effect of leptin on mouse adipocytes: ewidence for a possible autocrine/paracrine role of leptin. Biachem Biophys Res Commun. 240:590-594.

284. Shimabukuro, M. Koyama $K_{\text {. }}$ Chen, G., et al. 1997. Direct antidiabetic effect of leptin through triglyceride depletion of tissues. Proc Nat/ Acad Sci USA, 94:4637-4641.

285. Fruhbeck, G. Aguado, M., Gomez Ambrosi, J., and Martinez, J.A. 1998. Lipolytic effect of in wivo leptin administration on adipocytes of lean and ob/ob mice, but not db/db mice. Blochem Biophys Res Commun. $250: 99-102$

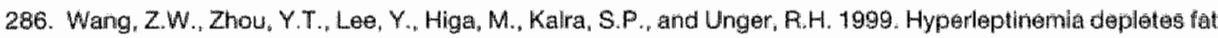
from denervated fal tissue. Biochem Biophys Res Commun. 260:653-657.

287. Zhou, Y.T. Shimabukuro, M. Koyama, K., at al. 1997. Induction by leptin of uncowpling protein-2 and enzymes of fatty acid oxidation. Proc Natl Acad Sci USA. 94:6386-6390.

288. Wang M.Y., Lee, $Y_{\text {" }}$ and Unger "R.H. 1999. Novel form of lipolysis induced by lleptin. I Eiol Chem. $274: 17541-17544$

289. Kakuma, T., Lee, Y., Higa, M. at al. 2000. Leptin, troglitazone, and the expression of stercl regulatory ele ment binding proteins in liver and pancreatic istets. Proc Natl ACad Sci USA. 97:8536-8541.

290. Unger, $R, H_{*}$ Zhou, $Y . T$, and Orci, L. 1999. Regulation of fatty acid homeostasiss in cells: Novel role of leptin. Proc NaH Acad Sci USA. 96:2327-2332.

291. Lee, Y., Wang, M.Y., Kakuma, T., et al. 2001. Liporegulation in diet-induced obesity. The antisteatotic role of hyperleptinemia. J Biol Chem. 276:5629-5635.

292. Unger, R.H. 2000. Leptin physiology: at secondl look. Regul Pept. 92:87-95.

293. Unger, R.H. 2002. Lipotoxic diseases. Anmu Rev Med. 53:319-336.

294. Campfield, L.A. Smith, F.J, and Burn, P. 1996. The OB protein (leptin) patthway-a link between adipose tissue mass and central neural netwotks. Horm Metab Res. 28:619-632.

295. Tritos, N.A., and Mantzonos, C.S. 1997. Leptim: its role in oblesify and beyond. Diaberologia. 40:1371-1379.

296. Rentsch, J., Levens, N., and Chiesi, M. 1995. Reconbinant ob*gene product reduces food intake in fasted mice. Brochem Biophys Res Commuri. 214:131-136.

297. Maffei, M. Halaas, J. Ravussin, E., et al, 1995 . Leptin levels in human and rodent: measurement of plasrna leptin and ob RNA in obese and weight-reduced subjects. Nat Med. 1:11155-116\%. 
298. Fradenich, R.C, Hamann, A, Anderson, S., Lollmann, B, Lowell, B.B., and Flier, J.S. 1995. Leptin levels reflect body lipid conthent in moce. evidence for dietwinduced resistance to leptin action. Nat Med. 1:1311-1314.

299. Weigle, D.S. 1994. Appotite and the regulation of body composition. FASEB J. 8.302-310.

300. Caro, J,F, Ginha, M.K. Kolaczyriskil, JWW. Zhang, P.L., and Considine, R.V. 1996. Leptin: the tale of an obesity gene. Diabetes: $45: 1455-1462$. 
CHAPTER 2

CSF Total Leptin Levels after Administration of Pegylated Human Recombinant Leptin (PEG-OB) - Research Letter

C.J. Hukshorn, G.B. Hull, and W.H.M. Saris 
To the Editor: The protein hormone leptin, primarily secreted by adipose tissue, appears to relay information regarding the state of the energy balance and energy stores to the brain. Thus, to exert its function, leptin must gain access to specific regions in the hypothalamus and needs to cross the blood-brain barrier.

The concentration of leptin in the cerebrospinal fluid (CSF) in humans is related to that of leptin in serum and varies from 1 to $20 \%$ of the latter. However, the ratio of leptin in CSF to serum differs at different concentrations of leptin being the highest whenleptin levels in serum are low, as in anorexia nervosa and lowest when leptin levels are high, as in obesity $(1,2)$. This curvilinear relationship has been attributed to the presence of a saturable system that transports leptin across the blood-brain barrier (3).

Also in favor of an impaired transport of leptin across the blood-brain barrier is the fact that some obese rats who do no langer respond to peripherally administrated leptin can still respond to leptin given intracerebroventricularly $(4,5)$. Several studies in rodents suggested that the leptin transport system is easily saturated and operating at maximum rate at near physiological concentrations in lean individuals $(6,7)$. This impairment in transport of leptin across the blood-brain barrier could account for the widespread leptin resistance present in obese animals and humans. In addition, this view suggests that the administration of exogenous leptin to treat obesity might be ineffective.

Long-acting pegyllated human recombinant leptin (PEG-OB) used in this study is a globular polyethylene glycol-native human leptin polymer with increased molecular size and extended serum half-life. Due to these modifications, it is conceivable that the ability of PEG-OB to cross the blood-brain barrier might be reduced. Therefore, the primary purpose of the present study was to determine if PEG-OB is able to cross the human blood-brain barrier in patients already scheduled for an elective lumbar punction to exclude the presence of neurologic Lyme disease.

Methods: One healthy overweight male subject (age: $40 \mathrm{yr}, \mathrm{BMI}: 28.5 \mathrm{~kg} / \mathrm{m}^{2}$ ) and one healthy underweight female subject (age: $31 \mathrm{yr}$, BMI: $18.6 \mathrm{~kg} / \mathrm{m}^{2}$ ) were recruited from the hospitall waiting list. Both patients were already scheduled for an elective lumbar punction to exclude the presence of neurologic Lyme disease. The Medical Ethics Committee of the University of Maastricht approved the study protocol and all participants provided written informed consent.

Both subjects received a single subcutaneous dose of $40 \mathrm{mg}$ PEG-OB (produced and provided by Hoffmann-La Roche Inc. Nutley, New Jersey, USA) in the para-umbillical region. After 4 days, CSF was obtained by lumbar punction. On both occasions (before $\mathrm{PEG}-\mathrm{OB}$ administration and execution of the lumbar punction, respectively), venous blood was sampled for measurements of plasma total leptin concentrations. Total leptin concentrations in plasma and CSF were measured according to the method described previously (8). Because the assay does not distinguish between endogenous leptin and PEG-OB, the total leptin concentration reported here is the sum of the two concentrations.

Results: The presence of neuroborreliosis was excluded in both patients. At baseline, plasma leptin concentrations were $9.0 \mathrm{ng} / \mathrm{mL}$ in the male subject and $6.5 \mathrm{ng} / \mathrm{mL}$ in the female subject. Four days after the PEG-OB treatment, prior to the lumbar punction, plasma concentrations of total leptin (endogenous leptin plus PEG-OB) were 189.3 $\mathrm{ng} / \mathrm{mL}$ in the male subject and $177.4 \mathrm{ng} / \mathrm{mL}$ in the female subject. Totall leptin concen- 
tration in CSF was $1.63 \mathrm{ng} / \mathrm{mL}$ in the male subject and $1.06 \mathrm{ng} / \mathrm{mL}$ in the fomale subject.

Comment: The total leptin concentrations measured in the CSF of the two subjects 4 days after PEG-OB treatment was approximately 10 times higher than predicted from their baseline plasma leptin concentrations (3). Although this study was limited by a very small number of subjects, the inability to distinguish between endogenous leptin and $P E G-O B$ in the CSF, and the lack of baseline leptin CSF concentrations, these results suggest (but do not prove) that PEG-OB is able to cross the blood-brain barrier. In agreement with these results, data of a separate cohort of a clinical trial indicated that exogenously administrated leptin crossed the blood-brain barrier, despite the very high serum leptin concentrations present that would be expected to saturate the transport system completely (9). Taken together, both observations are consistent with the proposed existence of a non-saturable pathway (10) and/or the hypothesis that more than one pathway may be involved in the transport of leptin into the brain. Three potential mechanisms have been proposed for leptin to enter into the central nervous system (11). The OB-Ra is the most abundant leptin receptor isoform at the blood-brain barrier and its presence was demonstrated in the choroid plexus and vascular endothelium of the human brain. Also the binding and internalizing of leptin by this receptor isoform was shown. The expression of high levels of the $\mathrm{Ob}-\mathrm{Ra}$ in the endothelial cells of the blood-brain barrier would allow the access of leptin through the capillary wall to specific hypothallamic nuclei and other locations, to exert its actions. A second route could be the transportation of leptin (both receptor-mediated and by diffusion) through the choroid plexus and ventricular system into the CSF and subsequently into the brain. Finally, leptin might enter the brain by diffusion through the circumventricular organs, which lack tight junctions.

In summary, the findings of the present study suggest (but do not prove) that PEG-OB is able to cross the human blood-brain barrier.

\section{C.J. Hukshorn, G.B. Hul, and W.H.M. Saris}

Nutrition and Toxicology Research Institute Maastricht (NUTRIM), Department of Human Biology, Maastricht University, Maastricht, The Netherlands.

\section{References}

1. Caro, J.F., Kolaczynski, J.W., Nyce, M.R., ot al, 1996. Decreased cerebrospinal-fluädserum leptin ratio in obesity: a possible mechanism for leptin resistance. Lancet. 348:159-161.

2. Mantzoros, C., Flier, J.S., Lesem, M.D., Brewerton, T.D., and Jimerson; D.C. 1997. Cerebirospinal fluid leptin in anorexia nervosa: correlation with nutritional status and potential role in resistanco to welght gairi. 1 Clin Endocrinol Metab. 82:1845-1851.

3. Schwartz, M.W. Peskind, E., Raskind, M., Boyko, E.J., and Porte, D., Jr. 1996. Cerebrospinal fluid leptin levels: relationship to plasma levels and to adiposity in humans. Nat Med. 2:589-593.

4. Halaas, J.L., Boozer, C., Blair West, J., Fidahusein, N., Denton, D.A., and Friedman, J.M. 1997. Physiologi" call response to long-term peripheral and central leptin infusion in lean and obese mice. Proc Nath Acad SCi US.A. 94:8878-8883.

5. Van Heek, M. "Compton, D.S., France, C.F., et al. 1997. Diel-induced obese mice develop peripheral, but not central, resistance to leptin. I Clin Irwest. 99:385-390.

6. Banks, W.A., Kastin, A.J., Huang, W., Jaspan, J.B., and Mantss, L.M. 1996. Leptin enters the brain by a saturable system independent of insulin. Peptides, 17:305-311.

7. Burguera, B., Couce, M.E., Curran, G.L., et al. 2000. Obesity is associated with a decreased leptin transport across the blood-brain barrier in rats. Diabetes. $49,1219-1223$. 


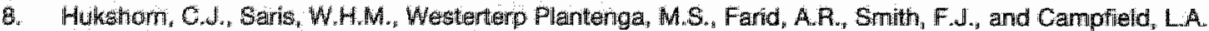
2000. Weetly subeutaneous pegylated recombinant native human leptin (PEG-OB) administration in obese men. I Chin Endocrinol Metab. $25,4003-4009$.

9. Fujloka, $K$, Patane, $J$, Lubina, J. and Lau, D. 1999. CSF leptin lewels after exogenous administration of rew combinant methiony human teptin. I Am Med Assoc, 282:1517-1518.

10. Wu-Peng, X.S. Chua, S.C., Hr, OKada, N., Liu, S.M., Nicolson, M, and Leibei, R.L. 1997. Phenotype of the obese Koletsiky (t) rat due to Tyr 763 stop mutation in the extractilular domain of the leptin receptor (Lepr): ewidence for deficient plasma-to-CSF transport of leptin in both the Zucker and Koletsky obese rat. Diabetos. $46: 519.518$.

11. Ahima, P. $\mathrm{s}_{x_{y}}$ and Fier, J.S. 2000. Leptin. Annu Rev Physiol. 62:413-437. 
CHAPTER 3

\section{Weekly Subcutaneous Pegylated Recombinant Native Human Leptin (PEG-0B) Administration in Obese Men}

C.J. Hukshorn, W.H.M. Saris, M.S. Westerterp-Plantenga, A.R. Farid, F.J. Smith and L.A. Campfield 


\section{Abstract}

To assess the biological activity and tolerability of pegylated recombinant native human leptin (PEG-OB), 30 obese men (mean body mass index, $33.9 \mathrm{~kg} / \mathrm{m}^{2}$ ) were randomized to a double-blind treatment with weekly sc injections of $20 \mathrm{mg} P E G-O B$ or placebo for 12 weeks, in addition to a hypocaloric diet (deficit, 2 MJ/day). Body compasition, energy expenditure, and metabolic parameters were measured before and after treatment $\mathrm{PEG}-\mathrm{OB}$ was generally well tolerated based on adverse event reports, lab values, and vital signs. Weekly sc PEG-OB led to sustained serum concentrations of $\mathrm{PEG}-\mathrm{OB}$ and leptin throughout treatment. No significant differences in the delta or percent weight loss, percent body fat, sleeping metabolic rate, or respiratory quotient were observed between the PEG-OB and placebo groups. Percent change in serum trigllycerides from baseline was significantly correlated with bady weight loss in the $P E G-O B$ group, but not in the placebo group. Although larger reductions in serum triglycerides were observed in the PEG-OB group compared with the placebo group, these differences were not statistically significant. We concluded that weekly injection of PEG-OB leads to sustained serum concentration of PEG-OB and leptin throughout the 12-week treatment period and is generally well tolerated. The trends observed in serum triglycerides suggest that weekly $20-\mathrm{mg}$ sc treatment with $\mathrm{PEG}-\mathrm{OB}$ may have biological effects in obese men.

\section{Introduction}

Obesity is a complex, increasingly prevalent and important health problem throughout the world (1). Human obesity is characterized by increased adipose tissue mass resulting from a complex interaction of genetic predisposition to metabolic efficiency and environmental/iffestyle factors (2-5). Obese individuals are at increased risk for conditions such as noninsulin-dependent diabetes mellitus, hypertension, hyperlipidemia, coronary heart disease, stroke, and certain cancers (1). Although treatment [e.g. healthy eating (including behavior modification), physical activity, drugs] is available and most people can achieve medically significant weight loss (5-10\% initial body weight), the long-term maintenance of that weight loss and its associated improvement in health is, urfortunately, very rare (2-4). These factors and the psychological, social, and economic costs of obesity are matters of growing concern in the scientific, medical, and public health communities (1).

New scientific information concerning the regulation of energy balance and fat mass has emerged since the discovery of leptin (also known as OB protein). Evidence from many animal studies and observational studies in humans suggests that this hormone, which is secreted primarily from adipocytes in proportion to cell size, seems to play a role in the control of body fat stores by acting within the central nervous system to coordinate the regulation of feeding behavior, metabolism, autonomic nervous system, and body energy balance in rodents, primates, and humans (4-6). Although obese individuals have increased serum concentrations of leptin $(7,8)$ and concomitant decreased sensitivity to leptin "therapeutic augmentation of the circulating leptin levels, by administration of leptin, may result in increased leptin signaling and action in a manner similar to use of exogenous insulin to increase insulin signaling in noninsulin-dependent diabetes mellitus $(4,5)$. Thereby, reductions of food intake, 
body fat mass, and body weight in obese patients may result from treatment with recombinant leptin.

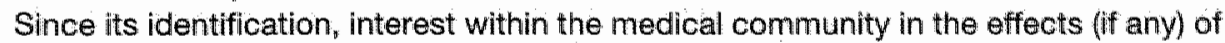
treatment of obese individuals with leptin has been significant (4). However, only initial interventional studies in humans are available to support these suggestions. In trials sponsored by Amgen Inc., significant dose-related reductions in body fat and body weight (up to $-7.1 \mathrm{~kg}$ in the highest dose group) were observed following daily se treatment with from $0.01-0.30 \mathrm{mg} / \mathrm{kg}$ recombinant human met-lleptin for 24 weeks in obese subjects (9). In the treatment of a young very obese girl with a mutated ob gene, daily sc injection of low doses of met-leptin (dose of $0.028 \mathrm{mg} / \mathrm{kg}$ of leain mass calcullated to cause a circulating concentration $\sim 10 \%$ of what would be predicted based on her body faty has been reported. Daily met-leptin treatment caused a dramatic reduction in appetite, food-seeking behavior, food intake, and body weight ( 10$)$. The results of treatment of this girl with congenital leptin deficiency (10), taken together with the results of the clinical trials in obese adults (9), indicate that leptin has biological activity in at least some obese humans and that among its activities are reductions in appetite and food intake at low doses and reductions in body fat and body weight at the maximal dose studied.

Leptin has been reported to have a very short apparent half-life in animals $(11,12)$ and humans (13). Polyethylene glycols (PEG) are amphiphilic polymers of ethylene glycol with varying average molecular weights that can be activated and covalently attached to proteins. Modification of proteins through pegylation, covalent linkage of PEG polymers to the protein, has resulted in increased serum half-life and reduced immunagenicity for a number of proteins (14-16). This technology was applied to leptin to produce pegylated recombinant native human leptin or PEG-OB protein (PEG-OB), which was used in this study. Preclinical studies with PEG-OB indicate an extended half-life in rodents $(>48 \mathrm{~h}$ ) compared with that reported for recombinant native human leptin (data not shown) and efficacy for reduction of food intake and body weight of rats treated daily with SC PEG-OB for 8 days $(17,18)$.

We undertook a double blind, randomized study to determine the biological activity and safety of elevating serum levels of leptin using PEG-OB in comparison with placebo in obese men on a mild hypocaloric diet.

\section{Subjects and Methods}

\section{Experimental subjects}

This single center trial had a prospective, randomized double blind placebo-controlled group design. This study was conducted according to the guidelines for Good Clinical Practice and was monitored by Hoffmann-La Roche, Inc. (Welwyn, UK).

Obese [body mass index (BMI), $\left.\geq 27.0 \mathrm{~kg} / \mathrm{m}^{2}\right]$ men 18-60 yr of age were eligible for inclusion. Recruitment was from the Institute waiting list or by local advertising. All aspects of the study conformed to the declaration of Helsinki. The ethics committee of the University of Maastricht approved the study, and all participants gave written informed consent. Patients with obesity-related diseases requiring pharmacological treatment (e.g. diabetes, hypertension, dyslipidemia) were excluded. Other exclusion criteria were: weight loss more than $3 \mathrm{~kg}$ in the previous 3 months; presence of any 
significant ulliness, including laboratory or electrocardiogram abnormalities; history or presence of drug abuse or alcoholism; and smoking more than five cigarettes or equivalent per day. Also, known allergy, history of atopy or hypersensitivity to pegylated proteins, and use of any drug that might have influenced body weight or serum lipids led to exclusion.

\section{Study design}

After screening, 30 patients were selected and enrolled. Baseline energy expenditure, body composition, and metabolic profile (including lipid profile and insulin sensitivity) were measured. Patients were stratified and matched into pairs according to age, BMI, and serum leptin and insulin concentrations to achieve balanced treatment groups. Randomization numbers for patients were generated and incorporated into the double blind labeling by a third party. During the treatment period, either an injecthon of $20 \mathrm{mg}$ PEG-OB $\left(2 \mathrm{~mL}, 10 \mathrm{mg} / \mathrm{mL}^{-1}\right)$ or placebo $(2 \mathrm{~mL})$ were given $\mathrm{sc}$, in the para-umbilical region, weekly for 12 weeks. In addition, all subjects were prescribed a hypocaloric diet (500 kcall or $2 \mathrm{MJ} /$ day deficit). The energy content of the diet was based on the measured energy expenditure of each subject (see below). The dietary prescription was discussed every 2 weeks with a dietitian. Subjects came to the laboratory in the morning, in a fasting state, each week to receive treatment. Vital signs and body weight were recorded, and blood samples were taken for standard laboratory tests. At the end of the 12-week treatment period, energy expenditure, body composition, and metabolic profile were measured again.

\section{Measurements of energy expenditure and body composition}

Energy expenditure and substrate utilization were measured during a $36-\mathrm{h}$ stay in a respiration chamber while the subjects were maintained in energy balance by adjusting the food provided (19). Macronutrient composition of the diet was fixed at $45 / 15 / 40 \%$ of energy for carbohydrate, protein, and fat, respectively. The respiration chamber is a $14 \mathrm{~m}^{2}$ room furnished with a bed, chair, wash bowl, toilet, and radio/TV set and telephone. While in the chamber, subjects had to follow a standardized physical activity program, including controlled exercise for 35 min on a bicycle ergometer (starting at $40 \mathrm{~W}$ for $5 \mathrm{~min}$, followed by $80 \mathrm{~W}$ for $30 \mathrm{~min}$ ). Two exercise sessions took place; one in the morning at $1000 \mathrm{~h}$ and the other one in the afternoon at $1500 \mathrm{~h}$. Gas sampling and analysis from the chamber is described in detail elsewhere (20).

Total energy expenditure, sleeping metabolic rate (SMR), and respiratory quotient (RQ) were calculated during the last $24 \mathrm{~h}$ in the chamber. Energy expenditure was calcullated from the $\mathrm{O}_{2}$ consumption and $\mathrm{CO}_{2}$ production according to the method of Weir (21). SMR was calculated from the sleep period between 0300 and $0600 \mathrm{~h}$, controlled for physical activity by a Doppler radar system. Body weight was measured (with a calibrated digital scale accurate to $0.01 \mathrm{~kg}$ ), and height was measured to the nearest $0.001 \mathrm{~m}$. Body composition was determined after leaving the respiration chamber in the morning by using hydrodensitometry and deuterium dilution (22). Body composition was calculated using the combined equation of Siri (23). 


\section{Blood chemistry and pharmacokinetics}

Fasting serum concentrations of glucose, insulin, free fatty acids, glycerol, triglycerdes, total cholesterol, and high-density lipoprotein (HDL) cholesterol were measured at baseline (day 1) and after 12 weeks of treatment (day 85). Samples were stored at $-80 \mathrm{C}$ and analyzed by a certified laboratory. Low-density lipoprotein (LDL) cholesterol was calculated using the Friedewald equation (24).

Insulin sensitivity was assessed by the short insulin tolerance test (25). After an overnight fast, sampling and injection catheters were placed. Arterialized venous blood samples were collected after insulin was iv injected (Human Actrapid; Novo Nordisk A/S, Bagsvaerd, Denmark; $0.1 \mathrm{U} \mathrm{kg}^{-1}$ body weight). The test was terminated after 16 min by an iv glucose injection. The rate constant for plasma glucose disappearance $\left(K_{\text {itt }}\right)$ was calculated using a linear regression line fitted through the bload glucose values from 4-16 min because no changes in blood glucose were noted within 4 min after insulin injection.

Fasting blood samples for the measurement of serum concentrations of leptin and PEG-OB were collected weekly before the next dosing and analyzed at Hoffmann-La Roche Inc. (Nutley, NJ). For the pharmacokinetics of leptin and PEG-OB, a frequent sampling schedule was applied in weeks 1 and 12 . Serum leptin concentrations were measured using a double-antibody "sandwich" enzyme-linked immunosorbent assay using a monoclonal antibody specific for human leptin. The lower level of detection is $0.5 \mathrm{ng} / \mathrm{mL}$, and the upper limit is $50 \mathrm{ng} / \mathrm{mL}$. The intra- and interassay variations were $9 \%$ and $12 \%$, respectively. The leptin levels of normal weight subjects ranged from 2-12 ng/mL. PEG-OB concentrations were measured using a simillar enzyme-linked immunosorbent assay after separating $P E G-O B$ from leptin by size exclusion. Quality controll samples covering a range of leptin and $P E G-O B$ concentrations were included in each assay. Both assays were verified by appropriate recovery and cross-reaction experiments.

\section{Safety}

Safety of PEG-OB was monitored during each visit by documentation of adverse events and the recording of vital signs on Case Report Forms. Routine clinical hematology and biochemical tests and urine analysis were done weekly.

\section{PEG-OB}

Recombinant native human leptin, expressed and purified from Escherichia coli, was. chemically conjugated to a species of branched PEG molecule with an average molecular weight of $42 \mathrm{KD}$ in a $1: 1$ ratio. The result was a globular $\mathrm{PEG}$-native human leptin polymer with increased molecular size (26,27). PEG-OB at a concentration of 10 $\mathrm{mg} / \mathrm{mL}$ was placed in sterile glass vials containing $1.3 \mathrm{~mL}$.

\section{Statistical analysis}

The number of subjects needed was calculated as follows. Results of clinical trials using a hypacaloric diet and orlistat treatment $(120 \mathrm{mg}$ t.i.d.) for 12 weeks reported weight loss in 1022 placebo-treated subjects as $2.23 \mathrm{~kg}$ with a SD of $3.04 \mathrm{~kg}$ (Roche 
orlistat protocols 14119B, M14119, M14149, M14161, and M14185). With this information, power calculation indicated that 25 subjects per treatment group were needed to detect an additional weight reduction in the PEG-OB group of $4.0 \mathrm{~kg}$ over that seen in the placebo group with a power of $90 \%$, assuming a $\mathrm{SD}$ of $3 \mathrm{~kg}$. Assuming a $20 \%$ dropout rate, 30 subjects per treatment group would be required. This number of subjects was also sufficient to detect a difference in change from baseline SMR between the groups of $0.21 \mathrm{~kJ}$ per min with a power of $90 \%$. This calculation was based on a SD of SMR in a single subject of $0.16 \mathrm{~kJ}$ per min with an estimated SMR of $5.3 \mathrm{~kJ}$ per min, accordingly to the WHO equation (28). However, after the first 30 subjects completed the study, a planned interim analysis was conducted and the study of weekly 20-mg SC PEG-OB was prematurely stopped by the sponsor due to lack of efficacy for weight loss at the dose tested.

Changes from baseline after 12 weeks of treatment were compared between the PEG-OB-treated and placebo group using factorial ANONA. Post hoc, for each comparison separately, ANOVA with repeated measures was used. Additional statistical tests were used when appropriate. All statistical tests were two-sidled, and significance was defined as $P<0.05$. All data are presented as mean $\pm S E M$, unless otherwise indicated.

\section{Results}

Of the 38 subjects screened 8 did not meet the inclusion criteria. The initial demographic characteristics of the subjects are shown in Table 1. The characteristics of the 15 subjects randomized to each treatment group were similar. All 30 subjects who were randomized into the two treatment groups completed the trial.

Table 1.5 subject charactedstios

Charagtoristis

Body weloht (ko)

BHol (kodn?

Ato $01 \%$

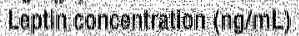

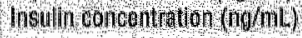

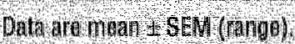

\section{Pacelo $(h=15)$}

$108.6 \% 46(89.5$-139.6)

$338,12(30.3+43)$

$4422(33 \cdot 64)$

$20,4,4,92,2,473)$

$2+1,15(6,4,28$ (9)
PEGOB $(n-15)$

$1073+34(856-1374)$

$340+10(293-397)$

$4522(33-58)$

$219+4965.4160$

$106+26(0.8,292)$

\section{Serum concentrations of PEG-OB and leptin}

Serum concentrations of PEG-OB during the study are shown in Fig. 1. Following weekly sc dosing, sustained serum levels of PEG-OB, measured just before the next dose, ranging from $200-300 \mathrm{ng} / \mathrm{mL}$, were observed. The PEG-OB serum profile after sc injection was similar after the first (day 1) and 12th weekly (day 78) dose (Fig. 1). Following a sc injection, mean peak serum PEG-OB concentrations were achieved $72 \mathrm{~h}$ after dosing, followed by a return to the elevated pre-dose levels after 1 week.

Baseline total leptin concentrations during the study are shown in Fig. 2. Baseline total leptin concentrations were $20.4 \pm 4.9$ and $21.9 \pm 4.9 \mathrm{ng} / \mathrm{mL}$ (mean \pm SEM) in the placebo and PEG-OB treatment groups, respectively. Total leptin serum concentrations 


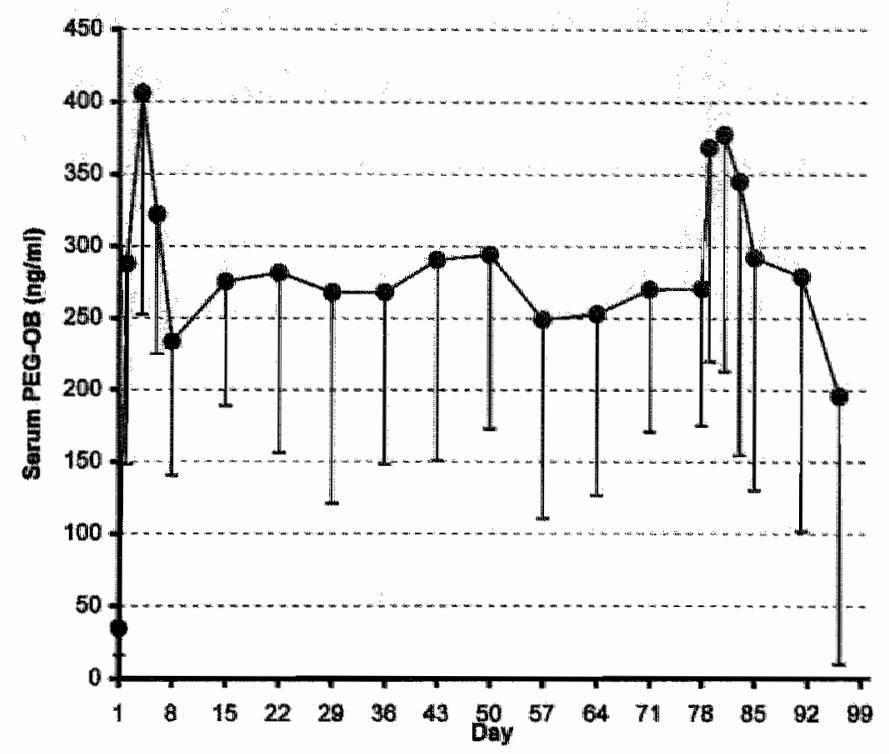

Figure 1: Serum levels of PEG-OB following weekly sc dosing d uring the study. PEG-OB waS administered sc on days $1,8,15$, $22,29,36,43,50,57,64,71$, and 78 . PEG-OB concentrations are mean $\pm \mathrm{SD}$. More frequent lood sampling occurred after the first (day 1) and 12th weekly (day 78) dose. Note the sustained blood levels of PEG 0 B in samples taken fust before the next weekly dose of PEG-OB throughout the study, these sustained PEG-OB levels ranged from 200-300 ng/mL. Note that the PEG-OB serum profille following the first and 12 th weekly sc injection was similar. Following a SC PEG-OB injertion, mean peath serum PEG OB concentrations were achieved $72 \mathrm{~h}$ after dosing, followed by a return to the elowated pre-dose levels after 1 week

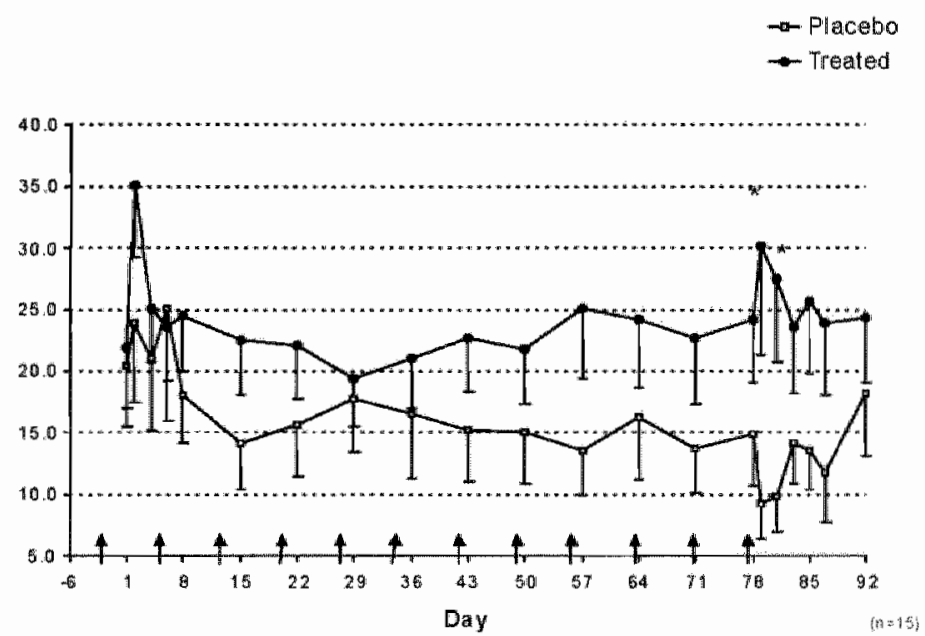

Figure 2: Total serum leptin concentrations following weekly SC PEG-OB dosing during the study. PEG-OB was administered sc on days $1,8,15,22,29,36,43,50,57,64,71$, and 78 . Total leptin concentrations are mearl \& SEM. Baseline total leptin concentrations were $20.4 \pm 4.9$ and $21.9 \pm 4.9 \mathrm{ng} / \mathrm{mL}$ in the placebo (IC) and PEG.0B treatment (O) groups, respectively. Total leptin serum concentrations in blood samples taken just before the next weekly dose of $\mathrm{PEG}-0 \mathrm{~B}$ increased to a new steady-stato level during weeks 9-12 of the study in subjects treated with PEG-OB, wthereas total leptin concentrations fellt with weight loss in placebo-treated subjects during weeks $9-12$ of the study. More frequent blood sampling accurred after the first (day 1) and 12th weekly (day 7B) dose. Wote that total leptin serum proflle following the first and 12th weekly sc PEG-OB injection were similar. Folowing a sc PEG-OB injection mean preak serum total leptin concentrations were achieved 72 hafter dosing. followed by a retum to the elevated pre-dose levels after 1 week. * Significant differences between PEG-OB and placebo groups. 


\begin{tabular}{|c|c|c|c|c|c|c|}
\hline & \multicolumn{3}{|c|}{ Placeba $(\mathrm{n}-1 \mathrm{i})$} & \multicolumn{2}{|c|}{ PEC $00 \mathrm{O}(n=15)$} & \multirow[b]{2}{*}{$\begin{array}{l}\text { Della } \\
\text { (day } 85-\text { day })\end{array}$} \\
\hline & Oay 1 & Day 65 & $\begin{array}{l}\text { Della } \\
\text { (day } 85 \text { day } 1)\end{array}$ & Dayt & Day 85 & \\
\hline Borty w wigh ingl & $108.6+46$ & 1022,41 & -6.4 & $107.3 \times 34$ & 103043.0 & $-4,3$ \\
\hline boty fat $(\%)$ & $367+16$ & $32.2+17$ & 1.82 & $352+15$ & $329+15$ & 0.99 \\
\hline $24, f \in E$ MUday & 14.0104 & 128.04 & $12^{\circ}$ & $14,+0,3$ & $13.4+0.3$ & $0.7^{6}$ \\
\hline SMR (M)/day) & $83+02$ & 77102 & $0.0 \%$ & $85+02$ & $8.01+02$ & $0.5^{\circ}$ \\
\hline & 08400002 & $0855+0.01$ & 000 & $084 \pm 0001$ & $0.84=0.01$ & 0.0 \\
\hline
\end{tabular}

increased slightly to a new steady-state level $(24.0 \mathrm{ng} / \mathrm{mL}$ during weeks $9-12$ of the study) in subjects treated with PEG-OB, whereas total leptin concentrations fell with weight loss in placebo-treated subjects $(14.6 \mathrm{ng} / \mathrm{mL}$ during weeks $9-12$ of the study) (Fig. 2)

\section{Body weight, body composition, and energy metabolism}

The effect of PEG-OB treatment or placebo treatment on body weight, body composition, and energy expenditure are given in Table 2 . The mean body weight change was $-5.4 \pm 0.8 \mathrm{~kg}$ in all 30 subjects studied. Subjects in both the placebo $(n=15)$ and PEG-OB $(n=15)$ treatment groups lost weight, and the amount of weight loss was similar in both groups (day 85 body weight: placebo, $102.2 \pm 4.1 \mathrm{~kg}$; delta, $-6.4 \mathrm{~kg}$; PEG-OB, $103.0 \pm 3.0$; delta,$-4.3 \mathrm{~kg}$ ). There was no significant difference in the delta or percent weight loss between the PEG-OB and pllacebo groups (Table 2). The mean changes in percent body fat and sleeping metabolic rate of all 30 subjects were $-1.4 \pm$ $0.4 \%$ and $-0.4 \pm 0.07 \mathrm{~kJ} / \mathrm{min}$, respectively, and there were no significant differences between PEG-OB and placebo. No differences were observed in RQ between the treatment groups. Using a technique pioneered in the clinical trials with the lipase inhibitor orlistat, subjects were classified as "good" losers (delta body weight at 4 weeks $\geq 2.5 \mathrm{~kg}$ ) and "poor" losers (delta bodyweight at 4 weeks $<2.5 \mathrm{~kg}$ ) in each treatment groups (29-31). An imbalance of the distribution was observed with more good losers ( 8 of 15 or $53 \%$ ) in the placebo group than the PEG-OB group (5 of 15 or $33 \%$ ).

\section{Metabolic profile}

The effect of $20 \mathrm{mg}$ PEG-OB or placebo treatment on the metabolic profile is shown in Table 3. No significant differences in serum glucose or insulin concentrations from baseline were observed at the end of the 12-week treatment period, and there were no differences between the treatment groups. Insulin sensitivity (measured by the short insulin tolerance test) also showed no significant differences between both groups before and after treatment.

Mean baseline (day 1) serum concentrations of free fatty acids, triglycerides, and total cholesterol were larger in the PEG-OB group than in the placebo group. However, when the range of the serum concentrations is considered (Table 3), no significant differences were observed. Although larger reductions in serum concentrations of triglycerides within subjects were observed at the end of the 12-week treatment period 


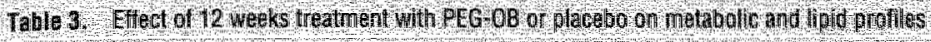

\begin{tabular}{|c|c|c|c|c|c|c|}
\hline & $\begin{array}{l}\text { Placebo } \\
\text { bay } 1\end{array}$ & Dart & Delta (day) & Day & Dov 85 & Deita day \\
\hline 100se (nimolny) & $5.66+0.7$ & $5,58+011$ & -129 & $619+017$ & $6.99+118$ & 0019 \\
\hline Suln (nimoll) & 21,3115 & 170171 & 4.3 & $19.6+26$ & $185+20$ & +11 \\
\hline (rothing) & $207,0.18$ & $3.11,0.14$ & 022 & 285.016 & $304+018$ & 919 \\
\hline egtin/ng/m/) & $204+49$ & $186+32$ & -6.8 & $21 / 9+49$ & $257+58$ & 06 \\
\hline free fatty acids & $\frac{395}{(157-87}$ & $\begin{array}{l}3654 \times 43 \\
(54.707\end{array}$ & -20 & $\begin{array}{l}474,33 \\
(17,761)\end{array}$ & 541845 & 58 \\
\hline (ilgcerol (molly) & $847 \pm 9.4$ & $845+8.2$ & -0.2 & $827-62$ & 807,5 & 31 \\
\hline Triglycerides & $\begin{array}{l}1,54,0,15 \\
(0,88,2,78)\end{array}$ & 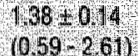 & $=017$ & $\begin{array}{l}209 \times 10.28 \\
7 \times 6,63)\end{array}$ & $\begin{array}{l}178,021 \\
\text { /17.5 }\end{array}$ & 10, \\
\hline Tetal cholesteno & $408 \times 019$ & $471=019$ & 0,16 & $506-0.26$ & $4.85,0.5$ & 02 \\
\hline$($ mmoll $)$ & $(3.79-6.08)$ & $(3,6,572)$ & & $(3,70-6,31)$ & $(368,768)$ & \\
\hline LDLAnolestero & $3,31,0,16$ & $318+018$ & 0.1 & $327+027$ & 318,129 & 40 \\
\hline ADLtholestero/ (nnmold) & $0.07+0.05$ & $090+005$ & 月ด? & 0.8500 .08 & 0.0810 .04 & 004 \\
\hline
\end{tabular}

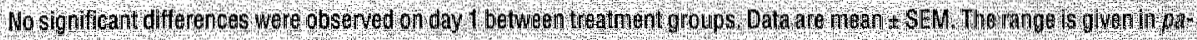
roptheses.

in the PEG-OB treatment compared with the placebo treatment group (PEG-OB, delta $=-0.35 \pm 0.15 \mathrm{mmol} / \mathrm{L}$ vs. placebo, delta $=-0.17 \pm 0.12 \mathrm{mmol} / \mathrm{L}$ ), these differences were not statistically significant. The change in serum triglycerides from baseline as a function of body weight loss is shown in Fig. 3 . Percent change in serum triglycerides from baseline was significantly correlated with the amount of body weight loss in the PEG-OB treatment group $(P<0.01)$ but not in the placebo treatment group. No significant differences in serum glycerol, LDL-cholesterol, and HDL-cholesterol concentrations from baseline were observed at the end of the 12-week treatment period, and there were no differences between the treatment groups.

\section{Safety}

The most common adverse events related to PEG-OB treatment are shown in Table 4. The most significant findings were pain at the injection site and pruritis. These occurred with similar frequency in both the placebo and the PEG-OB groups and generally occurred only with the first or second series of injections.

One subject in the placebo group developed a kidney stone on study day 78 . The sub ject was hospitalized for 2 days, and the kidney stone was passed without intervention. This serious adverse event was classified as unrelated to treatment. The subject completed the study.

Safety data were reviewed as one composite group first and then by treatment group. There were no clinically relevant changes in the mean values of laboratory measurements or vital signs during the study. No difference was detected between the groups with regard to standard chemistry or hematology assessments. The mean total serum protein was reduced $(-2.3 \%)$ in the PEG-OB group, but not in the placebo group $(-0.5 \%)$. However, no difference in urinary protein was observed between the groups. In summary, at the dose studied, PEG-OB seemed to be generally well tolerated and safe. 
Placebo

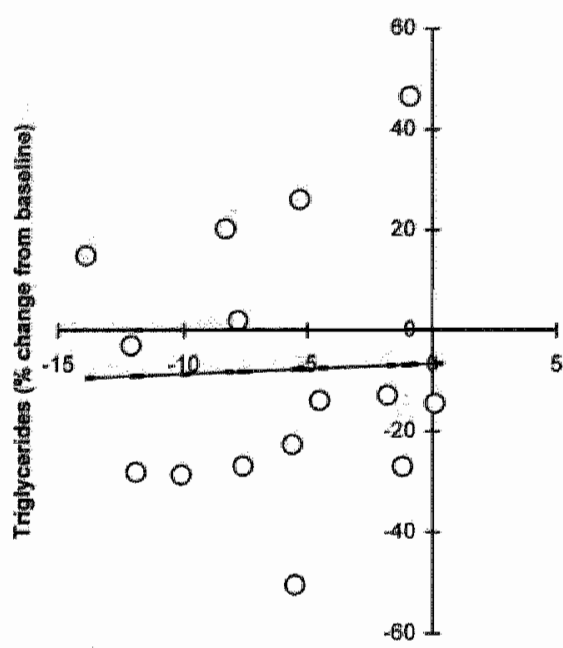

Eody welght loss (likg)
Treated

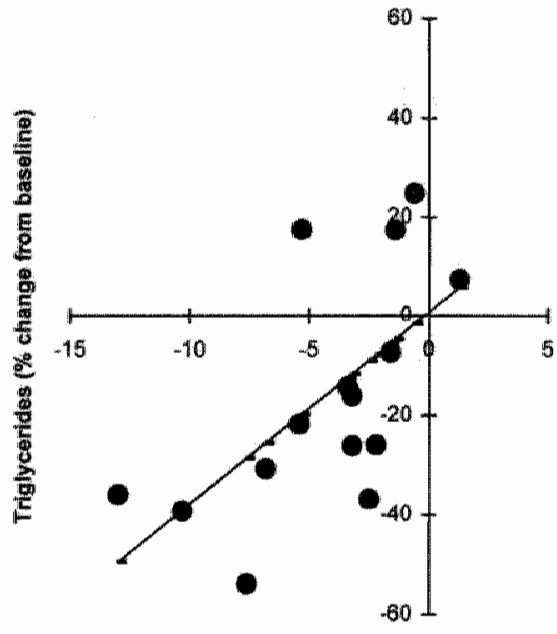

Body woight loss $(\mathrm{kg})$

Figure 3: The percent chanige in serum triglycerides from baseline following weekly SC PEG-OB dosing as a function of body weight loss at the end of the study. The percent change in serum triglycerides from baseline (day 1) at the end of the 12-week treatment period (day 85) in each sultject in the placebo (O) and PEG-OB treatment (e) groups is plotted as a function of the body weight loss. Regression lines were determined in both groups. In the placebo group, the slope was 0.2 with a $P \equiv 0.9$, whereas in the $P E G-O B$ group the slope was 3.9 willin $P=0$. O1. Thus, percent change in serum triglycerides firom baseline was significantly correlated with the amount of body weight loss it the PEG-OB treatment group but not in the placebo treatment group. When the data points for all 30 subjects were combined, the slope of the regression line between decrease in triglycetides (expressed as percent change from baseline) in the PEG-OB group was significantly different from the regression line in the placebo group (analysis of covariance; $P<0.05$ ).

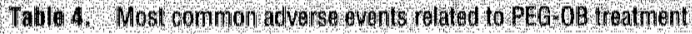

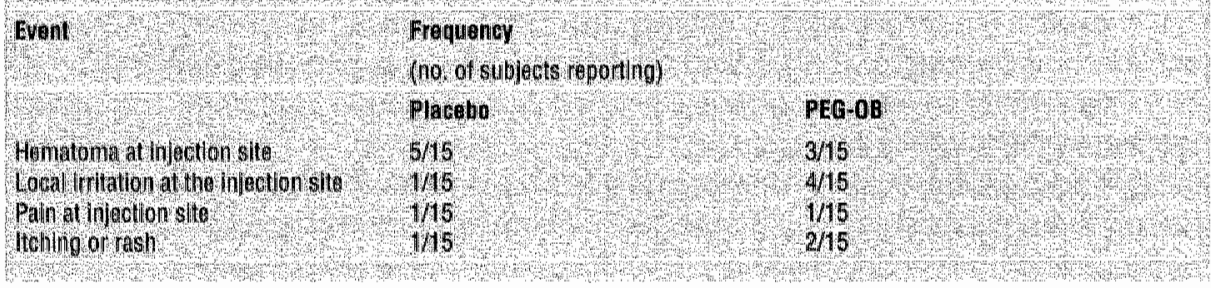




\section{Discussion}

These results demonstrate that weekly $20-\mathrm{mg}$ SC PEG-OB administration to obese men on a hypocialoric diet led to sustained serum concentration of both $\mathrm{PEG}-\mathrm{OB}$ and leptin, measured just before the next dose, throughout the 12-week treatment period. Mean peak serum $P E G-O B$ concentrations were achieved $72 \mathrm{~h}$ after dosing, followed by a return to the elevated pre-dose levels after 1 week. Total leptin serum concentrations increased to a new steady-state levell in subjects treated with PEG-OB, whereas total leptin concentrations fell with weight loss in placebo-treated subjects. In addition, weekly 20-mg sc PEG-OB was generally well tolerated and safe in these subjects.

No significant differences in the delta or percent weight loss, percent body fat, or sleeping metabolic rate were observed between the PEG-OB and placebo groups. No differences were observed in RQ between the treatment groups. Due to the premature termination of the study based on the interim analysis "the power of the study was suboptimal and it remains unknown whether PEG-OB has no effect on weight loss. Percent change in serum triglycerides from baseline was significantly correlated with the amount of body weight loss in the PEG-OB treatment group, but not in the placebo treatment group. Although larger reductions in serum concentrations of triglycerides were observed at the end of the 12-week treatment period in the PEG-OB group compared with the placebo treatment group, these differences were not statistically significant. The trends in serum triglycerides are consistent with similar changes repeatedly observed in studies in which obese rats or mice were treated with leptin at doses that did not reduce body weight $(4-6,32)$. It has been proposed by Unger et al. (33) that an important function of leptin is to confine the storage of triglycerides to the adipocytes, while limiting triglyceride storage in nonadipocytes and to selectively mobilize fat. Together with a small but consistent reduction in hunger ratings after overnight fasts throughout the treatment period and a reduction in generalized hunger as measured by the three-factor eating inventory in the PEG-OB group (34), these trends in serum triglycerides suggest that weekly $20-\mathrm{mg}$ sc treatment with $\mathrm{PEG}-\mathrm{OB}$ may have biological effects in obese men.

In trials sponsored by Amgen Inc., lean and obese subjects received multiple daily sc injections of met-leptin ranging from $0.01-0.3 \mathrm{mg} / \mathrm{kg}$. Significant dose-related reductions in body fat and body weight were observed following daily sc treatment with up to $0.30 \mathrm{mg} / \mathrm{kg}$ met-leptin for 24 weeks (9). Mean weight loss from baseline increased with increasing met-leptin dose in obese subjects at 24 weeks of treatment. The most effective dose for weight and fat loss was $0.3 \mathrm{mg} / \mathrm{kg}$ and would be equivalent to an average dose of $30 \mathrm{mg} /$ week in our $100 \mathrm{~kg}$ subjects. Mild and moderate injection site reactions were the most common adverse events reported (9).

The treatment of a young very obese girl with a mutated ob gene, with daily sc injection of low doses of met-leptin (dose of $0.028 \mathrm{mg} / \mathrm{kg}$ of lean mass calculated to cause a circulating concentration $-10 \%$ of what would be predicted based on her body fat), has been reported. Daily met-leptin treatment for 12 months caused a dramatic reduction in appetite, food-seeking behavior, food intake, and body weight (10). After 12 months of treatment, her body weight was reduced by $16.4 \mathrm{~kg}, 95 \%$ of which was body fat. As in the studies reported here with PEG-OB, met-leptin treatment had no effect on metabolic rate or energy expenditure in this girl. However, her lipid proffile, which was normal prior to treatment, was not effected by met-leptin administration. 
The results of treatment of this girl with congenital leptin deficiency (10), taken together with the results of the Amgen trials in obese adults (9), Indicate that leptin has biological activity in at least some obese humans and that among its activities are reductions in appetite and food intake at low doses and reductions in body fat and body weight at the maximal dose studied.

Other biological effects of leptin and PEG-OB observed in animal studies were not observed in this study. Most prominent among these were serum glucose and insulin concentrations $(5,6)$. We failed to observe any treatment effects on these variables possibly due to the small sample size or 20-mg PEG-OB dose or weekly dosing schedule. However, neither parameter was elevated in the group of obese men enrolled in this trial. We also failed to observe a reduction in body fat, as well as total energy expenditure and sleeping metabolic rate $(5,6)$.

The steady-state concentrations of PEG-OB (200-300 $\mathrm{ng} / \mathrm{mL})$ following weekly $20-\mathrm{mg}$ sc PEG-OB were lower than the blood levels of met-leptin associated with efficacy (13). Given the similarities in the biological activity to reduce appetite between weekly sc $20 \mathrm{mg}$ PEG-OB (34) and daily low-dose met-leptin in congenital leptin deficiency (10) and the difference in blood levels, it is possible that increasing the dose of PEG-OB or altering the dosing schedule may result in significant reductions in body fat and body weight in addition to larger decreases in appetite, hunger, food intake, and serum triglycerides concentrations. The testing of this hypothesis will be the subject of future research.

\section{Acknowledgments}

We greatly acknowledge the commitment and technical accomplishments of all of the members of the "MetFit", the Roche PEG-OB team, for making this study possible. They discovered PEG-OB and did all the work to support this clinical research. In particular, we acknowledge the major contributions of Pascal Bailon, Jill Porter, Jack Lipman, John Moschera, Dan Liberato, Jon Hauptman, Steve Maxwell, Garry Mackie, Irma Rivera, Cheryl Spence, Fariba Rabban, Rose Corrigan, Renata Tenenbaum, and Whitney Smith in Nutley, New Jersey; and Joanna Dorkings and Steve Dickinson in Welwyn, UK. We thank Dennis Loh and Wolf Berthoud for support and encouragement. We thank Tanja Hermans-Limpens, Mariëlle Engberink . Brian Buysse, and Mariella van Ransbeek for their assistance during the clinical trial. Finally, we acknowledge the cooperation, patience, and contributions of all of our subjects.

\section{References}

1. World Health Organization. 1998. Obesity: preventing artd managing the global epidemic. Geneva: World Health Organization.

2. Hill, J.O. and Peters, J.C. 9998 . Environmental contributions to the obesity epidemic. Science. 280:1371:1374.

3. Thomas, P.R. ed. 1995. Weighing the options: criteria for the evaluating weight-management programs. Washington, DC: Food and Nutrition Board, Institute of Medicine, National Acaderny Press.

4. Campfield, L.A., Smith, F.J., and Burn, P. 1998. Strategies and potential mollecular targets for obesity treatment. Science. 280:1383-1387.

5. Campfield, L.A., and Smith, F.J. 1998. Overview: neurobiology of OB protein (leptin). Proc Nutr Soc. $57: 429-440$

6. Camptield, L.A., Smith" F.ل mediating behavioral, metabolic and neuroendocrine responses. Endocrinol Metab. 4:81-102. 
7. Considine, RV., Sinha, M.K., Heiman, M.L; at al, 1996. Serum immunoreactive-leptin concentrations m nomal-weight and obese humans. N Engl $J$ Med. 334.292-295.

8. Maffei, M., Halaas, J., Rawussin, $\mathrm{E}_{0}$ et al. 1995. Leptin levels in human and rodant: measurement of pilasma leptin and ob RNA in obese and weight-reduced subjects Nat Med.1.155-1161.

9. Heymsfield, S.B., Greenberg. A.S., Fujioka, Kr. et al. 1999. Recombinant teptim for weight loss in obese and lean adults - A randomized, controlled, dose-escalation trial. $J$ Am Med Assoc. 282:1568-1575.

10. Faroogi, I.S., Jebb, S.A., Langmack, G. et al. 1999. Effects of recombinaint heptin therapy in a chitd with congenital leptin deficiency. N Engl J Med. 341:879-884.

11. Lau, D. Mallard, S., Wariner, G., Watson, A., Cheung, E. and Young. J. 1996. Phamacokinetics of recombinant human leptin in mice (Abstract). Obesity Res. 4:385.

12. Cumin, $F$, Baum, H.P., Chiesi, $M$, et al. 1996. Pharmacokinetics of recombinant leptin in rats (Abstract). Obesity Res. $4: 27 \mathrm{~S}$.

13. Lau, D., Lubina, J , Dixon, R.M. , al. 1998. Pharmacokinetics of recombinant human methionyl human leptin ( $\mathrm{L}$ ) and the effect of antibody formation in lean and obese subjects following subcutaneous (sc) dosing. Proc. of the 8th International Congress on Obesity, Paris, Firance, 1998.

14. Fuertges, F., and Abuchowski, A. 1990. The clinical efficacy of poly(ethylene-glycoly-modified protens. J Control Release. 11:139-148.

15. Meyers, F.d., Paradise "C., Scudder, S.A., Goodman, G., and Konrad, M. 1991. A phase I study including pharmacokinetics of polyethylene glycol conjugated interlaukin-2. Clin Phamacol Ther. 49:307-313.

16. Nucci, M.L., Shorr, R., and Abuchoweski, A. 1991. The therapeutic walue of poly(ethylene.glycol)modifled proteins. Adv Drug Delivery Rev. 6:133-15:.

17. Eckel, L.A., Langhans, W., Kahler, A., Campfield, L.A., Smith, F.J., and Geary, N. 1998. Chronic administration of $O B$ protein decreases food intake by selectively reducing ineal size in female rats. Am a Physiol. 275:R186-R193.

18. Kahler, A., Geary, N., Eckel, L.A., Campfield, L.A., Smith, F.J., and Langhans, W. 1998. Chronic admünistration of $O B$ protein decreases food intake by selectively reducing meal size in male rats. Am $J$ Physiol. 275:R180-R185.

19. Schrauwen, P., van Marken Lichtenbelt, W.D., Saris, W.H., and Westerterp, K.R. 1997. Changes in fat oxiّ dation in response to a hilgh-fat diet. Am J Clin Nutr. 66:276-282.

20. Schoffelen, P.F., Westerterp, K.R. Saris, W. H., and Ten Hoor, F. 1997. A dual-respliration chamber system with automated calibration. $J$ Appl Physiol. 83:2064-2072.

21. Weir, J.B.d.V. 1949. New methods for callculating metabolic rate with special refierence to protein metabolism. J Physiol. 109:1-9.

22. Westerterp, K.R., Wouters, $L_{n}$ and van Marken Lichtenbelt, W.D. 1995. The Maastricht protocol for the measurement of body composition and energy expenditure with labeled water. Obes Res. 3/Suppl 1): $49-57$

23. Siri, W.E. 1961. Body composition from fluid spaces and density: analysis of methods. In: J. Brozek, and A. Henschel, eds. Techniques for measuring body composition. Washington DC: National Academy of Schence; 223-244.

24. Frieclewald, W.T., Levy, R.I., and Fredrickson, D.S. 1972. Estimation of the concentration of low-density lipoprotein cholesterol in plasma, without use of the preparative ultracentrifuge. Chin Chem. 18:499-502.

25. Bonora, E., Moghetti, P., Zancanaro, C., et al, 1989. Estimates of in vivo insullin action in mam; cornparison

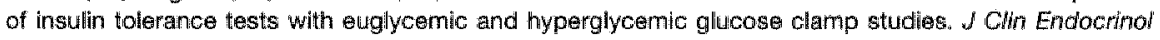
Metab. 68:374-378.

26. Campfield, L... Devos, R., and Guisez, Y. 2000. Pegylated obese (OB) protein compositions. US Patent Number $6,025,324: 2 / 15 / 2000$.

27. Bailon, P.S, Campfield, L.A., and Devos, R. 2000. Pegyllated obese (OB) protein compositions. US Patent Number 6,025,325:2/15/2000.

28. World Health Organization. 1985. Energy and protein requirements. Tech. Report Series 724. Geneva: World Health Organization.

29. Davidson, M.H., Hauptman, J., DiGirolamo, M. at al. 1999 . Weight contioll and risk factor reduction in obese subjects treated for 2 years with orlistat: a randomized controlled trial o Am Med Assoc. 281:235-242.

30. Sjostrom, L., Rissanen, A., Andersen, T, at al. 1998. Randomised placebo-controlled trial of orlistat for weight loss and prevention of weight regain in obese patients. European Muticentre Orlistat Sudy Group. Lancet. $352: 167-172$.

31. Hollander, P.A., Elbein, S.C., Hirsch, I.B. et all. 1998. Role of orlistat in the treatment of obese patients with type 2 diabetes. A 1-year randomized double-blind study. Diabetes Care. 21:1.288-1294.

32. Pelleymounter, M.A., Cullen, M.J., Healy, D., Hecht, R. Wimters, D., and McCaleb. M. 1998. Efficacy of ex. ogenous recombinant murine leptin in lean and obese 10- to 12-mo-old female $C D-1$ mice. Am id Physiof. 275:R950-R959:

33. Unger, R.H., Zhou, Y.T., and Orci, L. 1999. Regulation of fatty acid homeostasis in cells: Novel role of leptim. Proc Natl Acad Sci USA. 96:2327-2332. 


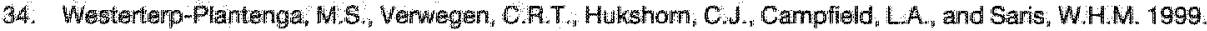
Changes in appethe following we wly PEG-OB protein administration during an energy restricted diet in obese men (ACstract) Int 1 Obes. 23 (suppl 5 ): 883 . 


\section{CHAPTER 4}

\section{The Effect of Pegylated Recombinant Human Leptin (PEG-OB) on Weight Loss and Inflammatory Status in Obese Subjects}

C.J. Hukshorn, F.M.H. van Dielen, W.A. Buurman, M.S. Westerterp-Plantenga, L.A. Campfield, and W.H.M Saris 


\section{Abstract}

Objective: To investigate whether weekly subcutaneous administration of $60 \mathrm{mg}$ of long-acting pegylated human leptin (PEG-OB) for 8 weeks was able to influence weight loss, metabolic profile, and inflammatory status of obese subjects on a mildly hypoenergetic diet (deficit: $32 \mathrm{MJ} /$ day).

Desilgni A prospective, randomized, double-blind and placebo-controlled single-center trial.

Subjects: Twenty-eight healthy, obese subjects (16 women, 12 men; age 22-65 y; body mass index $\left.27.7-38,7 \mathrm{~kg} / \mathrm{m}^{2}\right)$.

Measurements: Bodyweight, metabolic profile (including lipids), C-reactive pirotein (CRP) and soluble TNFa-receptor (STNF-R) 55 and 75 levels.

Results: At the end of the study no significant differences in the delta or percentage weight loss between the placebo $(n=14)$ and PEG-OB $(n=14)$ groups was observed. Also the changes in metabolic profile, CRP, sTNF-R55 and R75 concentrations between the two groups after 8 weeks of treatment did not differ.

Conclusion: Weekly injection of $60 \mathrm{mg}$ PEG-OB did not lead to additional weight loss after 8 weeks of treatment. Furthermore, PEG-OB administration did not affect the changes in metabolic profile and the inflammatory status of obese subjects.

\section{Introduction}

Leptin, the protein product of the ob gene, plays an important role in the regulation of food intake and energy expenditure in animal models wia hypothallamic mechanisms (1-3). Treatment of normal and diet-induced obese mice with recombinant leptin or long-acting pegylated recombinant leptin (PEG-OB) results in decreased food intake and weight loss, although the latter group requires a higher dose, indicating relative leptin resistance (4). The first clinical trial conducted by Heymsfield and coworkers observed a dose-response relationship with weight and fat loss in both lean and obese humans after exposure to recombinant human leptin supporting this concept (5). These early results suggested that high therapeutical doses of human recombinant leptin might be able to reduce body weight in obese subjects. In contrast, we failed to show an effect of $\mathrm{PEG}-\mathrm{OB}$ administration on body weight or energy expenditure in obese subjects (6). However, it should be noted that the dose used in the latter study (20 $\mathrm{mg}$ per week) only led to $60 \%$ of the maximal serum leptin concentrations observed in the highest dose cohorts of the study of Heymsfield. Hence, the administration of a higher dose of PEG-OB might be able to affect body weight in obese subjects.

The discovery that the leptin receptor is widely expressed in various non-neuronal tissues including lymph nodes, macrophages, and hemopoietic cells suggests that leptin also possesses other extrahypothalamic effects (7-9). Several lines of evidence indicate that leptin has immunoregulatory actions. The leptin receptor is structurally related to the class I cytokine receptor family and has been shown to have signaling capabilities of interleukin 6-type cytokine receptors (10). Rodents with defects at different sites in the leptin-dependent signaling pathway exhibit increased sensitivity to endotoxin-induced lethality, deficits in macrophage phagocytosis, impaired T-cell function, and lymphoid atrophy. Exogenous leptin was able to correct the majority of 
these immune dysfunctions (11-14). Moreover, leptin deficient human infants were reported to be more susceptible to infections (15). In vitro experiments showed that leptin activated human peripheral monocytes by inducing proliferation and proinflammatory cytokine production in a dose dependent fashion. These results prompted investigators to suggest that leptin might have an additional physiological role as a proinflammatony cytokine (16). Leptin levels are generally elevated in the obese population (17). Furthermore, obesity appears to be associated with a state of low-grade systemic inflammation (18). Together, it seems conceivable that increased leptin levels present in human obesity might contribute to this state of low-grade systemic inflammation.

The purpose of this study was to explore whether weekly administration of a high dose (60 mg per week) of longacting pegylated human leptin (PEG-OB) was able to induce additional weight loss and metabolic changes in obese subjects on a mildly hypoenergetic diet. Furthermore, we investigated if PEG-OB was able to change the inflammatory status of these subjects by measuring concentrations of the acute-phase C-reactive protein (CRP) and soluble TNFa-receptor (sTNF-R) 55 and 75 levels.

\section{Subjects and Methods}

\section{Subjects and study design}

Twenty-eight healthy obese subjects ( 16 women, 12 men) were recruited by local advertising and studied after provision of written informed consent. The study was approved by the Medical Ethical Committee of the Maastricht University. Obese (body mass index $\left.(B M l) \geq 27.0 \mathrm{~kg} / \mathrm{m}^{2}\right)$ subjects of $18-65$ y old were eligible for inclusion. Female subjects had to be sterile or post-menopausal $(1 \mathrm{y})$. Subjects with obesity-related diseases requiring pharmacalogical treatment (eg diabetes, hypertension, dyslipidemia) were excluded. Other exclusion criteria were: weight loss more than 3 $\mathrm{kg}$ in the previous 3 months, presence of any significant illness, including laboratory or electrocardiogram abnormalities, history or presence of drug abuse or alcoholism; smoking more than five cigarettes or equivalent per day. Also , known allergy, thistory of atopy or hypersensitivity to pegylated proteins and use of any drug that might have influenced body weight led to exclusion. This single-center trial had a prospective, randomized, double-blind, and placebo-controlled group design. After a lead-in diet period lasting 4 weeks, only those subjects who lost $1.75 \mathrm{~kg}$ or more from their initial body weight were allowed to continue to the treatment phase. Eligilble subjects were subsequently stratified and matched into pairs according to gender, agie, initial body weight, initial BMI, and the amount of body weight lost during the lead-in diet period to achieve balanced treatment groups.

Randomization numbers for subjects were generated and incorporated into the double-blind labeling by an independent third party. Treatment consisted of $60 \mathrm{mg}$ PEG-OB $(6 \mathrm{ml}, 10 \mathrm{mg} / \mathrm{ml}$; produced and provided by Hoffmann-La Roche $\|$ nc., Nutley, NJ, USA) or matching placebo $(6 \mathrm{mll}$ ) administrated subcutaneously (s.c.) once a week in the para-umbilical region for a total of 8 weeks. In addition, all subjects were prescribed a mildly hypoenergetic diet during the lead-in and 8 week treatment period designed to reduce daily energy intake by $3200 \mathrm{~kJ} /$ day ( $800 \mathrm{kcal} /$ day). The energy 
content of the diet was calculated from the patients" estimated basal metabolic rate multiplied by 1.6 to estimate the total dailly energy expenditure (19). From energy expenditure, $3200 \mathrm{~kJ} / \mathrm{day}(800 \mathrm{kcal} / \mathrm{day})$ was subtracted to abtain a mildy hypoenergietic diet. The dietary prescription was discussed every week with a dieticlan. Body weight was measured weekly on a calibrated digital scale accurate to 0.1 $\mathrm{kg}$ and height was measured to the nearest $0.01 \mathrm{~m}$. The BMI was calculated as body weight (kg) divided by height (m) squared. Safety of PEG-OB was monitored weekly by documentation of adverse events and the recording of vital signs. Routine clinical hematology and biochemical tests and urine analysis were conducted throughout the study by the certified central laboratory of the University Hospital Maastricht, The Netherlands.

\section{Collection and analysis of blood samples}

Blood samples were collected after an overnight fast on week -4 (start of the study), day 1 (start treatment period) and on week 8 (end of the study) and immediately cooled on ice (plasma) or allowed to clot at room temperature (serum). Plasma and serum were extracted by centrifugation (twice at $4^{\circ} \mathrm{C}$ ), frozen in liquid nitrogen and stored at $-80^{\circ} \mathrm{C}$ until further analysis. Plasma substrates were determined enzymatically in duplicate using the hexokinase method (Roche, Basel, Switzerland) for glucose, the Wako NEFA C kit (Wako Chemicals, Neuss, Germany) for FFA, the

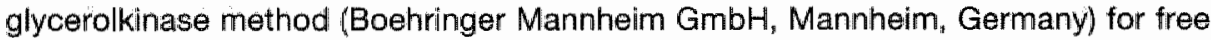
glycerol, the lipase method (Sigma Diagnostics "St Louis, MO, USA) for triglycerides " and the CHOD-PAP method (Boehringer Mannheim GmbH, Mannheim, Germany) for cholesterol. To avoid interassay variability, all specimens for a given substance were run in a single assay.

Insulin serum levels were measured by ELISA (Mercodia insulin ELISA; Mercodia AB, Uppsala, Sweden). Insulin resistance was estimated using the HOMA-R method (20). Total leptin concentrations (endogenous leptin plus PEG-OB) were measured according to the method described previously (6).

Plasma concentrations of both soluble TNF $\alpha$-receptors and CRP levels were measured using specific sandwich ELISAs. STNF-R55 and STNF-R75 were detected as described elsewhere (21). Plasma CRP levels were measured using an ELISA made up with a polyclonal antibody to human CRP that was used both as control and detector of CRP. The intra- and interassay coefficients of variations were both below the $10 \%$. All measurements were performed in duplicate.

\section{PEG-OB}

Recombinant methionyl hurnan leptin has a reported average terminal half-life of approximately $4 \mathrm{~h}$ in humans, which requires daily administration to obtain sustained blood levels (5). Modification of proteins through covalent linkage of polyethylene glycol polymers to the protein has resulted in reduced immunogenicity and increased serum half-life for a number of proteins. Recombinant native human leptin, expressed and purified from Escherichia coll, was chemically conjugated to a species of branched polyethylene glycols (PEG) with an average molecular weight of $42 \mathrm{kDa}$ in a

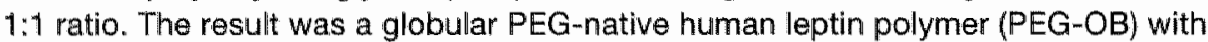
increased molecular size. PEG-OB at a concentration of $10 \mathrm{mg} / \mathrm{ml}$ was placed in ster- 
ile glass vials containing $1.3 \mathrm{ml}$. Preclinical studies with $\mathrm{PEG}-\mathrm{OB}$ indicate an extended half-life ( $>48 \mathrm{~h}$ ) and efficacy for reduction of food intake and body weight in animals (22). Our previous study in obese male subjects clearly showed sustained elevated blood levels following weekly s.c. dosing of PEG-OB in humans. Mean peak serum $\mathrm{PEG}-\mathrm{OB}$ concentrations were achieved $72 \mathrm{~h}$ after dosing followed by a return to the elevated pre-dose levels after 1 week (6).

\section{Statistical analysis}

Changes from baseline after 8 weeks treatment were compared between the PEG-OB treated and placebo group using factorial ANOVA. Post hoc, for each comparison separately, ANOVA with repeated measures was used. Additional statistical tests were used when appropriate. All statistical tests were two-sided and significance was defined as $P<0.05$. All data are presented as mean \pm SEM, unless otherwise undicated.

\section{Results}

The baseline demographic characteristics of the subjects are shown in Table 1. The characteristics of the 14 subjects randomized to each treatment group were similar. All 28 subjects that were randomized into the two treatment groups completed the trial. No subjects were excluded at the end of the lead-in diet period for dietary non-compliance. The most common adverse events related to treatment were injection site ecchymosis, pruritis, and pain (Table 2). These occurred with similar frequency in both the placebo and the PEG-OB groups. No difference was detected between the groups with regards to vital signs, standard chemistry or hematology assessments and urine analysis.

The effect of PEG-OB treatment or placebo treatment on body weight and BMI are illustrated in Figure 1. At the end of the lead-in period the mean body weight loss was $-5.3 \pm 0.45 \mathrm{~kg}$ in all 28 subjects studied (Table 1). After completion of the treatment period both the placebo $(n=14)$ and PEG-OB $(n=14)$ groups had lost a similar amount of weight (week 8 body weight: placebo $86.5 \pm 4.3 \mathrm{~kg}$; delta $-3.8 \mathrm{~kg}$; PEG-OB 85.8 4.8 ; delta $-4.8 \mathrm{~kg} ; P=0.32$ ). There was no significiant difference in the delta or percentage change in weight and $B M I$ between the $P E G-O B$ and placebo groups.

The effect of $60 \mathrm{mg}$ PEG-OB or placebo treatment on the metabolic profile (including lipids) is shown in Table 3. Plasma glucose and serum insulin concentrations decreased throughout the study. However, no significant differences were observed between the treatment groups. Insulin resistance (estimated by the HOMA-R method) also showed no significant differences between both groups before and after treatment. No significant differences in plasma FFA "glycerol, total cholesterol, and triglyceride concentrations were observed at the end of the $B$ week treatment period and there were no differences between the treatment groups. Following weekly S.C. dosing of PEG-OB, elevated serum levels of total leptin (endogenous plus PEG-OB), measured a week after the last dose, ranging from $800-3900 \mathrm{ng} / \mathrm{ml}$ were observed.

The result of PEG-OB or placebo treatment on the concentrations of CRP, STNF-R55 and 75 are given in Table 4 . Weight reduction during the lead-in period significantly decreased the levels of sTNF-R55 from $0.37 \pm 0.02 \mathrm{ng} / \mathrm{m} \|$ to $0.36 \pm 0.02 \mathrm{ng} / \mathrm{ml}(P=$ 
0.03 ) in the whole group, but did not affect the concentrations of STNF-R75 and CRP. No significant differences in CRP, STNF-R55, and STNF-R75 concentrations were obserwed after 8 weeks of treatment between the groups.

\section{Table 1. Baseline demographics}

\section{Characteristic}

Sex.

Male

Femala

Age 1

Weiver (ko)

Height (m)

Bul (koim?)

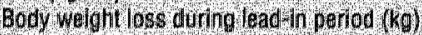

\section{Placebo $(n-14)$}

6

8

$527 \pm 32(220-650)$

$95.4+4.4 .68 .4 \cdot 135.5)$

$168 \pm 003 \cdot(1.49-187)$

$33.4 \div 0.8(27.7-38.7)$

$5.1 \pm 0.4(3.1-8.0)$
PEA OB $(n-14)$

6

8

$49.6 \pm 333(280.64 .0)$

$96,1+41734,1267$

$17.1=0.03(1 / 55 \cdot 1.92)$

$32.7 \pm 0.6(29.0-36.0)$

$5.5 \pm 0.5(29 \cdot 9.1)$

Baseline characteristics of the 28 subjects at the scriening. BMI body mass index. No statistical significant differences were found between both groups Data are presented as mean \& SEM (range).

Tabla 2. Most commoin adver se events related to treatmont

Event

Hematoma at the trigetilonsile

Itching at the iniegritions site

Pain al the injedton site
Frequency (rie of subjects reperting)

Plaeebio

PEQT-DB

$5 / 14$

$3 / 14$

$2 / 14$

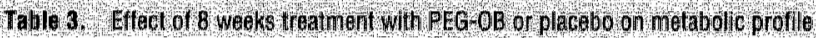

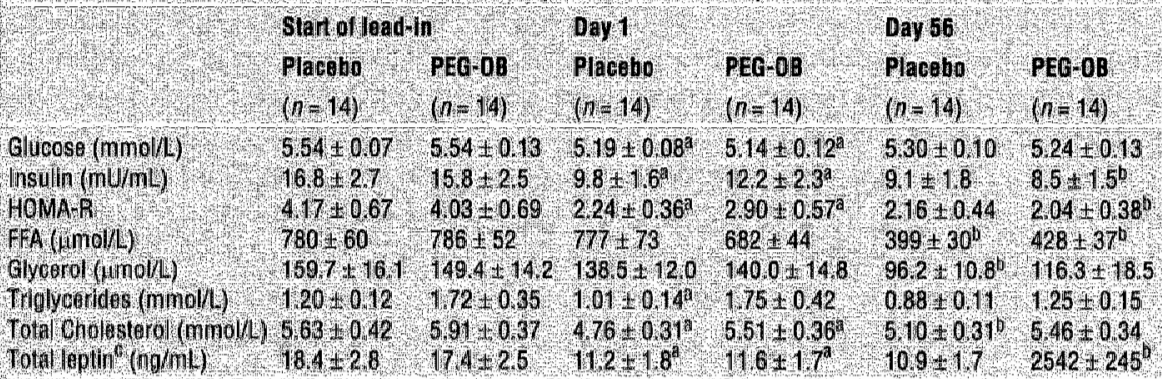

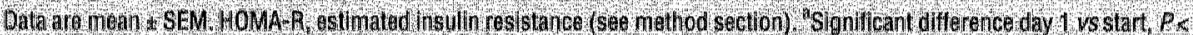

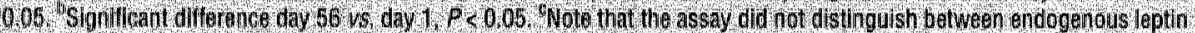

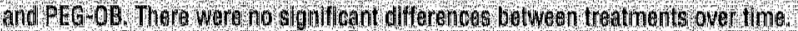

Table 4 . Eftect or 8 weaks treatrient with $P E G$ o 0 or placebo on the intlaminatory status

\begin{tabular}{|c|c|c|c|c|c|c|}
\hline & \multicolumn{2}{|c|}{ Start of loat/lot } & \multicolumn{2}{|l|}{ Day 1} & \multicolumn{2}{|l|}{ Day 66} \\
\hline & Placebo & PEG 00 & Placebo & PEGOB & Placelbo & PEG 018 \\
\hline & $(n=14)$ & $(n=14)$ & $(n=14)$ & $(n=14)$ & $(n-14)$ & $7=14$ \\
\hline in & 037.0 .03 & $0,38+0,03$ & $0,36+0.03$ & $0.36+0.03$ & $0.37+0.03$ & 3 \\
\hline in & $126+0,09$ & $1.26,0.09$ & $121+0.10$ & $130+0.09$ & $1,24+0,08$ & $=0$ \\
\hline & $4.31 \times 134$ & 5971113 & $4.47 \div 2.44$ & $5.88 \pm 117$ & $3.39+133$ & 5.28 \\
\hline
\end{tabular}

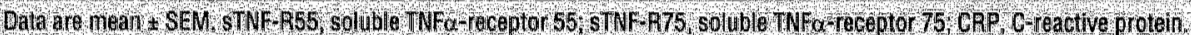
Siguifeant difference day 1 us stert $P<005$, signilleantdifference day 56 us day $1, P<0.05$ There were no stgnificant difterences between treatments over time: 

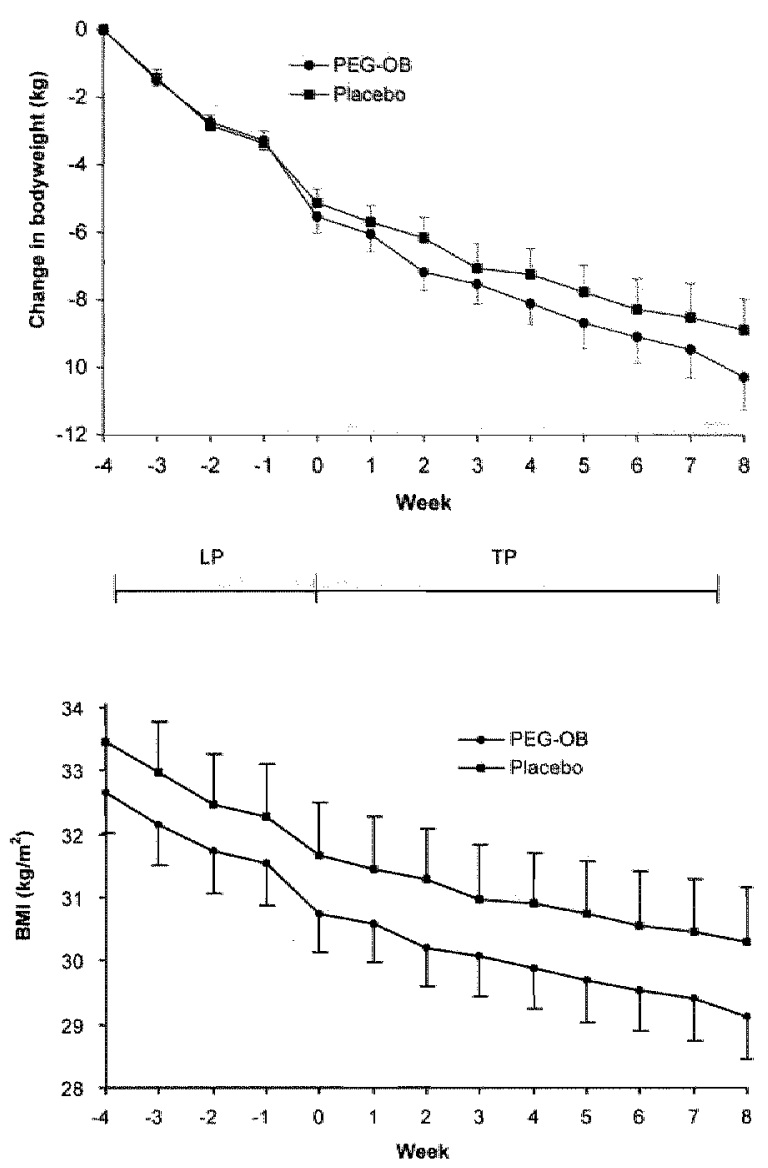

Figure 1: Mean change in bodyweight (a) and BM (b) from the startt of the llead-in period (ILP) of 4 wacks until the end of the 8 waek treatment period (TP). Error bars indicate SEM.

\section{Discussion}

The results show that exposure to $60 \mathrm{mg}$ PEG-OB weekly for 8 weeks did not influence weight loss in obese subjects on a mildly hypoenergetic diet despite the high serum levels of PEG-OB achieved at the end of this study. Thus, augmentation of serum leptin concentration using a liong-acting PEG-OB failed to promote additional weight loss over caloric restriction. The outcome of this study is, however, consistent with the alternative view of the physiologicial role of leptin proposed by the group of Flier (23). These investigators suggest that evolution would favor a leptin dose-response curve that functions briskly as a switch between the fed and fasted state, but would fail to limit further energy storage as levels rose with increased energy stores. The latter state could be described as leptin resistance'. In addition, they speculate that the shape of this biological dose-response curve may depend on the conditions in which a certain species evolved. This hypothesis provides a possible explanation for the in- 
effectiveness of high dose PEG-OB in our obese individuals on a mildy hypoenergetic diet as well for the fairly moderate results of the Heymsfield trial (5). According to this Vew, PEG-OB might cause additional weight loss when administrated during severe energy restriction or total leptin deficiency. The observation that recombinant human met-leptin treatment of a young hyperphagic very obese girl with a mutated ob gene resulted in welight loss by sustained reductions in appetite is consistent with this wiew (24). The fact that supraphysiological levels of PEG-OB cause weight loss in rodents (22) but not in humans suggests that the leptin dose-response curves of these species are different.

However, the possibility that the small number of subjects studied and the relative short duration of treatment might explain the lack of an effect of PEG-OB treatment on weight loss in this study cannot be excluded.

Also other biological effects of leptin in animal studies were not observed in this study (4). We failed to demonstrate any treatment effects on the levels of glucose, insulin (including estimated insulin resistance), and triglycerides. These results are supported by data obtained from the limited number of human patients with leptin deficiency or non-functional leptin receptors studied up to now who also lack substantial impairments in glucose homeostasis and lipids (unlike, respectively, the $a b / o b$ and $d b / d b$ mice) suggesting that leptin is not directly involved in the regulation of these systems in man $(15,25)$. Our previous study suggested that PEG-OB treatment might have an additional effect on triglycerides in obese subjects consistent with similar changes repeatedly observed in animal studies (6). In the present study with a higher dose of PEG-OB no added effect on triglycerides was observed.

Next, we studied whether administration of longacting pegylated human leptin affects the levels of soluble TNF $\alpha$-receptors (sTNF-R55 and 75) and CRP. Soluble TNF $\alpha$ receptor levels have been validated as sensitive indicators of activation of the TNF $\alpha$ system (26). CRP is an acute phase protein of the pentraxin family and a sensitive marker for systemic inflammation. Our data showed that administration of pegylated human leptin to obese subjects affected neither the levels of sTNF-R55 and 75 nor those of CRP, suggesting that leptin is not directly involved in the enhanced inflammatory status present in obesity. Thus ${ }_{n}$ it seems plausible that the definite long-term elevations in systemic leptin and CRP found in obesity result from a common pathogenic mechanism present in this condition.

In summary, weekly s.c. administration of $60 \mathrm{mg}$ PEG-OB to obese subjects on a mildly hypoenergetic diet did not affect weight loss, metabolic profile, and inflammatory status after 8 weeks. In addition, PEG-OB treatment was generally well tolerated and safe in these subjects.

\section{Acknowledgments}

We thank Hoffmann-La Roche Inc. for kindly providing pegylated human recombinant leptin (PEG-OB). We also wish to express our sincere appreciation to Gabby Hul for her help in performing the experimental protocols. Finally, we greatly acknowledge the co-operation, patience, and contributions of all of our subjects. 


\section{References}

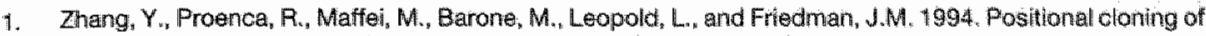
the mouse obese gene and its human homologue. Nature. $372: 425,432$.

2. Pelleymounter; M.A. Cullen, M.J., Baker, M.B., et al. 1995. Effects of the obese gene product on body weight regulation in ob/ob mice. Science. 269:540-544.

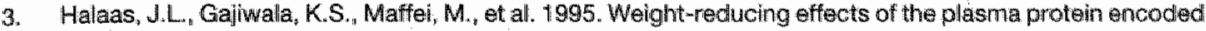
by the abese gene. Science. 269:543-546:

4. Campfield, L.A., Smith, F.J., and Bum, P. 1997, OB protein: A homonal controller of centrail neurial nelwork mediating behavioral , metabolic and neuro endocrine responses. Endocrinol Metab. 4:81-102.

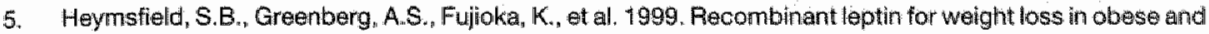
lean adults - A randomized, controlled, dose-escalation trial. $J$ Am Med Assoc. 282:1568-1575.

6. Hukshoin, C.J., Saris, W.H.M. Westerterp Plantenga, M.S. Farid, A.R., Smith, F.J. and Campilield, L.A. 2000. Weekly subcutaneous pegylated recombinant natiwe human leptin (PEG-OB) administration in obese men. I Clin Endocrinol Metab. 85:4003 4009.

7. Lollmann, B., Gruninger, S. Stricker Krongrad, A., and Chiesi, M. 1997. Detection and quantiftcation of the leptin receptor splice variants Ob-Ra, b, and, e in different mouse tissues. Biochem Biophys Res Commun. 238:648-652

8. Gainsford, T. Willson. T.A., Metcalf, D., et al. 1996. Leptin can induce proliferation, differentiation, and functionall activation of hemopotetic cells. Proc Nat Acad Sci USA. 93:14564-14568.

9. Cioffi, J.A., Shater. A.W., Zupancic, T.J., et al. 1996. Novel B219/OB receptor isoforms: passible role of leptim in hematopolesis and reproduction. Nat Med. 2:585-589.

10. Baumann, H., Morella, K.K., White, D.W., et al. 1996. The full-length leptin receptor has signaling capabilties of interleukin 6-type cytokine receptors. Proc Natl Acad Sci USA. 93:8374-8378.

11. Faggioni, R., Fantuzzi, G., Gabay, G., et al. 1999. Leptin deficiency enhances sensitivity to endotoxin-induced lethality. Am J Physiol. 276:R136-A142.

12. Loffreda, $S_{.}$Yang, $S . Q$. Lin, $H . Z_{.}$et al. 1998. Leptitn regulates proinflammatory immune responses. FASEB $J .12: 57-65$

13. Lord, G.M., Matarese, G. Howard, L.K., Baker, R. ل. "Bloom, S.R., and Lechler, R.. 1. 1998. Leptin modulates the T-cell immune response and reverses starvation-induced immunosuppression. Nature. 394:897-901.

14. Howard, J.K., Lord, G.M., Matarese, G., et al. 1999. Leptin protects mice from starvation-induced lymphoid atrophy and increases thymic cellularity in ob/ab mice. J Clin Invest. 104:1051-1059.

15. Ozata, M. Ozdemir, ll.C., and Licinio, J. 1999. Human leptin deficiency caused by a missense mutation: multiple endocrine defects ${ }_{1}$ decreased sympathetic tone, and immune system dysfunction indicate new targets for leptin action, greater central than peripheral resistance to the effects of leptin, and spontaneous correction of leptin-mediated defects. J Cin Endocrinol Metab. 84:3686-3695.

16. Santos Alvarez, J., Goberna, R., and Sanchez Margalet, V. 1999. Human leptin stimulates proliferation and activation of human circulating monocytes. Cell Immunol. 194:6-11.

17. Maffei, MA.- Halias, J., Plawussin, E., et al. 1995. Leptin lewels in human and rodent: measurement of plasma leptin and ob RNA in abese and weight-reduced subjects. Nat Med. 1:1155-1161.

18. Visser, M., Bouter, L.M., McQuillan, G.M., Wener, M.H." and Harris, T.E. 1999. Elevated G-teactive protein levels in overweight and obese adults J Am Med Assoc. 282:2131-2135.

19. World Health Organization. 1985. Energy and protein requirements. Aeport of joint FAO/WHO/UNU Expert consultation. Technical Report Series no. 12, WHO: Geneva.

20. Matthews, D.R., Hosker, w.P., Rudenski, A.S. Naylor, B.A., Treacher, D.F." and Turner, R.C. 1985. Homeostasis model assessment: insulin resistance and beta-cell function from fasthng plasma glucose and insuling concentrations in man. Diabetologia. $28 * 412-419$.

21. Leeuwenberg, J.F., Jeunhomme, T.M., and Buturman, W, A. 1994. Slow releabe of soluble TNifr receptors by monacytes in vitro. I /mmunol. 152:4036-4043.

22. Kahler, A. Geary, N., Eckell, L.A., Campfield, L.A., Smith, F.J., and Langhans, W. 1998. Chronic adminisw Iration of $\mathrm{OB}$ protein decreases food intake by selectivaly reducing meal size in male rats. Am ol Physid. 275:R180-Ris 85 .

23. Flier, J.S. 1998. Clinical review 94: What's in a name? in search of leptin's physiologic role. $J$ Clin Endocrinol Metab. $83 \times 1407 \div 1.413$

24. Farooqi, I.S., Nebb, S.A., Langmack, G., et al. 1999. Effects of recombinant leptin therapy in a chilld with Congenital leptin deficiency. N Engl J Med. $341: 879-884$.

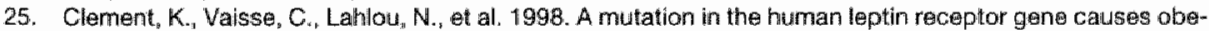
sity and pitititary dysfunction. Nature. 392:398-401.

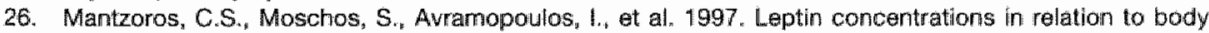
mass index and the tumor necrosis factor-alpha systerm in humans. I Clin Endocrinol Motab. $82: 3408-3413$ 

CHAPTER 5

Pegylated Human Recombinant Leptin
(PEG-OB) causes Additional Weight Loss in
Severely Energy-Resitricted, Overweight Men

C.J. Hukshorn, M.S. Westerterp-Plantenga, and W.H.M. Saris 


\section{Abstract}

Background: Increasing evidence suggests that falling leptin concentrations observed during fasting act as a peripheral signal of starvation, which serves to conserve energy in the face of limited reserves. An extention of this hypothesis is that exogenous leptin should affect energy regulation during severe energy restriction.

Objective: To explore this hypothesis, we assessed whether elevated leptin concentrations achieved with the use of long-acting pegylated human recombinant leptin [polyethylene glycol-OB protein (PEG-OB)] affected weight loss and changes in body composition, energy expenditure, appetite, and metabolic variables during semistarvation in healthy overweight men.

Design: A randomized, double-blind, and placebo-controlled study was executed in overweight men with a mean ( $¥$ SEM) age of $34.8 \pm 1.3 \mathrm{y}$ and body mass index (in $\left.\mathrm{kg} / \mathrm{m}^{2}\right)$ of $28.8 \pm 0.5$. All subjects received weekly treatment with $80 \mathrm{mg}$ PEG-OB $(n=$ 12) or matching placebo $(n=10)$ for $46 \mathrm{~d}$ while their energy intake was reduced to 2.1 MJ/d by means of a very-low-energy diet. Body composition (hydrodensitometry and deuterium dilution), energy expenditure (ventilated hood), and appetite (visual analog sciales) were evaluated at the start and end of the study. Metabolic variables were measured throughout the study period.

Results: Compared with placebo treatment, treatment with PEG-OB led to significant $(P<0.03)$ additional weight loss $(14.6 \pm 0.8$ compared with $11.8 \pm 0.9 \mathrm{~kg})$ and a reduction in appetite $(P<0.05)$ after $46 \mathrm{~d}$, but the 2 treatment groups did not differ significantly in changes in body composition, energy expenditure, and metabolic variables.

Conclusion: Our observations support the hypothesis that the decrease in leptin concentrations during starvation increases appetite in humans.

\section{Introduction}

Leptin, the 16-kDa protein hormone encoded by the ob gene, is secreted primarily from adipose tissue and is involved in the regulation of food intake and metabolism via hypothalamic mechanisms (1-4). Other extrahypothalamic areas in which leptin has been implicated are glucose homeostasis, hematopoieses, anglogenesis, and immune responses. Furthermore, leptin may act as an important regulator of neuroendocrine and reproductive functions (5).

Initially, leptin was considered to function as the predicted and long-sought adipostatic hormone. According to this hypothesis, rising concentrations of leptin with increasing adiposity would generate a signal to reduce food intake and increase energy expenditure to limit further weight gain. However, resistance to the proposed antiobesity action of leptin is observed in both animals $(6,7)$ and humans $(8)$. In addition, even supraphysiological leptin concentrations obtained during several clinical trials to date falled to significantly affect weight loss during mild hypoenergetic conditions (9-11) or energy expenditure during weight maintenance (12).

The widespread occurrence of leptin resistance may reflect the fact that the inability to store energy efficiently at times of abundance is evolutionarily disadvantageous. According to this alternative view proposed on the basis of animal data, evolution would favor a leptin dose-response curve that functions briskly as a switch between the fed and fasted state but fails to limit further energy storage as concentrations increase 
with increasing energy stores $(13,14)$. An extention of this hypothesis is that exogenous leptin should affect energy regulation when administrated during severe energy restriction. To test this hypothesis, we executed a randomized, double-blind, placebo-controlled study to investiglate whether evevted leptin concentrations achieved with the use of long-acting pegylated human recombinant leptin [polyethylene glycol-OB protein (PEG-OB)] affected weight loss and changes in body composition, energy expenditure, appetite, and metabolic variables during semistarvation induced by a very-low-energy diet (VLED) in healthy, overweight men.

\section{Subjects and Methods}

\section{Subjects}

Twenty-four healthy, overweight male volunteers were recruited by local advertising, screened, and enrolled in the study after they provided written informed consent. The study was approved by the Medical Ethical Committee of Maastricht University. Overweight and mildly obese men who were 18-45 y of age and had a body mass index (BMl; in $\mathrm{kg} / \mathrm{m}^{2}$ ) between 25 and 32 were eligible for inclusion. Additional inclusion criteria were detailed medical and psychilatric histories and a physical examination with negative findings, including no medical condition present, no use of prescription medication, and no smoking. Each participant had normal biochemical tests of renal, hepatic, metabolic, and hematological function and no electrocardiogram abnormallties. Subjects who had a history of drug abuse or alcoholism or were currently using drugs or alcohol, had atopy or hypersensitivity to pegylated proteins, or had experienced a weight loss of $>3 \mathrm{~kg}$ in the previous 3 mo were excluded from the study.

\section{Study design}

This single-center trial had a prospective, randomized, double-blind, placebo-controlled group design. After the screening, 24 subjects were selected and enrolled in the trial. The study was divided into 3 phases: 1) baseline characterization (days -14 , -8, and 1), 2) PEG-OB or placebo treatment and a VLED for 46 d (days 1-46), and 3) follow-up for 2 wk (days 50 and 57). Baseline measurements were performed before (days -14 and -8 ) and at the start (day 1) of the diet and treatment period. The measurements on day 1 consisted of measurements of energy expenditure, body composition, and metabolic profile (including oral glucose tolerance). Subjects were stratified and matched into pairs according to age, BMI, and fasting serum leptin and insulin concentrations to achieve balanced treatment groups. Randomization num bers for subjects were generated and incorporated into the double-blind labeling by an independent thiird party.

At the start of the treatment period (day 1) all subjects were prescribed a VLED to induce a state of semistarvation for the next $46 \mathrm{~d}$. The VLED (Modifast; Novartis, Breda, The Netherlands) was a protein-enriched formula diet (containing $44 \%, 14 \%$, and $42 \%$ of energy as protein, fat, and carbohydrate, respectively) that provided $2.1 \mathrm{MJ} / \mathrm{d}$. The dietary prescription was discussed every week with a dietitian. Adherence to the diet was confirmed by measurements of body weight loss. Treatment consisted of 
weekly administration of either $80 \mathrm{mg}$ PEG-OB [8 $\mathrm{ml}$ of a $10 \mathrm{mg} / \mathrm{mL}$ solution; mean (ESEM) of $1.17 \pm 0.02 \mathrm{mg} / \mathrm{kg}$ fat-free mass (FFM); Hoffmann-La Roche Inc, Nutley. NJj or matching placebo ( $8 \mathrm{~mL}$ ) that was given subcutaneously in the paraumbilical region during the VLED period. The subjects returned to the laboratory in a fasting state on days $8,15,22,29,36$, and 43 to receive treatment after their weight and vitall signs (pulse, respiratory rate, and blood pressure) were recorded. Blood samples were drawn for safety laboratory tests and measurements of metabolites on days $1,8,15$, 25 , and 46 . At the end of the 46-d treatment period, measurements of energy expenditure, body composition, and metabolic profile were repeated. During the next 2 wk, the subjects received less formula diet and were instructed to supplement this with a free cholce of habitual food items. Vital signs and body weight during this follow-up period were measured on days 50 and 57 . Safety was monitored by documentation of adverse events and recording of wital signs at each visit. In adidition, urine analyses, routine serum chemistry measurements, and blood cell counts were conducted regularly throughout the study. Standard clinical chemistry measurements and blood cell counts were conducted at the certified central laboratory of the University Hospital Maastricht, The Netherlands.

\section{Polyethylene glycol-OB protein}

Recombinant methionyl human leptin has a reported average terminal half-life of $\approx 4 \mathrm{~h}$ in humans, and daily administration is requirred to obtain sustained blood concentrations (9). Modification of proteins through covalent linkage of polyethylene glycol polymers to the proteins results in reduced immunogenicity and increased serum half-life for many proteins (15). Recombinant native human leptin, expressed and purified from Escherichia coll, was chemically conjugated to a species of branched PEGs with an average molecular mass of $42 \mathrm{kDa}$ in a $1: 1$ ratio. The result was a globular $P E G-n a t i v e$ human leptin polymer (PEG-OB) with increased molecular size. PEG-OB at a concentration of $10 \mathrm{mg} / \mathrm{mL}$ was placed in sterile glass vials containing $1.3 \mathrm{~mL}$. Preclinical studies with PEG-OB indicate an extended half-life $(>48 \mathrm{~h})$ and efficacy for reduction of food intake and body weight in animals (16). Our previous study in obese male subjects clearly showed sustained ellevated blood concentrations after weekly subcutaneous dosing of $\mathrm{PEG}-\mathrm{OB}$ in humans. Mean peak serum PEG-OB concentrations were achieved $72 \mathrm{~h}$ after dosing, followed by a return to the elevated predose concentrations after 1 wh $(10)$.

\section{Body composition, energy expenditure, and appelite prolille}

Body weight was measured on a calibrated digital scale accurate to $0.1 \mathrm{~kg}$ " and height was measured to the nearest $0.01 \mathrm{~m}$. Body composition was determined after the ventilated-hood measurements obtained in the morning by using the combination of hydrodensitometry and deuterium dilution according to the Maastricht protocol (17). Body composition was calculated according to the equations of Siri (18). Energy expenditure and substrate utilization were measured with the use of a ventilated hood after the subjects fasted overnight. After the subjects had been supine for $15 \mathrm{~min}$, their oxygen consumption and carbon dioxide production were measured for $45 \mathrm{~min}$ by means of a computerized, open-circuit ventilated-hood system. The resting metabolic 
rate and the respiratory quotient were calculated according to the method of Weir (19) over the 15-min interval with the lowest SD.

The subjects" appetite profile was measured while they were in a fasted state before breakfast and included determination of the degree of dietary restraint. The appetite profile was determined by averaging the ratings of actual appetite, hunger, and desire to eat on $100-\mathrm{mm}$ anchored visual analog scales (20). The appetite profile before breakfast was completed on days 1 and 46 .

\section{Measurements of metabolic profile and pharmacokinetics}

Venous blood was sampled on days $1,8,15,25$, and 46 after the subjects had fasted overnight. Plasma or serum was extracted by centrifugation for $10 \mathrm{~min}$ at $1000 \times \mathrm{g}$ and $4^{\circ} \mathrm{C}$, frozen in liquid nitrogen and stored at $-80^{\circ} \mathrm{C}$ until further analysis. Plasma substrate concentrations were determined enzymatically in duplicate using the hexokinase method (Roche, Basel, Switzerland) for glucose, the Wako NEFA C kit (Wako chemicals, Neuss, Germany) for free fatty acids, the glycieralkinase method (Boehringer Mannheim GmbH, Mannheim, Germany) for free glycerol, the lipase method (Sigma Diagnostics, St Louis) for triacylglycerol, the CHOD-PAP method (Boehringer Mannheilm $\mathrm{GmbH}$ ) for cholesterol, and the $\beta$-hydroxylbutyrate dehydrogenase method (Sigma Diagnostics, St Louis) for $\beta$-hydroxybutyrate. To avoid interassay variability, all specimens for a given substance were run in a single assay.

Serum insulin concentrations were measured at the certified central laboratory of the University Hospital Maastricht, The Netherlands. Total leptin concentrations (endogenous leptin plus PEG-OB) were measured according to the method described previously (10).

Insulin resilstance throughout the study was estimated by using the HOMA-R method with fasting plasma glucose and serum insulin concentrations (21). For determining oral glucose tolerance, a standard $2-h$ oral-glucose-tolerance test was performed on days 1 and 46 after the subjects had fasted overnight. In short, an intravenous cannula was placed in an antecubital vein. After a baseline blood sample was drawn, the subjects ingested $75 \mathrm{~g}$ of glucose dissolved in $250 \mathrm{~mL}$ of water. Next, blood samples were obtained 30,60 , and 120 min after the consumption of the solution for measurements of plasma glucose concentrations.

\section{Statistics}

Changes from baseline to the end of the study were compared between the PEG-OB and placebo groups with two-factor repeated-measures analysis of variance with a group $X$ time interaction. When significant differences were found, a post hoc Scheffe's procedure was used to determine the lociation of the difference. All statistics were executed with STATVIEW (version 5.0; SAS Institute Inc, Cary, NC). All statistical tests were two-sided, and significance was defined as $P<0.05$. All data are presented as means \pm SEMs. 


\section{Results}

The characteristics of the subjects before the intervention are presented in Table 1. The variables used to match subjects into pairs were not significantly different, and thus balanced treatment groups were achieved. All subjects in the trial were of white origin. Two subjects in the placebo group dropped out voluntarily after 1 wk because they were not able to maintain the strict VLED regime. However, after exclusion of the data for these 2 subjects, the 2 groups still did not differ significantly in baseline characteristics (data not shown). The most common adverse events related to treatment were injection-site ecchymosis, pruritis, and pain. These occurred with similar frequency in the PEG-OB and the placebo groups and generally occurred only with the first or second series of injections. No significant differences between the groups in vital signs, standard chemistry or hematology measures, or urine analysis results were detected.

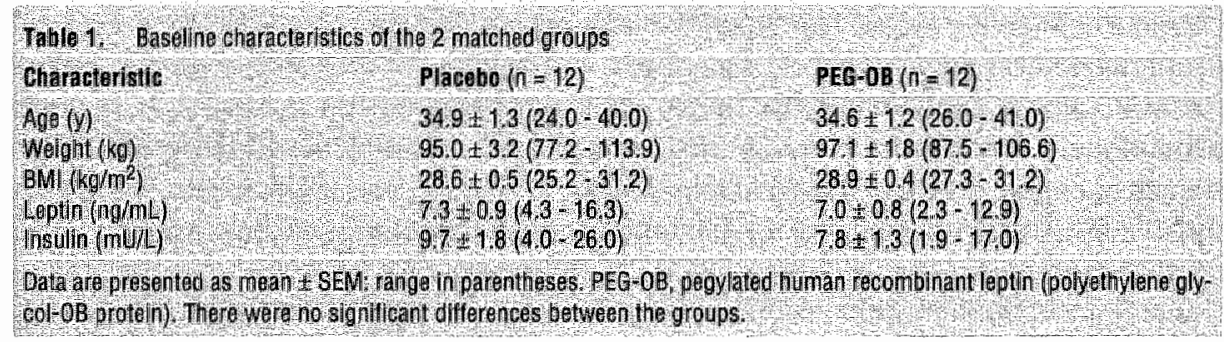

\section{Weight loss, body composition, energy expenditure, and appetite profile}

By day 46 , treatment and energy restriction had resulted in an absolute weight loss of $14.6 \pm 0.8 \mathrm{~kg}(14.9 \pm 0.7 \%)$ in the PEG-OB group and of $11.8 \pm 0.9 \mathrm{~kg}(12.4 \pm 1.1 \%)$ in the placebo group $(P=0.027$; Figure 1$)$. There was a significant difference in absolute weight loss between the PEG-OB and placebo groups on days 25,43 , and 46 (during the treatment period) and on days 50 and 57 (during the follow-up period) (Figure 1). The percentage of weight loss on days 43 and 50 was significantly different between the 2 groups $(P=0.013$ and $P=0.045$, respectively). A tendency for a difference in percentage welght loss was observed on days 46 and 57 of the study $(P=0.062$ and $P$ $=0.068$, respectively). Absolute and percentage changes in BMII were significantly different between the PEG-OB and placebo groups on days 43,46 , and 50 and day 43 , respectively.

The loss in fat mass accounted for most of the loss of body mass in both the PEG-OB group and the placebo group (74\% compared with $79 \%$; NS). The resting metabolic rate significantly decreased in both groups after 6 wk of the VLED and treatment, as did the respiratory quotient. The mean absolute changes in resting metabolic rate and respiratory quotient of all 22 subjects were $-0.817 \pm 0.096 \mathrm{M} / / \mathrm{d}$ and $-0.05 \pm 0.01$, respectively. None of the changes in body composition and energy expenditure were significantly different between the 2 groups (Table 2). In addition, comparison of the changes in resting metabolic rate adjusted for FFM over the treatment period did not show any significant differences between the PEG-OB and placebo groups. Appetite, 


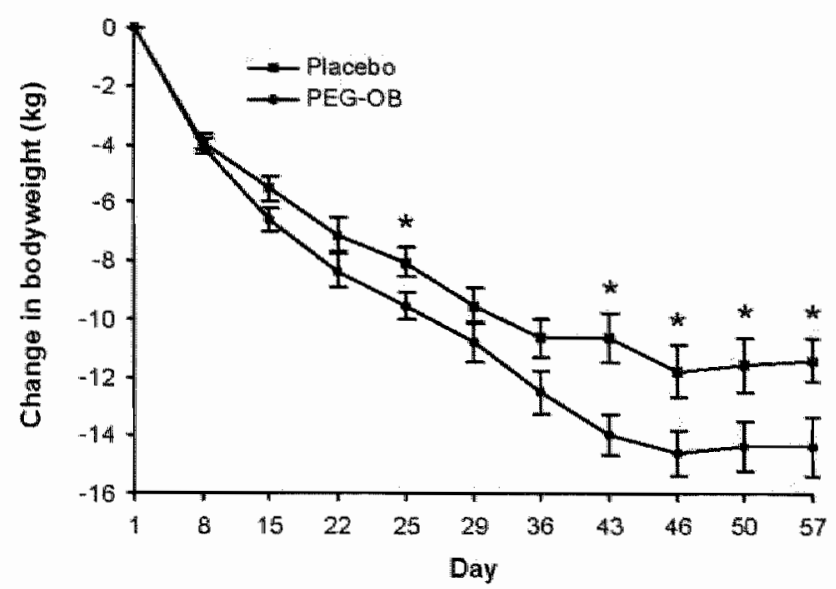

Flgure 1: Effect of $80 \mathrm{mg}$ pegylated humar recombinant leptin [polyethylene glycol-OB protein (PEG-OB)] $(0 ; n=12$ ) or matching placebo $(E ; n=10)$ administered weekly and of severe energy restriction (2.1 MJ/d) on mean ( $E$ SEM) weiglat loss fiom tho start of the treatment (day 1), through the diet period (day 46), to the end of the 2-wk followw-up period (day 57 ).

"Significamtly different from the PEG-OB group, $P$ e 0.05 unteraction of time and treatment: two-factor repeated-measures ANOVA with Scheffe's Fprocedure).

which was measured before breakfast, significantly changed from baseline after the VLED and treatment: appetite decreased from $40 \pm 17$ to $34 \pm 16 \mathrm{~mm}$ on the visual analogue scale in the PEG-OB group but increased from $38 \pm 17$ to $48 \pm 16 \mathrm{~mm}$ in the placebo group $(P=0.03)$.

\section{Metabolic profile and pharmacokinetics.}

The weight reduction observed during treatment was accompanied by a significant decrease in glucose, cholesterol, and triacylglycerol concentrations and by a significant increase in $\beta$-hydroxybutyrate, free fatty acid, and free glycerol concentrations in the PEG-OB and placebo groups (Table 3). The changes in metabolites were not significantly different between the 2 groups throughout the study. There were no effects of PEG-OB treatment on glycemic control, as evidenced by the serum insulin concentrations (Table 3), glucose profiles obtained during the baseline and end-of-treatment oral-glucose-tolerance tests, and the estimated insullin resistance (HOMA-R method) at different time points (data not shown).

Food restriction for 6 wk by means of a VLED reduced circulating leptin concentrations to $2.0 \pm 0.2 \mathrm{ng} / \mathrm{mL}(72 \%$ ) in the placebo group (Table 3). After weekly subcutaneous dosing, sustained serum concentrations of total leptin (endogenous leptin plus PEG-OB), which were measured just before the next dose on days 8 and 15 and ranged from 950 to $3700 \mathrm{ng} / \mathrm{mL}$, were observed. Peak total leptin concentrations on days 25 and 46 , which were measured $72 \mathrm{~h}$ after subcutaneous injection, ranged from 2300 to $6050 \mathrm{ng} / \mathrm{mL}$. 


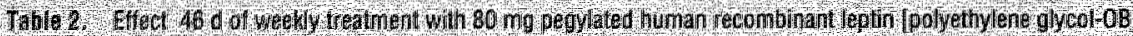
protein (PEG OBV] or riatching placebo and of severe enercy restriction $(2.1 \mathrm{M} / \mathrm{d}$ ) on body composition and eneroy expendinure

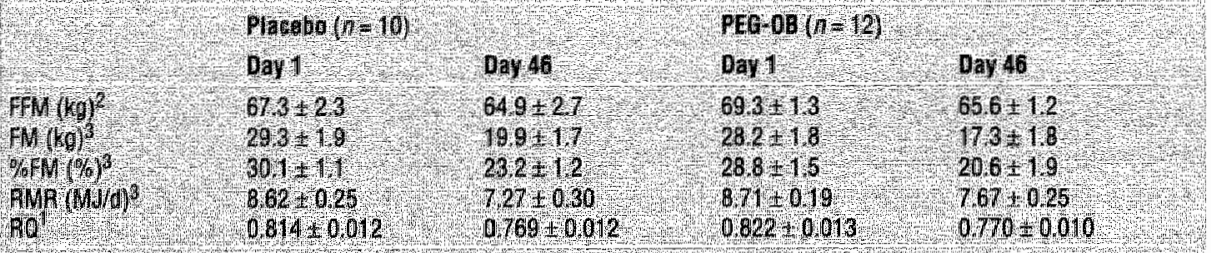

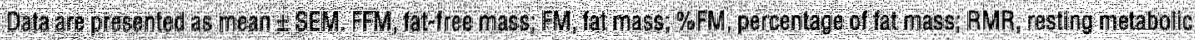

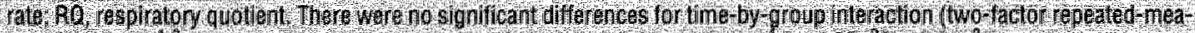

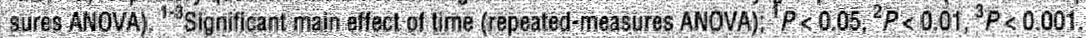

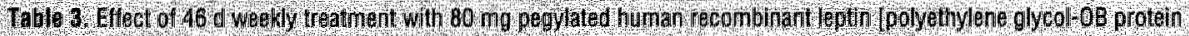
(PEG-108) or matefing placelbo and of severe energy restriction (21 Mud) on metabolites and endocrine measures

\begin{tabular}{|c|c|c|c|c|c|c|c|c|}
\hline & \multicolumn{2}{|c|}{ cluense? (nimol/) } & \multicolumn{2}{|c|}{ Cholosterol ${ }^{2}$ (mmo/h) } & \multicolumn{2}{|c|}{$\begin{array}{l}\text { (AHydraxy gutyrate } \\
\text { (emolis) }\end{array}$} & \multicolumn{2}{|c|}{$\begin{array}{l}\text { Triacylglyceroul' } \\
\text { (mmollh) }\end{array}$} \\
\hline & Placeho & $\mathrm{PEC}-\mathrm{OP}$ & Plasebo & PEGOB & Placebo & PEC-0B & Placebo & PEG OB \\
\hline & $\ln (10)$ & $(n-12)$ & $(n-10)$ & 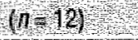 & $(n-10)$ & $(n-12)$ & $(n-10)$ & $(n-12)$ \\
\hline & 8 & $53+108$ & 27 & $47 \times 0.24$ & & 80 & $15 \div 0 \div 19$ & 1,1 \\
\hline & & & & & & & & \\
\hline & & & & & & & & \\
\hline bays & & & & & 402 & 252 & & \\
\hline & 47 & & 37 & & & $806+186$ & & \\
\hline & & & & & & & & \\
\hline \multirow[t]{2}{*}{ Day } & \multicolumn{2}{|c|}{ FFA (uning) } & \multicolumn{2}{|c|}{ Free Glycerol? (umo/lu) } & \multicolumn{2}{|c|}{ Insuln? $(\mathrm{m}$ u/s) } & \multicolumn{2}{|c|}{ Total Lepin 3 (ingrm } \\
\hline & $\begin{array}{l}\text { Placebo } \\
(n=10)\end{array}$ & $\begin{array}{r}P E G O B \\
(n=12)\end{array}$ & $\begin{array}{l}\text { Placebo } \\
(n-10)\end{array}$ & $\begin{array}{l}P E G-0 B \\
(n-12)\end{array}$ & $\begin{array}{l}\text { Placebo } \\
(n-10)\end{array}$ & $\begin{array}{r}P E G=0 B \\
(n=12)\end{array}$ & $\begin{array}{l}\text { Placebo } \\
(n=10)\end{array}$ & $\begin{array}{l}P E G-019 \\
(n-12)\end{array}$ \\
\hline & 40 & & & & & 7 & & 7 \\
\hline & & & & & & & & \\
\hline & & & & Now & & & & \\
\hline & & & & & & & & \\
\hline & $600+50$ & $597 \pm 4$ & $67.7+44$ & $\ln 8+49$ & 36.07 & 2010.3 & $20 \pm 02$ & 3980 \\
\hline
\end{tabular}

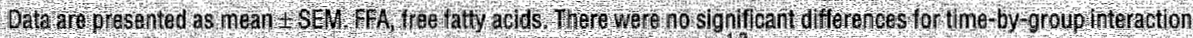

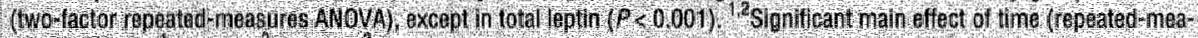
sures AMOVA) $7<0.05, P<0.01$. The assay did not distinguish botween endogenous leptili and PEG-OB.

\section{Discussion}

In the present study, we show for the first time that exogenous leptin induces additional weight loss in humains under severely energy-restricted conditions. Weight loss in both the PEG-OB- and placebo-treated subjects was primarily due to fat loss, which is in line with the results of previous animal studies (2-4). However, the fact that changes in fat mass contrary to changes in body weight did not differ significantly between the 2 groups in the present study may be explained by the small sample size. Conservation of FFM, which was observed in rodents treated with leptin $(3,22)$, was not observed in the present study, in which both treatment groups lost equal amounts FFM after 6 wk of severe energy restriction. The loss of FFM in both groups was within the normal physiological range of $\approx 25 \%$ of total body weight loss. 
Treatment of normal mice with leptin prevented the decrease in energy expenditure that would normally occur with a reduction in food intake (22). As reported before, we failed to reproduce similar results with humans under different energy-deficit conditions and PEG-OB doses (10). Also, a study of never-obese subjects on weight-maintenance regimen failed to show an effect of leptin administration on energy metabolism (12). In contrast, a recent study reported reversal of the effects of sustained weight reduction on energy expenditure by a low dose of exogenous leptin (23). A reduction in appetite before breakfast under negative energy-balance conditions was present in the PEG-OB-treated group at the end of the present study. This result is consistent with the results of several studies in rodents and primates that also showed a decline in food intake after leptin administration (2-4,24). Furthermore, reductions in appetite were also observed in our first study with $20 \mathrm{mg}$ PEG-OB/wk, but the effect was too small to result in additional weight loss (25). Because the decrease in energy expenditure was not significantly different in the 2 groups, it is concelvable that the additional weight loss caused by PEG-OB administration was largely attributable to reductions in appetite that resulted in better compliance with the dietary restriction. Thus, the results above suggest that exogenous leptin may influence human energy balance during starvation by reducing appetite.

No other metabolic effects of leptin and PEG-OB observed in animal studies were detected in the present study (5). Most prominent among these were effects on fasting plasma glucose and insulin, oral glucose tolerance, and triacylglycerol. We failed to observe an additional enhancement of the well-known effects of weight loss an these variables by weekly $\mathrm{PEG}-\mathrm{OB}$ treatment in the presence of severe energy restriction. These findings suggest that leptin may not be directly involved in the regulation of these systems in humans under the conditions of this experiment. However, these variables were not elevated in the group of overweight and mill dy obese men enrolled in this trial. Because the weight loss induced by the energy restriction and negative energy balance decreased fasting plasma glucose and insulin, oral glucose tolerance, and triacylglycerol, these improvements may have masked the effects of $\mathrm{PEG}-\mathrm{OB}$ treatment on these variables.

The findings of the present study are consistent with the characteristics of homozygous human patients with total leptin deficiency or nonfunctional leptin receptors (26-28). These rare and very obese individuals have been shown to have a normal body temperature and normal resting energy expenditure but to be markedly hyperphagic. Also, the few such patients studied up to now exhibit normal glucose homeostasis, a normal cholesterol concentration, and only moderate impairments in metabolites such as free fatty acids and triacylglycerol despite their severe obesity. In addition, mice heterozygous for the ob giene $(29,30)$ and persons who are genetically partially deficient in leptin (31) appear to have an intermediate phenotype. When a young, very obese girl with a mutated ob gene received daily subcutaneous treatment with human recombinant leptin, she experienced a rapid and progressive reduction in body weight. This weight loss was mainly due to a reduction in food intake as a result of decreased appetite and food-seeking behavior but not to changes in energy expenditure (32).

The hypothesis first proposed by Flier and coworkers $(13,14)$ suggests that the falling concentration of leptin during starvation and its effects may constitute part of the thrifty genotype, a set of genes postulated to promote survival during periods of insufficient energy intake in human evolution by increasing the efficlency of energy storage. 
In this updated thity genotype concept, the decrease in leptin concentrations during perlods of limited energy intake might signal the brain to initiate several physiological responses to increase the chances of survival. In addition, this concept suggests that an effective adipostatic role of leptin would subvert the thrify genotype by limiting the capacity of energy storage during periods of abundance, which would result in reduced survival in subsequent periods of food shortages. Stated differently, evolution would favor resistance to leptin action when leptin concentrations are rising or high during periods of sufficient energy intake or storage. The fact that exogenous leptin resulted in additional welght loss only during severe energy restriction in the present study but falled to significantly affect weight loss during mild hypoenergetic conditions in the previous study (11) with comparable total leptin concentrations appears to support this concept.

Whether the results of the present study can be generalized to subjects with a BMI > 32 is uncertain. However, evidence showing that the marked decrease in leptin production and leptin concentrations after fasting is reduced in obesity suggests that fasting-induced adaptations to starvation and the effect of exogenous leptin may depend on the degree of obesity present (33).

In summary, our results support the hypothesis that the physiollogical role of leptin is as a signal of starvation. We propose that falling concentrations of leptin after severe energy restriction influence human energy regulation by increasing appetite.

\section{Acknowledgments}

We thank Hoffmann-La Roche Inc. for kindly providing pegylated human recombinant leptin (PEG-OB). We also express our sincere apprecilation to inge van lerssel, Marja van der Hulst, and Fiona Ong for their commitment and assistance during this study. We also greatly acknowledge the cooperation, patience, and contributions of all of our subjects.

Chris J. Hukshorn participated in the study design, data collection, data analysis, and the writing of the manuscript. Magriet S. Westerterp-Plantenga and Wim H.M. Saris discussed the study design, data analysis, and versions of the manuscript. All authors declare that they had no conflicts of interest.

\section{References}

1. Zhang, $Y_{.,}$Proenca, $\mathrm{F}_{\text {. }}$ Maffei, M., Barone, M., Leopold, L., and Friedman, J.M. 1994. Positional cloning of the mouse obese gene and lits human homologue. Nature 372:425-432.

2. Pelleymounter, M.A., Cullen, M.J., Baker, M.B., et al. 1995. Effects of the obese gene product an body weight regulation in ob/ob mice. Science. 269:540-543.

3. Halaas, J.L., Gajifwala, K.S., Maffel, M., at al, "1995. Weight-reducing effects of the plasma protein encoded by the obese gene. Science. 269:543-546.

4. Campfield, L.A., Smith, F. H, Guisez, Y, Dewos, R., and Bum, P. 1995. Recombinant mouse OB protein: evidence tor peripheral signal linking adiposity and central neural networks. Science. 269:546-549.

5. Himms Hagen, J. 1999. Physlological roles of the leptin endocrine system: differences between mice and humans. Crit Rev Clin Lab Sci, 36:575-655.

6. Van Heek, M., Comptom, D.S., France, C.F., et al. 1997. Diet-induced abese mice develop peripheral, but not centrat, resistance to leptin. $J$ Cin Invest. $99: 385-390$.

7. Frederich, R.C., Hamanm, A. Anderson, S., Lollmann, B., Lowell, B.B., and Flier, J.S. 1995. Leptin levells reflect body lipid content in mice: evidence for diet-induced resistance to leptin action. Nat Med. $1: 1319-1314$. 


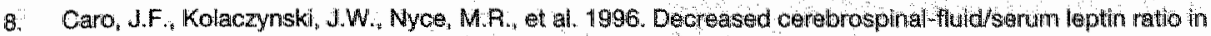
obusity" a possible mechanism for leptin resistance. Lancet. 348.159 .161 .

9. Heymstield, S.B., Greenberg, A.S., Fujioka, K., et al. 1999. Recombinant lepth for weight loss in obese and lean adults - A randomized, controlled, dose-escalation trial. UMm Med Assoc. 282:1569-1575.

10. Hukshom, C.J., Saris, W.H.M., Westerterp Plantenga, M.S., Farid, A.R., Smith, F.d., and Compfield, L.A. 2000. Weekly subcutaneous pegytated recombinant native human leptin (PEG-OB) administration in abese men. J Clin Endocrinol Metab. 85:4003-4009.

11. Hukshorm, C.d., van Dielen, F.M.H., Butman, W.A., Westerterp Plantenga, M.S., Campifield, L.A., and Saris, W. H.M. 2002. The effect of pegylated recombinant human leptin (PEQ-OB) on weight loss and inflam matory status in obese subjects. In J Obes Relat Metab Disord. 26:504-509.

12. Mackintosh, R.M., and Hirsch, J. 2001. The effects of leptin administration in non-obese human subjects. Obes Res. 9:462-469.

13. Ahima F.S., Prabakaran, D., Mantzoros, $C_{n,}$ et al. 1996. Pole of leptin in the neuroendocring response to fasting. Nature. 382:250-252.

14. Flier J.S. 1998. Clinical review 94: What's in a name? in search of leptin's physiologic rola. $J$ Clim Endocrinol Metab. 83:1407-1413.

15. Nucci, M.L., Shorr, R, and Abuchoweski, A. 1991 . The therapewtic value of poly(cethylene-glycol)-modified: proteins. Adv Drug Delfivery Rew, 6:133-151.

16. Kahler, A., Geary, N., Eckel, L.A., Camptield, L.A., Smith, F, d, and Langhans, W. 1998. Chronic administration of $\mathrm{OB}$ protein decreases food intake by selectively reducing meal size in male rats. Am $J$ Physiol. 275:R180-R185.

17. Westerterp, K.R., Wouters, $L_{\text {, }}$ and ven Marken Lichtenbelt, W.D. 1995. The Maastricht protocol for the measurement of body composition and energy expenditure with labeled water. Obes Res. 34Suppl. 1): $49-57$.

18. Siri, W.E. 1961. Body composition from fluid spaces and density: analysis of methods. ln: J. Brozek, and A. Henschel, eds. Techniques for measuring body composition. Washington DC: National Academy of Science, 223-244.

19. Weir, I.B.d.V. 1949. New methods for calculating metabolic rate with special reference to pratein metabo*

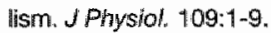

20. Westerterp Plantenga, M.S., Rolland, $V_{n, 1}$ Wilson, S.A., and Westerterp, K.R. 1999. Satiety related to $24 \mathrm{~h}$ diet-induced thermogenesis during high protein/carbohydrate vs high fat diets measured in a respiration chamber. Eur J Clin Nutr. 53:495-502.

21. Matthews, D.I., Hosker, J.P., Rudenski, A.S., Naylor, B.A., Treacher, D.F, and Tumer, R.C. 1985. Homeostasis model assessment: insulin resistance and beta-cell function from fasting plasma glucose and insulin concentrations in man. Diabetologia. 28:412-419.

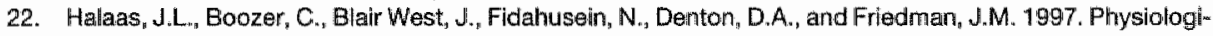
cal response to long-term peripheral and central leptin infusion in lean and obese mice. Proc Natl Acad Sci USA. $94: 8878-8883$.

23. Rosenibaum, M., Murphy, E.M. Heymsfield, S.B., Matthews, D.E., and Lelbel, R. L. 2002. Low dase leptin administration reverses effects of sustained weight reduction on energy expenditure and circulating concentrations of thyroid homones. J Cin Endocrinol Metab. 87:239" 2394.

24. Tang Christensen, M. Havel, P.w., Jacobs, F.R., Larsen, P.d., and Cameron, J.L. 1999. Central administration of leptin inhibits food intake and actiwates the sympathetic nerwous system in rhesus mackquesi. $J$ Clin Endocrinol Metab. 84:711-717.

25. Westerterp-Plantenga, M.S., Saris, W.H., Hukshorn, C.d, and Campfield, L.A. 2001. Effects of werkly admimistration of pegylated recombinant human $O B$ protein on appetite protite and energy metabolism in obesie men. Am J Cin Nutr. $74: 426-434$.

26. Montague, C.T., Farooqi, I.S., Whitehead, J.P., et al. 1997. Congenital leptin deficiency is associated with severe early-onset obesity in humans. Nature. $387: 903.908$.

27. Ozata, M., Ozdemir, L.C., and Licinio, J. 1999. Human leptin deficlency caused by a missense mutation: multiple endacrine defects, decreased sympathetic tone, and immune system dysfunction indicate inew targets for leptin action, greater centrail than peripheral resistance to the effects of leptin, end spontaneous correction of leptin-mediated defects. 1 Clin Endocrinol Metab. 84:3686-3695.

28. Clement, $K_{\text {, Vaisse, }} \mathrm{C}_{\text {. }}$ Lahlow, $\mathrm{N}_{\text {., }}$ et all 1998 . A mutation in the human leptin receptor gene causes obe sity and pituitary dystumcition. Nature. 392:398-401.

29. Coleman, D.L 1979. Obesity genes: beneficial effects in heterozygous mice. Scierce. 203:663-665.

30. Chung, W.K., Belfi, K. Chua, M." et al. 1998. Heterozygosity for Lep(ob) or Lep(rdb) affects body composition and leptin homeostasis in adult mice. Am J Physiol 274:R985-R990.

31. Faroogi, I.S., Keogh, U.M., Kamath, S., et al. 2001. Partial leptin deficiency and human adiposity. Nature. $414: 34-35$.

32. Faroogil, I.S., Jebb, S.A., Langmack, G. et al. 1999. Effects of recombinant leptin therapy in a child with conglenital leptin deficiency. N Engl J Med. 341:879-884. 


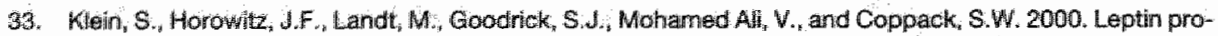
duction during ty starvation in lean and obese women. Am J Fhysiol 278:E280-E284. 


\section{CHAPTER 6}

\section{The Effect of Pegylated Human Recombinant} Leptin (PEG-OB) on Neuroendocrine Adaptations to Semi-starvation in Overweight Men

C.J. Hukshorn, P.P.C.A. Menheere, M.S. Westerterp-Plantenga, and W.H.M. Saris 


\section{Abstract}

Objective: Starvation induces a complex neuroendocrine response in humans thought to have evolved to defend against reduced energy intake. The drop in leptin levels observed during fasting has been implicated as a factor that triggers this adaptive response. To explore this hypothesis, we executed a randomized, double-blind, placebo-controlled study to investigate whether ellevated leptin levels using long-acting pegylated human recombinant leptin (PEG-OB) influenced the neuroendocrine responses to semi-starvation in human subjects.

Design: Twenty-four overweight male subjects (mean \pm SEM; $34.8 \pm 1.3 \mathrm{yrs} ; 28.8 \pm$ $\left.0.5 \mathrm{~kg} / \mathrm{m}^{2}\right)$ were prescribed a very low energy diet $(2.1 \mathrm{MJ} /$ day) to induce a state of semi-starvation for the next 46 days. In addition, all subjects received a weekly treatment of $80 \mathrm{mg} P E G-\mathrm{OB}$ or matching placebo. Hormone measurements were performed throughout the study period and included 5 -h frequent hormone samplings and 24-h urine collections.

Results: Weekly subcutaneous administration of PEG-OB led to significant additional weight loss $(2.8 \mathrm{~kg})$ but it did not reverse the fasting-induced changes in the thyroid, corticotropic, somatotropic axes and sympathetic nervous system activity. However, after adjustment for weight loss, the drop in mean luteinizing hormone levels was attenuated in the PEG-OB group compared with the placebo group.

Conclusions: These results suggest that a reduced level of leptin accompanying food restriction might be a component of the fasting-induced neuroendocrine inhibition of the human reproductive axis.

\section{Introduction}

Starvation or severe energy restriction rapidly evokes severall neuroendocrine adaptive responses in humans. These responses are thought to have survival value in periods of inadequate energy intake. Among these neuroendocrine adaptations is a suppression of both the reproductive and thyroid axes while selected components of the corticotropic and somatotropic axes are stimulated $(1,2)$. The mechanisms that trigger these adaptive responses to energy restriction are still not clear.

Leptin, the protein hormone encoded by the ob gene, is primarily secreted from adipose tissue and plays an important role in body weight homeostasis by regulating food intake and energy expenditure (3-5). Serum leptin concentrations are directly proportional to adipocyte mass and are reduced in humans and animals that have lost body fat, or are energy-restricted (6).

Some investigators have suggested that leptin has a broader physiological rolle and evolved as a mediator of the adaptations to fasting, and thus promotes the chances of survival during periods of starvation $(2,7)$. In favor of this hypothesis is the fact that during fasting leptin levels drop rapidly and out of proportion to fat mass changes (8). Ir addition, leptin administration to rodents attenuates many of these fasting-induced neuroendocrine changes in gonadal, adrenal, and thyroid axes $(7,9)$. In male non-human primates conflicting reports exist regarding the effect of peripheral infusion of leptin during a short-term fast. Reversal of the inhibitory effects of fasting on gonadotropin release accurred in one study while no effect was found in two others (10-12). In one study, intravenous replacement with homologous leptin did not reverse the acute 
changes in growth hormone (GH) and cortisol secretion observed with fasting in the adult male macaque (12).

One approach to study whether the neuroendocrine effects of leptin administration to animals during fasting can be extended to humans is to administer exogenous leptin in conditions associated with a (relative) deficiency ar absence of leptin, such as during severe energy restriction.

Therefore, we undertook a randomized, double-blind, placebo-controlled study to investigate whether elevated leptin levels using long-acting pegylated recombinant leptin (PEG-OB) were able to attenuate the neuroendocrine adaptations to semi-starvation induced by a very low energy diet (VLED) in healthy overweight male subjects.

\section{Subjects and Methods}

\section{Subjects}

Twenty-four healthy overweight male volunteers were recruited by local advertising, screened and enrolled in the study after execution of written informed consent. The study was approved by the Medical Ethical Committee of the Maastricht University. Overweight and mildly obese men aged $18-45 \mathrm{yrs}$ and with a body mass index (BMI) between 25 and $32 \mathrm{~kg} / \mathrm{m}^{2}$ were eligible for inclusion. Additional inclusion criteria were: detailled medical and psychiatric histories and a physical examination with negative findings, including a normal adult sexual maturation, a normal 12-lead resting electrocardiogram, no medical condition present, no use of prescription medication, no smoking and no transmeridian travel in the prewious 4 weeks. Each participant had normal biochemical tests of renal, hepatic, metabolic and hematological function, and morning fasting serum concentrations of insulin, cortisol, insulin-like growth factor-1 (IGF-1), thyroid stimulating hormone (TSH), prolactin (PRL), and total testosterone within the normal ranges. Subjects with a history or presence of drug abuse or alcoholism, atopy or hypersensitivity to pegylated proteins and with a weight loss of more than $3 \mathrm{~kg}$ in the previous 3 months were excluded from the study.

\section{Study design}

This single center trial had a prospective, randomized, double-blind, placebo-controlled group design. After screening, 24 subjects were selected and enrolled in the trial. The study was divided into three phases: a) baseline characterization (day -14 , -8 , and 1); b) PEG-OB or placebo treatment and a VLED for 46 days (day 1 to 46 ); c) follow-up for 2 weeks (day 50 and 57). Baseline characterization consisted of a 5-h frequent blood sampling protocol (day -14) and a 24-h urine collection (day -8) to measure the 24-h excretion of norepinephrine (NE) performed in the 2 weelks before the start of the diet and treatment period. All subjects were asked to maintain a constant body weight until the beginning of the diet and treatment phase and their normal levels of physical activity throughout the study period. Subjects were stratified and matched into pairs according to age, BMI, fasting serum leptin and insulin concentration to achieve balanced treatment groups. Randomization numbers for subjects were generated and incorporated into the double-blind labeling by an independent third party. At the start of the treatment period (day 1) all subjects were prescribed a VLED 
to induce a state of semi-starvation for the next 46 days. The VLED (Modifast, Novartis, Breda, The Netherlands) provides $2.1 \mathrm{MJ}$ daily and is a protein enriched formula diet (containing 44,14 , and $42 \%$ of energy as protein, fat and carbohydrate, respectively). The dietary prescription was discussed every week with a dietician. Adherence to the diet was confirmed by measurements of body welight loss. Treatment consisted of either weekly $80 \mathrm{mg} \mathrm{PEG-OB}\left(8 \mathrm{ml}, 10 \mathrm{mg} \mathrm{ml}^{-1}\right.$; produced and provided by Hoffmann-La Roche Inc., Nutley, New Jersey, USA) or matching placebo (8 $\mathrm{m}$ ll) given s.c. in the para-umbilical region during the VLED period. Subjects returned in a fasting state on day $8,15,22,29,36$, and 43 to the laboratory to receive treatment after weight and vital signs (pulse, respiratory rate, and blood pressure) were recorded. Blood samples were drawn for safety laboratory tests and hormone measurements on day $1,8,15,25$, and 46 . On day 24 the 24 -h urine collection and on day 25 the 5-h frequent blood sampling protocol were repeated. After the treatment period (day 46) all subjects received less formula diet and were instructed to supplement this with a free choice of habitual food items in order to gradually increase their energy intake over the next 2 weeks. Vital signs and body weight during this follow-up period were measured on day 50 and 57 . Safety was monitored by documentation of adverse events and recording of vital signs at each visit. In addition, urine analysis and routine measurements of serum chemistry and blood cell counts were conducted regularly throughout the study. Standard clinical chemistry and blood cell counts were conducted at the certified central laboratory of the University Hospital Maastricht, The Netherlands.

\section{PEG-OB}

Recombinant methionyl human leptin has a reported average terminal half-life of approximately $4 \mathrm{~h}$ in humans, which requires daily administration to obtain sustained blood levels (13). Modification of proteins through covalent linkage of polyethylene glycol polymers to the protein has resulted in reduced immunogenicity and increased serum half-life for a number of proteins (14). Recombinant native human leptin, expressed and purified from Escherichia coli, was chemically conjugated to a species of branched polyethylene gilycols (PEGs) with an average molecular weight of $42 \mathrm{kDa}$ in a 1:1 ratio. The result was a globular PEG-native human leptin polymer (PEG-OB) with increased molecular size. PEG-OB at a concentration of $10 \mathrm{mg} / \mathrm{ml}$ was placed in sterile glass vials containing $1.3 \mathrm{ml}$. Preclinical studies with $P E G-O B$ indicate an extended half-life ( $>48 \mathrm{~h}$ ) and efficacy for reduction of food intake and body weight in animals (15). Our previous study in obese male subjects clearly showed sustained elevated blood levels following weekly s.c. dosing of PEG-OB in humans. Mean peak serum PEG-OB concentrations were achieved $72 \mathrm{~h}$ after dosing, followed by a return to the elevated pre-dose levels after 1 week (16).

\section{Hormone measurements}

Venous blood was sampled on day $1,8,15,25$, and 46 after an overnight fast and allowed to clot for $20 \mathrm{~min}$ at room temperature. Immediately after clotting the samples were put on ice and serum was extracted by centrifugation. The sera obtained were frozen in liquid nitrogen and stored at $-80^{\circ} \mathrm{C}$ for later measurements of serum cortisol, insulin, $\| G F-1$, free $3,5,3^{\prime}$-trilodothyronine $\left(F_{3}\right)$, and free thyroxine $\left(F_{4}\right)$. Mean 5-h 
hormone levels were determined using a 5 -h frequent blood sampling protocol. In both the fed (day -14) and the energy restricted (day 25) states, blood sampling was carried out at 10-min intervals for $5 \mathrm{~h}$ beginning at $0800 \mathrm{~h}_{n}$ at least $1 \mathrm{~h}$ after venapuncture. Blood was withdrawn through an indwelling i. $\mathrm{v}$. catheter placed into an antecubital vein and collected with aprotinin (Trasylol, 10,000 Kallikrein inhibiting U/: Bayer, Etobicoke, Canada). Subjects remained in bed during sampling and daytime naps were not allowed. Serum concentrations of cortisol, GH, luteinizing homone $(\mathrm{LH})$, follicle stimulating hormone (FSH), TSH, PRL, total testosterone, sex hormone binding protein (SHBG), and albumin were assayed in a single 5-h pool of serum.

\section{Assays}

The serum concentrations of cortisol, insulin, IGF-1, FT, $\mathrm{FT}_{4, x} \mathrm{GH}_{n} \mathrm{LH}, \mathrm{FSH}, \mathrm{TSH}, \mathrm{PRL}$, total testosterone, SHBG, and albumin were all measured at the certified central laboratory of the University Hospital Maastricht. Serum cortisoll was measured with a luminescence enzyme-immunoassay ((LEIA), immulite 200, DPC, Los Angeles, USA), which has a sensiltivity of $25 \mathrm{nmol} / \mathrm{l}$ and a reproducibility better than $10 \%$. Serum insulin was measured by an immunofluorimetric sandwich assay ((IFMA), Autodelfia, Perkin Elmer, Turku, Finland), which has a sensitivity of $1.4 \mathrm{mU} / \mathrm{l}$ and a reproducibility better than $6 \%$. Serum IGF-1 was measured by IRMA (Nichols Institute Diagnostics, San Juan Capistrano, USA), which has a sensitivity of $17 \mathrm{ng} / \mathrm{l}$ and a reproducibility better than $15 \% . \mathrm{FT}_{3}$ and $\mathrm{FT}_{4}$ were measured by two-step fluoroimmunoassay ( $\left.\mathrm{F} \mid \mathrm{A}\right)$, Autodelfia), which has a sensitivity of $0.04 \mathrm{pmol} / /$ and a reproducibility better than $4 \%$ for $\mathrm{FT}_{3}$ and a sensitivity of $1.3 \mathrm{pmol} / \mathrm{l}$ and a reproducibility better than $4 \%$ for $\mathrm{FT}_{4}$. Serum GH was measured by IFMA method, which has a sensitivity of $0.1 \mathrm{mU} / \mathrm{l}$ and a reproducibility better than $7 \%$. Serum LH was measured by IFMA, which has a sensi-tivity of $0.01 \mathrm{U} / \mathrm{l}$ and a reproducibility better than $3 \%$. Serum FSH was measured by IFMA $A_{1}$ which has a sensitivity of $0.2 \mathrm{U} / \mathrm{I}$ and a reproducibility better than $10 \%$. Serum TSH was measured by IFMA, which has a sensitivity of $0.012 \mathrm{mU} / \mathrm{l}$ and a reproducibility better than $2 \%$. Serum PRL was measured by IFMA, which has a sensitivity of $0.0005 \mathrm{U} / /$ and a reproducibility better than $6 \%$. Total serum testosterone was measured by radioimmunoassay (DPC), which has a sensitivity of $0.7 \mathrm{nmol} / 1$ and a reproducibility better than 10\%. Serum SHBG was measured by LEIA, which has a sensitivity of $1 \mathrm{nmol} / \mathrm{l}$ and a reproducibility better than $4.5 \%$. Free testosterone was calculated from serum total testosterone, SHBG, and albumin according to Swinkels et al. $(17,18)$ using the equilibrium constants of testosterone to SHBG and albumin to testosterone derived from Dunn et al. (19). Urinary NE was determined by HPLC using the ClinRep kit from Recipe (Munich, Germany). Total leptin concentrations (endogenous leptin plus PEG-OB) were measured according to the method described previously (16).

\section{Statistïics}

Data were analyzed using two-factor repeated-measures ANOVA to compare differences in parameters across the two groups over time. When significant differences were found, a post hoc Scheffe's procedure was used to determine the location of the difference. A multiple-linear regression model with the percentage change in 5-h mean hormone concentrations from baseline as the dependent variable and the per- 
centage change in weight and treatment status as independent variables was used to analyze the difference in percentage charige in 5-h mean hormone concentrations from baseline between both treatment groups, adjusted for the independent variables. All statistical tests were two-sided and significance was defined as $P<0.05$. All data are presented as mean \pm SEM, unless otherwise indicated.

\section{Results}

The characteristics of the subjects before the intervention are presented in Table 1. The parameters used to match subjects into pairs were not different and balanced treatment groups were achieved. The baseline hormone levels of the 12 subjects randomized to each treatment group were similar. All subjects in the trial were of Caucasian origin. Two subjects of the placebo group dropped out voluntarily after 1 week because they were not able to maintain the strict VLED regime. However, baseline characteristics of the two groups remained comparable (data not shown). As this study was a part of a greater study, results on body weight, body composition, energy expenditure, and appetite have been published elsewhere (20). In summary, at the end of the treatment period (day 46), weight loss was $14.6 \pm 0.8 \mathrm{~kg}$ in the PEG-OB group, compared with $11.8 \pm 0.9 \mathrm{~kg}$ in the placebo group $(P=0.027)$. Furthermore, significant reductions in appetite were observed in the PEG-OB group.

Table 2 shows the effect of energy restriction and treatment on cortisol, $\mathrm{FT}_{3}, \mathrm{FT}_{4}$, $\mid G F-1$, insulim, and total leptin measured on day $1,8,15,25$, and 46 . In the first 3 weeks of the study cortisol levels increased significantly from initial values in the PEG-OB group. However, the rise of cortisol levels in the placebo failed to reach significance. At the end of the treatment period (day 46) cortisol fell below baseline levels in both groups. $\mathrm{FT}_{3}$ declined significantly in the first 3 weeks of study in both groups but the fall remained significant in the PEG-OB group on day 46 only. $\mathrm{FT}_{4}$ levels were increased in placebo and PEG-OB group during the whole study, but only on days 8 and 15 was this rise significantly different from the baseline. IGF-1 declined similarly in both groups to levels well below the normal range during the study and reached a minimum on day 25. Insulin levels declined from baseline in both groups and remained significantly reduced throughout the study. Urinary excretion of NE fell from $54.5 \pm 3.4$ $\mu \mathrm{g} / 24-\mathrm{h}$ to $42.3 \pm 3.5 \mu \mathrm{g} / 24 \mathrm{~h}$ in the placebo group and from $51.5 \pm 4.3 \mathrm{\mu g} / 24 \mathrm{~h}$ to $44.6 \pm 5.4 \mu \mathrm{g} / 24-\mathrm{h}$ in the PEG-OB group. No significant differences were observed in levels of cortisol $\mathrm{FT}_{3}, \mathrm{FT}_{4}, \mathrm{IGF}-1$, insulin, and 24-h urinary NE excretion between treatment groups over time.

Food restriction for 6 weeks by means of a VLED reduced circulating leptin levels by $72 \%$ to $2.0 \pm 0.2 \mathrm{ng} / \mathrm{ml}$ in the placebo group $(P<0.001)$. Following weekly s.c. dosing, sustained serum levels of total leptin (endogenous leptin plus PEG-OB), measured just before the next dose on day 8 and 15 , ranging from 950 to $3700 \mathrm{ng} / \mathrm{ml}$ were observed. Peak total leptin concentrations on day 25 and 46 , measured $72 \mathrm{~h}$ after s.c. injection, ranged from 2300 to $6050 \mathrm{ng} / \mathrm{ml}$.

The 5-h mean concentrations of serum cortisol, GH, LH, FSH, TSH, PRL, total testosterone, SHBG, albumin, and estimated free testosterone on both study days (day -14 and 25) for the two treatment groups are shown in Table 3. Serum 5-h mean cortisol, $\mathrm{TSH}, \mathrm{FSH}$, and albumin levels were unchanged by energy restriction and treatment in both groups. The 3 weeks of semi-starvation resulted in a more than 4 -fold increase in 
Table 1. Baseline characteristics on the 24 subjets at the screaning

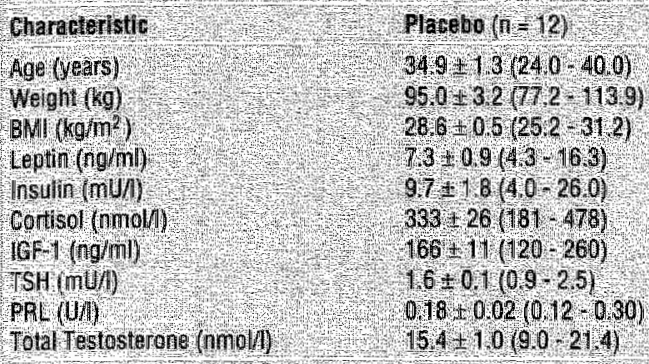

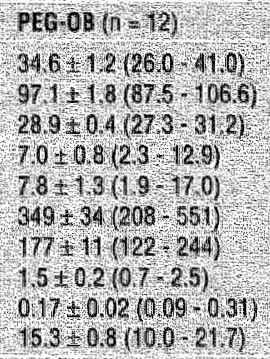

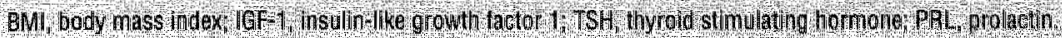

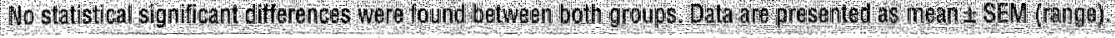

Table 2. Ghanges throughout the intenvention lin encocrine measures

\begin{tabular}{|c|c|c|c|c|c|}
\hline \multirow[t]{3}{*}{ Day } & Coritsol (nomoly) & \multicolumn{2}{|c|}{ Free T. (pnold) } & \multicolumn{2}{|c|}{ Frea 1, (mong) } \\
\hline & Placebo & Placebo & PEQOOH & Placaba & PEGOB \\
\hline & $(n=10)$ & $n=10)$ & $(10-12)$ & $(n=10)$ & $n-(2)$ \\
\hline 4 & $303: 51$ & $61 \pm 03$ & $60 \leq 0,1$ & $127+05$ & $141+0$, \\
\hline & $422+34 \mathrm{E}$ & $5.0+0.2$ & $48+0,1$ & $13.9=19.4^{4}$ & $154 \geq 0.4$ \\
\hline y 15 & $413+27^{6}$ & $5.0 \div 0.2^{6}$ & $5.2+0.3^{\mathrm{B}}$ & $14.1 \pm 0.4$ & $15: 8 \pm 0,7$ \\
\hline 1y 25 & $393^{\circ}+28^{\circ}$ & $52 \times 0.2^{6}$ & $50+02^{C}$ & $13.4+0.5$ & $160+05$ \\
\hline 46 & 227,18 & 5.600 .3 & 9.4 .0 .2 & $130 \div 0.5$ & 148,07 \\
\hline \multirow[t]{3}{*}{ Day } & $(6 / 7)(n / m)$ & Insullin (mu & & Tolal Lopti & (gimi) \\
\hline & Placeloo & Plasebo & PEQOOA & Placebo & PEGOB \\
\hline & $(n-12)$ & $(n-10)$ & $n=12$ & $(n-10)$ & $(n-12)$ \\
\hline y & $165 \pm 10$ & $9,4+1.0$ & $22+00$ & $7 / 108$ & $7.6 \pm 12$ \\
\hline & $140 \% 10^{\mathrm{b}}$ & $4.5 \pm 0.7$ & $34+0.6$ & $34+06^{\circ}$ & $1828+183^{6}$ \\
\hline 5 & $129 \cdot 13$ & 50,111 & $3.2,0.5$ & 3110.68 & $277 \div 194$ \\
\hline 1) 25 & $121 \pm 11$ & $34+0.6$ & $22=0.4$ & 2.140 .3 & 4994,285 \\
\hline 846 & $128 \cdot 10$ & $36+07^{6}$ & $20+0.8$ & $2,0 \pm 0.2$ & $3960+203$ \\
\hline
\end{tabular}

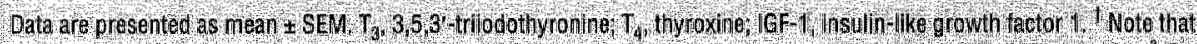

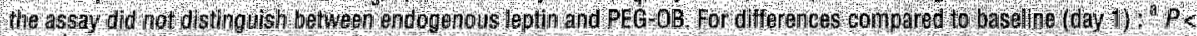
$0,05,1 \mathrm{P}, 0.01, \mathrm{P} \times 0.001$

the mean (5-h) serum $\mathrm{GH}$ concentrations and an approximately 2-fold increase in mean SHBG levels in all subjects. In contrast to the group receiving $P E Q-O B$, mean LH and PRL levels decreased significantly in the placebo group. Mean total testosterone levels increased significantly in the PEG-OB treatment group but remained unaltered in the placebo group. Calculated free testosterone concentrations declined significantly in both the placebo and PEG-OB groups. There was no significant difference in the delta or percent change from baseline of 5-h mean concentrations of serum cortisol, GH, LH, FSH, TSH, PRL, total testosterone, SHBG, albumin, and estimated free testosterone between the groups.

A multiple-linear regression model with the percentage change in 5 - $h$ mean hormone concentrations from baseline as a dependent variable and the percentage change in weight and treatment status as independent variables was used to analyze the differences between both treatment groups, defined by the binary variable group. The percentage change in 5-h mean LH concentrations of the PEG-OB group, plotted as a 


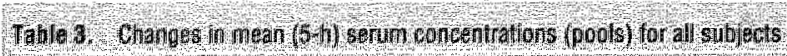

\begin{tabular}{|c|c|c|c|c|}
\hline 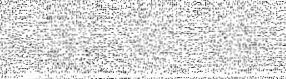 & 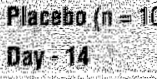 & 02425 & 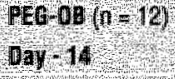 & Dar) 25 \\
\hline Oontis of $(10$ nion) & 2042,240 & 240,9119 & $2145=176$ & $2418=18$ \\
\hline $6+1 \mathrm{~m} U \mathrm{~g})$ & $1,10+012$ & 175,0416 & $055+021$ & $2,17,0,440$ \\
\hline (S) (mU) & 124,007 & $109 \times 1014$ & 11121014 & $109+0115$ \\
\hline pal (d)! & $0127 \times 0,010$ & $0107+0.010$ & 018510018 & 0,1261900 \\
\hline $140 / 0$ & 07220.75 & $307+070$ & $360+047$ & 3.4409 \\
\hline (6) 140 & $428+1145$ & $401=116$ & $371 \div 0.72$ & $3,35=0.48$ \\
\hline Tolat Ths tostorgnel & $19,6,200$ & $1908 \%, 26$ & 19309,106 & $2217=10$ \\
\hline SHBG (1010) & $202+24$ & $384+6,1$ & $2018+18$ & $38.5 \div 290$ \\
\hline Nbwing $(9 / 1)$ & $40 \%+0$ & 103109 & 41.840 .5 & $405=07$ \\
\hline 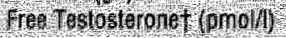 & 438.4321 & $2057+20,1$ & $4222=253$ & $3455+20$ \\
\hline
\end{tabular}

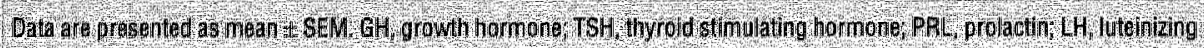

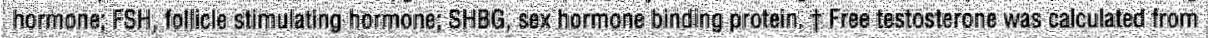

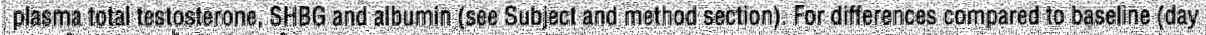
14. $P$ P $005 \%$ P 001 , P 50001

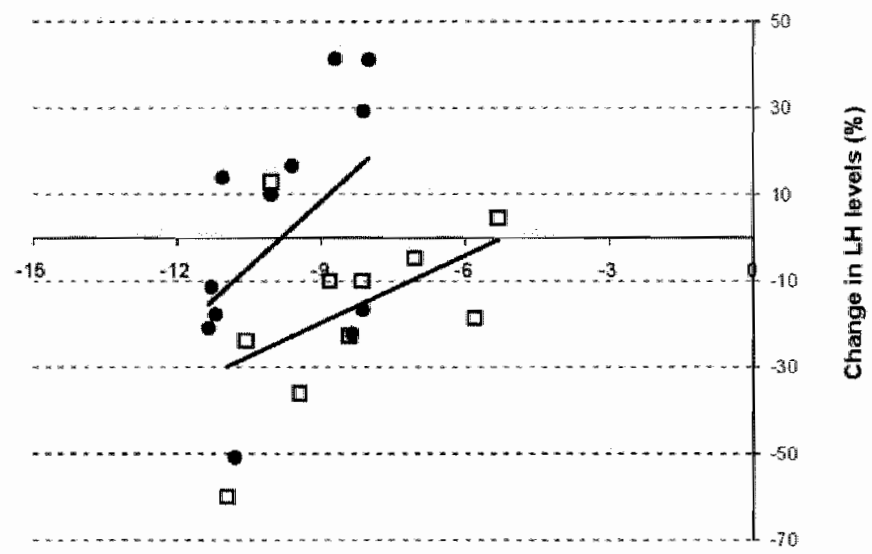

Change in bodyw elght (\%)

Figure 1: Percentage change in 5-h mean LH concentrations as a function of percentage change in weight plotted for the PEG-OB group (C) and placebo group (D). The regrossion line of the PEQ-OB group is significantly different from the regression lino of the placebo group (Mutliple-tinearegression analysis: $P=0.03$ )

function of percentage change in weight, resulted in a positive relationship, i.e. a regression line that was superimposed on the regression line of the placebo group (Fig. 1). The regression line of the PEG-OB group was significantly different from the regression line of the placebo group $(P=0.03)$. The percentage change in $5-h$ mean $L H$ concentrations adjusted for percentage weight loss resulted in a reduced decrease in percentage change in 5-h mean $\mathrm{LH}$ concentrations for the PEG-OB group compared with the placebo group. For the complete study sample, both independent variables accounted for $31 \%$ of the variance in mean 5 -h serum LH concentrations. 


\section{Discussion}

We previously reported that exogenous leptin induces additional weight loss in humans under severe energy-restricted conditions by reducing appetite. In the present report, we studied the effect of elevated leptin levels using long-acting PEG-OB on the neuroendocrine responses to severe energy-restriction in human subjects.

Introducing a state of semi-starvation in this study triggered an array of neuroendocrine responses similar to those previously reported (21). Changes in the thyroid ( $\mathrm{FT}_{3}$ and $\mathrm{FT}_{4}$ ), corticotropic (cortisol), and somatotropic axes (GH and IGF-1) paralleled the severity of the energy deficit and were therefore more pronounced (but not significantly different] in the PEG-OB group, which lost significantly more weight. In addition, PEG-OB treatment did not prevent the inhibition of the sympathetic nervous system activity, which normally occurs during energy restriction. The suppression in several reproductive hormones (LH, PRL, and estimated free testosterone with the exception of FSH) tended to be reduced in the PEG-OB treated group but failed to reach significance. However, after adjustment for weight loss using multiple linear regression, the drop in mean LH levels was attenuated in the PEG-OB group compared with the placebo group.

A recent study reported reversal of the effects of sustained weight-reduction on circulating concentrations of thyroid hormones $\left(T_{3}\right.$ and $T_{4}$ but not TSH) in four subjects by a low dose of exogenous leptin (22). In contrast, our study falled to demonstrate an effect of leptin administration on the weight-loss decline in $\mathrm{FT}_{3}$.

The findings of this study are in line with the characteristics of two human syndromes associated with absent or very low leptin levels. Patients with total leptin deficiency or non-functional leptin receptors have been shown to be markedly hyperphagic and the majority of these rare very obese patients identified until now fail to attain normal adult reproductive capabilities (23-25). Daily s.c. recombinant human leptin treatment of a young very obese girl with a mutated ob gene caused rapid and progressive reductions in body weight as a result of decreased appetite and food-seeking behavior. Furthermore, after 1 year of treatment with a low dose of leptin, the appearance of pulsatile nocturnal changes in LH was noted, which suggested the onset of early puberty (26).

Four months of leptin replacement in seven female patients with severe lipodystrophy and leptin deficiency improved menstrual abnormalities and low oestradiol levels and corrected the blunted $\mathrm{LH}$ response to luteinizing hormone-releasing hormone. No clinical or key regulatory effects of treatment were observed on thyroid or adrenocortical function (27).

Taken together, our results seem to support the hypothesis that the reduction in leptin is one of the factors that may be responsible for the fasting-induced inhibition of the reproductive axis and subsequent impaired fertility in humans $(28,29)$.

Several limitations of our study are of note that could account for the limited effect of leptin observed in this study. The lowest leptin levels reached in the placebo group in this study are still higher than the leptin levels found in the syndromes mentioned above. Furthermore, reproductive function is known to continue in males under limited energy availability in which it is completely blocked in females, suggesting that female reproduction is more sensitive to nutritional deprivation $(30,31)$. Both observations could account for the limited effect of leptin therapy on reproductive hormones found in this study with severe energy-restricted overweight males. Also 
the serum leptin levels achieved in this pharmacological study are supraphysiological. Recent studies suggest that the threshold for the various responses to leptin is set at different levels. Some evidence suggests that especially the effects on neuroendocrine function elfcited by hyperleptineamia might differ from those caused by leptin in the physiological range $(32,33)$. Finally, more subtle effects on these dy namic neuroendocrine axes might have been revealed by direct measurements of diumal variations or the pulsatility of secretory patterns.

In conclusion, we demonstrated that although weekly $80 \mathrm{mg}$ s.C. PEG-OB administration to severe energy-restricted healthy overweight men led to significant additional weight loss after 6 weeks, it did not reverse the fasting-induced changes in the thyroid, corticotropic, somatotropic axes, and sympathetic nervous system activity. However, the drop in mean LH llevels when adjusted for weight loss was attenuated in the PEG-OB group compared to the placebo group. This result suggests that a reduced level of leptin accompanying food restriction might be a component of the fasting-induced neuroendocrine inhibition of the human reproductive axis.

\section{Acknowledgments}

We thank Hoffmann-La Roche Inc. for kindly providing PEG-OB. We also wish to express our sincere appreciation to Inge van lerssel, Marja van der Hulst, and Fiona Ong for their commitment and assistance during this study. Finally, we greatly acknowledge the co-operation, patience, and contributions of all of our subjects.

\section{References}

1. Sichwartz, M.W. Dallman, M.F., and Woods, S.C. 1995. Hypothalamic response to stanation: implications for the situdy of wastiring disorders. Am J Physiol. 269:R949-R957.

2. Flier, J.S. 1998. Clinical review 94: What's in a name? In search of leptin"s physiologic role. I Clin Endocrinol Metab. 83:1407-1413.

3. Zhang, Y., Proenca, P., Maffel, M., Barone, M., Leopold, L., and Friedman, w.M. 1994, Positional cloning of the mouse obese gene and its thuman homologue. Nature. 372:425-432.

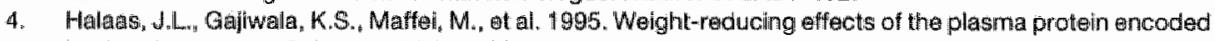
by the obese gene. Sciance. 269;543-546.

5. Pelleymounter, M.A., Cullen, M.J., Baker, M.B., et al, 1995 , Effects of the obese gene product on body weight regulation in ob/ob mice. Science. 269:540-543.

15. Considine, R.V., Sinhe. M.K., Heiman, M.L. et al. 1996. Serum immunoreactive leptin concentrations in normat-welght and obese thumans. N Eng! J Med. 334.292-295.

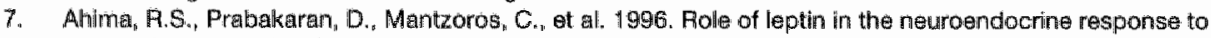
fasting. Nature. 382:250-252.

8. Boden, G. "Chen, X. Mozzoll, M., and Ryan, 1. 1996. Effect of fasting on serum leptin in normal human subJects. J Clin Endocrinal Metab. 81:3419-3423.

9. Hegrad, G., Emerson, C.H., Ahima, R.S., Flier, W.S., and Lechan, F.M. 1997. Leptin prevents fasting-unduced suppression of prothyrotropin releasing hormone messenger ribonucleic acid in meurons of the hypothalamio paraventricular nucleus. Endocrinology. 138:2569-2576.

10. Finn, P.D., Cunningham, M.J., Pau, K.Y., Sples, H.G., Clifton, D.K., and Steiner, R.A. 1998. The stimulatory effect of leptin on the neuroendocrime reproductive axis of the monkey. Endocrinology. 139:4652-4662.

11. Lado Abeal, J., Lulyanenko, Y.O., Swamy, S., Hentida, R.C., Hutson, J.C., and Norman, R.L. 1999. Short-term leptin infusion does not affect circulating leveis of LH, tesitosterone or cortisol in food-restricted pubertal male rhesus macaques. Clin Endocrinol Oxf. $51: 41-51$.

12. Lado Abeal. J., Hickox, J.R., Cheung, T.L., Veldhuis, J.D., Hardy, D.M.* and Norman, R.L. 2000. Neuroendocrine consequences of fasing in adult male maceques: effects of recombinant rhesus maceque leptin infusion. Neuraendocrinology. 71:196-208.

43. Heymstield, S.B., Greenberg, A. S. Fujoka, K, et al. 4999. Recombinant leptin for weight loss in obese and lean adults - A randomized, controlled, dose-escalation trial. J Am Med Assoc. 282:1568-1575. 
14. Nucci, ML, Shorr, R. and Abuchoweski, A. 1991 . The therapeutic walue of polyethylene glycoll modiried proteins. Adv Drug Delvery Rev. 6:133-151.

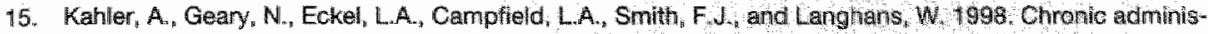
tration of OB protein decreases iood intake by selectively reducing meal size in malo mats. Amo s physioh 275:A180-R185.

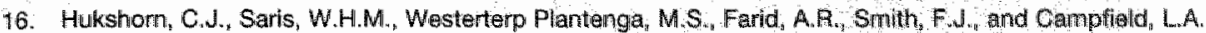
2000. Weekly subcutaneous pegylated recombinant native tuman leptin (PEC-OE) administration in obese men. J Clin Endacrinol Metab. $85: 4003-4009$

17. Swnkels, L.M. Ross, H.A., and Benraad, T.J. 1987. A symmetric dialysis method for the determination of the testosterone in human plasma. Chn Chim Ach 165.31-349.

18. Swinkels, L.M. Meulenberg, P.M., Ross, H.A., and Benraad, T., 1986 . Salivary and plasma tree testosterone and androstenediore levels in women using oral contraceptives containing desogistrel or lewonorgestrel. Ann Clir Biochem. 25:354 359.

19. Dunn , J.F. Nisula, B.C., and Rodbard, D. 1981. Transport of steroid homones bindino of 21 andogemous

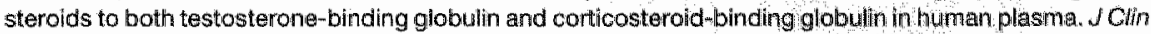
Endocrinal Metab. 53:58-68.

20. Hukshorn, $\mathrm{C}_{\text {J. }}$, Westerterp-Plantenga, M.S. and Saris, W.H. 2003. Pegylated human recombinant laptin (PEG-OB) causes additional weight loss in severely energy-restricted, ovenweight men. Am $\checkmark$ Chin Nutr. $77: 77$ 1-.776.

21. Fified, K.E "Moore, R.u, Hoyt, R.W., Marchitelli, L.U., Martinez Lapez, L.E., and Askew, EW, 2000. Endocrine markers of semistarvation in healthy lean men in a multistressor enviromment. A Appl physiol. 88:1820-1830.

22. Rosenibaum, M., Murphy, E.M., Heymsfield, S.B., Matthews, D.E and Leibel "R.L. 2002. Low dose lipptin administration reverses effects of sustained weight-reduction on energy expenditure and chrculating concentrations of thyroid hormones. J Clin Endocrinol Metab. 87:2391-2394.

23. Montague, C.T., Faroogi I.S., Whitehead, J.P., et all. 1997. Congenital Ieptin deficlency is associated with severe early-onset obesity in humans. Nature. 387:903-908.

24. Ozata, M., Ozdemir, I.C., and Licinio, J. 1999. Humar leptir deficiency oaused by a missense mutation: multiple endocrine defects, decreased sympathetic tone, and immune systern dystunction incticate neww targets for leptin action "greater central then peripheral resistance to the weffects of leptin, and spontanieous. correction of leptin-mediated defects. J Clin Endocrinol Metab. 84.3686-3695.

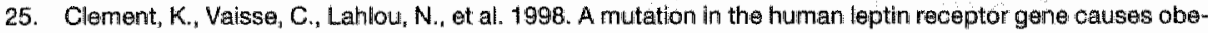
sity and pituitary dysfunction. Nature. 392:398-401.

26. Farooqi, li.S., Jebb, S.A. Langmack, G., et al. 1999. Effects of recombinant leptin therapy in a child with congenital leptin deficiency. N Engl J Med. 341:87:9\%884.

27. Oral E.A. $_{\text {, Ruiz, E., Andewelt }}$ A., at al. 2002, Effect of leptin replacement on pituitary hormone regulation in patients with severe lipodystraphy. J Clin Endacrinol Metab. 87:3110-31117.

28. Himms Hagen, J. 1999. Physiological roles of the leptin endocrime system. differences between mice and humans. Crit Rev Ciin Lab Sci. 36:575-655.

29. Hiliman, S.M., Pierroz, D.D., and Flier, J.S. 2000. Leptin, nutrition, and reproduction: timaing is everything. $\checkmark$ Crin Endocrinol Metab. 85:804-807.

30. Hamilton, G.D., and Bronson, F.H. 1986. Food pestriction and reproducilve development: malle and femalo mice and male rats. Am J Physiol. 250:18370-R376.

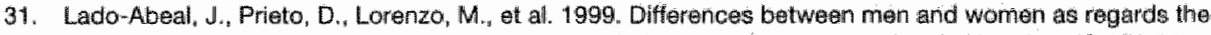
effects of protein-energy malnutrition on the hypothalanic patuitary-gonadal exis. Nutrition. $15: 351-358$.

32. Yu, W.H., Kimura, M., Walczewske, A., Karanth, S., and MCCamn, S.M. 1997. Role of leptin in liypothaIarmic pitutary function. Proc NaU Acad Sci USA. 94:1023-1028.

33. Ahima, R.S., Kelly, J., Elmquist, d.K, and Flier, J.S. 1999. Distinct physiologic and neuronal responges to decreased leptin and mild hyperleptinemia. Endocrinology. 140:4923-4931. 


\section{CHAPTER 7}

\section{Leptin and the Proinflammatory State Associated with Human Obesity}

C.J. Hukshorn, J.H.N. Lindeman, K.H. Toet, W.H.M. Saris, P.H.C. Eilers,

M.S. Westerterp-Plantenga, and T. Kooistra 


\section{Abstract}

It has been suggested that elevated leptin levels underlie the low grade proinflammatory state in human obesity. We reasoned that if elevated leptin levels are an important factor in the proinflammatory state in obesity, then exogenous leptin administration during weight loss should counteract the concurrent beneficial effects of weight loss on the proinflammatory state. We therefore determined whether long-acting pegylated recombinant leptin ( $P E G-O B$ ) prevents the decrease in cellular and humoral inflammation parameters during a very low calorie diet in healthy owerweight young men. Except for $\mathrm{B}$ cells, $\mathrm{PEG}-\mathrm{OB}$ treatment did not influence the decline in total leukocyte count and mononuclear subfractions during the diet. Weight loss decreased the humoral inflammation parameters TNFa, tissue plasminogen activator, and von Willebrand factor $(P<0.05)$, but in combination with $P E G-O B$ treatment, a significant decrease was shown for inflammation markers as a whole $(P<0.014)$ and that of the individual parameters tissue plasminogen activator, von Willebrand factor, plasminogen activator inhibitor type 1 , and intercellular adhesion molecule-1 $(P<$ $0.05)$. The increase in $\mathrm{C}$-reactive protein levels $(P<0.05)$ was the sole indication for a humoral proinflammatory action of leptin. Although PEG-OB treatment significantly increased weight loss $(P<0.03)$, the data do not support a proinflammatory role of leptîn in human abesity.

\section{Introduction}

Human obesity is associated with a chronic low grade, proinflammatory state as indicated by leukocytosis (1), increased plasma levels of the proinflammatory cytokines IL-6 (2) and TNFa, (3) elevated acute phase proteins (4,5), and increased levels of markers of endothelial cell dysfunction and activation (6). Weight loss attenuates this proinflammatory state (7).

Leptin is an adipocyte-derived polypeptide hormone that controls body weight through central regulation of food intake and energy expenditure (8). Abundance of leptin mRNA in adipose tissue and concentrations of leptin in the circulation are strongly positively correlated with body weight and adiposity in man; and human obesity is characterized by elevated circulating leptin levels (9). Both leptin and its receptor share structural and functional similarities with the IL-6 family of cytokines (10), and leptin appears to play a critical role in the inflammatory response. Defective immune responses are present in both leptin-deficlent mice $(11,12)$ and infants (13) as well as during starvation and malnutrition, two conditions characterized by low levels of circulating leptin (12). CD $34^{*}$ hemopoietic stem cells (14) and most leukocytes express the leptin receptor (15), and the stimulating effects of leptin on leukocyte proliferation has been well established in vitro (10). Further evidence from in vitro and animal studies suggests that leptin is allso involved in regulation of the humoral inflammatory response through its direct effects on T cells $(10)$, monocytes $(10,16)$, neutrophils $(17)$, and endothelial cells $(18,19)$.

Weight loss reduces circulating leptin levels (20) and concomitantly lowers the plasma levels of inflammation markers associated with obesity (7). The question thus arises whether raised leptin levels underlie the proinflammatory state in human obesity (21). In this paper we sought evidence for a proinflammatory role of leptin in obesity 
through maintaining elevated plasma leptin levels during weight loss. To that end. moderately obese men were subjected to profound weight loss induced by a vary low calorie diet (VLCD) and either received weekly injections of long-acting pegylated human recombinant leptin (PEG-OB) $(22,23)$ or placebo. It was reasoned that if elevated leptin levels are an important factor in inducing an inflammatory state in obese humans, exogenous leptin administration during weight loss would counteract the concurrent beneficial effects on the proinflammatory state.

\section{Subjects and Methods}

\section{Study population}

The study was part of a larger study into the effects of PEG-OB treatment on weight loss. Twenty-four overweight and moderately obese Caucasian men (body mass index, 25-32 $\mathrm{kg} / \mathrm{m}^{2}$ ) were recruited through advertisements in local newspapers. All subjects thad a stable weight and were healthy according to medical history, clinical examination, and routine laboratory findings. To achieve balanced treatment groups, patients were stratified and matched into pairs according to age, body mass index, and plasma leptin and insulin concentrations. Randomization numbers were generated and incorporated into the double-blind labeling by an independent third party. Within the first week of the study, two subjects in the placebo group dropped out voluntarily because they were unable to sustain their diet; this did not influence baseline characteristics of the study population. The study was approved by the medical ethical committee of the University of Maastricht, and all participants gave written informed consent.

\section{Weight loss and treatment}

Weight loss was induced through a very llow calorie diet $(2 \mathrm{MJ} / \mathrm{d}$; Modifast, Novartis, Breda, The Netherlands). The dietary prescription was discussed weekly with a dietician, and compliance with the diet was verified by measurement of weight loss. Body weight was measured on a calibrated digital scale accurate to $0.1 \mathrm{~kg}$.

During the study, patients either received weekly sc injections of $80 \mathrm{mg}$ PEG-OB (10 $\mathrm{mg} / \mathrm{ml}$; produced and provided by Hoffmann-La Roche Inc., Nutley, N I] or matching placebo $(8 \mathrm{ml})$ in the para-umbilical region. PEG-OB treatment was well tolerated. No indication could be found for the occurrence of significant amounts of PEG-OB neutralizing antibodies at the end of the study (d 46).

\section{Blood sampling and biochemical analysis}

Blood samples and plasma samples were obtained on 11 (before the start of the diet and PEG-OB treatment), 8, 15, 25, and 46 of the study. Blood sampling was performed in the morning after at least an 8-h overnight fast, immediately before study medication. Samples were directly placed on melting ice and centrifuged within 1 h of sampling. The extracted plasma was recentrifuged, frozen in liquid nitrogen, and stored at $-80 \mathrm{C}$ until further analysis. All assays were performed in duplicate. 
Glucose was measured by the hexokinase method (Roche, Basiel, Switzerland), and insulin levels were measured at the certified central laboratory of the University Hospital Maastricht (Maastricht, The Netherlands). Estimated insulin sensitivity was assessed by homeostasis modell assessment (24): (fasting glucose $X$ fasting insuliny/22.5.

Total cholesterol was measured by the CHOD-PAP method (Roche, Mannheim "Germany), and the lipase method (Sigma-Aldrich Corp., St. Louis, MO) was used to measure triglycerides. High density lipoprotein (HDL) cholesterol was measured at the certified central Vaboratory of the University Hospital Maastricht, The Netherlands. Low density lipoprotein (LDL) cholesterol was calculated with the Friedwald formula (25): LDL cholesterol = total cholesterol - (0.45 X triglycerides) - HDL-cholesterol.

Total leukocytes and mononuclear subpopulations were analyzed on $\mathrm{d} 1$ and 25 by fluorescence-activated cell sorting analysis. Plasma leptin levels were measured by a double-antibody sandwich ELISA using a monoclonal antibody specific for human leptin. This assay measures both pegylated and free leptin (26). Plasma IL-1, IL-6, TNFa, intercellular adhesion molecular-1 (ICAM-1), and tissue plasminogen activator (tPA) were assessed by commercially available ELISA kits: Pelikane compact kit (CLB, Amsterdam; The Netherlands) for IL-6, HS Quantikine (R\&D Systems, Abingdon, UK) for IL-1, TNF $\alpha$, and ICAM-1, and Imulyse-1 (Biopool, Umea, Sweden) for tPA. C-Reactive protein (CRP), WWF, and fibrinogen were measured by in-house ELISAs using commercially available antibodies (DakoCytomation BV, Heverlee, Belgium) as described previously (27-29). Details of the ELISAs for soluble p55 and p75 TNF $\alpha$ receptors (sTNFR-55 and STNFR-75) have been described previously (30). Plasminogen activator inhibitor type 1 (PAl-1) antigen levels were assessed by a specific in-house sandwich ELISA that measures latent, active "and complexed forms. The linearity of this assay ranges from $2-30 \mathrm{ng} / \mathrm{ml}$. The coefficients of varation for these assays were less than 10\%. The within- and between-day coefficients of varation were $2.9 \%$ and $7.2 \%$ for CRP, $1.7 \%$ and $6.3 \%$ for fibrinogen, and $6 \%$ and $12 \%$ for PAl-1, respectively.

\section{Statistics}

Results are expressed as means (SD) or medians (range) where indicated. Differences between start ( $d$ 1) and end of diet ( $(46)$ valules were determined by paired $t$ test or Wilcoxon rank-order test for paired observations when applicable. For clarity, uncorrected $P$ vallues are provided in the text, but a Bonferroni correction should be considered when interpreting the data.

The effects of weight loss on the proinflammatory state in the placebo and PEG-OB groups were assessed by combining the individual proinflammatory parameters in a single model. To that end, plasma PAI-1, IL-6, tPA, fibrinogen, and ICAM-1 values on d $1,8,15,25$, and 46 were logarithmically transformed and incorporated into a single model, and the effect was analyzed as a multivariate response by multivariate analysis of covariation, with time as the independent variable. 


\section{Results}

Baseline characteristics of the study population and the effects of weight loss on metabolic parameters are shown in Table 1. The VLCD resulted in a rapid and substantial weight loss and a significant decline in serum leptin levels in the placebo-treated group $(P<0.0001)$. Compensating for the fall in serum leptin levels by PEG-OB treatment resulted in total (i.e. pegylated and endogenous) leptin levels of $3980 \pm 704$ $\mathrm{ng} / \mathrm{ml}$. Weight loss was significantly higher in the PEG-OB group than in the placebo group $(14.6 \pm 2.7$ vs. $11.7 \pm 2.9 \mathrm{~kg}$, respectively; $P<0.03)$. Baseline leptin serum concentrations immediately before leptin injection ranged from $950-3700 \mathrm{ng} / \mathrm{ml}$. Peak concentrations, measured $72 \mathrm{~h}$ after sc PEG-OB injection, ranged from 2300-6050 $\mathrm{ng} / \mathrm{ml}$.

Weight loss led to a significant decrease in fasting glucose levels $(P<0.03$ and $P<$ 0.0001 in the placebo and PEG-OB groups, respectively) and fasting insulin levels $(P<$ 0.001 and $P<0.0001$ in the control and the $P E G-O B$ groups, respectively), resulting in an improved estimated insulin sensitivity in both the placebo group $(P<0.03)$ and the PEG-OB group $(P<0.001)$.

Total plasma cholesterol, LDL cholesterol, and triglycerides were significantly lower after weight loss $(P<0.02$ in both study groups). HDL cholesterol was not significantly influenced by the $V L C D$.

The effects of the VLCD and PEG-OB treatment on the cellular and humoral components of the immune system have been summarized in Tables 2 and 3. In general, these parameters show a gradual decline over the 46-d study period, indicating that the fall in proinflammatory parameters is not simply related to the VLCD (see also Fig. 1.). Table 2 shows the effects of the VLCD and PEG-OB treatment on circullating cellular components of the immune system at the end of the 46-d study period. Weight loss significantly lowered total leukocyte count in both the placebo and PEG-OB groups $(P$ $<0.01$ and $P<0.001$, respectively). The fall in total leukocytes was, with one exception, evenly distributed over the various mononuclear subfractions. Monocytes, CD4 CD8 ${ }^{*}$, and NK celis decreased proportionaliy; only $\mathrm{CD} 19^{+*}$ cells (B Iymphocytes) showed a small, but significant $(P<0.04)$, increase in the $P E G-O B$ group.

Data on the evaluation of humoral inflammatory markers are shown in Table 3. Of the parameters tested, only the vascular endothelial cell activation markers IPA $(P<$ $0.004)$ and WWF $(P<0.03)$ and the proinflammatory cytokine TNFq $(P<0.04)$ significantly decreased upon weight loss. Compared with baseline values, no significant change was found for IL-1, IL-6, sTNFR-55, sTNFR-75, CRP, fibrinogen, PAI-1, or ICAM-1. Overall assessment of humoral inflammatory markers in a model incorporating all relevant inflammatory parameters showed a tendency to decline upon weight loss $(P<0.09)$.

The VLCD in combination with PEG-OB treatment resulted in significant changes in the endothelial activation markers tPA $(P<0.001)$, WWF $(P<0.002)$, and $\| \mathrm{CAM}-1(P<$ $0.009)$ and in STNFR-75 $(P<0.044)$ and PAl-1 $(P<0.002)$. No significant changes in TNF $\alpha$, sTNFR-55, or fibrinogen were observed. Overall assessment of all relevant parameters by multivariate analysis of covariation revealed a gradual, significant decline over time in the proinflammatory parameters $(P<0.014)$.

Although the VLCD generally induced a decrease in humoral inflammatory markers, two exceptions were noticed (Fig. 1). First, in the placebo group, but not in the PEG-OB group, the VLCD induced a significant $(P<0.02) 2$-fold increase in median 
L-6 values on 8 , which had disappeared by d 15. Second, in the PEG-OB group, CPP levels peaked on $\mathrm{B}(\mathrm{P}<0.004)$ and remained elevated for the remainder of the study period.

Table 1. Metabolic charactenistics of placebo-and PEG OB-treated groups belore and atter weightl loss

\begin{tabular}{|c|c|c|c|c|}
\hline 10 & $\begin{array}{l}\text { Placebo f } n=10 \text { ) } \\
\text { Betore weingt loss } \\
\text { (d o) }\end{array}$ & $\begin{array}{l}\text { After weight loss } \\
(\mathrm{A} 46)\end{array}$ & $\begin{array}{l}\text { PEG ob }(n=12) \\
\text { Before weight loss } \\
\text { (d o) }\end{array}$ & $\begin{array}{l}\text { After woight loss } \\
(d 46)\end{array}$ \\
\hline Age Wh & $364+28$ & & $34.6+42$ & \\
\hline Weloht (kg) & 9661.118 & $84.8+127^{3}$ & $979+66$ & $83.3=5.6^{2}$ \\
\hline Weighat loss (kg) & & $11.9 \pm 2.9$ & & $14.6 \pm 2.7$ \\
\hline BWl kom? & $288+18$ & $25.4+2.3^{a}$ & $28.9+13$ & $24.8 \pm 1.5^{3}$ \\
\hline Leptin (ngiriol) & $7,10 \div 237$ & $201 \pm 0759$ & 7.6114 .22 & $3980+704$ \\
\hline Glucase (nmono-Aiter) & 5.2 .02 & 47.105 & $5.3 \pm 0.3$ & $4.7 \pm 0.3^{\circ}$ \\
\hline Insuln (nudtiter) & 94432 & $36+2.2$ & $7.2+2.8$ & $20+10^{\circ}$ \\
\hline HOMA. & $22+0 \mathrm{~B}$ & $0.8+0.5^{\circ}$ & $17 \pm 0.6$ & $0.4 \pm 0.2$ \\
\hline of & $48 \times 0.9$ & $37+0.5$ & $4,7+0.8$ & $3.2+10.5$ \\
\hline HoL whalesterol (nmelliter) & $3.2 \pm 0.8$ & $24 \leq 03^{2}$ & $28+05$ & $1,8+0,3^{\circ}$ \\
\hline molestorol in & 1.140 .1 & $1,1+0.3$ & $12 \pm 0.3$ & $1.1 \pm 0.2$ \\
\hline & $175 \pm 06$ & $0.58+0.22$ & $113+0.9$ & $0.480 .21]$ \\
\hline
\end{tabular}

Values are given as mement $\triangle \mathrm{SD}$ BM, Body mass index SIgnficeant difference between placebo and $\mathrm{PEG}$-OB-treated group. $0, P<0.05,0 P<0.03,0.9<0.001$.

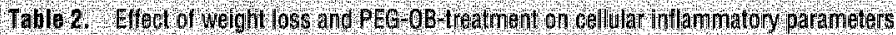

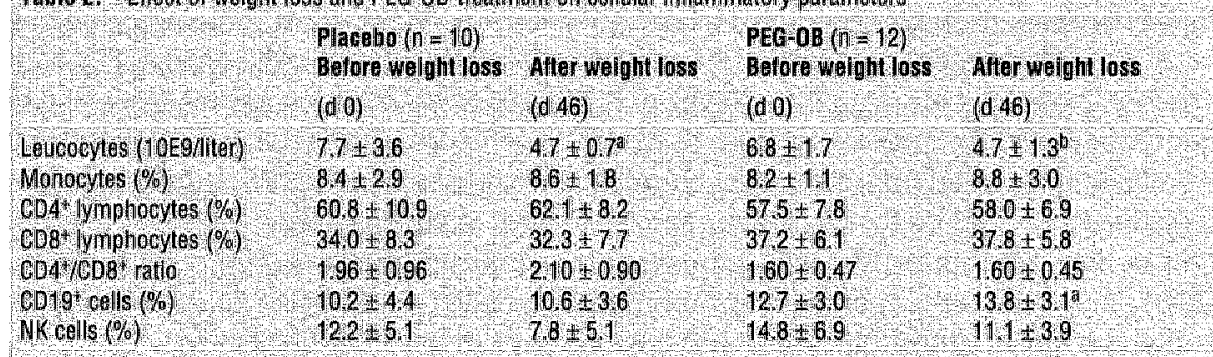

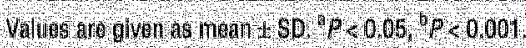

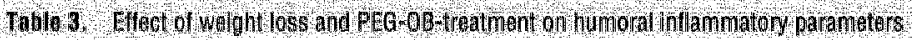

\begin{tabular}{|c|c|c|c|c|}
\hline & 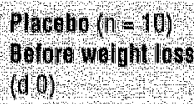 & $\begin{array}{l}\text { Aftar wolght loss } \\
(d 46)\end{array}$ & $\begin{array}{l}\text { PEG } 0 \text { os }(n=12) \\
\text { Before wolght loss } \\
\text { (d o) }\end{array}$ & $\begin{array}{l}\text { Atter walohit loss } \\
(46)\end{array}$ \\
\hline (t) vinliter) & No & No & ND & No \\
\hline (I) 6 rnalitat) & $1,52[0.233 .3431$ & $0.62[0,18-3.64]$ & $1,20[0.30 ; 8,90]$ & $0.74[014-3,45]$ \\
\hline TNFa (ngilien) & 410110653301 & 3.46 $11.46-4,74)$ & $3.04[207.4 .33]$ & $272[126.503]$ \\
\hline sinenss (uniluen & 0.3340 .08 & $0.31 \pm 0.09$ & $0,30+0,09$ & $028 \pm 0.07$ \\
\hline sinemor (nollor) & 10810.29 & $108+0.22$ & $1,35 \div 0.24$ & $115 \pm 0.26^{\circ}$ \\
\hline SRP (minglen) & $275[0.04776]$ & $0.93[011<9.35]$ & $130[0.8311 .66]$ & $2.66[0.79-14.45]$ \\
\hline Tibrinogen (aller) & 3104111 & $290,0.93$ & $2.56 \pm 0.77$ & $2.36 \div 0.52$ \\
\hline PAI & 207175 & $1 3 . 5 \longdiv { 1 1 . 0 }$ & $21.5,100$ & $6.9+4.7$ \\
\hline PA & $134 \pm 10.6$ & $68 \pm 71$ & $119 \pm 5.0$ & $4.03 \pm 2.05$ \\
\hline ghltier) & $152 \div \geq 39.6$ & $136,5+36,0^{\mathrm{a}}$ & $160.8=30.7$ & $1361+253^{9}$ \\
\hline (hioliter) & $1558+13: 2$ & $144.6+23.9$ & $165.4 \pm 34.1$ & $141.9131 .4^{\mathrm{a}}$ \\
\hline
\end{tabular}

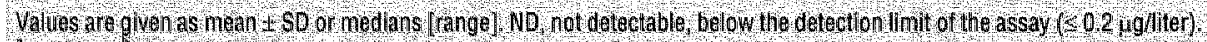
P $P<0.05 P$ P $<0.001$ 

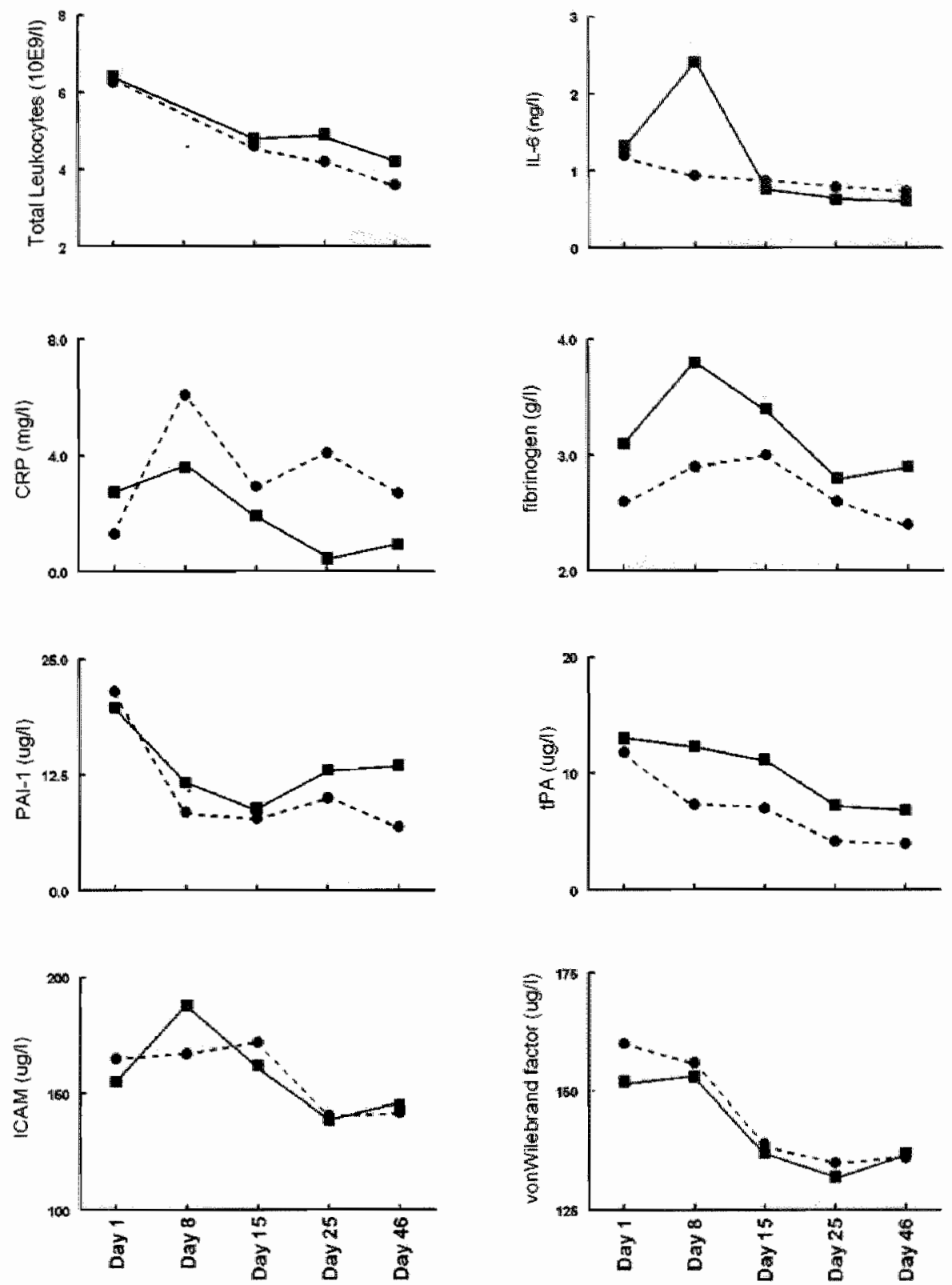

Figure 1: Changes in the proinflanmatory parameters [total feucocytes (miean), plasmul L-6 (mindian), CAP (median), fibrinogen (mean), PAl-1 (median), IPA (mean), ICAM (mean), and wWF (mean)] dung weight loss in the placebo group (O) and the PEG-OB group (M). 


\section{Discussion}

In addition to acting as a regulator of food intake and energy expenditure (8), there is a growing body of evidence to suggest that leptin is a modulator of the immune and proinflammatory responses $(10,12)$. Consequently, it has been hypothesized that elevated leptin levels underlie the low grade proinflammatory state associated with human obesity (21). In the present study we found that high leptin levels produced by $P E G-O B$ treatment of overweight young men during a $V L C D$ significantly increased welght loss (31), but our data do not support a proinflammatory role for leptin in human obesity. With the exception of small increases in CD19 cells and plasma CRP levels, PEG-OB treatment, which compensated for the fall in serum leptin levels during weight loss, did not counteract the changes in plasma levels of cellular and humoral inflammatory markers during the VLCD period. In fact, PEG-OB treatment further strengthened the beneficial effects of the diet on the inflammatory state.

The additional weight loss in the PEG-OB group is in line with studies in rodents, which also showed enhanced weight loss upon leptin administration (8). The higher weight loss in the PEG-OB-treated subjects appears primarily related to a suppression of appetite during the VLCD. Voluntary weight loss in man has been shown to be accompanied by an increase in baseline appetite (32) and in the relevant human studies reported to date a decrease in appetite, rather than an increase in energy expenditure, was found to underlie the enhanced weight loss in leptin-treated individuals $(31,33-35)$.

The current data on the beneficial effects of weight loss on cellular and humoral markers of inflammation are in accordance with other reports. Field et al. (36) also reported that total leukocyte count and mononuclear subfractions diecline during weight loss induced by a VLCD in moderately obese subjects. A beneficial effect of weight loss on circulating levels of TNF $\alpha$ in obesity has been shown by Dandona et al. (3) and Zahorska et al. (37). Heilbronn et al. reported a decline in plasma CRP levels in proportion to weight loss (38).

With the exception of a minor fractional enrichment in $\mathrm{CD}_{1} 9^{+}$lymphocytes and an increase in plasma CRP levels, we found that PEG-OB treatment enhanced, rather than antagonized, the beneficial effects of weilght loss on proinflammatory markers. Our data are seemingly in contrast with previous reports that showed a proinflammatory role for leptin. Fantuzzi et al. (10) extensively reviewed a putative role of leptin in the modulation of the innate immune response, inflammation "and hemopoiesis. Also, Yamagishi et al. (18) and Bouloumié et al. (19) reported proinflammatory effects of leptin on endothelial cell activation. Wang et al. (39) and Dowidar et al. (40) showed direct effects of leptin on the hepatocyte. The discrepancies between the present results and those reported in the cited references are unlikely to be related to the high leptin levels in our study, because Zarakesh-Esfahani et al. (16) also used high leptin concentrations in their leukocyte studies. Also, the apparent efficacy of PEG-OB is less than that of native leptin (Campfield, L.A. unpublished observations), resulting in lower effective leptin concentrations. The discrepancies may be related, however, to in vitra / in vivo differences, specles differences (13), as well as differences in model systems. For example, several reports indicate that exogenous leptin induces a profound suppression of appetite in rodents (8), whereas exogenous leptin administration in humans induces only a very modest suppression of appetite $(31,33-35)$. Moreover, most data on the proinflammatory role of leptin were obtained in leptin-deficient ani- 
mals and/or situations such as starvation, which are characterized by low circulating leptin levels (12). Apparently these findings cannot simply be extrapolated to the human situation, un which obesity is characterized by elevated plasma leptin levels and diminished leptin responsiveness (41).

The increase in plasma CRP levels in the PEG-OB-treated group is the only significant proinflammatory effect of leptin. CRP is a classical and highly sensitive acute phase protein, plasma levels of which typically increase 100-fold or more during inflammation. The 2-fold increase in CRP levels upon PEG-OB treatment is indicative of only a weak inflammatory response and may result from the direct interaction of leptin and its receptor on hepatocytes, which interaction has been reported to induce IL-6-type responses $(12,40,41)$. CRP is a strong predictor of cardiovascular risk, and indirect evidence suggests that CRP may directly be involved in atherosclerosis (42). No evidence for such a mechanism was found in this study, and the decline in endothelial cell activation markers WWF and ICAM-1 was similar in both study groups.

An interesting finding is the increase in $1 \mathrm{~L}-6$ concentration on $\mathrm{d} 8$ in the placebo-group, an increase that was absent in the PEG-OB group. We are not aware of similar observations during acute (semi) starvation. An increased plasma IL-6 concentration has been reported upon strenuous exercise, and it was speculated that these elevated levels reflect a muscle-derived signal, indicating critically low muscle glycogen stores and signalling the liver to increase glucose output (43). The observed increase in IL-6 upon initiation of the very low calorie diet may serve similar purposes. The apparent suppression of the IL- 6 surge by PEG-OB concurs with the proposed role of leptin as a peripheral signal, signalling the brain to initiate adaptive responses to starvation (44). In conclusion, in this prospective study no evidence was found for a causative role of leptin in the proinflammatory state associated with human obesity. We found that high leptin levels, produced by PEG-OB treatment, increased weight loss in moderately obese men during a VLCD. The apparent higher decline in inflammatory parameters in the $\mathrm{PEB}-\mathrm{OB}$ group may relate to the higher weight loss in this group.

\section{Acknowledgments}

We thank Hoffmann-La Roche Inc., for kindly providing the PEG-OB. We also griatly acknowledge the cooperation, patience, and contributions of all of our subjects. This work was supported by a grant from The Netherlands Heart Foundation (NHS 97. 100).

\section{References}

1. Perfetto, F., Mancuso, F., and Tarquini, F. 2002. Leukocytosis and hyperteptinemid in obesity: is there a link? Haematologica. 87:ELT25.

2. Yudkin, J.S., Kumari, M. Humphries, S.E and Mohamed-All, V. 2000. Infllammation, obesity, stress and coronary heart disease: is interleukin-6 the link? Atherasclerosis. 148:209-21:4,

3. Dandona, P., Weinstock, R., Thusu, K., Abdel-Rahman, E., Aljada, A., and Wadiden, T. 4998 . Tumor necrosis factor-alpha in sera of obese patients: fall with weight loss. I Clin Endocrinol Matab. 83:2907.2910.

4. Visser, M., Bouter, L.M. McQuillan, G.M., Wener, M.H., and Harris, T.B. 199g. Elevated C-reactive protein levels in overweight and obese aduits. $J$ Am Med Assoc. 282:2131-2135.

5. van Dielen, F.M., van't Veer, C., Schols, A.M., Soeters, P.B., Buurman, W.A., and Grewe, J.W. 2001. Inw creased leptin concentrations correlate with increased concentrations of inflammatory markers im morbidly obese indivictuals. Int $J$ Obes Relat Metab Disord. 25:1759-1766. 


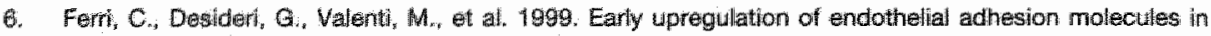
obese hypertensiwe men. Hypertension. 34.568.573.

7. Ziccardi, P. Nappo, F. Gugliano, $G$, et al. 2002. Peduction of inftammatory cytoikine concentrations and improvement of endothelial functions in obese women after weight loss over one year. Circilation. 105:804-809.

8. Ahima, R.S, and Fller, J.S.2000. Leptin. Annu Fev Physiol 62:413-437.

9. Considine, P.V. Sinha, MK. Heiman, M.L, et al, 1996. Serum immunoreactive-teptin concentrations in nomalwoight and obese humans. N Eng I Med $334: 292-295$.

10. Famtivzi, $Q$, and Faggioni, $P .2000$. Leptin in the regulation of immunity, inflamination, and hematopoiesis. $\checkmark$ Laukoc Biol. 68:437-446.

11. Lord, G.M. Matarese, G., Howard L.K., Baker, R.J, Bloom, S.R. and Lechler, R. I. 1998. Leptin modulates the T-Gell immune response and reverses starvation-induced mmunosuppression. Nature. 394:897-901.

12. Faggioni, . F. Felngold, K.R, and Grunfeld, $\mathrm{C}$. 2001 . Leptin regullation of the immune response and the immunideficiency off malnutrition. FASEB $J: 15: 2565-2571$.

13. Faroogi, 1.S., Mattarese, G. Lord, G.M., et al. 2002. Beneficial effects of leptin on obesity. T cell hyporesponsiverness, and neuroendocrine/metabolic dystunction of human congenital leptin ceficiency.J Cin Irvest 110:1093-1103.

14. Laharrague, P., Oppert. J.M., Brousset, P., ett al. 2000. High concentration of leptin stimulates myelioid differentiation from human bome marrow CD34" progenitors: potential involvement in leukocytosis of obese subiects. Int J Obes Relat Metab Disord. 24:1212-1216.

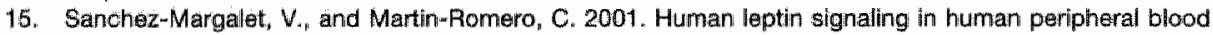
mononuchear cells: activation of the JAK-STAT pathway. Cell Immunol. 211:30-36.

16. Zarkesh-Esfahani, H. Pockley, G., Metcalfe, R.A., et al. 2001. High-dose leptin activates humam leukocyter via receptor expression on monocytes. Jimmunol. 167:4593-4599.

17. Caldefie-Chezet, F., Poullin, A., Tridon, A., Sion, B, and Vasson, M.P. 2001. Leptint a potential regulator of polymorphonuclear nautrophil bactericidal action? J Leukoc Biol. 69:414-418.

18. Yamagishi, S.ll, Edelstein, D., Du, X.L., Kaneda, Y., Guzman, M. and Brownlea, M. 2001. Leptin induces mitochondrial superox ide production and monocyte chemoattractant protein-1 expression in aortic endothelial cells by increasing fatty acid oxidation wia protein kinase A. 4 Biol Chem. 276:25096-25100.

19. Botlloumie, $A_{b}$, Marumo, $T$. Lafontan, M., and Busse, R. 1999. Leptin induces oxidative stress in human endothellal cells. FASEB $U$. 13:1231-1238.

20. Rosenbaum, M. Nicolson, M., Hirsch, N., Murphy, E., Chu, F., and Leibel , R.L. 1997. Effects of weight change on plasma leptin concentrations and energy expenditure. J Clin Endocrino Metab. 82:3647-3654.

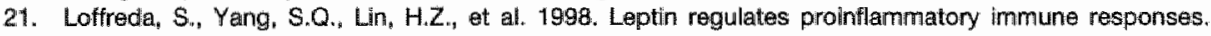
FASEB J. 12:57-65.

22. Campfield, L.A., Devos, R., and Guisez, Y. 2000. Pegylated obese (OB) protein compositions. US Patent Number $6,025,324: 2 / 15 / 2000$.

23. Bailon, P.S. Campfield, L.A., and Devos, F, 2000. Pegylated obese (OB) protein compositions. US Patent Number 6,025,325:2/15/2000.

24. Matthews, D.R., Hosker, J.P, Rudenski, A.S., Naylor, B. A, Treacher, D.F, and Tumer, R.G. 1985. Homeostas model assessment: Unsulin resistance and betawell funcition from fasting plasma glucose and insulin concontrations in man. Diabotologia. 28:412-419.

25. Warnick, G.R., Knopp, Ri, Ha Fitzpatrick, V., and Eranson, L. 1990 . Estimating low-density lipoprotein cholestorol by the Friodewald equation is adequate for classifying patients on the basis of nationally recommended cutpoints. Clin Chem. 36:15-19.

26. Huksthorn, C.J., Saris, W.H.M. Westerterp Plantenga, M.S., Farid, A.F., Smith, F.J., and Campfield, L.A. 2000. Weekly subcutaneous pegylated racombinant native human leptin (PEG-OB) administration in obese men. J Clin Endocrinol Metab. 85:4003-4009.

27. Myrup, B., de Maat, M., Rossing P., Gram J., Kluft, C. and Jespersen, ل. 1996. Elevated fibrinogen and the reitition to acute phase response in diabetic nephropathy. Thromb Res. 81:485-490.

28. Vischer, U.M., Ingerslew , w., Wollhelim, C.B., al al. 1997. Acute von Willebrand factor secretion from the en* dothelium in vivo: assessment through plasma propeptide (wWf:Agll) levels. Thromb Haemost. 77:387-393.

29. de Maat, M.P., de Bart, . $_{n}$, Hennis, B.C., et al. 1996. Interindividual and intraindividual variability in plasma fiburinogen, TPA antigen, PAl actiwity, and CRP in healthy, young volunteers and patients with angina pectoris. Arterioscler Thromb Vasc Brol. 16:1156- 162.

30. Leenwenberg, J.F., Jeumhomme, T.M., and Butrman, W.A. 1994. Slow release of soluble TMF receptors by monocytes in vitro. J Imomunal. 152:4036-4043.

31. Hukshom, C.d., Westerterp-Plantenga, M.S., and Saris, W.H. 2003. Pegylated human recombinant leptin (PEG-OB) causes additional weight loss in sewerely energy-restricted, overweight men. Am I Clin Nutr. $77.771-776$.

32. Doucet, E., Imbeault, P., St-Pierre, S., et al. 2000. Appetite after weight loss by energy restriction and a low-fat diet-exercise follow-up. Int J Obes Relat Metab Disord. 24:906-914. 
33. Heymsfield, S.B., Greenberg, A.S., Fujoka, K, et al. 999 . Fecombinent leptin lor weight loss Wobese and leen adults - A randomized, controlled, dose-iescalation trial J Am Med Assoc 282.7668-1575.

34. Westerterp-Plantenga, M.S., Saris, WH. Hukshom, $\mathrm{cu}$, and Camptilik, L. A. 2001. Effects of weekly administration of pegylated recombinant human $O B$ protein on appetife profile and energy metabolism in obese men. Am J Chin Nutr. 74:426-434.

35. Petersen, K.F., Oral, E.A., Dufour, $S$, et all. 2002. Leptin reverses insulin resistance and hepatic steatosis hn patients with severe lipodystrophy. 1 Clin invest. $109: 1345-1350$.

36. Field, C.J., Gougeon, R, and Marliss, E. B. 1991 . Changes in circulating leukocytes and mitogen responses during very-low-energy all-protein reducing diets. Am 1 Clin Nutr. 54,123-12.

37. Zahorska-Markiewicz, B., Janowska, J., Olszanecka-Ginianowicz, M., and Zurakowski, A. 2000. Serum concentrations of TNF-alpha and soluble TNF-alpha receptors in obesity. Int J Obes Relat Metab Disord. 24:1392-1395.

38. Heibrann, L. K., Noakes, M., and Clifton, P.M. 2001. Energy restriction and weight loss on very low fiat diots reduce Cireactive proteir concentrations in obese, healthy women. Arterioscler Thromb Vasc Biol. $21: 968-970$.

39. Wang, $Y$., Kuropatwinski, K.K. White, D.W., at ai, 1997. Leptin receptor action in hepatio cells. Siol Chem. 272:16216-16223.

40. Dowidar, N.L. "Dejong, C.H.C., Fearon, K.C.H., Garden, O.J, and Ross, J.A. 2000. Effects of leptin on iso" Hated human hepatocyte C-reactive protein production. Eur J Gastroenterol Hepatol. 12:A18.

41. Mantzoros "C.S., and Flier, J.S. 2000. Ediltorial: leptin as a therapeutic agent: trials and tribulations. $J$ Clin Endocrinol Metab. 85:4000-4002.

42. Verma, S., Wang, C.H., Li, S.H., et al. 2002. A self-fulfiling prophecy; C-reactive protein attenuates nitric oxide production and inthibits angiogenesis. Circulation. 106:913-919.

43. Febbraio, M.A., and Pedersen, B.K. 2002. Muscle-derived interleukin-6: mechanisms for activation and possible biological roles. FASEB $U_{1}, 16: 1335-1347$.

44. Bowles, L., and Kopelman, P. 2001. Leptin: of mice and men? J Clin Pathol. 54:1*3. 
CHAPTER 8

Experimentally Induced Hyperleptinemia Supresses Luteinizing-Hormone Pulsatility in Underweight Women

C.J. Hukshorn, E. van Breda, H.A. Keizer, P.P.C.A. Menheere, J.D. Veldhuis, and W.H.M. Saris 


\section{Abstract}

It is well known that both loss or excess body fat is associated with impaired reproductive function in humans. Leptin, an adipocyte-derived hormone, plays an important role in the regulation of food intake and energy expenditure through hypothalamic mechanisms. Low leptin states in women are frequently associated with reduced or absent menstrual cycles, which suggests that leptin depletion might be responsible for the hypothalamic hypogonadism that accompanies these conditions. To address the capability of leptin to influence pulsatile LH secretion in the human, seven underweight and otherwise healthy young women received a single sc injection of placebo vs. long-acting pegylated human recombinant leptin (PEG-OB) designed to mimic leptin concentrations present in obesity. LH pulsatility was assessed objectively ten days after onset of menses by monitoring LH release every 10 minutes for $15 \mathrm{~h}$ before and $3 \mathrm{~h}$ after $\mathrm{GnRH}$ injection. Pharmacologically elevated leptin concentrations significantly decreased mean and integrated concentration of $\mathrm{LH}$ by reducing the mass of $\mathrm{LH}$ secreted per burst and 15-h LH secretion rate in all subjects. The intervention did not alter $\mathrm{LH}$ secretion in response to a maximal dose of exogenous $\mathrm{GnRH}$ or (15-h mean) concentrations of the thyrotropic " corticotropic, and somatotropic hormones. The present study indicates that experimentaliy induced hyperleptinemia is associated with lower mean, integrated and pulsatile $L H$ release in healthy young underweight women. On the basis of the present study and earlier data, we postulate that gender, mechanisms and/or duration of weight loss, and leptin concentrations and/or pulsatility determine GnRH/LH secretion in the human.

\section{Introduction}

Initiation and preservation of reproductive function is very sensitive to nutritional status. Chronic undernutrition is known to delay the onset of sexual maturation in children (1) and the loss of body fat often leads to impaired reproductive function $(2,3)$. Although it is known that menarche typically occurs at a younger age in obese girls, obesity in adulthood frequently has been shown to produce menstrual disturbances and infertility $(4,5)$. Several potential silgnals capable of relating the nutritional status to the hypothalamic regulators of reproduction have been implicated over time. The discovery of leptin 1994 revealed a putative afferent component of the regulatory loop linking body fat mass to the reproductive system (6).

Leptin is an adipocyte-derived hormone that is involved in the regulation of food intake and energy expenditure through hypothalamic mechanisms (6). Genetic leptin deficlency causes marked hyperphagia and profound obesity in both mice and humans, which can be overcome by leptin treatment (6-9). In the rodent leptin may also play an important role as metabolic regulator of neuroendocrine functions by signaling the brain of the changes in energy balance and energy stores (10), thereby limiting reproduction and lactation when energy demands are excessive (11).

Both $a b / o b$ (which lacks functional leptin) as the $d b / d b$ (which lacks the functional leptin receptor) mice fail to undergo normal sexual maturation and exhibit infertility due to hypothalamic hypogonadotropism. The administration of leptin was able to restore fertility to both female and male ob/ob mice (but not to $d b / d b$ mice) and counter- 
act the inhibitory effects of fasting on gonadotropin secretion in rodents $(10,12-14)$, Leptin administration but not weight reduction in the female ab/ob mouse restored fertility indicating an effect of leptin on reproductive homeostasis (12,13). Intracerebroventricular (ICV) immunoneutralization of leptin disrupts the estrous cycle in the female rat (15), whereas ICV administration of leptin at doses that did not influmence peripheral leptin concentrations restored luteinizing hormone (LH) secretion in fasting rats, which implies that leptin acts centrally to influence reproduction (16).

Humans with mutated leptin peptide or receptor may also fail to achieve normal adult reproductive function $(7,17-19)$. Less severe loss of leptin availability does not necessarily produce this effect (18). Secondary leptin depletion in women with anorexia nervosa, hypothalamic amenorrhea, some individuals with lipodystrophy, and highly trained female athletes also results in reduced or absent menstrual cycles (20). However, pubertal associations with leptin are less clear and two patients with lipodystrophy and undetectable leptin had normal menstrual function (21). Leptin administration in fasting men and the adult, but not prepubertal, male monkey restore suppressed LH pulsatility (22-25). On the other hand, repeated ( 7 -min) blood sampling for $24 \mathrm{~h}$ in healthy women in the late follicular phase of the menstrual cycle revealed an inverse relationship between nighttime leptin concentrations (elevated) and concomitant LH pulse frequency (decreased)(26). Accordingly, unlike data in the rodent, studies in the human and monkey do not establish a clear unifying role for leptin in the reproductive hormone outflow. Moreover, fewer data exist in women.

To address the capability of leptin to influence pulsatile LH secretion in the human, we studied seven healthy young women with a BMI of $20 \mathrm{~kg} / \mathrm{m}^{2}$ or less. Subjects received a single sc injection of placebo vs. long-acting pegylated human recombinant leptin (PEG-OB), designed to mimic leptin concentrations present in obesity. LH pulsatility was assessed abjectively by monitoring LH release every 10 minutes for $15 \mathrm{~h}$ before and $3 \mathrm{~h}$ after $\mathrm{GnRH}$ injection. Studies were timed to fall ten days after onset of menses so as to occur during induced hyperleptinemia and the expected mid-to late-follicular phase of the menstrual cycle.

\section{Subjects and Methods}

\section{Human subjects}

Underweight and otherwise healthy young women (see detailed criteria below) who were $18-28$ years of age and had a body mass index (BMI) of $20 \mathrm{~kg} / \mathrm{m}^{2}$ or less were elligible for inclusion. Recruitment was from the Institute waiting list or by local advertising. The Medical Ethics Committee of the University of Maastricht approved the study protocol and all participants provided written informed consent.

During the screening period, body composition was measured in each participant. Body composition was determined by using the combination of hydrodensitometry and deuterium dilution according to the published Maastricht protocol and calculated according to the equations of Siri $(27,28)$. Subjects with a fat mass percentage of $24 \%$ or more were excluded from the study.

Additional inclusion criteria were detailed medical and psychiatric histories and physical examination with negative findings, including no organic disease, normal adult sexual maturation and timing of menarche, no use of prescription medication (includ- 
ing oral contraceptives during the previous 6 months), absence of pregnancy or lactathon, willingness to use barrier methods of contraception during the study, no smoking and no transmeridian travel in the previous 4 weeks. All participants in the trial were of female Caucasian origin and reported irregular menstrual cycle lengths varying from 33 days to 42 days during the previous 6 months without the use of oral contraceptives. Each participant had normal ECG and biochemical tests of renal, hepatic, metabolic, and hematologicall function and morning fasting serum concentrations of insulin, cortisol, insulin-like growth factor-1 (IGF-1), thyrotropin-stimulating hormone (TSH), prolactin (PRL) within the normal physiological range. Subjects with a history or presence of drug abuse or alcoholism, atopy or hypersensitivity to pegylated proteins and with a weight change of more than $2 \mathrm{~kg}$ in the previous 3 months were excluded from the study.

Eating disorders were verified by a score of 5 points or less on the validated Dutch translation of the Eating Attitudes Test questionnaire (29). No participant exercised more than $1.5 \mathrm{~h}$ at a time or more than 5 times/week during the study period. All subjects were asked to maintain their conventional levels of physical activity and food intake throughout the study period.

\section{Study design}

Seven subjects met the enrollment criteria for the single-center, single-blind, sequential intervention (placebo, followed by the active drug) study. On day 1 of the first menstrual cycle after screening, each subject received a single subcutaneous placebo injection in the para-umbilical region. Ten days post-treatment, a frequent blood sampling protocol (see below) was executed (menstrual cycle day 10). Long-acting pegylated recombinant leptin (PEG-OB; produced and provided by Hoffmann-La Roche Inc., Nutley, New Jersey, USA) was administrated on day 1 of the second menstrual cycle. All subjects received a single subcutaneous dose of $0.15 \mathrm{mg} / \mathrm{kg}$ PEG-OB. After 10 days, the frequent blood sampling protocol was repeated.

Subjects were admitted to the Clinical Research Center of the University of Maastricht $24 \mathrm{~h}$ before initiation of the frequent blood sampling protocoll (menstrual cycle day 9) for adaptation to the Unit. At $2200 \mathrm{~h}$, an indwelling non-thrombogenic venous catheter was inserted into an antecubital veiln and subsequently connected through a coated non-thrombogenic catheter (ConFlo ${ }^{T M}$, Carmeda AB, Stockholm, Sweden) to a constant withdrawal pump (ConTouch ${ }^{T M}$ "Carmeda $A B$. Stockholm, Sweden; rate: 12 $\mathrm{mL} / \mathrm{h}$ ) after venous blood was withdrawn for serum total leptin measurements. Based

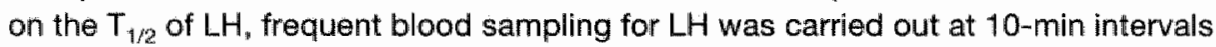
for 18 h on both occasions beginning at 2300 h of menstrual cycle day 10 . After sampling for $15 \mathrm{~h}$, a slingle pulse of $10 \mu \mathrm{g}$ gonadotrophin-releasing hormone $(\mathrm{GnRH})$ was given iv followed by another 3 h of blood sampling (GnRH-test). Blood samples ( $2 \mathrm{~mL}$ ) were collected every $10 \mathrm{~min}$ in EDTA-containing tubes and immediately placed on melting ice. Samples were centrifuged within $1 \mathrm{~h}$ of sampling, and the extracted plasma was frozen in liquid nitrogen and stored at $-80^{\circ} \mathrm{C}$ until further analysis. Mean concentrations of $\mathrm{LH}$, follicle stimulating hormone (FSH), $\mathrm{PRL}, 17 \beta$-estradiol, total testosterone, TSH, growth hormone (GH), IGF-1, insulin, cortisol, and dehydroepiandrosterone sulfate (DHEA-S) were assayed in a single 15-h pool of plasma.

Subjects remained in bed during the entire sampling period except for bathroom privileges. Daytime naps and caffeine-, alcohol-, or energy-containing beverages were not 
allowed during sampling. The study subjects were exposed to darkness from 0000-0800 $h$, during which they were allowed to sleep. Blood samples were withdrawn from outside the subject's room to avoid disturbing sleep patterns. Three standardized isocaloric meals were provided at 0830,1230 , and $1800 \mathrm{~h}$.

Body weight was recorded and safety was monitored by documentation of adverse events and recording of vital signs at each visit. In addition, urine analyses (including pregnancy tests) and routine serum chemistry measurements and blood cell counts were also conducted at each visit. Standard clinical chemistry measuremerts and blood cell counts were conducted at the certified central laboratory of the University Hospital Maastricht, The Netherlands.

\section{PEG-OB}

Modification of proteins through covalent linkage of polyethylene glycol polymers to the protein has resulted in reduiced immunogenicity and increased serum half-life for a number of proteins (30). Recombinant native human leptin, expressed and purified from Escherichia coli, was chemically conjugated to a species of branched polyethylene glycols (PEG) with an average molecular weight of $42 \mathrm{kDa}$ in a $1: 1$ ratio. The result was a globular PEG-native human leptin polymer (PEG-OB) with increased molecular size. $P E G-O B$ at a concentration of $10 \mathrm{mg} / \mathrm{mL}$ was placed in sterile glass vials containing $1.3 \mathrm{~mL}$. Preclinical studies with PEG-OB indicate an extended half-life $(>48 \mathrm{~h})$ and efficacy for reduction of food intake and body weight in animals (31). A previous study in obese male subjects showed sustained elevated blood concentrations following weekly sc dosing of PEG-OB in humans. Mean peak serum PEG-OB concentrations were achieved $72 \mathrm{~h}$ after dosing followed by a return to the elevated pre-dose concentrations after 1 week (32).

\section{Assays}

Plasma LH was measured in each sample in duplicate by an immunofluorimetric sandwich assay (IFMA method, Autodelfia, Perkin Elmer, Turku, Finland) which has a sensitivity of $0.01 \mathrm{U} / \mathrm{L}$ and within-assay $\mathrm{CV} \leq 3 \%$. Concentrations of FSH, PRL, $17 \beta$-estradiol, total testosterone, TSH, GH, IGF-1, insulin, cortisol, and DHEA-S were all determined at a certified laboratory.

Insulin was measured by ELISA (Mercodia insulin ELISA; Mercodia AB, Uppsala, Sweden), and total leptin (endogenous leptin plus PEG-OB) as described previously (32).

\section{Anallytical techniques}

Deconvolution analyses was used to estimate the half-life of $L H_{n}$ secretory-burst frequency (pulses $/ 15 \mathrm{~h}$, before GnRH administration), and mass released per burst (IU/L) before $(15 \mathrm{~h})$ and after $\mathrm{GnRH}$ administration $(3 \mathrm{~h})$. A waveform-independent deconvolution analysis was used to calculate mean and nadir $\mathrm{LH}$ secretion (33). Approximate entropy analysis was applied as a model-free measure of the feedbackdependent regularity of $\mathrm{LH}$ rellease patterns (34). 


\section{Statisticall analyses}

Differences between placebo treated and PEG-OB treated deconvolution measures were assessed using a paired two-tailed nonparametric (Wilcoxon) test. Mean (15-h) concentration values were compared via paired two-tailed Student's t-testing. Data were log-transformed before analysis if necessary. Computations were performed using SPSS 10 for Windows (SPSS Chicago, IL, USA). All statistical tests were two-sided and significance was defined as $P<0.05$. All data are presented as mean $\pm S E M$, unless otherwise indicated.

\section{Results}

The characteristics of the subjects before the intervention are presented in Table 1 . Body weight, BMl, percentage body fat, leptin, and insulin concentrations were low at baseline. Body weight did not change significantly between the two admissions (52.2 $\pm 2.0 \mathrm{~kg} \mathrm{vs} .52 .4 \pm 2.0 \mathrm{~kg}$ ). The most common adverse events were injection-site ecchymosis, pruritis and pain which occurred with similar frequency during both interventions. Vital signs, screening chemistry or hematologic assessments, and urine analyses did not change.

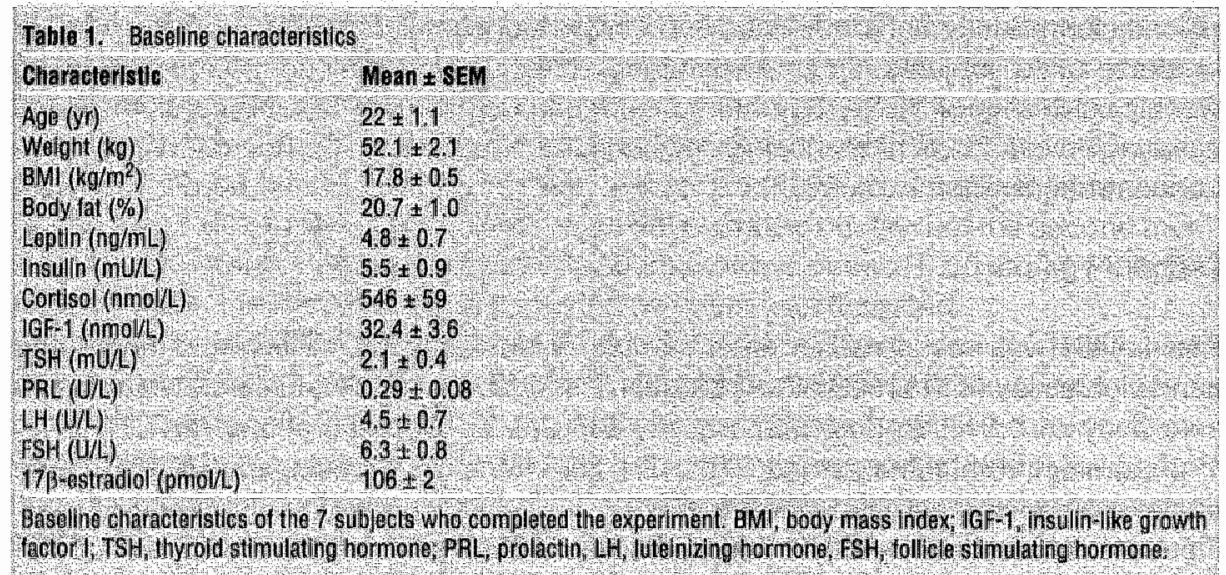

\section{Pulsatile LH secretion}

The $15-h$ pulsatile LH profiles measured in the follicullar phase of the menstrual cycle of the 7 subjects during the two admissions are illustrated in Figure 1. Quantitative changes in specific attributes of deconvolution-estimated LH secretion and half-life are surmmarized in Table 2. Exposure to PEG-OB for 10 days decreased mean and integrated concentrations of $\mathrm{LH}$ by approximately $9 \%$ (respectively $P=0.018$ and $P=$ $0.015)$ by rediucing the mass of $\mathrm{LH}$ secireted per burst $(P=0.018$; Figure 2$)$. The number of LH secretory pulses and mean LH interpulse interval were not affected. The 12-h LH production rate decreased significantly $(P=0.028)$. $\mathrm{LH}$ ApEn ratio $(1,20 \%)$ 

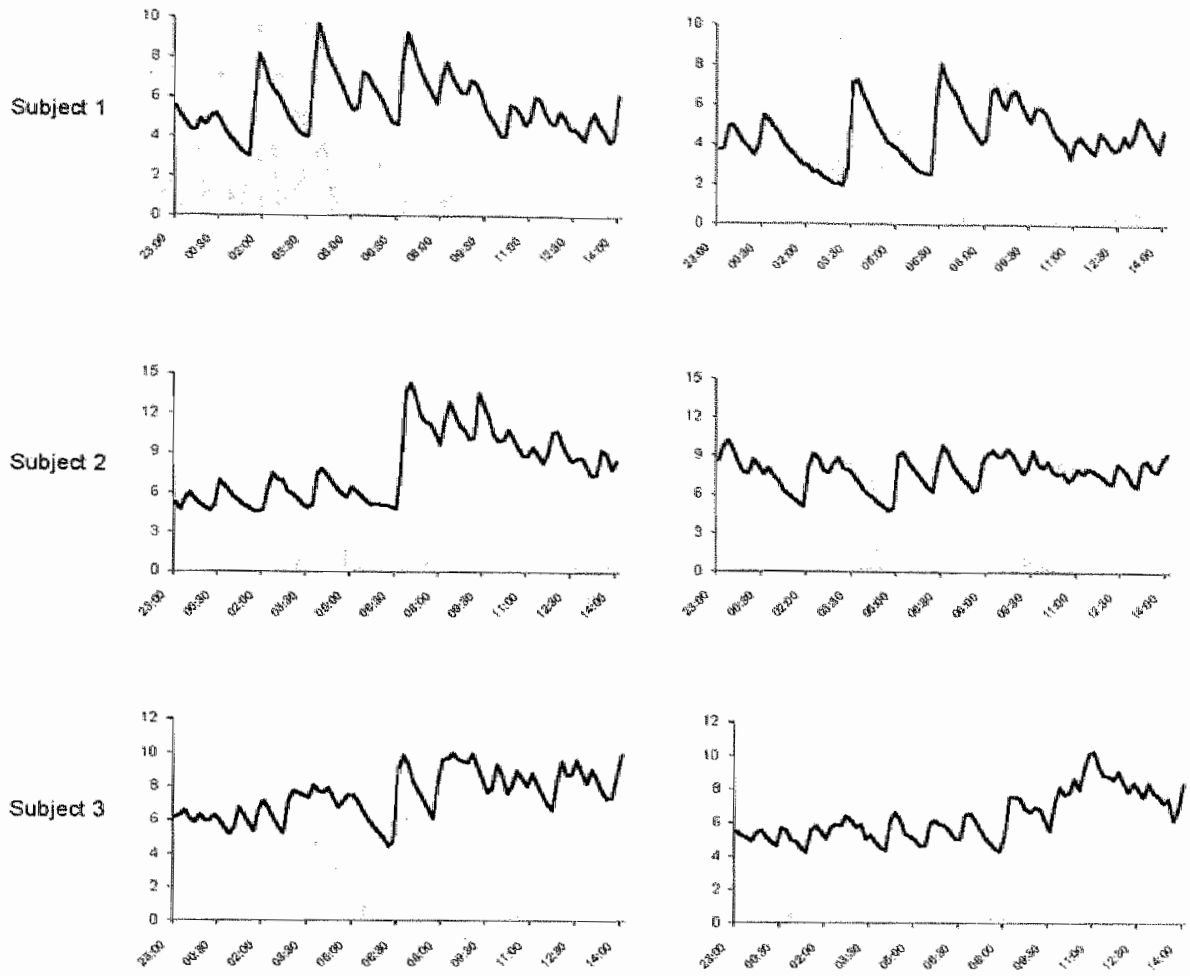

Subject 4
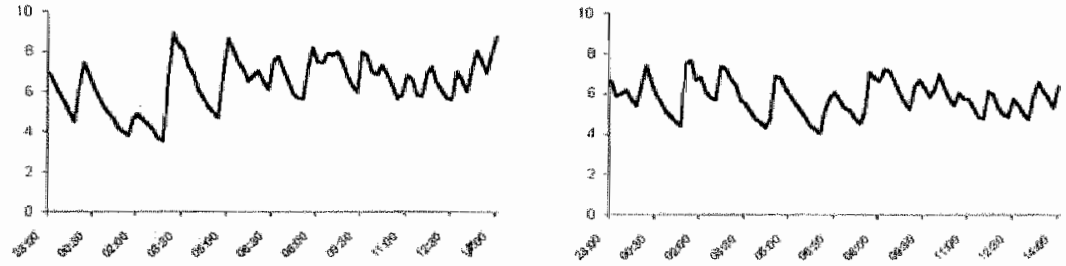

averaged $0.749 \pm 0.047$ during the placebo treatment and $0.727 \pm 0.069$ during PEG-OB treatment $(P=N S)$. However, 6 of 7 women had a decrease in LH ApEn with PEG-OB treatment consistent with more orderly $L H$ release patterns.

GnRH injection elicited peak LH concentrations after 28.6 12.6 min (placebo) and $30.0 \pm 2.2 \mathrm{~min}$ (PEG-OB, $P=N S$ ). Integrated LH responses were also comparable at $2835 \pm 647$ vs. $3259+851$ UU/L.min, respectively. 

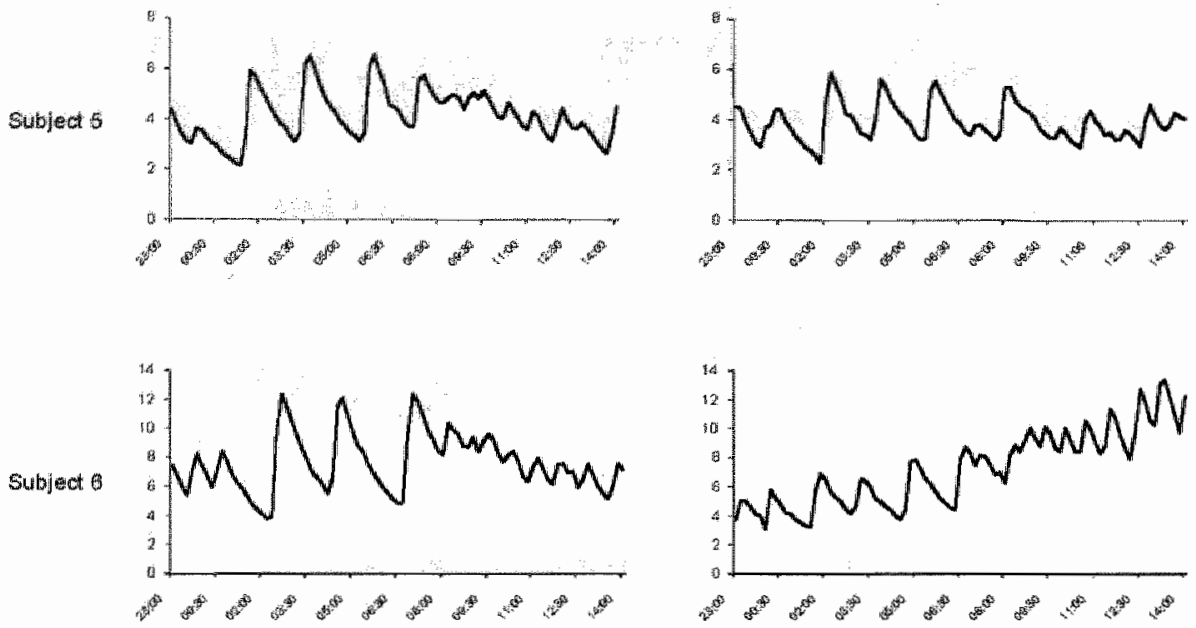

Subject 7
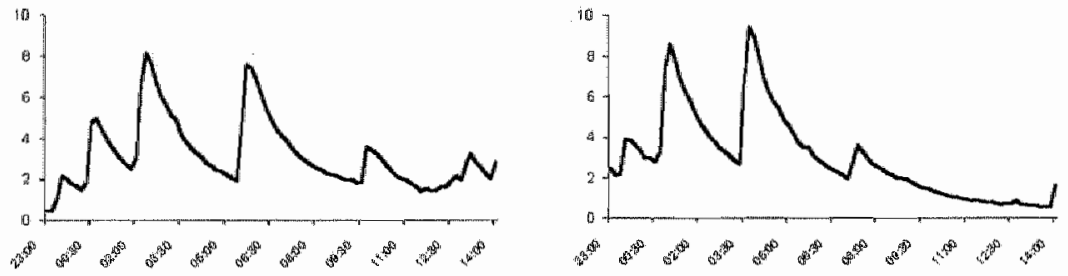

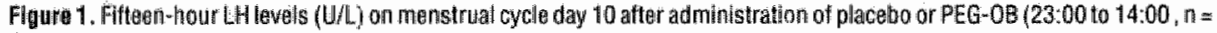
7). Total lêptin $=$ endogenous leptin plus PEG-OB.

\begin{tabular}{|c|c|c|c|}
\hline LH outibura & Belore traatment & Afier troathont & Pralue \\
\hline 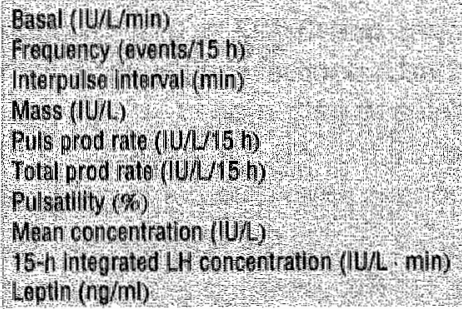 & $\begin{array}{l}0.0096+0.0023 \\
16+17 \\
58+38 \\
357+0.37 \\
57+67 \\
66+66 \\
86+30 \\
606+0.69 \\
5400+626 \\
51+0.8\end{array}$ & 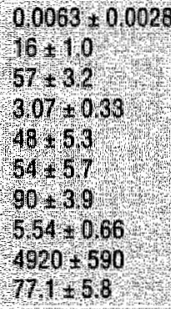 & 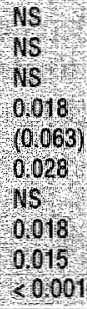 \\
\hline
\end{tabular}




\section{Other hormones}

Plasma (15-h mean) concentrations of $\mathrm{FSH}_{3} \mathrm{PRL}, 17 \mathrm{\beta}$-estradiol, total testosterone, TSH, GH, IGF-1, insulin; cortisol, and DHEA-S on both study days are shown in Table 3. None changed with intervention.

Ten days after the PEG-OB treatment fasting serum concentrations of total leptin (endogenous leptin plus $P E G-O B)$ ranged from 51 to $100 \mathrm{ng} / \mathrm{mL}(P<0.001 \mathrm{vs}$. placebo $)$.

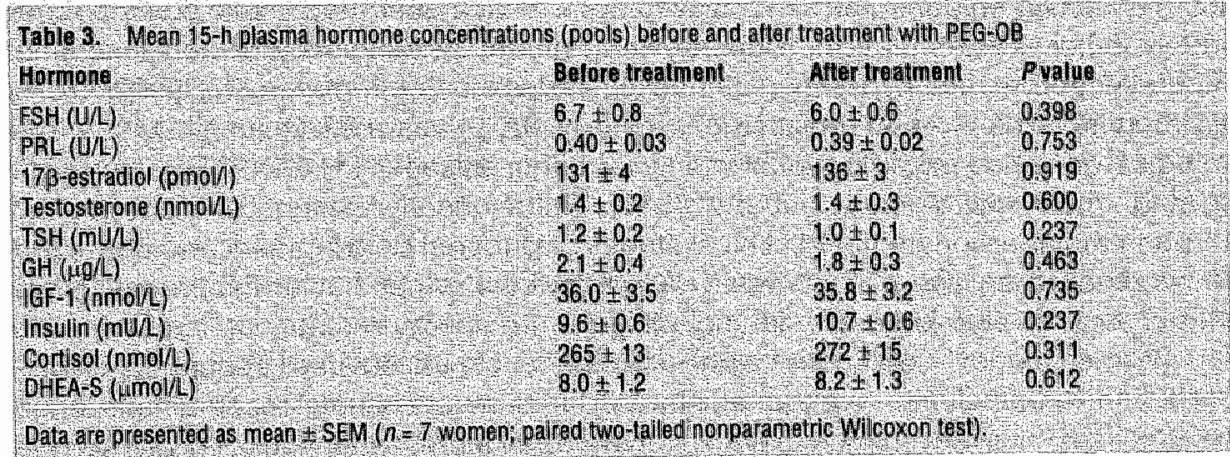
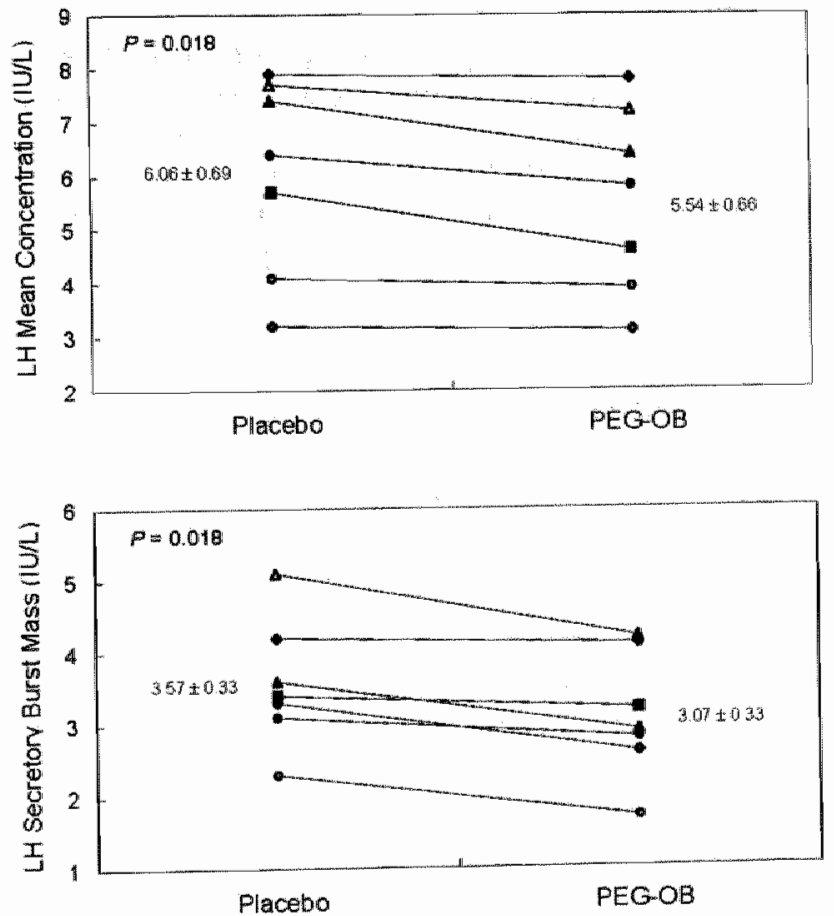

Figure 2 Specific deconviolution-calculated LH secretory characteristics of 15-h plasma LH concentration profiles in young, healthy undenweight women $(n=7)$ studied in the mid- to late follicular phase of the menstrual cycle 10 days after administration of placebo or PEG-OB. 


\section{Discussion}

This study demonstrates that pharmacologically elevated leptin concentrations significantly decrease mean and integrated concentration of $\mathrm{LH}$ by reducing the mass of $\mathrm{LH}$ secreted per burst and 15- $\mathrm{h} \mathrm{LH}$ secretion rate in underweight and otherwise healthy young women.

Conflicting reports exist regarding the effect of peripheral infusion of leptin during a short-term fast in male non-human primates. For instance, reversal of the inhibitory effects of fasting on gonadotropin release has been demonstrated in one study but not in two other studies (22-24). Patlents with total leptin deficiency or non-functional leptin receptors are hyperphagic, obese, and sexually immature (7,17-19). After 24 -months of daily leptin replacement therapy, an 11 year old obese girl with a mutated ob gene had multiple synchronous nocturnal pulses of $\mathrm{LH}$ and $\mathrm{FSH}$, which suggested the onset of early puberty $(9,35)$. Subsequently, the patient progressed through the appropriate timed clinical stages of pubertal development and started to menstruate at an age of 12.1 years. Albeit indirect, other human ieptin-deficiency states such as anorexia nervosa (including severe energy restriction), hypothalamic amenorrhea, lipodystrophy, and highly trained female athletes are frequently associated with hypothalamic hypogonadlism (20). In a recent study, recombinant leptin treatment in women with hypothalamic amenorrhea increased mean $\mathrm{LH}$ levels and $\mathrm{LH}$ pulse frequency after two weeks and increased maximal follicular diameter, the number of dominant follicles, ovarian volume, oestradiol levels, and improved menstrual cyclicity over a period of three months (36). Furthermore, seven female patients with lipodystrophy were treated with a replacement-dose of leptin for 4 months, which improved menstrual cyclicity and increased oestradiol concentrations (37). In addition, our previous study demonstrated that weekly subcutaneous administration of PEG-OB to severe energy-restricted healthy overweight men not only led to significant additional weight loss but also attenuated the drop in weight loss-adjusted mean $\mathrm{LH}$ concentrations (38). In agreement with these results, a replacement dose of recombinant methionyl human leptin during acute fasting restored $L H$ pulsatility characteristics and testosterone concentrations (25). Together, these observations implicate that leptin deficiency is responsible for the reduced LH secretion and impaired reproductive function accompanying these conditions.

The current outcomes indicate that 10 days of exposure to exogenous leptin decreased LH pulsatility in healthy young underweight women during the follicular phase. LH secretion in response to a maximal dose of exogenous GnRH remained unchanged, which indicates that gonadotrope secretory capacity (but not necessarily sensitivity) is preserved. The PEG-OB intervention did not alter (15-h mean) concentrations of the thyrotropic, corticotropic, or somatotropic hormones.

Studies using median-eminence arcuate nucleus explants from adult rats indicate that leptin exposure stimulates GnRH release at low, but inhibits GnRH release at high concentrations (39). Comparable data were obtained using an immortalized GnRH-secreting neuronal cell line (40). Although previous studies suggest a direct effect of leptin on endogenous GnRH secretion, most double-labeling studies fail to demonstrate the expression of full-length leptin receptors in GnRH neurons $(22,41)$. Thus, leptin may act indirectly, such as via internuncial neurons. Other studies also support concentration-dependent actions of leptin $(39,42)$. For example, female transgenic skinny mice overexpressing leptin exhibit late-onset hypothalamic 
hypogonadism after an accelerated puberty (43). Also female A/a mice that develop hyperleptinemia at older ages, manifest infertility due to hypothalamic dysfunction (44). However, male mice of both models are unaffected. Moreover, leptin does not normalize fasting-induced hypogonadism in the immature male thesus monkey (23). Collectively, these findings could indicate that chronic hyperleptinemia downregulates hypothalamic leptin signal pathways that maintain reproduction. thereby leading to hypothalamic hypogonadism. This action may be predominant to the female.

Recombinant methionyl human leptin therapy designed to mimic the normal diumal variation in leptin levels improved reproductive function in women with hypothalamic amenorrhea (36). In contrast, the pharmacokinetic nature of long-acting PEG-OB used in our study led to continuous hyperleptinemia and disruption of the normal physiological secretory rhythms of leptin which might have resulted in the lower mean, integrated and pulsatile LH release secondary to desensitization of the GnRH-secreting neurons.

Obese women often exhibit anovulatory cycles and infertility, with variable impaired $\mathrm{LH}$ secretion in response to $\mathrm{GnRH}$, suggesting hypothalamic-pituitary dysfunction (45). Leptin concentrations are elevated in obese compared with lean individuals and correlate positively with fat mass (46). In addition, obesity is associated with blunted diurnal excursions and dampened pulsatility of leptin $(47,48)$. Thus, one might speculate that the continuous hyperleptinemia present in obesity could be involved in the impaired reproductive function present in this condition. However, the exact role of pheripheral leptin excess in the reproductive dysfunction associated with obesity has not been established.

In conclusion, we demonstrated that hyperleptinemia induced by exposure to PEG-OB is associlated with lower mean; integrated and pulsatile LH release in healthy young underweight women. On the basis of the present study and earlier data, we postulate that gender, mechanisms and/or duration of weight loss, and leptin concentrations and/or pulsatility determine GnRH/LH secretion in the human. Further clinical investigation will be required to explore this inference.

\section{Acknowledgments}

We thank Hoffmann-La Roche Inc. for kindly providing pegylated human recombinant leptin (PEG-OB). We also wish to express our sincere appreciation to Roy Langeveld for his commitment and assistance during this study. Finally, we greatly acknowledge the co-operation, patience, and contributions of all of our subjects.

\section{References}

1. Cameron, J,L. 1996. Nutritional determinants of puberty. Nutr Rev. 54:S17-S22.

2. Van der Spuy, Z.M. 1985. Nutrition and teproduction. Cim Obstef Gynaecol. 12:579-604.

3. Wade, G.N., Schneider, J.E., and Li, H.Y. 1996. Control of fertility by metabolic awes.. Am I Physiol. 270:E1-E19.

4. Januratanasirikul, S., Mo-suwan, L., and Lebel, L. 1997. Growth pattem and agle at menarche of obese girfs in a transitional society. I Pediatr Endocrinol Metab. 10:487-490. 


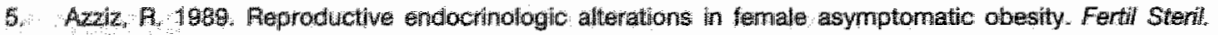
$52.709-725$.

6. Zhang, Y, Proenca, R., Maffel, M., Barone, M., Leopold, $L$, and Fredinan, J.M. 1994. Positional cloning of the mouse obese gene and its human homologue. Nature. $372,425-432$.

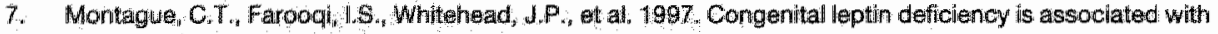
gewere garly onset obesiby in humans. Neture. 387.903 .908 .

8. Pelleymounter, M.A, Cullen, M,J, Baker, M.B, et al. 1995 . Efects of the obese gene product on body woight regulation in ob/ob mice. Science, $269: 540-543$.

9. Faroogi, $1.5 .$, debb. 5 A. Langmack, 9 , al 1999. Effects of recombinant leptin therapy a child with congenital leptin deficiency. N Engl J Aed. 341;879-884.

10. Ahima, F.S. Prabakaran, D., Mantzoros, $C$. et all. 1996. Role of leptin in the neuroendocrine response to fasting. Nature. $382250-252$.

11. Flier 4.8 .1998 Clinical revew 94 . What's in a name? In search of leptin's physiologic role $J$ Clin Endocrhor Metab, 83:1407-1413,

12. Chethab, F, L Lm M.E.g and LU, R. 1996. Correction of the sterility defect in homozygous obese fernale mice by treatment with the human recombinant leptin. Nat Gonet: 12:318-320.

13. Mounin, $K, L{ }_{i}, A$, and chehab, FF, 1997 . Leptin treatment rescues the sterility of gemetically obese ob/ob males. Endocrinalogy, 138:1190-1193.

14. Nagatand, S., Guthikonda, P., Thompsion, R.C., Tsukarnura, H., Maeda, K.I. and Foster, D. L. 1998. Evidence for GnPH regulation by leptin: leptin administration prevents reduced pulsatile $\mathrm{LH}$ secretion during fasting, Nauroendoctinolagy, 67,370-376.

15. Carro, E, Pinilla L., Secane, LM., et al 1997. Influence of endogenous leptin tone on the estrous cycle and luteinizing hormone pulsatility in female rats. Neuroencochnology. $66,375-377$,

16. Gruez, N.M., Lalacui, M., Plerroz, D.D. at al. 1998. Chronic administration of leptin into the lateral wentricle induces sexuel maturation in severely food-restricted female rats. J Neuroendocrinol. 10:627-633:

17. Strobet. A, Hssad, T, Camoin, $L_{n}$ Ozata, M, and Strosberg A.D. 1998. A leptim missense mutation associated with hypogonadism and morbid obesity. Nat Genet. 18:213-215.

18. Ozata, M., Ozdemir, 1.C., and Licinio, J.1999. Human leptin deficiency caused by a missense mutation: multiple endocrine defects, decreased sympathetic tone, and immune system dysfunction halicate new targets for leptin action, greater central than peripheral resistance to the effects of leptin, and spontaneous correction of leptin-mediated defects. J Ckin Endocrinol Metab. 84:3686-3695.

19. Clement, $K$. Vaisse, $C_{0}$, Lahlou, $N_{\text {, }}$ ot all. 1998. A mutation in the human leptin receptor gene causes obesity and piltuitary dysfunction. Nature. 392:398-401.

20. Hirmins-Hagen, J. 1999, Physiological roles of the teptin endocrine system: differences between mice and humans. Crit Rev Clin Lab Sci. 36:575-655.

21. Andreelli, F.g Hanaire Broutin, H., Laville, M., Tauber, J.P., Riou, J.P., and Thiwolet, C. 2000. Normal reproductive function in leptin-deficient patients with lipoatropic diabetes. J Clin Endocrinol Metab. 85:715-719.

22. Finn, P.D., Cunningham, M.J., Pau, KY, Spies, H.G., Clifton, D.K., and Steiner, R.A. 1998. The stimulatony effect of leptin on the neuroendocrine reproductive axis of the monkey. Endocrinology, 139:4652-4662.

23. Lado Abeal, J., Lukyanenko, Y.O., Swamy, S., Hermida, R.C., Hutson, ل.C., and Norman, R.L. 1999. Short-tierm leptin infusion does not affect circulating levels of LH, testosterone or cortisol in food-restricted pubertal male thasus macaques. Glin Endocrinol Oxf. 51:41-51.

24. Lado Abeal, J. Hickox, J.R., Cheung, T.L., Voldhuis, J.D." Hardy, D.M, and Norman, R.L. 2000. Neuroendocine consequences of fasting in adult malle macaques: effects of recombinant rhesus macaque leptir infusion. Neuroendocrinology. 71:196-208.

25. Chan, J.L., Heist, K., DePeoli, A.M. Vetdhuls, J.D, and Mantzoros, C.S, 2003. The role of falling leptin levols in: the neuroendocrine and metabolic adaptation to short-term starvation in healthy men. I Clin invest. $111: 1409-1421$.

26. Licimid, J., Negrao, A.B., Mantzoros, C., al 1998. Synchronicity of frequenty sampled, 24-h concentrations of clrcullating laptin, luteinizing hormone, and estraetiol in healthy women. Proc Nall Acad Sci USA. $95: 2541-2546$

27. Westerterp, K.R., Wouters, L., and van Marken Lichtenbelt, W.D. 1995. The Maastricht protocoll for the measurement of body composition and energy expenditure with labeled water. Obas Res. 3(Suppl 1): $49-57$.

28. Sirt, W.E, 1961. Body composition from fluid spaces and density: analysis of methods, In, J. Brozek, and A. Henschel, eds. Techniques for measuring body composition. Washington DC: National Academy of Science. 223-244.

29. Gamer, D.M., and Gartinkel, P. E. 1979. The Eating Attitudes Tesit: an index of the symptoms of anorexia nerwose. Psychol Med. 9:273-279.

30. Nucci, M.L., Shorr, R., and Abuchoweski, A. 1991. The therapeutic value of poly(ethylene-glycol)-modified proteins. Adv Drug Delivery Rev. 6:133-151. 


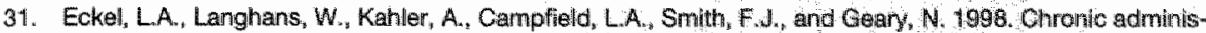
tration of $O B$ protein decreases food intake by selectwely reducing meal sice in famale rats. Am al physhol. 275:R186-R193:

32. Hukshorm, C.J., Saris, W.H.M., Westerterp Plantenga, M.S, Farid, A.R., Smith, Fu, and Campfield, LA. 2000. Weokly subcutaneous pegyated recombinant native human leptin (PEGMOB) administration in obese men. J Clin Endocrinol Metab. 85:4003-4009.

33. Veldhuis, J.D., and Johnson, M.L. 1992. Deconvolution analysis of hormone data. Methods Enzymol. $210.539-575$

34. Veldhuis, J.D., and Pincus, S.M. 1998. Orderliness of hormone release palternat a complementary meesure to conventional pulsatille and circadian analyses. Eur J Endocrinol 138.358-362.

35. Farooqi, L.S., Matarese, G., Lord, G.M., et al. 2002. Benefficial effects of leptin on obesity; T cell hyporesponsiveness ${ }_{n}$ and neurcendocrime/metabolic dysfunction of humen congenital leptim deficiency. $J$ Clin Invest. $110: 1093-1103$.

36. Welt, C.K. Chan, J.L., Bullen, J., et al. 2004. Recombinant human leptin in women with hypothalarmic amenorthea. N Engl i Med. 351:987-997.

37. Oral, E.A., Fuiz, E. Andiewelt, A., et al. 2002. Effect of leptin repllacement on pitultary hormone regulation in patients with severe lipodystrophy. I Clin Endocrinor Metab. $87: 31$ 10-3117.

38. Hukshom, C.U., Menheere, P.P., Westerterp-Plantenga, M.S., and Saris, W.H. 2003. The effect of pegylated human recombinant leptin (PEG-OB) on meunoendocirine adlaptations to semi-starvation in ovepweight men. Eur J Endocrinol. 148:649-655.

39. Yu, W.H., Kimura, M., Walczewska, A, Karanth, $S_{2}$ and McCann, S.M. 1997. Role of leptin in hypotha lamic-pituitary function. Proc Natl Acad Sci USA, 94"1023-1028.

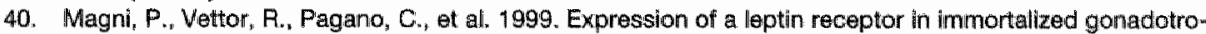
pin-releasing homone-secreting neurons. Endocrinology. 140:1581-1585.

41. Hakansson, M.L., Brown; $H_{n}$ Ghilardi, N., Slkoda, R.C. and Meister, B, 1998. Leptín receptor immunoreactivity in chemically defined target neurons of the hypothalamus. U Neuroscl. $18: 559-572$.

42. Ahima, R.S., Kelly, J.. Eimquist, $J$ J.K., and Flier, J.S. 1999. Distinct physiologic and neuronal responses to decreased leptin and mild hyperleptinemia. Endocrinology. 140:4923-4931.

43. Yura, S., Ogawa, Y., Sagawa, N., et al. 2000. Accelerated puberty and llate-onset hypothatamic hypogonadism in female transgenic skinny mice overexpressing leptin. $J$ Clin Invest. 105:749-755.

44. Granhoim, N.H., Jeppesen, K.W., and Japs, R.A. 1986. Progressive infertility in female lethal yeillow mice (Ay/a; strain C57BL/6.). J Fieprod Fentil. 76:279-287.

45. Bouwattier, $C_{.}$Lahlou, $N_{1}$, Roger, $M_{*}$ and Bougneres, $P_{n}$ 1998. Hyperleptinaemia is associated with irmpaired gonadotrophin response to GnRH during late pubeirly in obese girls, not boys. Eur J Endocrinol. 138:653-658.

46. Considine, R. V. Sinha, M.K., Heiman, M.L., et al. 1996. Senum immunoreactive-leptin concentrations in nomal-weight and obese humans. N Engl i Med. 334:292-295.

47. Sinha, M.K., Sturis, J., Ohannesian, J, et at. 1996. Ultradian oscillations of leptin secretion in thumans. Biochem Biophys Res Commun. 228:733-738.

48. Saad, M.F. Fiad-Gabrie, M.G., Khan A.g $_{\text {. }}$ et al. 1998 . Diurnal and utradian rhythmicity of plasma leptin: effects of gendier and adiposity. $J$ Clin Endocrinol Metab. 83:453-459. 
CHAPTER 9

General Discussion 


\section{Díscussion}

Since the discovery of leptin at the end of 1994, the view of its physiological role in humans has constantly evolved and broadened based on new data and theoretical considerations. The aim of our research presented in this thesis was to test these new insights using different approaches and experimental protocols,

In this general discussion, the major findings obtained in our studies will be discussed and integrated in the existing literature.

First, the physiological role of leptin as a regulator of body weight, energy balance, and metabollic profile will be reviewed. Secondly, the neuroendocrine effects of leptin administration during several experimental conditions will be considered against the proposed physiological mechanisms. Finally ${ }_{n}$ the hypothesis that elevated leptin levels underlie the low-grade proinflammatory state in human obesity is discussed.

\section{Leptin and the human energy balance}

A fundamental advance in our understanding of endocrine control of energy balance and body weight came with the discovery of leptin (1). The leptin pathway appeared to be the long-sought peripheral signal pathway from the adipose tissue to the brain involved in the regulation of feeding and energy balance. Due to the fact that leptin was discovered during obesity research, most investigators initially focused on the implications of leptin as an anti-obesity hormone. Soon after the cloning of the ob gene, leptin-deficient $a b / o b$ mice were injected with recombinant leptin, which led to weight loss due to decreased food intake and increased energy expenditure (1-4). This outcome supported the original concept that leptin's function was to control weight-gain by reducing food intake as its concentration in blood rises with increasing adiposity. This impressive effect of leptin administration to ob/ob mice raised expectations that human obesity could also be a (relative) leptin-deficient state that could possibly be treated with exogenous leptin. However, several early population studies failed to demonstrate mutations in the human gene encoding for leptin (5-7). In contrast, after the development of radioimmunnoassays for human leptin it became clear that in the majority of obese individuals elevated serum leptin levels are found (8), which apparently falled to prevent obesity. From these results, the hypothesis of leptin resistance or reduced sensitivity to leptin in human obesity emerged, comparable to insulin resistance in type 2 diabetes $(9,10)$. The observation that higher doses of recombinant leptin are required to affect feeding behavior "metabolism, and body fat in diet-induced obese mice compared to normal mice supported this concept of leptin resistance (4). These early results suggested the possibility that high therapeutical closes of human recombinant leptin might be able to overcome the presumed increased leptin resistance present in obese subjects and result in reductions in body weight.

In the experiment described in chapter 3, we studied the effect of weekly administration of $20 \mathrm{mg}$ PEG-OB on body weight loss, energy expenditure, and metabolic profile in obese men during mild hypocaloric conditions (deficit: $2.0 \mathrm{MJ} / \mathrm{day}$ ) for 12 weeks. Treatment with PEG-OB sustained elevated levels of both PEG-OB and leptin and increased post-absorptive satiety throughout the treatment period without an effect on weight loss (11). Despite sustained elevated levels of both PEG-OB and leptin throughout the treatment period, no effect was observed on weight loss or energy ex- 
penditure measured by a respiration chamber. Other biologlical effects of $\mathrm{PEG}-\mathrm{OB}$ or leptin shown in animal studies were also not observed in this study. Especially, wo failed to demonstrate any effect of $\mathrm{PEG}-\mathrm{OB}$ on metabolic parameters such as triglycerides, glucose or insullin concentrations, and insulin sensitivity. However, PEG-OB treatment was found to be well tolerated and safe in these subjects.

After the conclusion of our first study, the results of the clinical trial conducted by Heymsfield and coworkers became available (12). A significant dose-response relationship with weight and fat loss in both lean and obese humans was demonstrated in this study. The dose used in our first trial only led to about $60 \%$ of the maximum serum leptin concentrations observed in the most effective highest dose cohorts of the study of Heymsfield. Hence, the administration of a higher therapeutical dose of PEG-OB might be able to reduce body weight in obese subjects. To test this hypothesis, the study described in chapter 4 explored whether weekly administration of a higher dose of PEG-OB (60 mg per week) was able to induce additional weight loss and metabolic changes in obese male and female subjects on a mild hypocaloric diet (deficit: 3.2 $\mathrm{MJ} /$ day) for 8 weeks. The results of our second study clearly showed that even exposure to the increased dose of PEG-OB (300\%) failed to promote additional weight loss over caloric restriction despite the augmented leptin levels. Furthermore, no treatment effects on the levels of glucose, insulin (including estimated insulin resistance), and triglycerides were observed.

The outcome of our first two clinical studies showed that even supraphysiological leptin concentrations failed to significantly affect body weight, which implicates that humans are highly leptin resistant. This observation was, however, consistent with an alternative view of the physiological role of leptin, which emerged in 1998 (13). The group of Flier hypothesized that the widespread occurrence of leptin resistance (14-16) might reflect the fact that the inability to store energy efficiently at times of abundance is evolutionarily disadvantageous. These investigators postulate that the falling concentration of leptin during starvation and its effects may constitute part of the thrifty genotype, a set of genes postulated to promote survival during periods of insufficient energy intake in human evolution by increasing the efficiency of energy storage. The fact that during starvation leptin levels drop rapidly and out of proportion to body adiposity changes appears to support this hypothesis $(17,18)$. In this updated thrifty genotype concept, the drop in leptin concentrations during periods of limited energy intake might signal the brain to initiate the complex neural, metabolic, neuroendocrine, and behavioral responses thought to have survival value in periods of inadequate energy intake. In addition, this concept suggests that an effective adipostatic role of leptin would subvert the thrifty genotype by limiting the capacity of energy storage during periods of abundance, which would result in reduced survival in subsequent periods of food shortages. Stated differently, evolution would favor resistance to leptin action (leptin resistance) when leptin concentrations are rising or high during periods of sufficient energy intake/storage. Furthermore, they speculate that the shape of the biological dose response curve of leptin may depend on the conditions in which a certain species evolved.

In 1997, two children (first cousins of Pakistanl origin) were reported who were homozygous for a deletion of a single guanine nucleotide in codon 133 which led to a frameshift mutation ( $\triangle \mathrm{G} 133$ ) in the ob gene that resulted in undetectable circulating 
leptin levels (19). This frameshift mutation results in a truncated protein with 14 aberrant amino acids at the $\mathrm{C}$-terminus that cannot be secreted but accumulates intracellularly, as a consequence of misfolding/aggregation, and is subsequently degraded by the proteasome (20). Recently, another unrelated leptin-deficient child, also from a consanguineous family of Pakistani origin was identified with the same mutation (21). In a highly consanguineous Turkish family, four adult homozygous members were described with a missense mutation $(C-T)$ in codon 105 (Arg $\left.{ }^{105} \mathrm{Trp}\right)$ in the leptin gene which also results in a protein that cannot be secreted (22). One year after the description of human congenital leptin deficlency, three sisters of a consanguineous family of Kabillan origin were reported in which a $G \rightarrow A$ substitution in the splice donor sitte of exon 16 led to a truncated leptin receptor lacking both transmembrane and intracellular domains (23). Both leptin (including free leptin) and these mutant receptors were found to circulate at a high level and the receptors were capable of binding leptin.

The hypothesis proposed by Flier et al. provided an expllanation for the ineffectiveness of a high dose PEG-OB in our obese individuals on a mild hypocaloric diet as well for the fairly moderate results of the Heymsfield trial (12). Furthermore; an extension of this hypothesis is that exogenous leptin should affect energy regulation when administrated during severe energy restriction. Therefore to test this hypothesis, we executed a third, randomized, double-blind, and placebo-controlled study described in chapter 5 to investigate whether elevated leptin levels using PEG-OB affected weilght loss or body-composition, changes in energy expenditure, appetite, and metabolic proflle during semistarvation induced by a very low calorie diet (2 $\mathrm{MJ} /$ day) in healthy overweight male subjects. Weekly subcutaneous administration of $80 \mathrm{mg}$ PEG-OB led to significant additional weight loss and reductions in appetite after 6 weeks of treatment and severe energy restriction but did not affect changes in energy expenditure, body composition , and other metabolic parameters.

A reduction in appetite before breakfast under negative energy balance conditions was present in the PEG-OB treated group at the end of this study. Since the decrease in energy expenditure was not different in the two groups, it is concelvable that the additional weight loss caused by PEG-OB administration was largely attributable to recuctions in appetite resulting in better compliance with the dietary restriction. In line with this hypothesis, the increase in body weight was larger in the PEG-OB group compared to the placebo group during 8 weeks of follow-up after cessation of pharmacological treatment (24). This suggests that the need for lifestyle changes necessary for weight maintenance after weight lass was limited in the PEG-OB group due to the suppression of appetite during therapy. In rodents, the absence of leptin (e.g. the obese ob/ob mouse) results in hyperphagia due to an increase in meal size (25). The ICV administration of leptin to normal rats maintained ad libitum inhibits feeding through a specific reduction of meal size whereas meal frequency and meal duration were unaffected (26-28). This effect started only after a lag phase and was long-lasting. Leptin administrated ICV to thesus monkeys had no immediate effect on food intake, but caused a significant and sustained suppression of food intake during the entire following day (29). Interestingly, high dose ICV leptin infusion in mice resulted in complete depletion of visible adipose tissue but subsequently did not lead to a complete suppression of food intake (30). These mice consumed enough food to maintain 
their lean body mass and did not waste away. Thus, a substantial part of the food intake in mice appears to be leptin independent. In line with these experimental results, chronic hyperleptinemia in transgenic mice overexpressing leptin in the liver resulted in complete disappearance of white and brown adipose tissue over the long term (31). In addition, the dose-response curve for this partial inhibition of food intake by leptin is very steep and might function as an on-off switch. This observation combined with the findings of our third study seem to support the hypothesis that low/falling leptin levels might serve as a signal of starvation and induce hunger. The fact that hyperleptinemia normally present in obese humans and the supraphysiologilical leptin levels reached in our first two trials did not result in weight loss suggests that the shape of the biological dose response curve of leptin is fundamentally different in humans ws. rodents at least at the higher end. However, additional differences between humans and rodents in other feeding regulatory systems cannot be excluded. Recombinant human leptiln administration in a short-term starvation study tended to reduce the increase of food intake during the refeeding phase though no significant effect on hunger or satiety measured by visual analogue scales could be detected (32). Patients lacking leptin or lacking leptin receptors had normal weight at birth but severe obesity rapidly developed within the first months $(19,22,23,33,34)$. These children exhibit marked hyperphagia, are constantly hungry, continually demand food and are disruptive when denied food. Four morbidly abese children, who were congenitally deficient in leptin, were treated with daily subcutaneous injections of recombinant human leptin up to 4 years $(21,34)$. Leptin therapy produced a marked decrease in the amount of food ingested at an ad libitum test meal and subsequent weight loss in all chilldren. These findings were supported by parental reports of a marked amelioration of hyperphagia in the domestic setting. Also a significant increase in the levels of their physical activity was noted. Adult homozygous patients were not eating as voraciously as they reportedly had during their childhood. Physiological replacement therapy with recombinant leptin in three morbidly obese homozygous leptin-deficient adult patients for 18 months resulted in profound weight loss caused by the combination of an initial reduction in food intake followed by a progressive increase in the amount of physical activity (35). Several other syndromes have been associated with very low leptin levels. Females suffering from lipodystrophy, hypothalamic amenorrhea or anorexia nervosa and highly trained female athletes have very low plasma leptin levels. The majority of these patients are not markedly hyperphagic suggesting that these low leptin levels are sufficient to prevent abnormal eating behavior. However, normallzation of serum leptin concentration did significantly reduce caloric intake and body weight, deceased satiation time, increased satiety time, and influenced subjective perceptions of hunger, fullness, and desire to eat in patients with lipodystrophy and hypoleptinemia (36-38). Also females suffering from hypothalamic amenorrhea who were treated with recombinant leptin reported a qualitative decrease in appetite, primarily during the third month of therapy which resulted in a small but significant decrease in body weight (39). A recent clinical trial demonstrated that reductions in leptin concentrations during a lead-in diet period were positively correlated with the body weight loss following leptin treatment (40). Combined with the findings of our third study this suggests that although low or very low leptin levels do no result in overt hyperphagia, they do tend to increase appetite. This concept is supported by the findings in 13 subjects of three unrelated families of Pakistani origin who were heterozygous for a frameshift mutation ( $\triangle \mathrm{G} 133)$ in the ob gene, which resulted in markedlly lower circulating leptin 
concentrations (41). The lower leptin levels in these individuals appeared to be accompanied with an increased prevalence of obesity.

Leptin treatment of normal mice fed ad libitum prevented the decrease in energy expenditure that would normally occur with the leptin-induced reduction in food intake (30) In contrast to rodents, exogenous leptin in our study did not prevent or blunt the physiological fall in energy expenditure, which normally occurs during food deprivation. Two major factors reducing energy expenditure during fasting are the inhibition of the SNS activity and the drop in thyroid hormones. Both fasting-induced effects were blunted in rodents treated with leptin $(42,43)$. Moreover, administration of lleptin directly into the brains of rhesus monkeys acutely activated the SNS suggesting that leptin might also influence energy expenditure in these non-human primates (29). The fact that $P E G-O B$ administration did not disinhibit SNS activity or prevented the fall in thyroid hormones might account for the absence of a stimulatory effect on energy expenditure in this human study. In agreement with our findings, recombinant replacement therapy during a short-term starvation in healthy men did not significantly alter the changes in energy expenditure (32). Also a study executed in never-obese subjects on a weight maintenance regime and another study in obese subjects on a mild hypocaloric diet failed to demonstrate an effect of leptin administration on energy metabolism $(44,45)$. In contrast, yet another study reported reversal of the effects of sustained weight-reduction on energy expenditure by a low dose of exogenous leptin (46). Both patients with total leptin deficiency or non-functional leptin receptors have been shown to have a normal core temperature and normal resting energy expenditure $(19,22,23,33)$. In addition; leptin therapy in two congenital leptin-deficient children failed to affect basal metabolic rate or free-living energy expenditure (measured using doubly labeled water) who were both adjusted for lean body mass (21). Also resting energy expenditure (and lean body mass) remained stable during leptin treatment of two hypoleptinaemic children with Rabson-Mendenhall syndrome (47), Leptin-replacement therapy in patients with lipodystrophy and very low leptin levels led to a decrease in resting metabolic rate most likely secondary to weight loss $(36,37)$. No effect of $\|$ eptin replacement in females suffering from hypothalamic amenorrhea on resting metabolic rate was observed (39). A major drawback, however, of some studies is the fact that the changes in energy expenditure are not adjusted for changes in lean body mass over the treatment period.

The reported conservation of lean body mass in rodents treated with leptin $(3,30)$ was not observed in our study in which both treatment groups lost equal amounts fat free mass after 6 weeks of severe energy restriction. A possible explanation for this discrepancy might be the fact that contrary to rodents, leptin administration in this study in lhumans did not blunt the changes in the hormones known to reduce lean body mass during starvation such as cortisol, testosterone and GH/IGF- $1(42,48)$. A prolonged fast combined with leptin replacement therapy tended to induce weight loss due to small decreases in both fat mass and fat-free mass which supports our results (32). More than $98 \%$ of the weight lost in leptin-deficient children during leptin administration was represented by fat mass (21). Lean body mass increased in all children in keeping with their linear growth with the exception of one child (34). Similarly, leptin replacement therapy in adult congenital leptin-deficient patients resulted in body weight loss preferentially due to loss of fat mass (35). Also no conservation but rather a 
loss of lean body mass was reported in patients with severe lipodystrophy treated with leptin replacement therapy (37). Body weight decreased slightly in females suffering from hypothalamic amenorrhea who were treated with recombinant leptin owing to $a$ simall but significant decrease in body fat and an absence of a change in lean mass (39).

No other metabolic effects of leptin and PEG-OB observed in animal studles were detected in this study $(9,10)$. Most prominent among these were effects on fasting plasma glucose and insulin, oral glucose tolerance, and triglycerides. We failed to observe an additional enhancement of the well-known effects of weight loss on these variables by weekly PEG-OB treatment in the presence of severe energy restriction. However, since the weight loss induced by the energy restriction and negative energy balance decreased fasting plasma glucose and insulin, oral glucose tolerance, and triglycerides, these improvements may have masked the effects of PEG-OB treatment on these variables. Individuals who lack leptin or the leptin receptor appear to exhibit normal fasting glucose, normal cholesterol concentrations, and only moderate impairments in metabolites such as free fatty acids and triglycerides despite their severe obesity $(19,22,23,33,34)$. Four children with congenital leptin deficiency had hyperinsulinemia which was consistent with their age and degree of obesity $(21,34)$. Insulin levels fell gradually after the initiation of leptin treatment in parallel with their loss of fat mass. Similarly, the levels of cholesterol, triglycerides, low density lipoprotein (LDL) cholesterol, and high density lipoprotein (HDL) cholesterol changed in all three subjects. Leptin replacement therapy in adult homozygous leptin-deficient patients led to the resolution of type 2 diabetes in one patient and decreased insulin resistance in two other patients, most likely mediated by their weight loss (35). The main lipoprotein abnormality in this group was reduced HDL cholesterol, a common correlate of excess adiposity. Changes in HDL cholesterol, LDL cholesterol, triglycerides, and apolipoprotein B during the course of treatment were consistent with the effects. of reduced adiposity. These observations suggested that, contrary to rodents, an acute effect of leptin on glucose homeostasis and lipid metabolism does not dominate in humans. Leptin replacement therapy in the low-leptin state of llpodystrophy was shown to improve glycemic control and decrease triglyceride levels (36). This effect appeared to be at least partially independent of the reductions in food intake, In addition, the mean liver volume decreased significantly during treatment, which suggests a decrease in hepatic stores of triglycerides (37). These findings suggested that a lack of leptin contributes to the metabolic abnormalities associated with severe lipodystrophy. The mechanisms by which leptin improves insulin sensitivity in lipodystrophic patients remain unclear although it is proposed that this effect is the result of a marked reduction in hepatic and muscle triglyceride content $(49,50)$. Recently, two siblings with Rabson-Mendenhall syndrome (severe insulin resistance and presumed insulin receptor mutations) were treated with recombinant human leptin for 10 months which resulted in improvement of fasting hyperglycemia, hyperinsulinemia, glucose, and insulin tolerance (47). Unlike lipodystrophic patients, these patients do not exhibit steatosis or hypertriglyceridemia and have normal leptin concentrations for their percent body fat. Several mechanisms by which leptin improves insulin sensitivity in this syndrome were proposed including activation of 5'-AMP kinase or an effect of leptin on IRS2. The discrepancy of the effects of leptin treatment between leptin-deficient individuals and patients with lipodystrophy or the Rabson-Mendenhall 
syndrome on glucose homeostasis and lipid metabolism are intriguing and warrant further investigation.

In summary, increasing evidence to date suggests that leptin predominantly influences the human energy balance through appetite but appears not to be involved in regulating energy expenditure. Both animal and human studies indicate that low or falling leptin levels (as observed during fasting) act as a peripheral signal of starvation; which subsequently increases appetite thereby ensuring survival of the species. At the other end of the spectrum, resistance to the proposed anti-abesity action of high or rising leptin levels is observed in both animals and humans. Even supraphysiological leptin concentrations reached during clinical trials (including our own studles) failed to affect the human energy balance. This widespread occurrence of leptin resistance might reflect the fact that the inability to store energy efficiently at times of abundance is evolutionarily disadvantageous. Contrary to rodents, no selective conservation of lean body mass in humans during weight loss was observed in healthy individuals or genetically leptin-deficient patients. Conflicting reports exist concerning the relationship between leptin and the human metabolic profile (including glucose homeostasis and lipid metabolism). Especially, the marked differences between the effects of leptin therapy in congenital leptin deficiency and patients with severe lipodystrophy or the Rabson-Mendenhall syndrome are intriguing and warrant further investigation.

\section{Leptin effects on the neuroendocrine axes}

Leptin-deficient ob/ob mice show many of the abnormalities seen in starved animals, including decreased body temperature, hyperphagia, decreased energy expenditure (including activity), decreased immune function, and several neuroendocrine changles (51). These observations led to the idea that leptin deficiency is perceived as a state of continuous starvation in $a b / o b$ mice and that the resulting biological response in the presence of food leads to obesity $(13,42)$. Prevention of the characteristic fall in leptin during fasting using exogenous leptin blunted the expected fasting-induced neuroendocrine changes in the gonadal, adrenal, and thyroid axes (42). Fasted wild type mice receiving leptin continued to ovulate, whereas fasted control animals experienced an ovulatory delay (42). In male, non-human primates conflicting reports exist regarding the effect of peripheral infusion of leptin during a short-term fast. Reversal of the inhibitory effects of fasting on gonadotropin release occurred in two studies while no effect was found in two others (52-54). In one study, intravenous replacement with homologous leptin did not reverse the acute changes in growth hormone and cortisol secretion observed with fasting in the adult male macaque (54). However, in another study leptin administration did increase nocturnal concentrations of $\mathrm{LH}$ and $\mathrm{GH}$ in juvenile female thesus monkeys (55).

Starvation or severe energy restriction also rapidly evokes several neuroendocrine adaptive responses in humans (56). In humans, the HPA axis is activated during times of stress, like starvation $(57,58)$. The main products of the HPA axis, cortisol and ACTH, are therefore elevated during a period of fasting. Also the circadian periodicity of cortisol and ACTH secretion are abolished if the stress is prolonged. As starvation is 
a time of stress, the actions of cortisol that relate to the stress response would be advantageous. Furthermore, cortisol promotes the shift to hepatic glucose production that is needed by the CNS when exogenous sources of nutrition are limited. The exact mechanism(s) that drive starvation-associated hypercortisolism remain unknown. Studies of patients with anorexia nervosa suggest that hypercortisolism in this context reflects hypersecretion of $\mathrm{CRH}(59,60)$. In contrary, other studies found reduced $\mathrm{CRH}$ levels during fasting, suggesting that the HPA axis is stimulated by a $\mathrm{CRH}$-independent mechanism (61).

Thyroid hormone economy accompanying total fasting are characterized by a substantial fall in serum total $T_{3}$ and free $T_{3}$ in association with a reciprocal increase in totall reverse $T_{3}\left(r T_{3}\right)$ and free $r T_{3}(62-65)$. Thyroid hormone kinetic studies have shown that the reduction in serum total $T_{3}$ and increase in serum total $r T_{3}$ levels result from decreases in both $T_{3}$ production and $\mathrm{r}_{3}$ metabolic clearance (66). There are conflicting data concerning the changes in serum total $T_{4}$ and free $T_{4}$ in the fasted state in man. Most studies found a decreased total $T_{4}$ level $(65,67,68)$, others found no change in total $T_{4}$ level after a period of fasting $(62,66)$. In contrast, free $T_{4}$ levels seem to increase during starvation (65), or remain normal in humans (67). TSH serum levels are transient suppressed in the initial phase of fasting (69). After a more prolonged fast TSH levels in blood are normal but pituitary responsiveness to TRH is depressed $(65,66)$. TRH expression is also suppressed following caloric restriction (62). It is apparent that the changes in thyroid hormone economy obserwed in fasting reflect alterations in both peripheral thyroid hormone metabolism and central regulatory control of pituitary TSH release. Data from previous studies suggest that fasting inhibits $T_{3}$ production in peripheral tissues by lowering the activity of the enzyme $5^{\prime}$-delodinase type $I$ resulting in a decreased peripheral conversion of $T_{4} t \circ T_{3}(63)$. In addition, it is suggested that the peripheral deiodination of $T_{4}$ to $r T_{3}$ which is biologically inactive, is increased. In contrast, the activity of type II $5^{\prime \prime}$-delodinase in the CNS is maintained. Thus producing a relative hypothyroidism in peripheral tissues to decrease energy demand of the body and at the same time maintaining euthyroidism in the CNS to allow normal brain function during starvation. These findings cannot provide a good explanation of the blunted TSH response to TRH during underfeeding. It is likely that other hormones or CNS factors also modulate the TSH response to TRH (62). Thyroid hormones are important regulators of basal energy expenditure and it is theorized that decreased levels following caloric restriction are an attempt of the body to conserve the energy stores (including the nitrogen stores) as much as possible.

Contrary to rodents, the fasting-induced hypersecretion of $\mathrm{GH}$ in humans is accompanied by a reduction of IGF-11 levels $(70,71)$. GH has direct lipolytic effects (providing fatty acids, the main fuel source during fasting) and indirect anabolic and growth-promoting effects mediated by IGF-1, which is released by the liver through the action of $\mathrm{GH}$. This rise of $\mathrm{GH}$ secretion suggests that fasting suppresses the amount of somatostatin released and concomitantly increases GHRH secretion in the hypothalamus (71). The fasting-induced decrease in IGF-1 levels may also be responsible for GH hypersecretion. It is well recognized that while GH normally stimulates IGF-1, caloric restriction and fasting impose a state of $\mathrm{GH}$ resistance, probably mainly on the level of the liver $(72,73)$. Chronic undernutrition has long been known to lead to stunted linear growth. This phenomenon may be a protective mechanism (mediated by low levels of IGF-1) during periods when calories are scarce, which prevents high metabolic needs. 
It is well established that initiation and maintenance of reproductive function is very sensitive to nutritional status. Decline of reproductive function is one of the most striking effects of starvation. For example, the presence of amenorrhea was already noted in the earliest descriptions of anorexia nervose in the $17^{\text {th }}$ century (59). Chronic nutritional deficiency (e.g., anorexia nervosa), wasting diseases (e.g., insulin-dependent diabetes) or heavy exercise (e.g., ballet dancing and long distance runners) are known to delay the onset of sexual maturation and disrupt normal menstrual function in women (74-76). About 20 years ago, Frisch et al. proposed that somatic fractional fat mass might play an important role in mediating fertility (threshold: $22 \%$ body fat) in women $(77,78)$. Undernutrition also negatively affects sexual behavior (79). Furthermore, its known that menarche frequently occurs at a younger age in obese girls (80). The most likely teleological explanation for this specific neuroendocrine response is that the development of live and healthy progeny requires a large allotment of callories, and it would compromise both mother and fetus if the process began with insufficient calories stored as fat (13). It is less clear what benefit derives from the reproductive axis being diminished in starved males, but this is also described to occur. However, it is known that reproductive function continues in males under energy availability conditions in which it is completely blocked in females, which seems to indicate that female reproductive functions are far more sensitive to undernutrition than those of males (81). Reproductive failure caused by metabolic stress is attributable to hypothalamic-pitultary dysfunction and even subtle changes in diet produce significant alterations in LH secretion (82). Several studies in young men and women disclosed that a short-term fast suppressed mean (24-h) serum LH concentrations and several gonadal sex-steroid hormones $(83,84)$. Reduced $\mathrm{LH}$ secretion was caused by two neuroendocrine mechanisms: a fall in LH-pulse frequency and a decrease in the mass of LH secreted concurrently. Pulsatile GnRH infusions were able to completely restore $\mathbb{L H}$ release, which suggest that reduced release of hypothalamic $\mathrm{GnRH}$ plays a key role in the acute fasting-associated suppression of reproductive function in humans (85). Animal studies revealed that the reduction of $\mathrm{GnRH}$ release rather than its synthesis is most likely the major cause of decreased LH secretion during acute starvathion (57). This assumption was reinforced by the discovery of in vitro GnRH accumulation in the hypothalamus and decreased pituitary stores of LH in starved rodents $(86,87)$. Pituitary $\mathrm{GnRH}$ receptor expression, which is dependent on $\mathrm{GnRH}$ secretion "also declines with fasting in the male rat (88). However, the underlying mechanism resulting in suppression of $\mathrm{GnRH}$ secretion during starvation remains unclear.

PRL secretion has probably been the least studied hormone in starvation research. In acutely and chronically starved rats circulating PRL was significantly depressed $(57,89)$. Several studies suggest that pituitary PRL release was impaired in acute starvation. This impairment was caused by extra- or suprapituitary inhibition, most probably by an increased hypothalamic dopamine release (57). Data derived from human starvation studies are conflicting. In a short-term fasting study no effect was found on PRL blood levels but in a long-term study a decrease was abserved $(71,90)$.

In contrast to rodents, congenital absence of leptin or functional leptin deficiency due to inactivating mutations of the leptin receptor in humans induce only a part of the neuroendocrine changes seen in human starvation (91). The most striking resemblance between the obese human mutants and the obese rodent mutants is that the 
majority of the rare human patients with a mutated leptin gene or the gene of its receptor identified until now also fail to attain normal adult reproductive capabilities $(19,22,23,92)$. To date, two adult leptin-deficlent female homozygous patients started to menstruate, albeit with a luteal phase defect with low midluteal phase progesterone levels (92). The hypogonadism of patients with a leptin gene mutation appeared to be a defect at the hypothalamic level, since these patients demonstrate normal gonadotropin responses to $\mathrm{GnRH}$ stimulation (92). However, the LH (but not the FSH) response to $\mathrm{GnRH}$ in two sisters with a mutated leptin receptor remained low suggesting a possible different underlying mechanism (23). One functional copy of the human leptin or leptin receptor gene seems to be enough to allow normal reproductive functions in heterozygous male and female patients $(19,23,92)$. After 24 -months of daily leptin therapy, an 11 years old very obese girl (bone age: 12.5 years) with a mu-

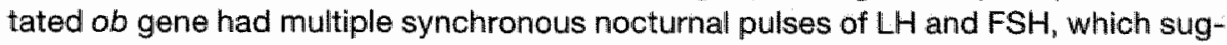
gested the onset of early puberty $(21,33)$. Subsequently, the patient progressed through the appropriate timed clinical stages of pubertal development and started to menstruate at an age of 12.1 years. In two prepubertal leptin-deficient children, basal gonadotropins and sex steroids remained in the prepubertal range after a maximum of 36 months of leptin therapy (21). In addition, no evidence for pulsatille secretion of gonadotropins was observed in one of the children at an age of 4.9 years. Leptin replacement therapy for 6 months to an adult hypogonadic leptin-deficient male had a profound effect on the dynamics of sex hormone concentrations while concurrently causing the onset of puberty at age 27 (35). After leptin therapy, two adult leptin-deflcient females had regular menstrual periods that were associated with serial midluteal phase progesterone measurements over $10 \mathrm{ng} / \mathrm{ml}$, which are indicative of ovulation (35). Together with the observation of two leptin-deficient females with regular menstrual periods, this suggests that leptin is not the primary signal for the onset of human puberty but acts as an important permissive factor for the development of puberty together with other leptin-independent factors.

Most children with either leptin or leptin receptor mutations suffered from mild hypothalamic hypothyroidism $(19,23,92)$. in contrast to these observations, all adult leptin-deficient individuals had normal thyroid hormone levels and function tests (92). However in one study, all adult homozygous and heterozygous leptin-deficient patients demonstrated abnormal patterns of TSH secretion (93). Allthough thyroid function tests were within normal range before the start of leptin therapy in three congenital leptin-deficient children, free $T_{4}$ showed a significant early post-treatment increase and subsequently stabilized at that llevel (21). Also plasma free $T_{3}$ concentrations rose after leptin administration in two children but no change in TSH llevels was observed. A fourth pediatric patient with congenital leptin deficiency suffered from subclinical hypothyroidism. After leptin therapy was established her thyroid function normalized allowing withdrawal of $T_{4}$ therapy (34). These findings support a role for leptin in the regulation of the hypothalamic-pituitary-thyroid axes although not a critical one.

A marked difference between genetically obese mice and genetically obese humans is the lack of any major impact of leptin deficiency or non-functional leptin receptors on the HPA axis. Both the urinary free cortisol as the ACTH levels were within normal ranges in these patients and also a normal cortisol response to a dexamethasone suppression test was noted $(19,23,92)$. In addition, morning cortisol measurements and urinary free cortisol levels were not influenced by leptin therapy in three children lack- 
ing leptin (21). However, leptir replacement in three adult leptin-deficient patients led to higher 24-th mean concentrations, with fewer pulses of greater height including a greater morning rise. The results of this recent study suggests that leptin plays a role in organizing the dynamics of human HPA function (35). One study suggested that sympathetic system dysfunction (low sympathetic tone) might be present in the four leptin-deficient subjects studied (92). Three sisters with homozygously mutated leptin receptors showed mild but significant growth delay due to impaired basal and stimulated GH secretion and decreased IGF-1 and IGF-binding protein (IGFBP) 3 levels (19). In contrast, leptin-deficient children exhibit normal linear growth $(19,92)$. Furthermore, morbidly obese patients with leptin deficiency had $\mathrm{GH}$ secretion that was related to adiposity and nof to leptin levels (94). Also, no effect of leptin treatment on plasma IGF-1 levels and skeletal maturation was observed in leptin-deficient children (21). By 18 months of leptin treatment of three leptin-deficient adult patients, $\| G F B P-1$ and IGFBP-2 levels were increased while IGF-1, IGF-2, IGFBP-3, and IGFBP-6 were not changed in response to treatment (35).

Another approach to study whether the neuroendocrine effects of leptin administration to animals during fasting can be extended to humans is to administer exogenous leptin in other conditions associated with a (relative) deficiency or absence of leptin such as during severe energy restriction. Therefore, we undertook a randomized, double-blind, and placebo-controlled study described in chapter 6 to investigate whether elevated leptin levels using PEG-OB were able to attenuate the neuroendocrine adaptations to semistarvation induced by a very low energy diet in healthy overweight male subjects. Introducing a state of semistarvation induced changes in the thyroid (free $\mathrm{T}_{3}$ and free $\mathrm{T}_{4}$ ), corticotropic (cortisol) and somatotropic axes (GH and IGF-1), which paralleled the severity of the energy deficit and were therefore more pronounced (but not significantly different) in the PEG-OB group, which lost significantly more weight. In addition, PEG-OB treatment did not prevent the inhibition of the SNS activity "which normally occurs during energy restriction. The suppression in several reproductive hormones ( $\mathrm{LH}, \mathrm{PRL}$ and estimated free testosterone with the exception of FSH) tended to be reduced in the PEG-OB treated group but failed to reach significance. However, after adjustment for weight loss using multiple linear regression, the drop in mean LH levels was attenuated in the PEG-OB group compared to the placebo group.

One study reported reversal of the effects of a sustained weight-reduction of $10 \%$ on circulating concentrations of thyroid hormones $\left(T_{3}\right.$ and $T_{4}$ but not TSH) in four subjects by a replacement dose of exogenous leptin (46). In contrast, our study failed to demonstrate an effect of leptin administration on the weight-loss decline in free $T_{3}$, In line with our findings, a study executed in never-obese subjects on a weight maintenance regime for 6 days failed to demonstrate an effect of leptin administration on autonomic activity or urinary catecholamines (44). Recently, to elucidate the role of leptin in regulating neuroendocrine function, the effect of either placebo or a replacement-dose of exogencus leptin administrated during an 72 -hour acute fast in six healthy lean men was studied (32). The most significant effect of leptin replacement was found on the hypothalamic-pituitary-gonadal axis with full restoration of LH pulsatility characteristics and testosterone levels. In addition, leptin administration blunted the fasting-induced changes of pulsatile TSH secretion and resulted in a slight increase of free $T_{4}$, similar to leptin-deficient children. No effect was observed on $T_{3}$ and $r T_{3}$ levels, which 
suggests that leptin does not affect the peripheral deiodinases. Also thyroxine-binding globulin (TBG) levels remained unaffected. Replacement therapy failed to prevent or blunt the fasting-induced activation of the HPA axis evidenced by 24 -hour urine free cortisol levels and cortisol pulsatility characteristics. Also sympathoadrenal activity, assessed by 24-hour urine catecholamines (epinephrine and norepinephrine) and the renin-aldosterone system were not influenced by leptin therapy. The fasting-induced changes in GH pulsatility and total and free IGF-1 levels were not altered by leptin administration.

Several syndromes have been associated with very low leptin levels such as females suffering from lipodystrophy, hypothalamic amenorrhea or anorexia nervosa and highly trained femalle athlete's (91). Interestingly, in all these syndromes menstrual irregularities and amenorrhea are common findings. Köpp et al. demonstrated that the very low plasma leptin level in women with eating disorders correllated with the LH concentration and was predictive of amenorrhea. Moreover, these authors also showed that fasting leptin levels were a better predictor of menstrual function than body mass index, fat mass, or percentage body fat and that a critical blood leptin concentration ( $1.85 \mathrm{ng} / \mathrm{mL}$ ) was required to maintain menstruation (95). Especially when the usual circadian variation in plasma leptin is lost in women suffering firom one of these syndromes, amenorrhea occurs, whereas persistence of the circadian variation is associated with persistence of cycling $(96,97)$. Severe lipodystrophy is characterized by low leptin levels caused by deficiency or destruction of adipose cells. This condition has been frequently (but not always) associated with menstrual cycle irregularities and amenorrhea $(98,99)$. Seven female patients with lipodystrophy were treated with a replacement-dose of leptin for 4 months (98). Leptin replacement improved menstrual abnormalities, low oestradiol levels, and corrected the blunted LH response to $\mathrm{GnRH}$ in this patient group. Although remaining in the normal range, serum $\mathrm{TSH}$ and $\mathrm{T}_{4}$ fell significantly after 4 months of leptin therapy. In contrast, $T_{3}, r T_{3}$ TBG, albumin, and the response to a TRH stimulation test were unaffected by treatment. The status of the HPA axis remained unaltered, as the ACTH/cortisol levels and a $\mathrm{CRH}$ stimulation test were similar before and after 4 months of leptin therapy. In women with hypothalamic amenorrhea, the administration of human recombinant leptin in an effort to normalize the relative leptin deficlency resulted in increased mean LH llevels and LH pulse frequency after two weeks and increased maximal follicular diameter, the number of dominant follicles, ovarian volume, oestradiol levels, and improved menstrual cyclicity over a period of three months (39). Treatment with exogenous leptin resulted in increased levels of free $T_{3}$ and free $T_{4}$ (within normal ranges) but failed to influence TSH levels or pulsatility. No significant effect of leptin therapy was abserved on cortisol or ACTH levels and treatment failled to affect $\mathrm{ACTH}$ pulsatility. Both the levels of IGF-1 and IGFBP-3 increased during administration of human recombinant leptin. Leptin treatment of two children suffering from the Rabson-Mendenhall syndrome (characterized by severe insullin resistance and presumed insulin receptor mutations) for 4 months did not affect growth rate, the response to $\mathrm{Gn} R \mathrm{H}$, thyroid and adrenal function (47).

Three observations could account for the limited effect of leptin therapy on reproductive hormones found in our semistarvation study described in chapter 6 with severe energy restricted overweight males. First, reproductive function is known to continue in males under limited energy availability in which it is completely blocked in females 
suggesting that female reproduction is more sensitive to nutritional deprivation $(81,100)$. Secondly, some evidence suggests that the supraphysiological leptin levels acheved in this study elicit different effects on neuroendocrine function than leptim levels in the physiological range $(101,102)$. Finally, more subtle effects of leptin treatment on the neuroendocrine axes might have been revealed by measurements of their pulsatility characteristics. These considerations prompted us to execute the last study described in this thesis (chapter 8 ). To address the capability of leptin to influence pulsatile $L H$ secretion in the human, we studied seven healthy young women with a body mass index of $20 \mathrm{~kg} / \mathrm{m}^{2}$ or less. Subjects received a single subcutaneous injection of placebo vs. PEG-OB, designed to mimic leptin concentrations present in obesity. LH pulsatility was assessed objectively by monitoring LH release every 10 minutes for $15 \mathrm{~h}$ before and $3 \mathrm{~h}$ after GnRH injection. Studies were timed to fall ten days after onset of menses so as to occur during induced hyperleptinemia and the expected mid-to late-follicular phase of the menstrual cycle. Unexpectedly, the current outcome indicates that 10 days of exposure to exogenous leptin decreases $\mathrm{LH}$ pulsatility in healthy young underweight women during the follicular phase. LH secretion in response to a maximal dose of exogenous GnRH remained unchanged, which indicates that gonadotrope secretory capacity (but not necessarily sensitivity) is preserved. The PEG-OB intervention did not alter (15-h mean) concentrations of the thyrotropic, corticatropic, or somatotropic hormones. Studies using median-eminence arcuate nucleus explants from adult rats indicate that leptin exposure stimulates GnRH release at low, but inhibits GnRH release at high concentrations (101). Comparable data were obtained using an immortalized GnRH-secreting neuronal cell line (103). Although previous studies suggest a direct effect of leptin on endogenous GnRH secretion, most double-labeling studies fail to demonstrate the expression of full-length leptin receptors in GnRH neurons $(52,104)$. Thus, leptin may act indirectly, such as via internuncial neurons. Other studies also support concentration-dependent actions of leptin $(101,102)$. For example, female transgenic skinny mice overexpressing leptin exhibit late-onset hypothalamic hypogonadism after an accelerated puberty (105). Also female $A^{y} / a$ mice that develop hyperleptinemia at older ages, manifest infertility due to hypothalamic dysfunction (106). However, male mice of both models are unaffected. Moreover, leptin does not normalize fasting-induced hypogonadism in the immature male rhesus monkey (53). Collectively, these findings could indicate that chronic hyperleptinemia downregulates hypothalamic leptin signal pathways that maintain reproduction, thereby leading to hypothalamic hypogonadism. This action may be predominant to the female. Obese women often exhibit anovulatory cycles and infertility, with variable impaired $\mathrm{LH}$ secretion in response to $\mathrm{GnRH}$, suggesting hypothalamic-pituitary dysfunction (107). Leptin concentrations are elevated in obese compared with lean individuals and correlate positively with fat mass (8). In addition ${ }_{\text {" }}$ obesity is associated with blunted diurnal excursions and dampened pulsatility of leptin $(108,109)$. Thus, one might speculate that the continuous hyperleptinemia present in obesity could be involved in the impaired reproductive function present in this condition. However, the exact role of peripheral leptin excess in the reproductive dysfunction associated with obesity has not been established.

In conclusion, all human observational and interventional studies (including our own studies) to date point out that leptin is a critical factor in maintaining human reproduc- 
tive function. Many lines of evidence indicate that leptin deficiency or absence is responsible for the impaired reproductive system present in these states. However, it is possible that leptin has a dual effect on human reproduction as chronic hyperleptinemia (normally present in obesity) also appears to have a detrimental effect on the human reproductive axis.

The exact role of leptin in the regulation of the human hypothalamic-pituitary-thyroid and HPA axes remains to be elucidated. Although definite effects of leptin substitution were observed in interventional studies, both adult leptin-deficient patients and female patients with severe lipodystrophy or hypothalamic amenorrhea were euthyroid and possessed normal HPA function. It is proposed that leptin has a role in organizing the dynamics of both these hormonal axes. In contrast to the findings in rodents, leptin appears to play no major role in the regulation of the human somatotropic axes and SNS activity.

\section{Leptin and the immune system}

It is now generally accepted that malnutrition is the most common cause of immunodeficiency worldwide $(110,111)$. Epidemiological and clinical data suggest that nutritional deficiencies increase the risk of infection and death from infectious diseases (112). Several starvation-induced defects of the immune system in man have been described, particularly distorted T-lymphocyte subpopulations and responses. $(113,114)$

Mice lacking leptin (ob/ob mice) have immunological abnormalities similar to those of starved mice. Leptin administration reversed the immunological changes of both starved mice as well as ob/ob mice (115-118).

The limited published data in humans with an ob genotype suggest that leptin-deficient human infants were more susceptible to infections. In one family 7 of 11 individualls born with the obese phenotype died in childhood during the course of infections (92). Four leptin-deficient children, from other families, also had a clinical history of frequent childhood infections especially of the upper respiratory tract $(21,34)$. Prior to treatment, two of these patients showed moderate to severe selective CD4 ${ }^{+} \mathrm{T}$-cell lymphopenia, T-cell hyporesponsiveness, and lower production of several cytokines to several stimuli (21). In this leptin-deficient state, secretion of Th2/regulatory cytokines (such as interleukin-4 (IL-4), interleukin-10 (IL-10), and transforming growth factor $\beta$ (TGF- $\beta$ ) ) were impaired and the production of the proinflammatory cytokine interferon- $\gamma$ was virtually absent. After chronic leptin replacement therapy, CD4 T-cell numbers increased to normal levels and the T-cell responsiveness significantly improved. Interferon- $\gamma$ production was fully restored after 2 months of treatment and the levels of IL-4 and IL-10 increased. Also TGF- $\beta$ secretion was completely suppressed to normal levels. Other low-leptin states, such as anorexia nervosa and one case of lipodystrophy have been linked to cell-mediated immunity defects $(113,119)$. Furthermore, an association between the increase in leptin and the immunological recovery after refeeding of mainourished infants was suggested (120).

A growing bady of evidence implies that (relative) leptin deficiency results in immunodeficiency, which suggests that leptin is a modulator of the immune and proinflammatory responses. Contrary to these low-leptin states, leptin levels are gen- 
erally elevated in the obese population (121). In addition, human obesity appears to be associated with a low-grade proinflammatory state (122-127). Weight loss reduces circulating leptin levels and concomitantly lowers the plasma levels of inflammation markers associated with obesity (128). Consequently, it has been reasoned that the elevated leptin levels might contribute to this low-grade proinflammatory state in human obesity (129).

To that end, we first examined the effect of inducing supraphysiological leptin levels through weekly administration of $60 \mathrm{mg}$ PEG-OB on humoral inflammation parameters during mild hypocaloric conditions (deficit: $3.2 \mathrm{MJ} /$ day for 8 weeks) in obese male and female subjects (chapter 4). Leptin therapy in this study neither affected the levels of the soluble TNF $\alpha$-receptors (sTNF-R55 and 75) nor the C-reactive protein (CRP) levels suggesting that leptin is not directly involved in the enhanced inflammatory status present in obesity.

Next, we decided to study the relationship between the elevated leptin levels and the low-grade systemic inflammation present in human obesity more clasely by changing our experimental approach as described in chapter 7 . We reasoned that if elevated leptin levels are an important factor in the proinflammatory state in obesity, then exogenous leptin administration during weight loss should counteract the concurrent beneficial effects of weight loss on this proinflammatory state. Therefore, we determined whether weekly administration of $80 \mathrm{mg}$ PEG-OB prevented the changes in cellular and humoral inflammation parameters during semistarvation induced by a very low callorie diet ( $2 \mathrm{MJ} / \mathrm{day}$ ) in healthy overweight male subjects. Except for a small increase in B-cells, leptin treatment did not affect the decline in total leucocyte count and mononuclear subfractions during semistarvation. Also no effect on several humoral parameters was observed with exception of the CRP levels. The increase in CRP levels was the sole indication for a possible humoral proinflammatory action of leptin.

In summary, (relative) human leptin deficiency appears to be associated with an immunodeficient state. In contrast, our studies do not support a causative role of hyperleptinemia in low-grade proinflammatory state present in human obesity. Thus, it seems plausible that the definite long-term elevations in systemic leptin levels and the low-grade proinflammatory state found in obesity result from a common pathogenic mechanism present in this condition.

\section{Considerations for future research}

The studies described in this thesis were designed to provide information on our understanding of the physiological role of leptin in man. Although the research presented in this thesis provides us with some answers, it also confronts us with various gaps in our knowledge of leptin physiology which need to be addressed in future studies.

Several studies, including our own, indicate that exogenous leptin predominantly suppresses appetite when administrated during severe energy restriction, which leads to additional weight loss due to better compliance with the diet. Future experiments should be designed to investigate the long-term effect of exogenous leptin or leptin receptor agonists on weight maintenance after weight loss has been achieved, which might provide new therapeutic strategies for human obesity. A substantial amount of 
paradoxical observations concerning the metabolic profille followed after several leptin replacement studies were performed in humans. For instance, the marked differences between the effects of leptin therapy in congenital leptin deficiency and patients with severe lipodystrophy or the Rabson-Mendenhall syndrome (severe insulin resistance due to insulin receptor mutations) on glucose homeostasis and lipid metabolism are intriguing and the underlying mechanisms warrant closer investigation. Also a clinical trial should be executed to investigate whether leptin treatment in type 2 diabetes mellitus could improve glucase homeostasis despite the very complex nature of this metabolic disorder.

Recently, considerable advances in the understanding of the neuroendocrine role of leptin have been achieved by studying the effects of leptin therapy in several low-leptin states, including congenital leptin deficiency, lipodystrophy, hypothalamic amenorrhea, and severe energy restriction. However, the effect of leptin administration in other low-leptin states also associated with menstrual cycle irregularities and amenorrhea, such as highly trained female athletes, has not been studied yet and might provide new therapeutic strategies for human infertility. Although many lines of evidence support that leptin is a critical factor in maintaining human reproduction, the exact role of leptin in the regulation of the human hypothalamic-pituitary-thyroid and HPA axes remains less clear and should be elucidated.

The prevalence of obesity has increased explosively over the last few decades, and is rapidly becoming a major health issue even at a younger reproductive age. In addition, a substantial lack of information exists concerning the effect of obesity on several endocrine systems, especially human reproduction. Since our research suggests that high chronic leptin levels might contribute to the impaired fertility in obese females, this issue should be further researched. Furthermore, additional studies should address the effectiveness of pulsatile vs. steadily delivered leptin on several endocrine systems.

Finally, a better understanding of the role of leptin in the modulation of immune responses may lead to novel approaches in immunotherapy for human inflammatory and autoimmune conditions.

\section{References}

1. Zhang, Y., Proenca, P., Maffei, M., Barone, M., Leopold, L., and Friedman, J.M. 1994. Positional cioning of the mouse obese gene and its thuman homologue. Nature. 372:425-432.

2. Pelleymounter, M.A., Cullen, M.4., Baker, M.B., et al. 1995. Effacts of the obese gene product on body weight regulation in ob/ob mice. Science. $269.540-1543$.

3. Halaas, $J . L$., Gajiwala, K.S., Maffei, M., ef al 1995. Weight-reducing effects of the plasma protain encoded by the obese gene. Science. 269:543-546.

4. Camptiold, L.A., Smith, F.J., Guisez, Y., Devos, F., and Bum, P. 1995. Recombinant nouse OB protsin: avidence for a peripheral signal linking adiposity and central neurat neworks. Science, 269:546-549.

5. Maffel, M. Stofiel, M. Barone, M, et al. 1996. Absence of mutations in the human OB gene in obese/ciabetic subjects, Diabetes. 45:679-6B2.

6. Niki, T. Morh, H. Tamori, $Y_{\text {, }}$ el al. 1996. Human obese gene: molecular screening in Japanese and Asban Indian MDDM patients associated with obesity. Diabates. 45:675m678.

7. Considine, R.V. Considine, E.L., Willams, $\mathrm{C}_{2}$ t. et al, 1995 . Evidence against either a premature stop codon or the absence of obese gene mRNA in human obesity. $J$ Clin Invest. 952986-2988.

8. Considine, R.V., Sinha, M.K., Heman, M.L., et al. 1996. Serum immunoreactive-leptin concentrations in nomal-weight and abese humans. N Engf J Med. 334:292-295.

9. Campfield, L.A., Smith. F.J., and Bum, P. 1997, OB protein: A hormonal controller of central neurah network mediating behavioral, metabolic and neuro endocrine responses. Endocrinot Melab. 4:81-102: 
10. Campteid, LA., and Smint, F.J. 19g8. Overvew: neurobiclogy of OB protein leptin). Proc Nutr Soc. $57 \times 429-40.40$.

11. Westerterp.plantenga, M.S., Saris, W.H., Hukshom, C.J., and Campfield, L.A. 2001. Effects of weekfy administration of pegylated recombinant human $O B$ protein on appetite proflle and energy metabolism in obese men. Am i Clir Nutr. 744:426-434.

12. Heymstield, S.B., Greerberg. A.S. Fujioka, K. et al. 1999. Recombinant leptin for weight loss in obese and Jean adults - A randomized, controlled, dose-escalation trial J Am Med Assoc. 282:1568-1575.

13. Flier, J.S. 1998. Oinical rewiew 94: What's in a name? in search of leptin's physiologic role. $J$ Clin Enclocrinol Metab, 83:1407-1413.

14. Var Heek, M., Compton, D.S., France, C.F., at 1997. Diet-induced obese mice develop peripheral; but not central, resistance to leptin. J Clin Irivest. 99:385-390.

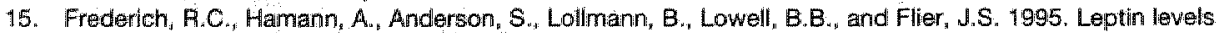
reflect body lipid content in mice: evidence for diet-induced resistance to leptin action. Nat Med. $1: 1311-1314$

16. Caro, J.F., Kolaczynski, J,W. Wyce, M.R., et al. 1996. Decreased cerebrospinal-fluid/serum leptin ratio in obesity: a possible mechanism for leptin resistance. Lancet. 348:159-161.

17. Frederich, R.C. Lolmann, B., Hamann, A., et al. 1995. Expression of ob mPINA and its encoded protein in rodents. Impact of nutrition and obesity. J Clin Invest. 96:1658-1663.

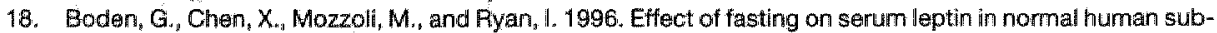
jects. J Chin Endocrinol Metab. 81:3419-3423.

19. Montague, C.T., Farooqi, I.S., Whitehead, J.P., et al. 1997. Congenital leptin deficiency is associated with severe early-onset obesity in humans. Nature. 387:903-908.

20. Rau, H. Reaves, B.J., O'Rahilly, $S_{n}$, and Whitehead J J. 1999. Truncated human leptin (delta 133) associated with extreme obesity undergoss proteasomal degradation after defective intracellular transport. Endocrinology. 140:1718-1723.

21. Farooql, I.S., Matarese; G., Lord, G.M. et al. 2002. Beneficial effects of leptin on obesity, T cell hyporesponsiveness, and neuroendocrine/metabolic dysfunction of human congenital leptin deflciency. $J$ Clin Invest. 110:1093-1103.

22. Strobel, A. Issad, T., Camoin; L., Ozata, M., and Strosiberg, A.D. 1998. A leptin missense mutation associated with hypogonadism and morbid obesity. Nat Genet. 18:2 $13-215$.

23. Clement, K., Vaisse, C., Lahlou, N., et al. 1998. A mutation in the human leptin receptor gene causes obesity and pituitary dysfunction. Nature. 392:398-401.

24. Lejeune, M.P. Hukshoin, C.J., Saris, W.H., and Westerterp Plantenga, M.S. 2003. Effect of dietary restraint during and following pegylated recombinant leptin (PEG-OB) treatment of overweight men. Int $J$ Obes Relat Metab Disord. 27:1494-1499.

25. Strohmayer, $A_{1} J_{2}$ and Smith, G.P. 1987. The meal pattern of genetically abese (ob/ob) mice. Appetite. 8:111-123.

26. Flynn, M.C., Scott, T.R., Pritchard, T.C., and Plata-Salaman, C.R. 1998. Mode of action of OB protein (leptin) on feeding. Am J Physiol. 275 R174-R179.

27. Kahler, A., Geary, N., Eckel, L.A., Campilield, L.A., Smith, F.J., and Langhans, W. 1998. Chronic administration of $O B$ protein decreases food intake by selectively reducing meal size in male rats. Am J Physiof. 275:R180-A185.

28. Eckel, L.A., Langhans, W., Kahler, A. Campfield, L.A, Smith, F.J., and Geary, N. 1998. Chranic administration of $O B$ protein decreases food intake by selectively reducing meal size in female rats. Am $J$ Physiof. 275:P186-A193.

29. Tang Christensen, M., Havel, P.J.s Jacobs, R.R., Larsen, P.J., and Cameron, J.L. 1999. Central admimistriation of leptin inhibits food intake and activates the sympathetic nervous system in rhesus macacues. $J$ Clin Endocrinol Metab. 84:711-717.

30. Halaas, J.L., Boozer, C, Blair West, J., Fidahusein, N., Denton, D.A., and Friedman, J.M. 1997. Physiological response to long-term peripheral and central leptin infusion in lean and obese mice. Proc Natl Acad Sci USA. 94:8878-88183.

31. Ogawa, Y., Masuzaki, H., Hosoda, K., ot al. 1999. Increased glucose metabolism and insulin sensitivity in transgenic skinny mice overexpressing leptin. Diabetes. 48:1822 1829.

32. Chan, J.L., Heist, K., DePaoll, A.M., Veldhuis, J.D, and Mantzoros, C.S. 2003. The role of falling leptin levels in the neuroendocrine and metabolic adaptation to short-term starvation in healthy men. J Clin invest. 111:1409-1421.

33. Farooqi, 1.S., Jebb, S.A., Langmack, $\mathrm{G}_{\text {, }}$ et al. 1999. Effects of recombinant leptin therapy in a child with congenitall leptin deficiency. N Engl J Med. 341:879-884.

34. Gibson, W.T., Farooqi, I.S., Moreau, M., all, 2004 Congenital leptin deficiency due to homozygosity for the (Delta) $133 \mathrm{G}$ mutation: report of another case and evaluation of response to four years of leptin therapy. I Clin Endocrinol Metab. 89:4821-4826. 
35. Licinio, J., Caglayan, S..Ozata, M., et al 2004. Phenotypic effects of leptin replacement on morbid obesity, diabetes mellitus, hypogonadism, and behavior in leptin-defficient adults. Proc Nat Acad Sol USA 101:4531-4536.

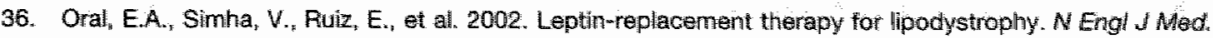
346:570-578.

37. Moran, S.A. Patten, N., Young, JiR., et al. 2004. Changes in body composition in patients with severe lipodystrophy after leptin replacement therapy. Metabolism, 53:513-519.

38. McDuffie, J.R., Riggs, P.A., Calis, K.A., et al. 2004. Effects of exogenous leptin on satiety and satiation in patients with lipodystrophy and leptin insufficiency. $J$ Chin Endocrinol Motab. 89:4258-4263.

39. West, C.K., Chan, J.L., Bullen, J, et al. 2004. Recombinant human leptin in women with twpothalamic amenomea. N Engl J Med. 351:987-997.

40. Fogteloo, J., Meinders, E., Frolich, M., McCamish, M., and Pijl. H. 2003. The decline in plasme leptin in response to calorie restriction predicts the effects of adjunctive leptin treatment on body weight in humans. Eur I Intern Med. 14:415-418.

41. Farooqi, I.S., Keogh, J.MM., Kamath, S., elt al. 2001. Partial leptin deticiency and human adiposity. Nature. $41.4: 34-35$

42. Ahima, R.S., Prabakaran, D., Mantzoros, $C_{\text {. }}$ et al. 1996. Role of leptin in the neuroendocrine response to fasting. Nature. 382:250-252.

43. Haynes, W.G. Morgan, D.A., Walsh, S.A., Mark, A.L., and Sivitz, W.1. 1997. Receptor mediated regional sympathetic nerve activation by leptin. J Clin Invest. 100:270-278.

44. Mackintosh, R.M., and Hirsch, J. 2001. The effects of leptin administration in non-obese humain subjects. Obes Res. 9:462-469.

45. Fogteloo, A.J., Pijl, Hh, Frolich, M., McCamish, M., and Meinders, A.E. 2003. Efferts of recombinant linuman leptin treatment as an adjunct of maderate energy restriction on body weight, resting energy expenditure and energy intake in obese humans. Diabetes Nutr Metab. 16:109-114.

46. Rasenbaum, M. Murphy, E.M., Heymstield, S.B., Matthews, D.E., and Leibeli, R.L. 2002. Low dose leptin administration reverses effects of sustained weight-reduction on energy expenditure and circulating concentrations of thyroid hormones. J Clin Endocrinal Metab. 87:2391-2394.

47. Cochran, E., Young, J.R., Sebring, N., DePaoli, A, Oral, E.A. and Gorden, P. 2004, Efficacy of recombinant methionyl human leptin therapy for the extreme insulin resistance of the Rabson-Mendenhall syndrome. J Clin Endocrinol Metab. 89:1548-1554.

48. LaPaglia, N., Steiner, J., Kirsteins, L. Emanuele, M., and Emanuele, N. 1998. Leptin alters the response of the growth hormone releasing factor-growth hormone-insulin-like growth factor-l axis to fasting.. $J$ Endocrinol. 1 159:79-83.

49. Petersen, K.F., Oral, E.A., Dufour, S., et al. 2002. Leptin reverses insulin resilstance and hepatic steatosis in patients with sewere lipodystrophy. $J$ Clin Invest. 109:1345-1350.

50. Simha, V., Szczepaniak, L.S., Wagner, A.J., DePaoli, A.M. and Garg, A. 2003. Effect of leptin replacement an intrahepatic and intramyocellular lipid content in patients wilth generalized lipodystrophy. Diabetes Care, 26:30-35.

51. Coleman, D.L. 1978. Obese and diabetes: two mutant genes causing diabetes-obesity syndromes in mice. Diabetologial, 14:141-148.

52. Finn , P.D., Cunningham, M.J., Pau, K.Y., Spies, H. G., Chton, D.K. and Steiner, F.A. 1998. Tho stimulatony effect off leptin on the neuroendocrine repraductive axis of the monkey. Endocrinokgy. $139: 4652-4862$.

53. Lado Abeal, J. Lukyanenko, Y.O., Swamy, S., Hermida, R.C., Hutson, J.C., and Noman, R.L, \#999. Short-term leptim infusion does not affect circulating levels of LH, testosterone or cortisol in food mestricted pubertall male rhesus macaques. Clin Endocrinol Oxf. 51:41-51.

54: Lado Abeal, J., Hickox, J.R., Cheung. T.L., Veldhuils, J.D., Hardy, D.M., and Norman, R.L. 2000. Neuroendocrine consequences of fasting in adult male macaques: effects of necombinant rhesus mam caque leptin infusion. Neuroendocrinology. 71:196-208

55. Wilson, M.E., Fisher, $\mathrm{J}_{\text {. }}$ Chikazawa, $\mathrm{K}_{\text {. }}$ et al, 2003. Leptim administration increases nocturnal concentra" tions of luteinizing hormone and growth hormone in juwenilie female thesus montheys. $J$ Clin Endocrino Metab. 88:4874-4883.

56. Schwartz, M.W., and Seeley, R.J. 1997. Seminars in medicine of the Beth Israel Deaconess Medical CenHer. Neuroendocrine responses to starvation and weight loss. $N$ Engl $/$ Med. 336:1802-1811.

57. Xie, QW. 1991. Experimental studies on changes of neuroendocine functions during starvation and refeeding. Neuroendocrinalogy. 1:52,59.

58. Friedl K.E., Moore, R.J., Hoyt, R.W., Marchitelli, L.J., Martirez Lopez, L.E., and Askew, E.W. 2000. Endocrine markers of semistarvation in healthy lean men in a multistresisor anwironment. $J$ Appl Physiol. $88: 1820-1,830$.

59. Newman, M.M., and Halmi, K.A. 1988. The endocrinology of anorexta riervosia and bulimia nervosa. Neurol Clin. 6:195-212. 


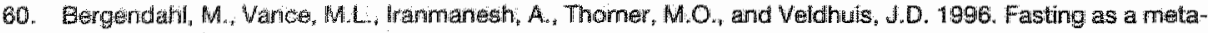
Wollc etress paradigm sebetively amplifies cortis al secretory burst mass and delays the thime of maximal nyctohemeral contisol concentrations in heathy men, 1 Clin Endocrinol Metab. $81: 692-699$.

61. Schwartz, M.W., Dallman, M.F, and Woods, S.C. 1995. Hypothalamic response to starvation: implications for the study of wasting disorders. Am J Physiol. 269:R949-R957.

62. Kalzeff, H.L. Yang, M.U. Presta, E. Leibel, R.L. Hirsch, $\mathrm{J}_{\text {, }}$ and Van ittallie, T.B. 1990. Calorie restriction and lopanoic acid effects on thyroid hormone metabolism. Am J Clin Nutr: 52,263-266.

63. Mermed, T. , and Fineberg, E.8. 1978. Starvation-induced alterations of circulating thyroid homone concentrations in man. Metabolism. 2579.83.

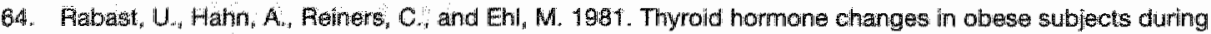
fasting and a very-lowicalorie diet. Int $J$ Obes Relat Metab Disord. 5:305-311.

65. Spencer, C.A. Lum, S.M., Wiber, J.F., Kaptein E.M., and Nicoloft, w.T. 1983. Dyramics of serum thyrotropin and thyroid homone changes in fastingy. $J$ Chin Endocrinol Metab. 56:883-888.

66. Palmblad, $J_{.,}$Levi, L., Burger, A., et al. 1977. Effects of total energy withdrawal (fasting) on thelevels of growth homone, thyrotropin, coittsol, adrenaline, noradrenaline, T4, T3, and $\mathrm{rT} 3$ in healthy malles. Acta Mend Scand. 201:15-22.

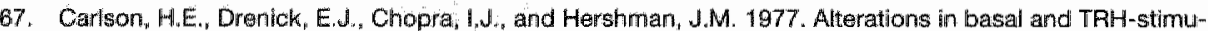
hated serum levels of thyrotropin, prolactin, and thyroid hormones in starved obese men. J Chin Endocrinol Metab. 45:707-713.

68. Legrad, G. Emerson, C.M. Ahima, F.S., Fler, J.S., and Lechan, R.M. 1997. Leptin prevents fasting-induced suppression of prothyrotropin-releasing hormome messenger ribonucleic acid in neuroms of the thypothalamic paraventricular nucleus. Endocrinology. 138:2569-2576.

69. Croxsion, M.S., Hall, T,D. Kletzky, O.A., Jaramillo, J.E., and Nicoloff, J.T. 1977. Decreased serum thyrotropin induced by fasting. J Cin Endocrinol Metab. 45:560-5618.

70. Snyder, D.K., Clemmons, D.F. and Underwood, L.E. 1989. Dietary carbohydrate content determines responsiweness to growth homone in energy-restricted thumans. J Clin Endocrind Metab. 69:745-752.

71. Bergendahl, M., Evans, W.S., Pastor, C., Patel, A. Iranmanesh, A, and Veldhuis, J.D. 1999. Short-term fasting suppresses leptim and (conversely) activates disorderly growth hormone secretion in miduteal phase women-a clinical research center study. J Clin Endocrinol Metab. 84:883-8:94.

72. Maes, M., Maiter, D., Thissen, J.P., Underwood, L. E., and Ketelslegers, J.M. 1991. Contributions of growth hormone receptor and postreceptor defects to growth hormone resistance in malnutrition. Trends Endocrinoi Metab. 2:92-97.

73. Thissen, J.P., Keteislegers, J.M... and Undeirwood, L.E. 1994. Nutritional regulation of the insulin growth factors. Endocr Rew. 15:80-101.

74. Van der Spuy, Z.M. 1985. Nutrition and reproduction. Clin Obstet Gynaecol. 12:579-604.

75. Griffin, M. "South, S., Yankov, V., et al. 1994. Insulin-dependent diabetes mellitus and menstrual dysfunction. Ann Mad. 26:331-340.

76. Loucks, A.B. 1990. Effects of exercise training on the menstrual cycle: existence and mechanisms. Med Sci Sports Exorc. 22:275-280.

77. Frisch, P.E., and McArthur, J.W. 1974. Menstrual cycles: fatness as a determinant of minimum weight for height necessary for their maintenaince or onset. Science. 185:949-951.

76. Frisch, Fi E. 4987. Body fat, menarche, fitness and tertilty. Hum Reprod, 2:521-533.

79. Qill, G.J, and Rissmen, E.F. 1997. Female sexual behavior is inhibited by short-and long-term food restric* thon. Physiol Behav. $61: 387-394$.

80. Wermetulen, $A_{\text {. }}$ and $A_{\text {indo, }} \mathrm{S}_{3}, 1979$. Metabolic clearance rate and interconversion of androgens and the influence of the free androgen firaction. J Chin Endocrinol Metab. 48:320-326.

81. Hamilton, $G, D_{1}$ and Bronson, F.H. 1986. Food restriction and reproductive development: male and female mice and male rats. Am of Physiol. 250:R370-R376.

82. Mattern, L.G., Helmreich, D.L., and Cameron, J.L. "1993. Diumal pattem of pulsatile luteinizing hormone and testosterone secretion in adult male mesus monkeys (Macaca mulatta). influence of the timing of daily moal intake. Endocrinology. 132:1044-1054.

83. Bergendahl, M., Alol, J.A., Iranmanesh, A., Mulligen, T.M., and Veldhuis, J.D. 1998. Fasting suppresses pulsatlle luteinizing hormone (LH) secretion and enhances orderliness of LH release in young but not older men. $J$ Clin Endocrinol Metab. 93:1967-1975.

64. Alvero, $\mathrm{A}$, Kimzey, $\mathrm{L}_{n}$, Sebring, $\mathbb{N}_{\text {., }}$ et al. 1998. Effects of fasting on neuroendocrine function and folliclle dewelopment in lean women. Wlin Endocrinol Metab. 83:76-80.

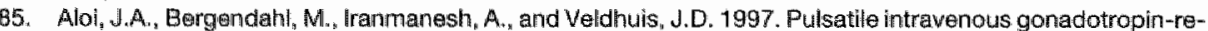
leasing hormone administration averts fasting-induced hypogonadotropism and hypoandrogenemia in healthy, normal weight men. J Clin Endocrinol Metab. 82:1543-1548.

86. Root, A.W. Reiter, E.O., Duckett, G.E, and Sweetland, M.L. 1975. Effect of short-term castration and starvation upon thypothalamic content of luteinizing homone-releasing hormone in adult imale rats. Proc SOC Exp Biol Med. 150,602-605. 
87. Root, A.W., and Russ, R.D. 1972. Short-term effects of castration and starvation upon pitultary vinu serum levets of luteinizing hormone and follicle stimulating thomone in male rats. Acta Endochno Copenh. $70: 665-675$.

88. Leonharct, S., Shahab, M., Luft, H. Wuttke, W., and Jarry. H. 1999. Reduction of lutainzing lhormone secretion induced by long-term feed restriction in male rats is associated with incrased expression of GABA-synthesizing enzymes without alterations of GnRH gene expression. I Neuroendocrinol. $11: 613-619$.

89. Campbell, $G_{i} A_{1,}$ Kurcz, M. Marshall, $S_{*}$ and Meites, 4 . 1977. Effects of starvation in rats on serum levels of follicle stimulating homone, luteinizing hormone; thyrotropin, growth homone and prolactin; responise to LHwreleasing homone and thyrotropin-releasing hormone. Endocrinology، 100:580-587.

90. Gorozhanin, V.S, and Lobkow, V.V. 1990. Hormonal and metabolic reactions in the thuman body during prolonged starvation. Kosm Biol Awiakosm Med. 24:4\% 550 .

91. Himms-Hagen, J. 1999 . Physiological roles of the leptin endocrine system: differences between mice and humans. Crit Rev Clin Lab Sci. 36:575-655.

92. Ozata, M., Ozdemir, I.C., and Licinio, ل. 1999. Human leptin deficiency caused by a missense mutation: multiple endocrine defects, decreased sympathetic tone, and immune system dysfunction indicate new targets for leptin action, greater central than peripheral resistance to the effects of leptin, and spontanews correction of leptin-mediated defects. J Cin Endocrinol Metab. 84:3686-3695.

93. Mantzoros, C.S., Ozata, M., Negrai, A.B., et al. 2004. Synchronicity of frequently sampled thyrotropin (TSH) and leptin concentrations in healthy adults and leptin-deficient subjects: evidence for possible partial TSH regulation by leptin in humans. I Clin Endocrinol Metab. 86:3284-3291.

94. Ozata, M., Dieguez, $C$., and Casanueva , F.F. 2003. The inhibition of growth homone secretion presented in obesity is not mediated by the high leptin levels: a study in human leptim deficiency patients. $J$ Clin Endocrinol Metab. 88:312-316.

95. Kopp, W., Blum, W.F. von Prittwitz, S., et al. 1997. Low lleptin lewels predict amenorrhea in underweight and eating| disordered fernales. Mol Psychiatry. 2.335-340.

96. Balligand, J.L., Brichard, S.M., Brichard, W" Desager", J.P., and Lambert, M. 1998. Hypoleptinemla in patients with anorexia nenosa: loss of circadian rhythm and unresponsiveness to short-term refeeding. Eur $J$ Endocrinol. 138:415-420.

97. Laughlin, G.A. and Yen, S.S. 1997. Hypoleptinemia in women athletes: absence of a diumal rhythm with amenorhea. J Cin Endocrinal Metab. 82:318-321.

98. Oral, $E_{n} A_{n}$, Ruiz, E., Andewelt, A., et all, 2002. Effect of heptin replacement on pituitary hormone regullation in patients with severe llpodystrophy. I Clin Endocrinol Metab. 87:3110-3117.

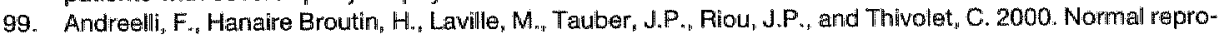
ductive function in leptin-deficient patients with lipoatropic diabetes. J Clin Endocrinol Metab. 85:715-719.

100. Lado-Abeal, J., Prieto, D., Lorenzo, $M_{2,}$ et al. 1999. Differences between men and women as regards the effects of protein-energy malnutrition on the hypothalamic-pitultary-gonadal axis. Nutrition. 15:351-358.

101. Yu, W.H. Kimura, M. Walczewska, A., Karanth, S., and MCCann, S.M. 1997'. Role of leptin in lhypothalamic-pituitary function. Proc Nat/ Acad Sci USA. 94:1023-1028.

102. Ahima, R.S., Kelly, J. Elmquist, J.K., and Flier, J.S. 1999. Distinct physiologic and neuronal responses to decreased leptin and mild hyperleptinemia. Endocrinology. 140:4923-4931.

103. Magni, P. Vettor " . . Pagano, $C_{\text {. }}$ et al. 1999 . Expression of a leptin receptor in immortalized gonadotropir-releasing homorne-secreting neuroms. Endocrinology-140:1581-1585.

104. Hakansson "M.L., Brown, H., Ghilardi, N., Skoda, R.C., and Meister, B, 1998. Leptin receptor immunoreactiwity in chemically defined target mewrons of the hypothalamus. J Nourosci. 18:559-572.

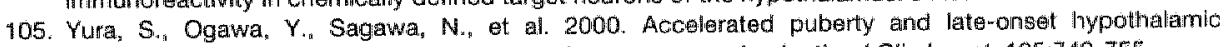
hypogonadism in lemale transgenic skinny mice overexpressing leptin. J Clin invest. 105:749-755.

106. Granholm, N.H., Jeppesen, K.W., and Japs, R,A. 1986. Progressive infertility in femate lothal yellow mice (Ay/a; strain C57BL/6J). J Reprod Fertil. 76:279-287.

107. Bouwattier, C., Lahlou, N. Roger, M., and Bougneres, P. 1998. Hyperleptinaemia is associated wwith irinpaired gonadotrophin mesponse to GnRH during late puberty h obese girls, not boys. Eur II Endockinol. $138: 653-658$.

108. Sinha, M.K., Sturis, J., Ohannesian, J., et at, 1996. Uitradian oscillations of leptin secretion in humans. Biochem Biophys Res Commun. 228:733-738.

109. Saad, M.F., Riad-Gabriel, M.G. Khan, A., at. 1998. Diumal and ultradian rhythmicity of plasme leptin: affects of gender and adiposity. I CKin Endocrinol Metab. 83:453-459.

110. Chandra, $R_{0} K .1996$. Nutrition, immunity and infection: from basic knowledge of dietary mentipulation of immune responses to practical application of ameliorating suffering and improwing survival. Proc Natl Acad Sci USA. $93: 14304-14307$.

111. Chandra, R.K. 1997. Nutrition and the immune system: an introduction. Am J Clin Nutr. 66:4605-4635.

112. Slhears, P. 1991. Epidemiology and infection im famine and disasters. Epidemiol Infect. 107:241-251.

113. Cason, J., Ainley, C.C., Wolstencroft, A.A., Norton, K.R., and Thompson, R.P. 1986. Cellmediated immunity in anorexia nervosia. Clin Exp Immunol. 64:370-375. 
114. Surnshaw, N.S, and SanGlowarni, J.P. 1997 . Symergism of nuthtion, infection, and immunty: an over Hon. Am J Chn Nutr. 66.4645-475.

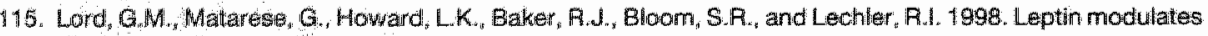
the T-edil immune response and tewerses starvation-induced immunosuppression. Nature. 394:897-901.

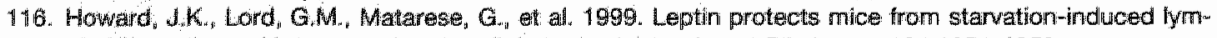
phoid atrophy and inereases thymic cellularity in ob/ob mice. J Clin Invest. 104:1051-1059.

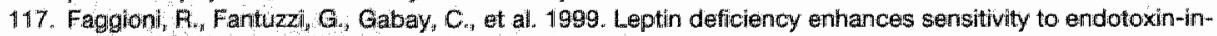
duced lethality Am a Physio: $276 \mathrm{F1} 36 \mathrm{FH} 42$

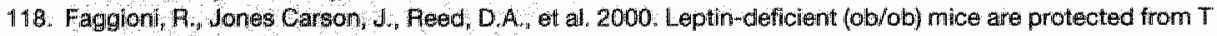
cell-medated hepatotoxidty: Role of tumor necrosis factor alpha and LL-1B. Proc Nat' Acad ScI USA. 97,23672372

110. Kher, A.S, Lahir, K. W, Jain, M.K. and Shah, M. D. 1990. Congenital lipodystrophy with defective leucocytefunction (a case report). I Postgrad Med. 36:48-50.

120. Pialacio A, Lopez, M., Perez-Bravo, F. Monkeberg. F, and Schlesinger, L. 2002. Leptin levels are associ. ated with imurrume response in mainourished infants. J Chn Endocinol Metab. 87:3040-3046.

121. Maffel, M, Hallaas, H, Rawussin, E., ot al. 1995. Leptin levels in human and rodent: measurement of plasma. leptin and ob RNA in obese and weight-reduced subjects. Nat Med. 1:1155-1161.

122. Perfetto, $F$, Mancusio, $F$, and Tarquini, R. 2002. Leukocytosis and hyperleptinemila in abesity: is there at link? Haematologica, 87,ELT25.

123. Visser, M., Bouter, L.M. MeQuillan, G.M., Wener, M.H. „, and Harris, T.B. 1999. Elevated Creactive protein levels in overweight and obese adults. J Am Med Assoc. 282:2131-2135.

124. Yudkin, J.S, Kumari, M., Humphries, S.E., and Mohamed-Ali, W. 2000. Inflammation, obesity, stress and coronary heart disease: is interleukin-6 the link? Atherosclerosis. $148.209-214$.

125. Dandona, $P_{.}$, Weinstock, R., Thusu, $K_{*}$, Abdel-Pahman, $E_{*:}$ Aljada,$A$, and Wadden, T. 1998. Tumor necro sis factor alpha in sera of obese patients: fall with welght loss. J Clin Endocrinol Metab. 83:2907-2910..

126. van Dielen, F.M., van't Weer, C., Schols, A.M., Soeters, P.B., Buurman, W.A., and Greve, J.W. 2001. Increased leptin concentrations correlate with increased concentrations of inflammatory markers in morbidly obese indiwiduals. Int I Obes Felat Metab Disord. $25: 1759 \mathrm{~m} 1766$.

127. Ferri, $\mathrm{C}_{*}$, Desideri, $\mathrm{G}_{*}$ Valenti, $\mathrm{M}_{\text {., }}$ et al. 1999. Early upregulation of endothelial adhesion molecules in obese hypertensive men. Hypertension. 34:568-573.

128. Ziccardl, P., Nappo, $F_{*}$ Giugliana, $G_{x}$, et al. 2002. Reduction of inflammatory cytokine concentrations and Improvement of endathelial functions in obese women after weight loss over one year. Circulation. 105:804-809.

129. Loffreda, $S_{* j} Y_{a n g}, S_{*} Q_{*}$ Lim, $H . Z_{*}$, et al 1998 . Leptin regulates proinflammatory immune respanses FASEB J. 12:57-65. 


\section{Summary}

The discovery of the hormone leptin in 1994 had an enormous impact both in understanding the molecular control of energy balance and in attitudes to the scientific study of obesity. The leptin pathway appeared to be the long-sought peripheral signal pathway from the adipose tissue to the brain involved in the regulation of feeding and energy balance. Since the discovery of leptin, the view of its physiological role in humans has constantly evolved and broadened based on new data and theoretical considerations. The aim of our research presented in this thesis was to test these now insights using different approaches and experimental protocols.

Leptin must gain access to specific regions of the brain to exert its effects and therefore needs to cross the bload-brain-barrier. The pilot study described in chapter 2 investigated the crucial question if the long-acting pegylated recombinant leptin (PEG-OB) used in all our trials could enter into the human central nervous system. Four days after PEG-OB treatment, leptin concentrations in the cerebrospinal fluid of two patients scheduled for an elective lumbar punction (to exclude the presence of neurologic Lyme disease) were approximately 10 times higher than predicted from their baseline plasma leptin concentrations. These findings strongly suggested (but did not prove) that $\mathrm{PEG}-\mathrm{OB}$ was able to cross the human blood-brain barrier.

Soon after the cloning of the ob gene, leptin-deficient $a b / o b$ mice were injected with recombinant leptin, which led to weight loss due to decreased food intake and increased energy expenditure. This result suggested that leptin functioned as an anti-obesity hormone. According to this hypothesis, rising concentrations of leptin with increasing adiposity would generate a signal to reduce food intake and increase energy expenditure to limit further weight gain. However, this early concept was challenged by the widespread occurrence of leptin resistance in both animals and humans. At that time, it was believed that leptin resistance might be overcome by therapeutic augmentation of circulating leptin levels in a manner similar to the use of exagenous insulim to overcome insulin resistance in noninsulin-dependent diabetes mellitus. To test this hypothesis, our first study described in chapter 3 investigated the effect of weeklly administration of $20 \mathrm{mg}$ PEG-OB on body weight loss, energy expenditure, and metabolic profile in obese men during mild hypocaloric conditions (deficit: $2.0 \mathrm{MJ} / \mathrm{day}$ ) for 12 weeks. Despite sustained elevated levels of both PEG-OB and leptin, which increased post-absorptive satiety throughout the treatment period, no effect was observed on weight loss ar energy expenditure. Also other biological effects of PEG-OB or leptin demonstrated in animal studies. (such as effects on glucose homeostatis and lipids) were not observed. However, PEG-OB treatment was found to be well tolerated and safe in humans.

After the conclusion of our first study, the results of another clinical trial became avallable which diemonstrated a significant dose-response relationship with weight and fat. loss in both lean and obese humans. The dose used in our first trial only led to about $60 \%$ of the maximal serum leptin concentrations observed in the most effective highest dose cohorts of this study. Hence, the administration of a higher therapeutical dose of PEG-OB might be able to reduce body weight in obese subjects. To that end, the study described in chapter 4 explored whether weekly administration of a higher 
dose (60 mig per week) of PEG-OB was able to induce additional weight loss and metabolic changes in obese male and female subjects on a mild hypocaloric (deficit: 3.2 MJ/dlay/h diet for 8 weeks. The results of our second study clearly showed that even exposure to the increased dose of $\mathrm{PEG}-\mathrm{OB}(300 \%)$ failed to promote additional weight loss over caloric restriction despite the augmented leptin levels. Furthermore, no treatment effects on the levels of glucose, insulin (including estimated insulin resistance) and triglycerides were observed.

The outcome of our first two clinical studies and the clinical trial conducted by another group demonstrated that even supraphysiological leptin concentrations failed to significantly affect body weight regulation, which implicates that humans are highly leptin resistant. This observation was, however, consistent with an alternative view of the physiological role of leptin, which suggests that leptin has a broader physiological role and evolved as a signal whose reduction indicates starvation and subsequently initiates the complex neural, metabolic, neuroendocrine, and behavioral responses thought to have survival value in periods of inadequate energy intake. A consequence of this hypothesis is that exogenous leptin should be able to blunt these fasting-induced adaptations when administrated during severe energy restriction. The answer to the question whether elevated leptin levells using PEG-OB changed the effects of semistarvation on weight loss or bady-composition, energy expenditure, appetite, metabolic profile and neuroendocrine measures in healthy overweight male subjects, is addressed in chapter 5 and 6 . Weekly subcutaneous administration of $80 \mathrm{mg}$ of PEG-OB led to significant additional weight loss and reductions in appetite after 6 weeks of treatment and severe energy restriction (by means of a very-low-energy diet) but did not affect changes in energy expenditure, body composition, and other metabolic parameters (chapter 5). Our findings suggested that leptin predominantly influences the human energy balance by stimulating appetite during starvation but appears not to be involved in regulating energy expenditure.

Leptin-deficient $a b / o b$ mice show many of the neuroendocrine changes observed in starved animals, which could be corrected by leptin treatment. In addition, prevention of the characteristic fall in leptin during fasting using exogenous leptin blunted the expected fasting-induced neuroendocrine changes in fasted wild-type mice. Starvation oi severe eneigy resinction aiso rapiaiy evokes severai neuroendocrine adaptive responses in humans thought to have survival value in periods of inadequate energy intake. To test whether elevated leptin levels using PEG-OB were able to attenuate the neuroendocrine adaptations to semistarvation in humans, we executed the study described in chapter 6 . Although administration of $\mathrm{PEG} \mathrm{OB}$ failed to reverse the fasting-induced changes in the thyroid, corticotropic, somatotropic axes and sympathetic nervous system activity, the drop in mean LH levels was attenuated in the PEG-OB group compared with the placebo group. These data and other observational and interventional studies to date indicate that human leptin deficiency or absence might be responsible for the impaired reproductive function accompanying these states.

A growing body of evidence suggested that leptin is a modulator of the immune and proinflammatory responses. Leptin administration reversed the immunological abnormalities of both starved mice as well as ob/ob mice. Leptin levels are generally elevated in the obese population. In addition, human obesity appears to be associated with a low-grade proinflammatory state, which is reversed by weight reduction. Consequently, it has been suggested that elevated leptin levels underlie the low-grade 
proinflammatory state in human obesity. To test this hypothesis, two studies desciribed in Chapters 4 and 7 were undertaken using two different experimental approaches. Our studies did not support a causative role of hyperleptinemia in low-grade proinflammatory state present in human obesity. Thus, it seems plausible that the definite long-term elevations in systemic leptin levels and the low-grade proinflammatory state found in obesity result from a common pathogenic mechanism present in this condition.

The neuroendocrine data derived from our previous study (chapter 6) prompted us to investigate the physiologicall role of leptin in regulating reproductive function in another low-leptin state. To that end, a detailed study described in chapter 8 was executed designed to investigate the capability of leptin to influence pulsatile LH secretion in healthy young underweight women who were treated with PEG-OB. Pharmacologically induced hyperleptinemia was associated with lower mean, integrated and pulsatile LH release in healthy young underweight women. Although many lines of evidence indicate that leptin is a critical factor in maintaining human reproductive function, the findings of our last study suggest that leptin might have a dual effect on human reproduction as chronic hyperleptinemia might have a detrimental effect on the human reproductive axis. 


\section{Samenvatting}

De ontdekking van het hormoon leptine in 1994 had een grote inviced op het inzicht in de moleculaire aansturing van de energiebalans als ook op de houding ten aanzien van wetenschappelijk onderzoek naar de regulatie van het lichaamsgewicht en obesitas. Het leptine systeem bleek het langgezochte perifere signaal systeem te zijn van het vetweefsel naar de hersenen betrokken bij de regulatie van de voedselinname en de energiebalans. Sinds de ontdekking van leptine zijn de opvattingen over de fysiologische rol daarvan bil mensen voortdurend geëvolueerd en verbreed op basis van nieuwe gegevens en theoretische overwegingen. Het doel van het onderzoek gepresenteerd in dit proefschrift, was deze nieuwe inzichten te testen door middel van verschillende benaderingen en experimentele protocollen.

Leptine dient specifieke gebieden van de hersenen te bereiken om zijn werking uit te kunnen oefenen en daarom moet het dus de bloed-hersenen barrière passeren. De pilot studie, die in hoofdstuk 2 beschreven staat, onderzoekt de cruciale vraag of het langwerkend gepegyleerd humaan recombinant leptine (PEG-OB), dat in al onze klinische studies gebruikt is, in staat is bij mensen het centraal zenuwstelsel te bereiken. Vier dagen na het toedienen van PEG-OB waren de leptine concentraties in liquor van patiènten die reeds gepland waren voor een elektieve liquorpunctie (om de aanwezigheid van neuroborreliose uit te sluiten) ongeveer 10 keer hoger dan voorspeld op basis van hun basale plasma leptine concentraties. Deze resultaten suggereren sterk (maar bewijzen niet) dat PEG-OB in staat is de bloed-hersen barrière bil de mens te passeren.

Al snel na het kioneren van het ob gen werden leptine-deficiente ob/ob muizen geinjecteerd met recombinant leptine hetgeen resulteerde in gewichtsverlies door verminderde voedselinname en een verhoogd energiegebruik. Deze uitkomst suggereerde dat leptine functioneerde als een anti-obesitas hormoon. Volgens deze hypothese zou de stijgende leptine concentratie, veroorzaakt door de toename van de vetmassa een signaal genereren dat resulteerde in verminderde voedselinname en een verhoogd energiegebruik hetgeen verdere gewichtstoename zou beperken. Echter dit vroege denkbeeld werd betwist omdat leptine resistentie wijdverbreid voorkomt in zowel obese dieren als mensen. Indertijd werd verondersteld dat leptine-resistentie mogelijk te overwinnen zou zijin door het therapeutisch verhogen van de leptine spiegels, vergelijkbaar met het gebruik van insuline om de insuline-resistentie te overwinnen bij patiênten met diabetes mellitus type 2 .

Om deze hypothese te testen werd tijdens de eerste studie, zoals beschreven in hoofdstuk 3 , het effect van wekelijkse toediening van $20 \mathrm{mg}$ PEG-OB onderzocht op het verlies van lichaamsgewicht, energiegebruik en metabool profiel bij obese mannen op een mild dieet (tekort: $2.0 \mathrm{MJ} / \mathrm{dag}$ ) gedurende 12 weken. Ondanks continu verhoogde spiegels van zowel PEG-OB als leptine wat leidde tot een toename van de post-absorptieve verzadiging gedurende de gehele behandelperiode, werd geen effect waargenomen op het verlies van lichaamsgewicht of energiegebruik. Ook andere biologische effecten van PEG-OB of leptine die aangetoond waren in dierproeven (zOals effecten op glucose homeostase en lipiden) werden niet waargenomen. Desialniet- 
temin werd de behandeling met $P E G-O B$ goed verdragen en bleek deze veilig voor mensen.

Na het beëindigen van deze eerste wetenschappelije studie kwamen de resultaten van een andere kinische studie beschikbaar die een significante dosis-respons relatie met verlies van lichaamsgewicht en vetmassa liet zien in zowel slanke als obese individuen. De dosis gebruikt in onze eerste studie leidde echter maar tot een leptine concentratie van maximaal $60 \%$ van die waargenomen in het meest effectieve en hoogst gedoseerde cohort van deze andere studie. Aldus zou mogelijk de toediening van een hogere dosis PEG-OB in staat zijn het lichaamsgewicht te reduceren van obese proefpersonen. Op basis hiervan werd de studie die beschreven staat in hoofdstuk 4 uitgevoerd om te bestuderen of wekelijkse toediening van een hogere dosis PEG-OB (60 mg per week) in staat was extra verlies wan lichaamsgewicht en metabolle veranderingen te induceren bij obese mannelijke en vrouwelijke proefpersonen op een milld dieet (tekort: $3.2 \mathrm{MJ} / \mathrm{dag}$ ) gedurende 8 weken. De resultaten van deze tweede studie lieten duidelijk zien dat zelfs blootstelling aan deze hogere dosis PEG-OB (300\%) geen extra verlies aan lichaamsgewicht veroorzaakte ondanks de verhoogde leptine spiegels. Bovendien werd er geen effect van de behandeling waargenomen op de bloedsplegels van glucose, insuline (inclusief de geschatte insuline resistentie) en triglyceriden.

Het resultaat van deze eerste twee wetenschappelijke studies en het klinisch onderzoek verricht door een andere wetenschappelijke groep lieten zien dat zelfs suprafysiologische leptine concentraties niet in staat waren de regulatie van het lichaamsgewicht te beînvloeden, hetgeen suggereert dlat mensen in hoge mate leptine-resistent zijn. Deze waarneming was echter wel verenigbear met een alternatieve zienswijze aangaande de fysiologische rol van leptine gebaseerd op dierexperimenteel onderzoek, hetgeen suggereerde dat leptine een bredere fysiologische rol speelt en geëvolueerd is om verhonglering te signaleren bij dalende bloedspiegels zodat vervolgens complexe neurale, metabole, neuroendocriene en gedrags responsen geactiveerd kunnen worden, waarvan gedacht wordt dat ze overlevingswaarde bezitten tijdens perioden van onvoldoende voedselinname. Een consequentie van deze hypothese is dat leptine therapie in staat zou moeten zijn om deze door honger geinduceerde aanpassingen te verminderen wanneer het toegediend wordt tijdens een streng dieet. Het antwoord op de viraag of de door PEG-OB veroorzaakte verhoogde leptine splegels de effecten van verhongering op het verlies van lichaamsgewicht of de veranderingen in lichaamssamenstelling, energlegebruik, honger, metabool profiel en neuroendocriene parameters beilnvloedt bij obese mannelijke proefpersonen wordt behandeld in hoofdstuk 5 en 6 . Wekelijkse subcutane toediening van $80 \mathrm{mg}$ PEG-OB leidde tot signiflcant extra verlies van lichaamsgewicht en een reductie in hongergevoel na 6 weken behandeling en het volgen van een streng dieet (door middel van een laag calorisch, eilwit verrilkt dieet) maar had geen effect op de veranderingen in energiegebruik, lichaamssamenstelling en andere metabole parameters (hoofdstuk 5). Onze resultaten suggereren dat leptine voornamelijk de menselijke energiebalans beinvloedt door het hongergevoel te stimuleren tijdens vasten maar niet betrokken lijkt bij de regulatie van het energiegebruik.

Leptine-deficiënte $o b / o b$ muizen bezitten vele neuroendocriene adaptaties die waargenomen zijn in uitgehongerde dieren hetgeen gecorrigeerd kan worden door leptine behandeling. Tevens bleek het voorkomen van cle karakteristieke daling van de leptine spiegel tijdens vasten door het toedienen van leptine de verwachte door honger 
geïnduceerde neuroendocriene veranderingen te verminderen in vastende wild-type muizen. Verhongering of strenge energie-inname beperking veroorzaakt snel diverse neuroendocriene adaptaties bij mensen. Hiervan wordt gedacht dat deze overlevingswaarde bezitten tijdens perioden van onvoldoende voedselinname. Om te testen of de door PEG-OB geînduceerde verhoogde leptine spiegels in staat waren de neuroendocriene aanpassingen te verminderen bij mensen die een streng dieet volgen is de studie beschreven in hoofdstuk 6 uitgevoerd. Ondanks het feit dat de toediening van PEG-OB niet resulteerde in het voorkomen van de door honger veroorzaakte veranderingen in de schildklier, corticotrope, somatotrope hormonen en sympatisch zenuwstelsel activiteit was wel de daling van de gemiddelde LH splegels verminderd in de PEG-OB groep ten opzichte van de placebo groep. Deze resultaten en andere wetenschappelijke waarnemingen en interventie studies tot nu toe geven aan dat een tekort aan of de afwezigheid van leptine mogelijk verantwoordelijk is voor de verminderde humane fertilliteit die hierbiji optreedt.

In toenemende mate is er bewijs die suggereert dat leptine in staat is de immunologische en proinflammatoire responsen te moduleren. Leptine toediening corrigeerde de immunologische afwijkingen van zowel vastende als ook ob/ob muizen. Leptine spiegels zijn in het algemeen verhoogd in de obese populatie. Ook lijkt humane obesitas geassocieerd te zijn met een laaggradig proinflammatoire toestand die gecorrigeerd wordt door het reduceren van het lichaamsgewicht. Derhalve is gesuggereerd dat de verhoogde leptine spiegels ten grondslag liggen aan deze laaggradig proinflammatolre toestand die aanwezig is bij humane obesitas. Om deze hypothese te testen zijn twee studies, beschreven in hoofdstuk 4 en 7 uitgevoerd, die gebruik maken van twee verschillende experimentele benaderingen. Dieze studies ondersteunen een causaal verband tussen de hoge leptine concentraties en de aanwezigheid van een laaggradig proinflammatoire tcestand in humane obesitas niet. Aldus lijkt het aannemelijk dat de uitgesproken langdurige verhoging van de systemische leptine bloedspiegels, alsmede de laaggradig proinflammatoire toestand aanwezig bij humane obesitas het resultaat zijn van een gemeenschappelijk pathologisch mechanisme, dat in deze conditie aanwezig is.

De neuroendocriene resultaten van de vorige studie (hoofdstuk 6) vormden de basis voor een nadere studie aangaande de fysiologische rol van leptine in een andere conditie, die ook geassocieerd is met een lage leptine bloedspiegel. Een uitvoerige studie die beschreven staat in hoofdstuk 8 werd ontworpen om het vermogen van leptine te bestuderen om de pulsatiele LH secretie van gezonde jonge vrouwen met ondergewicht te beïnvloeden 10 dagen na behandeling met PEG-OB. Farmacologisch geinduceerde verhoogde leptine bloedspiegels bij gezonde jonge vrouwen met ondergewicht waren geassocieerd met een verlaagd gemiddelde, geïntegreerde en pulsatiele LH secretie. Ondanks het feit dat er veel bewijs bestaat dat impliceert dat leptine deficiëntie leidt tot menselijke reproductief falen, suggereren de resultaten van deze laatste studie dat leptine mogelijk een tweeledig effect heeft op de menselijke reproductie, gezien het feit dat chronische continu verhoogde leptine bloedspiegels mogelijk een nadelig gevolg hebben voor die menselijke fertiliteit. 


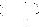




\section{Dankwoord}

Het is donker buiten en ik zit achter mijn beeldscherm te mijmeren over de inhoud van mijn dankwoord, iets wat velen ongetwijfeld voor mij hebben gedaan en nog in de toekomst zullen doen. Het besef begint maar langzaam door te dringen: "het is af!". Er" is een tijd geweest dat ik dacht dat het me nooit meer zou lukken dit proefschrift te schrijven. De door mij zwaar onderschatte overgang van de wetenschap naar de kliniek was hier zeker debet aan.

Alles begint ergens, al denken veel natuurkundigen daar anders over. Mijn wens te promoveren is zeker begonnen tijdens mijn bijbaantje als studenten-assistent op de afdeling Chemische Pathologie van de Erasmus Universiteit Rotterdam onder de bezielende leiding van Prof. dr. H.G. van Eijk. Zowel zijn inzet voor studenten alsmede zijn academische houding zijn tegenwoordig zeldzaam in de universitaire wereld.

Tijidens mijn werkzaamheden als AGNIO Interne in het Fransicus Ziekenhuis to Roosendaal solliciteerde ik eind 1997 naar een AIO positie bij de capaciteitsgroep Humane Biologie van de Universiteit Maastricht. Ondanks het feit dat ik tweede werd in deze sollicitatieronde had ik blijkbaar toch "een indruk" achtergelaten en werd mil gevraagd te solliciteren naar een AlO positie voor een ander project. Dit project betrof een fase 2 geneesmiddelen studie naar de werkzaamheid van leptine, een hormoon waar ik destijds nog nooit van gehoord had. Het bewijs dat dat in de tussentijd wel veranderd is ligt nu voor $u$.

Voor het tot stand komen van dit proefschrift ben ik met name mijn promotor en co-promotor veel dank verschuldigd. Wim, ondanks je ontzettend drukke werkschema heb je altijd tijd voor mij vrijgemaakt voor overleg en talloze andere zaken. Bovendien was je nooit te beroerd zelf de handen uit de mouwen te steken. Vooral de grote vrijheid en de steun die je mij hebt gegeven bij het opzetten en uitvoeren van de latere experimenten wordt zeer gewaardeerd. Jouw brede keninis en sterke gerichtheid op de nieuwste ontwikkelingen in de wetenschap waren niet alleen essentieel voor dit project maar hebben tevens tot überhaupt de start hiervan geleid. Ook buiten het werk was het altijd gezellig ook mede door jouw altijd genereuze sponsering van o.a. de bierrekening tijdens feestjes van de capgroep en je medewerking aan diverse promotievideo's. I hoop dan ook dat we in de toekomst contact zullen houden. Margriet, zonder jouw uitgebreide kennis van het menselijk eetgedrag en energiegebruik zou een belangrijk aspect van de leptine fysiologie in mijn studies zeker onderbelicht gebleven zijn. Ook ben ik je nog altijd dankbaar voor jouw opvallend snelle correctie van allerlei geschriften van mij en je hulp bij de statistiek (hetgeen wel nooit een hobby van me zal worden).

I would also like to thank ail members of the rewiewing committee. Prof. dr. ir. A.P. Mensink, Dr. S. Faroogi, Prof. dr. J.F.C. Glatz, Prof. dr. A.C. Nieuwenhulizen Kruseman, and Dr. H. Pill for their time and effort in carefully reading my thesis and for their positive remarks towards my work.

Freddy is mijn kamergenoot geweest gedurende minn gehele UNS-50 periade en is nu mijn paranimf. Ondanks het feit dat wij in vele opzichten van elkaar verschillen hebben we toch altijd heel goed met elkaar kunnen opschieten en het erg gezellig gehad op 
zowel het werk alls daarbuiten. Het zal inderdaad nooit meer hetzelfide worden zonder jou. Luc(as), mijn andere paranimf, ik maakte me pas echt zorgen om je als het gemopper verstomde. Toch denk ik dat het allemaal wel goed zal komen omdat ik je nog steeds en van de beste wetenschappers vindt die ik ooit ontmoet heb. Tanja, bedankt voor alles en heel veel succes toegewenst in San Francisco.

Ik bewaar nog altijd goede herinneringen aan een scala van activiteiten waarvan nu een kleiline bloemlezing volgt: "ouderwetsch in het weekend werken", de LDVDM (uiteraard De Pub), capgiroepuitjes \& borrels, de HB Sinterklaas viering (warme chocolademelk), Charlemagnefestijnen (peper moet je niet steengrillen), het ambtenarencarnaval (nog steeds geheugenproblemen), leerzame congressen (NWO-Papendal?), interne verhuizingen, promotiefeesten (als hoogtepunt $c . q$ dieptepunt natuurlijk de YMCA), het regisseren van promotievideo's (ik maak me nu al zorgen), de illustere ORGIETM (tsja...), de HBTOURPOOL ${ }^{T M}$ (ik won \#!\$* nooit), cartavondjes (verloor ik ook altijd), schaatsen (1x gedaan, geloof ik), Mega Meijer Mixer (groen $\neq$ goed), het pannenkoeken gelag bij mij thuis (zoveel eten kan niet gezond wezen), Jack Daniels (geen commentaar), en vele andere uitspattingen. Al deze ondernemingen waren niet mogelijk geweest zonder de vaak subtiele inbreng van mijn oud collega's: Enkhuizer Irritantje Erwin (tegenwoordig Sint Meijer), Joost the Omen, Collegia! Michiel(angelo), kindervriend $E(R)$ dgar, Professor Patrick, videomaatje Margriet, Clamp Koning Marco, Onze Vlaming Guy, tennislerares Marieke, Eva, Manuela, Annemiek "Petra, Ilse, Marleen, Neeltje, Eefje, Cyriel, Jochum, Annemie, Wendy, Frank, Arjen, Dean, Reinout, Annemarie, Sandra, Dorien, Daphne, Ellen, Ton, Klaas en Wouter.

Voor de technische ondersteuning m.b.t. rokende computers, ventilated hoods en respiratie kamers met negatieve RQ's tijdens een alcoholproef, en meer falend technisch spul gaat mijn dank uit naar de whizzkids van Humane Biologie, Paul en Loek. Naast het gezellig koffieleuten moet mijn bekering tot het Apple ${ }^{T M}$ geloof toch tot een van de kleine triomfen van Paul gerekend worden. De dames van het secretariaat: Desiree, Claudia, Peggy, llona, Mariëlle, Larissa en natuurlijk ons aller Truus worden bedankt voor al hun hulp bij verscheidene zaken die varteerden van "hoe ga ik met het fax apparaat om" tot en met hun inzet bij het organiseren van de diverse capgroep evenementen. Joan, ik heb nog steeds bewondering voor je omdat je al het "stalken" van de Roche dames tijdens mijn eerste onderzoek hebt weten te doorstaan. Tevens beken ik schuld aan het feit dat het radionucleotiden lab door mijn talloze leptine bepalingen je tweedle thuis geworden was. Jos, behoudens de gezellige Pub avondien, ben ik je nog steeds dankbaar voor alle hulp bij de diverse laboratorium analyses en Jouw langdurige speeches die mij altijd weer motivererden door te gaan met onderzoek.

Een proefschrift kan nooit tot stand komen zonder de hulp van vele andere collega's met hun eigen vakkennis. Allereerst will ik mijn waardering uitspreken voor zowel de wetenschappelijke alsmede de financiële steun van het "PEG-OB team" van Hoffmann-La Roche Inc. in zowel Engeland (Welwyn) als ook in de VS (Nutley, New Jersey). Wim Buurman en Francois van Dielen worden bedankt voor de prettige samenwerking hetgeen resulteerde in o.a. een gezamenlijk artikel. Paul Menheere ben ik met name veel dank verschuldigd omdat hij mij met zijn endocriene raald en daad terzijde heeft gestaan naast zijn eigen drukke klinisch chemische werkzaamheden in het AZM. Jan Lindeman, mede door jouw inzet en die van anderen bij TNO 
Leiden/LUMC is een belangrijk immunologisch deel van dit proefschrift tot stand gekomen. Eric van Breda en Hans Keizer ben ik buitengewoon erkentelijk voor hun hulp bij zowel de praktische uitvoering als ook de theoretische uitwerking van de pulsatiele LH metingen. Zonder jullie uitgebreide ervaring en kennis op dit gebied was dit experiment nooit gelukt.

I would like to thank Prof. dr. J.D. Veldhuis for his careful examination of the manuscript of my last study and for his constructive comments and suggestions.

Alle onderzoeken beschreven in dit proefschrift hadden nooit tot stand kunnen komen zonder de directe uitvoerende hulp van vele stagiaires: Mariëlla, Mariëlle, Brian, Inge, Marja, Fiona, "and last but not least" Roy. Ik denk dat er maar weinig stagiaires zulke lange werkdagen gemaakt hebben en zo vaak tijdens het weekend of zelfs s'nachts gewerkt hebben als jullie. Ook zonder de hulp van vooral Tanja Hermans tijdens mijn eerste studie in 1998 en Gabby Hul tijdens twee latere experimenten had ik het waarschijnlijk niet gered. Tenslotte wil ik al mijn proefpersonen bedanken voor hun niet geringe inzet tijdens mijn experimenten. Het is niet niks geweest wat zij zich hebben moeten laten welgevallen om mijn studies tot een "succes" te maken.

Intussen ben ik alweer ruim 2 jaar in de kliniek werkzaam en behoor daar alweer tot de "oude rotten assistenten" van het Meander Medisch Centrum te Amersfoort. Echter de voor mij $z$ ware overgang van de wetenschap naar de harde realiteit van de kliniek had ik zeker miet gered zonder de hulp van vele collega's, waaronder ik met name Michel mijn oude studiegenoat en vriend wil noemen.

Naast alle vrienden die ik heb gemaakt op het werk, heb ik mijn beste vriend Rutger juist buiten de universiteit leren kennen. Ik vind het nog steeds een gelukkig toeval dat wij nu allebei in Utrecht wonen en zo ellkaar nog vaak zlen.

Tenslotte wil ik mijn vader en moeder bedanken voor hun onvoorwaardelijke steun en vertrouwen in mij en mijj kunnen, ook tijdens periodes dat ilk daar zelf minder van overtuigd was. Ma, ondanks de zware tijden die je momenteel te wachten staan ben ik er van overtuigd dat je ook deze hindernis weer zult overwinnen. 



\section{Curriculum vitae}

\section{Hukshorn, Christian John (Chris)}

Date of birth June 11,1971

Place of birth Epping, United Kingdom

\section{Education}

1983 - 1989 Graduated from the Atheneum at "Het Nieuwe Lyceum", Bilthoven, The Netherlands.

$1989-1996$ M.D. degree, Erasmus University Rotterdam, The Netherlands.

1996 - 1998 Physician at the department of Intermal Medicine, Franciscus Hospital, Roosendaal, The Netherlands.

$1998-2002$ PhD student at the department of Human Biology, Nutrition and Toxicology Research Institute Maastricht (NUTRIM), Maastricht University, The Netherlands under the guidance of Prof. W.H.M. Saris and Dr. M.S. Westerterp-Plantenga. Project: "The physiological role of leptin in man".

\section{Future}

2002 - present Resident in Internal Medicine at the Meander Medical Center, Amersfoort, The Netherlands. 
. 


\section{Publications}

1. van Gelder, W., Huijskes Heins, M.I., Hukshorn, C..J., de Jeu Jaspars, C.M., van Noort, W.L., and van Eijk, H.G. 1995. Isolation, purification and characterization of porcine serum transferrin and hemopexin. Comp Biochem Physiol B Biochem Mol Biol. 111:171-179.

2. Hukshorn, C.J., Saris, W.H.M., Westerterp Plantengla, M.S., Farid, A.R., Smith, F.J., and Campfield, L.A. 2000. Weekly subcutaneous pegylated recombinant native human leptin (PEG-OB) administration in obese men. J Clin Endocrinol Metab. 85:4003-4009.

3. Westerterp-Plantenga, M.S., Saris, W.H., Hukshorn, C.J., and Campfield, L.A. 2001. Effects of weekly administration of pegylated recombinant human OB protein on appetite profile and energy metabolism in obese men. Am J Clin Nutr. 74:426-434.

4. Hukshorn, C.J., van Dielen, F.M.H., Buurman, W.A., Westerterp Plantenga, M.S., Campfield, L.A., and Saris, W.H.M. 2002. The effect of pegylated recombinant human leptin (PEG-OB) on weight loss and inflammatory status in obese subjects. Int $J$ Obes Relat Metab Disord. 26:504-509.

5. Hukshorn, C.J., Westerterp-Plantenga, M.S., and Saris, W.H. 2003. Pegylated human recombinant leptin (PEG-OB) causes additional weight loss in severely energy-restricted, overweight men. Am J Clin Nutr. 77:771-776.

6. Hukshorn, C.J., Menheere, P.P., Westerterp-Plantenga, M.S., and Saris, W.H. 2003. The effect of pegylated human recombinant leptin (PEG-OB) on neuroendocrine adaptations to semi-starvation in overweight men. Eur of Endocrinol. 148:649-655.

7. Lejeune, M.P., Hukshorn, C.J., Saris, W.H., and Westerterp-Plantenga, M.S. 2003. Effect of dietary restraint during and following pegylated recombinant leptin (PEG-OB) treatment of overweight men. Int I Obes Relat Metab Disord. 27:1494-1499.

8. Hukshorn, C.J., Lindeman, J.H., Toet, K.H., at al. 2004. Leptin and the proinflammatory state associated with human obesity. $J$ Clin Endocrinol Metab. $89: 1773-1778$.

9. Lejeune, M.P., Hukshorn, C.J., Saris, W.H., and Westerterp Plantenga, M.S. 2004. Reversal of changes in ghrelin and adiponectin during human pegylated recombinant leptin induced body weight loss. Obes Res. (accepted). 
10. Hukshom, C.J., van Breda, E, Keizer, H.A., Menheere, P.P., Veldhuis, J.D., and Saris, W.H. Experimentally induced hyperleptinemia supresses luteinizing-hormone pulsatility in underweight women. (submitted). 